\title{
Labour markets, family-relevant policies and reproductive behaviours: Quebec's fertility regimes between 1960 and 2010
}

by

Sophie Mathieu, B.A., M.A.

A thesis submitted to the Faculty of Graduate and Postdoctoral Affairs in partial fulfillment of the requirements for the degree of

Doctor of Philosophy

Department of Sociology and Anthropology

Carleton University

Ottawa, Ontario

May, 2014

(C) 2014, Sophie Mathieu 


\begin{abstract}
Using the gender equity theory to study fertility trends in Quebec between 1960 and 2010, this dissertation shows that fertility outcomes are more contingent upon policies that support a gender-egalitarian division of care work, than fertility policies aimed at increasing the number of births. Changes in reproductive trends are examined using an 'institutional approach' to fertility. Accordingly, fertility outcomes are theorised as resulting from the articulation between the economic context, the sequence of key transitions in family life and the extent to which social policy allows care work to be 'demotherized'. The dissertation introduces the concept of the 'demotherization' of care work, to convey the extent to which mothers can download their care-giving responsibilities to the state, grand-parents and their partner. In the 1960s, fertility is shown to have decreased in Quebec, despite the fact that women were faced with new opportunities in public institutions. Following the Quiet Revolution, the federal and the provincial governments offered a limited set of family-relevant policies that supported 'gendered familialism', with low levels of defamilialization and demotherization. Declining fertility was the result of the lower importance of the family as a pillar institution and of women's difficulty to combine earning and caring tasks. The introduction of Quebec's first family policy in 1988 which contained a baby bonus, had a positive effect on fertility, though not because of this new measure, but because of a favorable economic context. Quebec's provincial government continued to support the motherization of care work, while simultaneously offering allowances that favoured economic defamilialization. Finally, Quebec's second family policy, introduced in 1997 (yet fully implemented in 2006), challenged the traditional gendered division of care-giving responsibilities, through the provision of universal and targeted measures that allowed care work to be demotherized. In Quebec's fertility regime moved from 'implicit familialism' to a hybrid version of 'institutional' and 'de-gendered' arrangements of care work. In that context, women were able to maintain good activity rates, along with relatively high fertility.
\end{abstract}




\section{ACKNOWLEDGEMENTS}

Writing a dissertation is truly a collaborative effort in many respects. Many people helped me to translate my doctoral ambitions into realizations. First, I am very indebted to my supervisor, Wallace Clement, whose support and guidance have made the completion of this thesis possible. I am especially grateful to Wally for his patience, his encouragement and his feedback throughout the writing process. Writing a dissertation in one's second language is a challenging endeavour and Wally proved to be an enthusiastic guide in my journey. I am also grateful to my other two committee members, Rianne Mahon whose work and career path have been a great inspiration and Janet Siltanen for her constructive criticisms and for pushing me in new directions. Thank you to you both for your valuable insights and for your careful assessment of my work.

During both the MA and the PhD journeys, I had the opportunity to learn from established academics, whether we met at Carleton, at the Université de Montréal or elsewhere. I want to thank Deena White, Hicham Raïq, Marilyn Fortin, Stéphane Moulin and Stéphanie Gaudet. I am especially thankful to Paul Bernard, my former supervisor, who passed away in 2012. Paul was not only a great academics, he was a friend and a mentor. He is greatly missed. Though he did not supervise my doctoral work, he taught me how to think sociologically and he strongly recommended I pursue doctoral studies. I also wish to thank Paul's wife, Anne Laperrière, for her kind support and encouragement over the past two years. 
Three of my academic compatriots, Susan Salhany, Lindsey McKay and Emre Uckardesler, became dear friends over the years. Thank you for your encouragements and for sharing countless insights and productivity advices. Outside of academia, numerous friends such as Anne-Marie, Cléo, Karine, Marie-Pierre, Pablo and Valentina showed interest in my work, fed me intellectually by answering my numerous questions regarding their own fertility ambitions, and kept me balanced through the years.

My family provided me with unwavering support and love from the beginning. Through the ups and downs of the program, they never stopped believing in my abilities to complete the $\mathrm{PhD}$ program. My parents, Nicole and André supported me financially and emotionally through my entire university career. I would never have completed a $\mathrm{PhD}$ if it was not for them. My mother-in-law Hélène drove a countless number of times to my hometown, to help me with childcare duties when my husband was unavailable and I needed to work on my dissertation. I am fortunate to count numerous scholars in my extended family. Pierre Cossette, André Cossette and Camille Carrier both inspired and encouraged me to become an intellectual. Johanne Cossette and Nicole Dessureault took pride in my academic pursuit and never missed the opportunity to read my work.

More than anybody else, my husband Pierre-Mathieu lived through the trials and the tribulations of the $\mathrm{PhD}$ process. I could have never finished this project without his unconditional love and support. He spent countless nights and week-ends alone with our daughter, while I was in the process of finishing writing the dissertation. I am thus equally 
grateful to my lovely daughter Alice, who patiently let me work at night when she was home, though she often wished I had more time to play.

Finally, I benefited from numerous sources of financial support, which made the completion of this project possible: the Social Science and Humanities Research Council, the Ontario Graduate Scholarship programme, the Faculty of Graduate Studies and Research, and the Department of Sociology and Anthropology. Thank you.

I dedicate this dissertation to the two greatest women in my life: my mother and my daughter. 


\section{TABLE OF CONTENTS}

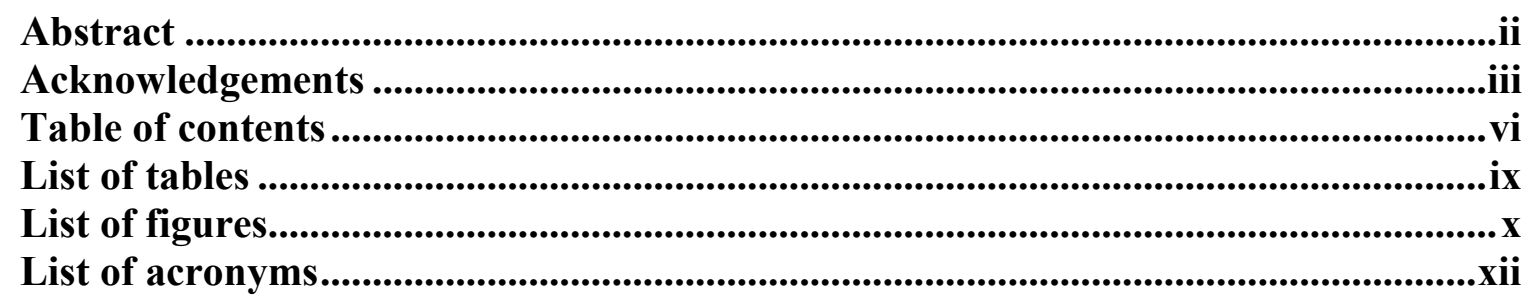

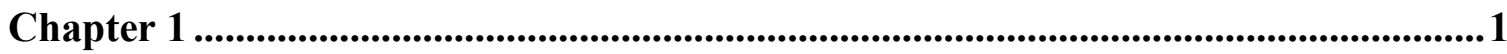

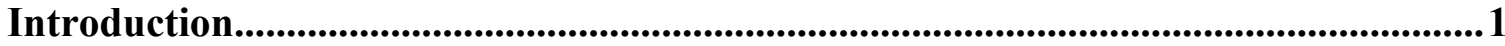

Defining key concepts: 'family policy', 'social reproduction' and 'fertility rates' ........ 6

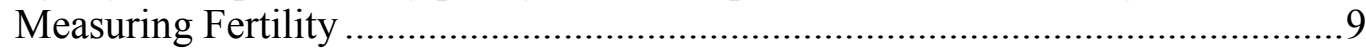

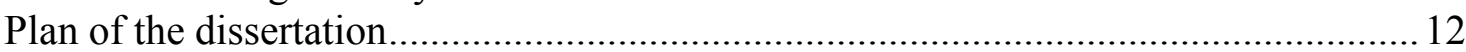

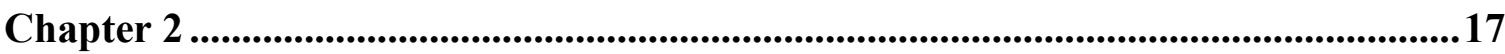

Why should we care about low fertility in Quebec? ...................................................17

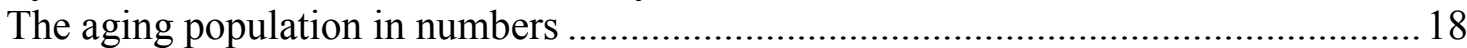

From economic growth to the survival of the culture............................................. 21

Fertility intention and fertility realization: a persistent gap ...................................28

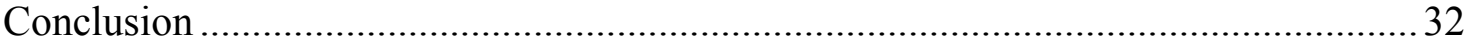

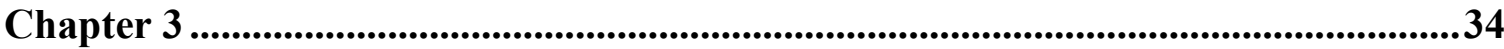

Explaning the drop in fertility: from economic theories to the gender equity theory34

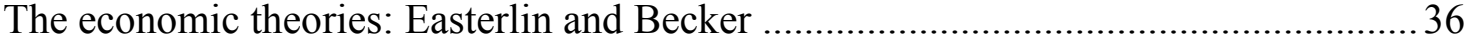

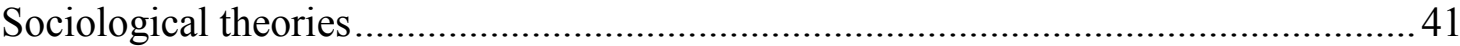

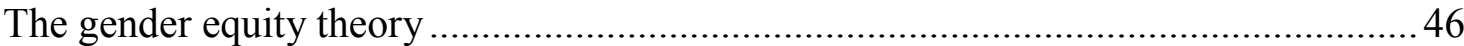

The gender equity theory: two clarifications ..............................................52

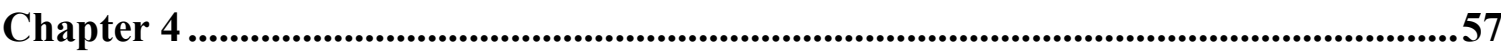

Between welfare and fertility regime: locating Quebec within the worlds of welfare

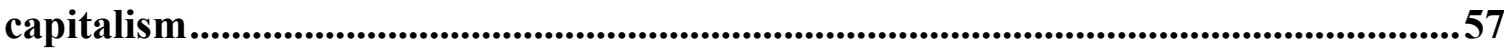

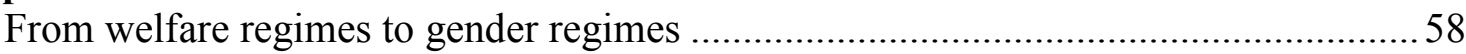

Between gendered welfare states and gender regimes .................................6 61

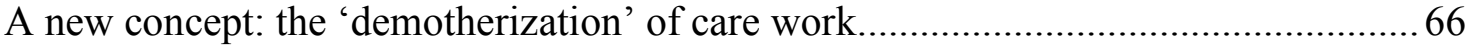

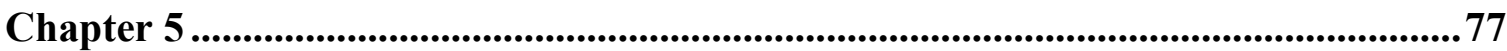

The institutional approach to fertility: state, market and fertility ...........................77

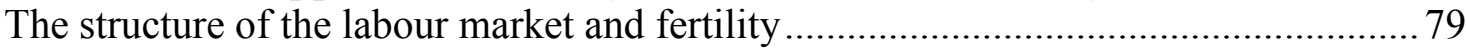

Is low fertility the result of the deinstitutionalization of the family? .......................... 87 
Between the tempo and the quantum of births: the effect of family policies on fertility

Previous literature reviews and comparative studies ............................................ 100

Public policies and fertility in the worlds of welfare capitalism .............................. 101

The Nordic countries ......................................................................... 102

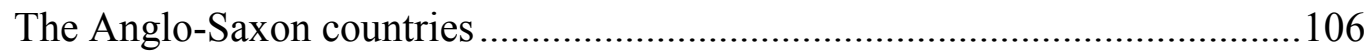

The Continental European countries ................................................................... 113

The Southern European countries ....................................................................119

Higher fertility as an outcome of better gender equality? ..................................... 122

Linking policies and outcomes: methodological approach and periodization............. 126

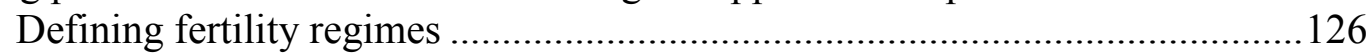

Between the Quiet Revolution and the early 2000s .....................................131

Chapter 7 .......................................................................................................................134

Between the Quiet Revolution and Quebec's first family policy ................................134

Fertility and social reproduction in Quebec in the 1960s and beyond: more adults, and

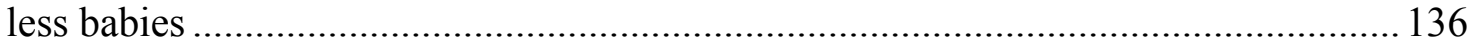

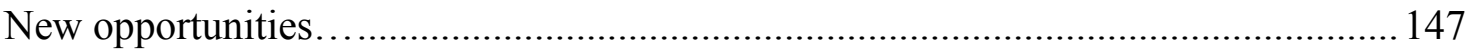

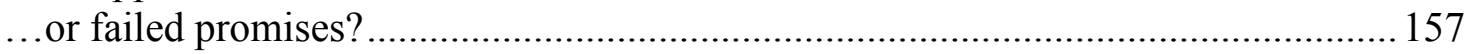

Chapter 8 .............................................................................................................................161

Fertility and social reproduction in the late 1980s: from Ottawa's targeting measures to Quebec's universal allowances .....................................................................161

Fertility and labour markets in Quebec and abroad ................................................ 163

Family policies in Quebec and in Ottawa in the late 1980s: two branches of the same tree?

Federal initiatives: between confusion and targeting .................................... 173

Quebec's first family policy: between pronatalism and universalism...............178

The (improbable) effect of the baby bonus on fertility decisions in Quebec ....182

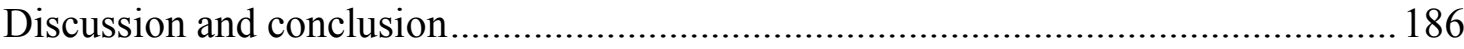

Chapter 9 ...............................................................................................................................188

On the road towards better gender equality: Quebec's fertility regime since 1997188

From decreasing fertility in the mid-1990s to rising births after 2005 ..................... 188

Family-relevant policies in Canada and Quebec since 1995 ................................... 196

Ottawa's family relevant policies since 1995: different lyrics, same melody ... 197

Quebec's fertility regime since the mid-1990s: sitting between two chairs? ....205

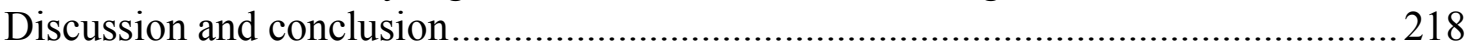




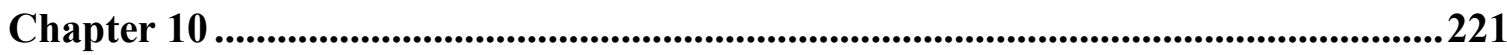

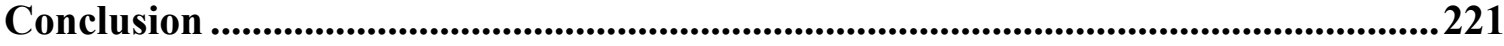

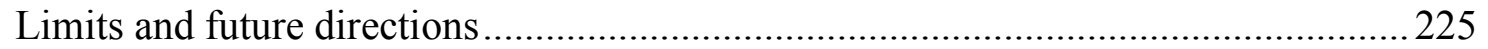

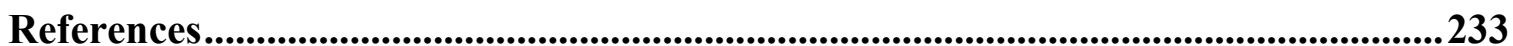




\section{LIST OF TABLES}

Table 1- The four types of famialialism 72

Table 2 - The four scenarios of gender equity and gender equality ..............................76

Table 3 - Prevalence of marriage and fertility rates in selected OECD countries ..........89

Table 4 - Birth and fertility rates in Quebec, 1968-1988.........................................138

Table 5 - Birth and fertility rates in Quebec, 1986-1997............................................ 165

Table 6 - Allowance for newborn children, family allowance and allowance for young children, annual amount per child, Quebec 180

Table 7 - Fertility rates by birth order, Quebec, 1985-1989 .....................................185

Table 8 - Birth and fertility rates in Quebec, 1995-2010 ........................................... 190

Table 9 - Proportion of children who are in their main care arrangement full-time ( 30 or more hours per week) and weekly number of hours in main care arrangement, Quebec and ROC, 1994-2003. 214

Table 10 - Distribution of women and men among recipients of Quebec's parental insurance plan, 2006-2009 216

Table 11 - Distribution of women and men among recipients of parental benefits in Quebec, 2006-2009..... 


\section{LIST OF FIGURES}

Figure 1 - Population 65 years and over, Canada and provinces, 2006 and projected 203120

Figure 2 - Age Pyramid of the population of Quebec, 2008 ........................................20

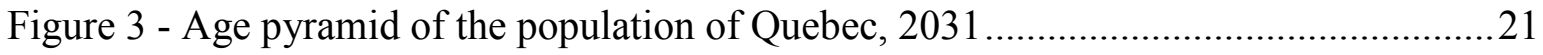

Figure 4 - Cross-country relationship between the share of births out of wedlock and the fertility rate, selected OECD countries, 2008 ........................................................... 91

Figure 5 - Fertility rates in the ROC and in Quebec, 1960- 2010 ................................. 133

Figure 6 - Fertility rates in Quebec and the ROC, 1961-1998 ....................................... 139

Figure 7 - Fertility rates in selected Nordic and Anglo-Saxon countries and Quebec, 1960-

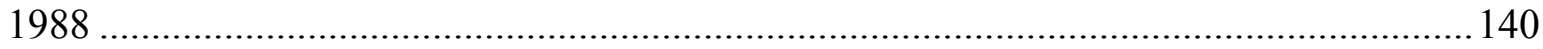

Figure 8 -Women's activity rate in Quebec, 1960-1970 ................................................ 141

Figure 9 - Relationship between the activity rates of women aged 25-34 and fertility rates in

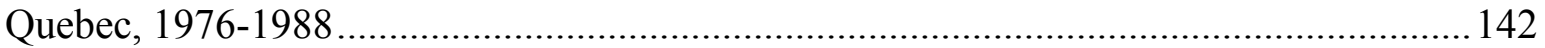

Figure 10 - Unemployment rates of men and women, aged 25-34 in Quebec, 1976-1988 144

Figure 11 - Birth rates of women of different age groups, Quebec, 1960-1988............... 145

Figure 12 - Birth rate in Quebec and the Rest-of-Canada, 1986-1997 .............................. 164

Figure 13 - Fertility rates in Quebec and in the Rest-of-Canada, 1986-1997................... 164

Figure 14 - Fertility rates in selected Nordic and Anglo-Saxon countries and Quebec, 19861997 166

Figure 15 - Relationship between the activity rates of women aged 25-34 and fertility rates

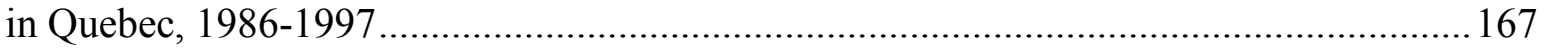

Figure 16 - Birth rates of women of different age groups in Quebec, 1986-1997............ 169

Figure 17- Fertility rates in Quebec and the Rest-of-Canada, 1995-2010 ...................... 189

Figure 18 - Fertility rates in selected Nordic and Anglo-Saxon countries and Quebec, 19952010 
Figure 19 -Relationship between the activity rate of women aged 25-34 and fertility rate in Quebec, 1995-2010. 192

Figure 20 - Unemployment rates of men and women in Quebec, aged 25-34, 1995-2010 193

Figure 21- Fertility rates by birth order, for children of rank 3 and over, Quebec, 1995-2010 .194

Figure 22 -Proportion of children in non-parental childcare, Quebec and the ROC, 1994-

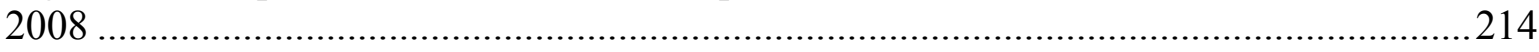

Figure 23 - Proportion of children in a childcare centre .................................................215 


\section{LIST OF ACRONYMS}

AA: Availability Allowance

ANC: Allowance for Newborn Child

APE: Allocation parentale d'éducation

AYC: Allowance for Young Children

BR: Birth rate

CAP: Canada Assistance Plan

CCCA: Canada Child Care Act

CCED: Child Care Expense Deduction

CCTB: Canada Child Tax Benefit

CFT: Crude birth rate

CLCA: Complément libre de choix d'activité

CMG: Complément de Mode de Garde

COLCA: Complément Optionnel de Libre Choix d'Activité

CPE: Centre de la petite enfance

CTB: Child Tax Benefit

CTB: Child Tax Credit

CHST: Canada Health and Social Transfer

CSST : Commission de la santé et de la sécurité du travail

ECDA: Early Childhood Development Agreement

ECEC: Early Childhood Education and Care

EI: Employment Insurance

FA: Family allowance

FR: Fertility rate 
FS: Family Supplement

GST: Goods and Services Tax

HST: Harmonized Sales Tax

ICA: Integrated Child Assistance

KCC: Kin Child Care

MFAELC: Multilateral Framework Agreement on Early Learning and Childcare

NCA: National Child Agenda

NCB: National Child Benefit

NCBS: National Child Benefit Supplement

OECD: Organisation for Economic Co-operation and Development

OSGE: Office des services de garde à l'enfance

PAJE: Prestation d'accueil du jeune enfnat

PBP: Parental Benefit Program

PWA: Parental Wage Assistance

QFA: Quebec Family Allowance

QMAP: Quebec Maternity Allowance Program

QPIP: Quebec Parental Insurance Plan

QUAD: Quality, universally inclusive, accessible, developmental

SSR: Social Security Review

SUFA: Social Union Framework Agreement

UCCB: Universal Child Care Benefit

UI: Unemployment Insurance

WIS: Work Income Supplement

WK: Work Premium 


\section{CHAPTER 1 \\ INTRODUCTION}

A few decades ago, the rapid increase in human population was considered to be an imminent threat. Though the world population continues to grow, it is also ageing. Decreasing fertility together with increasing life expectancy has reshaped the age structure of the population in most regions of the world by shifting the relative weight of the population from younger to older groups (United Nations, 2009). As a result, world population growth is predicted to come almost to a halt by 2050 . Shortly after, it may even start to shrink, as it already has in many highly developed countries (Takayama and Werding, 2011).

Part of the visceral dislike that some people feel about population shrinkage comes from the association of population shortage with tragic events such as wars, famine and epidemic (Sanderson, 2011). In developed countries however, population shrinkage occurs not because of privation but in an environment of high living standards, as people choose to have fewer children. There is no single theory that provides a comprehensive explanation for the long-term fertility decline in the developed world. What comes closest to this standard is the theory of the two demographic transitions (Lesthaeghe and Moors, 2000; Lesthaeghe and Neels, 2002). In the first transition, roughly from the end of the $19^{\text {th }}$ century to the $1960 \mathrm{~s}$, childbearing was confined to marriage, and family planning manifested itself by fertility reductions at higher ages, which led to declines in the mean ages at childbearing. The second demographic transition started with a contraceptive revolution, with the adoption of efficient methods of birth control that eliminated 
unplanned pregnancies. Hence, together with the postponement of marriage and the adoption of new living arrangements, fertility started to decline prior to age 30 . This explanation, however, is insufficient to theorize the variations between fertility trends experienced in rich nations, mainly because, most industrialised countries have now entered the second demographic transition.

Economists, sociologists and political scientists have all stepped in to propose theoretical frameworks for the study of contemporary reproductive decisions. For economists, fertility is seen as the result of rational choices by individuals or households, shaped by the preference of potential parents. Sociologists and political scientists have examined the parallels between gender inequalities and women's breadwinning and enduring caregiving responsibilities, in the light of different policy constellations. Since the 1990s, the comparative literature on social policies has shown the existence of different structural arrangements of states, markets and families that create social inequalities of a different nature and magnitude. Gender inequalities for instance, have been shown to be more acute in countries where the family is considered the main pillar of welfare, such as in Southern Europe, than where the state takes a more important role in the protection and promotion of welfare of its citizens, such as in Scandinavia. Fertility rates since the 1980s have also been much lower in the more conservative countries than in those that have had higher levels of gender equality. 
This dissertation offers a discussion of the social determinants of fertility, drawing connections between the demographic literature on fertility and the sociological literature on the existence of different models of 'fertility regimes'. More precisely, I examine patterns of reproductive behaviour in the Canadian province of Quebec between 1960 and 2010. Though Canada has shared with other Anglo-Saxon countries a preference for a minimalist welfare state and residual policies, the Canadian context offers not one, but ten distinct provincial variants, each reflecting a particular way in which the state reinforces or undermines the state and the family (Boychuk, 1998). One example of the variants is the province of Quebec, where class and gender inequalities are played out in a different way than in many other provinces, especially since the 1997 family policy. This dissertation examines the way in which social policies, economic cycles and norms regarding family formation have affected patterns of social reproduction in Quebec in the light of the gender equity theory developed by the Australian demographer Peter McDonald (2000a, 2000b, 2000c, 2002, 2006, 2010), and in the light of a new and related concept, the 'demotherization' of care work.

According to McDonald, low levels of fertility result from the tensions between high levels of gender equity in individual-oriented institutions such as the educational system and labour markets, and low levels of equity within families. Empirically, many studies have established a positive correlation between various measures of gender equality ${ }^{1}$ and fertility outcomes. Mencarini and Tanturri (2004) find evidence that a gender-symmetric role-set

\footnotetext{
${ }^{1}$ The reader will note the slip from the idea of gender equity to the notion of gender equality. I discuss gender equity and gender equality further in this chapter, and even more extensively so in chapter 4 .
} 
among parents with high socio-economic status in Italy increases their likelihood of having another child. Buber-Ennser (2004) argues that the active contribution of men in childrearing is a driving force behind plans for further childbearing in Austria. Feyrer et al. (2008), shows that the increased participation of men in the household reduces the disincentives for women to have additional children in Scandinavia and the United States. Similarly, Torr and Short (2004) demonstrate that a gender-egalitarian division of housework correlates with the transition to a second child among American couples. The common thread among these studies is that they show that gender-egalitarian environments, in which care-giving responsibilities are more equally shared between partners, favour higher fertility. Thus the need to introduce the idea of the 'demotherization' of care work, to express the degree of independence mothers enjoy from the necessity of performing care work.

Using the concept of the demotherization of care work, and building on McDonald's theoretical perspective and on the comparative literature on social inequalities within different welfare regimes, I argue that family-relevant policies that challenge the gendered division of care-work, by allowing women to download part of their caregiving responsibilities on the state and/or on their partners are the most effective in sustaining social reproduction and fertility. When women are offered opportunities in the market that are similar to those of men, and when maternity does not compromise gender equality, fertility rates remain relatively high. Inevitably, this observation raises the question of the effect of family policies on reproductive behaviour. One commonly tested hypothesis in comparative accounts of fertility regimes is whether family benefits increase births. The 
main problem with such an approach is that it assumes a unidirectional, dichotomous model (McDonald 2000a: 429).

This dissertation shows the uneasy correspondence between family-relevant policies and women's reproductive decisions. Most obviously, fertility was at its highest in Quebec when family policies were nonexistent, and has been at its lowest since family policies have been the most generous (i.e. since the mid-1990s). Yet, at the macro level of analysis, social policies are not the only determinants of reproductive behaviour. I suggest that changes in reproductive trends should be studied using an 'institutional approach' to fertility; accordingly, fertility outcomes are theorised as resulting from the articulation between the economic context, the sequence of key transitions in family life and the extent to which social policy allows care work to be demotherized. I also highlight the potential interaction effects between the economic context, social policies, the calendar of births and fertility outcomes.

To put it simply, I show that gender equality leads to higher fertility. This does not mean that women should be encouraged to act as 'honorary men' by opting out of all caregiving activities. Nor am I suggesting that all forms of care work should be institutionalised in order to make men and women more productive. There will always be children who wish to spend time with their parents, homework to do, lunch boxes to prepare and elderly who need to be driven to the doctor. Caregiving responsibilities will not go away, and many women (and men) enjoy looking after their children. A disproportionate focus on women's 
formal equality with men, most notably regarding earning and career path has a serious perverse effect. Equality strategies typically presuppose that men's life trajectories should be the norm, thereby disadvantaging women who take time off work to look after dependents (Lister, 1994; McDaniel, 2002, 2009; Cohen and Pulkingham, 2009). In this research, gender equality is understood and theorised as stemming from change in the gender structure of both caring and paid work, more as a result of men acting like women in taking dual responsibilities, than as women trying to follow men's life course (McDaniel, 2009). Rather than limiting the analysis to labour market inequalities, the emphasis takes into account the unequal structure of caring.

\section{Defining key concepts: 'family policy', 'social reproduction' and 'fertility rates'}

Besides the core concept of the demotherization of care work, there are two other key concepts at the heart of the thesis. The first is 'family policy'. There is a distinction to be made between a narrow and a broad definition of family policy. A narrow definition of family policy includes benefits and services that are exclusively targeted to couples with children and/or to single-parents (Gauthier, 2000; Takayama and Werding, 2011). These policies are mostly contingent on the number and age of children, as well as income and sometimes marital status of parents; they include direct transfers to families and subsidies, maternity and parental leaves as well as childcare facilities and subsidies (Gauthier, 2000; Takayama and Werding, 2011). However, other policies and regulations that may not a priori be regarded as being family-oriented can also modify the terms of the trade-off between work and maternity. According to a broad definition, family policy can be 
expanded to all public policies that may potentially have an impact on families (Gauthier, 2000; Takayama and Werding, 2011). Studies that have typically favoured empirical strategies have used what could be described as a 'narrow' definition of family policies. I have opted to use the broader concept of 'family-relevant policies' instead of 'family policies'. Family-relevant policies include for example, unemployment policies, divorce laws, access to free abortion, schooling hours, housing prices, etc. ${ }^{2}$ In other words, while some policy measures target family issues directly, others are part of broader policies that concern matters not primarily related to the family. Examined together, these policies may complement each other and form a holistic set of family-relevant policies, or they may be disjointed elements with no apparent coherent policy direction (Neyer, 2003).

The other concept utilised throughout the dissertation is 'social reproduction'. The concept of social reproduction is used in the literature to refer to three, often interrelated, realities (Luxton, 2006). First, the concept of reproduction refers to procreation, that is the ways in which any particular society organises conception, childbirth and infant viability. This definition of reproduction carries the ambiguities inherent in conception, pregnancy and birth (Luxton, 2006). Perhaps, a more precise term to discuss these processes would simply be the 'process of giving birth'.

Second, in Marxism, 'reproduction' is used to refer to the perpetuation of modes of production. This version of social reproduction analyses the ways in which paid

\footnotetext{
${ }^{2}$ For a discussion of the different component of family policies following a narrow and a broad definition, see Gauthier, 1999 and 2000.
} 
employment and unpaid domestic labour are part of the same socio-economic process. They are understood as independent processes of production and consumption that in combination generate the household's livelihood. Marxist scholars have highlighted the contradictions between productive and reproductive work. While accumulation in the economy depends upon the supply and regeneration of labour in households, the successful formation and maintenance of households is dependent upon the capacity of the economy to generate employment opportunities and wages at levels which permit households to initiate and maintain social reproduction (Dickinson and Russell, 1986). Hence, although there are tensions between social reproduction and production, these two aspects are part of one process of capital accumulation (Cameron, 2006).

Third, feminist political economists use the concept of social reproduction to describe the ordinary activities of daily life (Luxton, 2006: 36). This coincides with my understanding of the concept of social reproduction. Although the idea of social reproduction refers to the work involved in biological reproduction, it also goes beyond it to include the care and socialization of children. The unwaged aspect of the work of social reproduction is mostly performed by women in addition to their waged employment (Braedley, 2006). Consequently, social reproduction must be examined in tandem with family-relevant policies, and more specifically with policies that favour or hinder the reconciliation of work and family life. 
Social reproduction thus encompasses indicators such as fertility or birth rates. I use the concept of social reproduction to qualify social policies. I argue that family-relevant policies can be located on a continuum, from encouraging fertility to encouraging social reproduction, and from supporting the motherization to the demotherization of care work. In Quebec, some family-relevant policies have been specifically designed with the goal of raising fertility, without being particularly concerned with sustaining social reproduction in the long term. These policies have been less successful in increasing the number of births than policies that have helped women and couples to reconcile their earning and caring ambitions. In addition, social policies that have allowed care work to be moved away from the mother, such as universal childcare and daddy quotas, have not only supported social reproduction, but have also helped women translating their fertility ambitions into realizations.

\section{Measuring Fertility}

Statistics Canada, the Institut de la Statistique du Québec and other international agencies typically use three different variables to measure fertility: total fertility rate (TFR), crude birth rate $(\mathrm{CBR})$ and completed fertility rate (CFR). Both total fertility rates (TFR) and crude birth rates $(\mathrm{CBR})$ are cross-sectional measures of fertility. Both have the potential of shedding light on the effect of the institutional changes on reproductive behaviour. The CBR refers to the number of live births per 1,000 people. The major drawback of this indicator is that it is runs the risk of being affected by variations due to the age structure of the population. The CBR of a province with a high proportion of women of reproductive 
age for instance might be higher than the CBR of a province with a higher age profile. A high CBR would only reflect a large proportion of younger women in the population.

I thus use total fertility rates mainly to document changes in fertility trends. The TFR refers to the number of children a hypothetical female would have over the course of her reproductive life if she experienced the age-specific fertility rate observed in a given calendar year. The TFR is thus a cross-sectional and 'synthetic' rate, and not something that is actually measured. To put it simply, the TFR is an indicator of the average number of children an imaginary woman would have if she were to fast-forward through all of her childbearing years in a single year. In addition to the fact that TFRs rely on hypothetical behaviour, they also have the disadvantage of being affected by changes in the timing of birth (Kohler et al., 2002). A postponement or the anticipation of fertility has the potential of making TFR different from the level they would have in the absence of tempo changes (Kohler et al., 2002). The third indicator of fertility - the completed fertility rate (CFR) does not have this negative aspect. Unlike the TFR, the CFR does not rely on hypothetical behaviours. The CFR measures the number of children actually born per woman, in a given cohort of women at the end of their reproductive years (defined as 45 years old). CFRs therefore do not run the risk of being affected by changes in the timing of births.

There are nonetheless far more advantages to choosing TFRs over CFRs, at least in this research. First, the use of CFR requires researchers to wait a long time - that, is until a generation of women come to the end of their childbearing age - before they can analyse 
fluctuations in fertility. Therefore, in 2014, the completed fertility profiles could only be obtained for birth cohorts prior to 1969. Moreover, Henripin (1989) has shown that although fertility rates sometimes overemphasise trends that are observable in the completed fertility, the trends across the two measures of fertility are typically similar. Second, using TFR provides a yardstick for the benchmark level of replacement of fertility of 2.1 (Werding, 2011). Third, and most importantly, TRFs and CFRs are, as Mathews (1984) explains, two different measures. While TFR gives the researcher a snapshot of the fertility of all women of reproductive age on a specific year, the CFR concerns the behaviour of women of one generation. This is an important distinction, because this research is concerned with the reproductive behaviour of all women, when they are faced with a menu of options and constraints. Implied here is that changes in the gender and fertility regimes affect all women, independently of their age, or of the number of children they already have. CFR fails to indicate ongoing changes in fertility behaviour of younger women (Werding, 2011).

Mathew's argument is eloquent in this regard and is worth revisiting. According to Mathews (1984), when analysts argue that women reacted to the 1930 s crisis by postponing their pregnancy, but not by foregoing childbearing altogether, their interpretation is partly mistaken and even anachronistic. If the CFRs are indeed typically higher than the TFRs, it can only be because fertility increased after 1940. Women had reacted negatively to the economic crisis; they adjusted their reproductive behaviour in the light of the options and constraints they faced at that time. They could not know, however, that a decade later they 
would benefit from a better economic context. Hence, while some women might have decided to delay childbearing, others may have changed their plans. Put differently, the TFR of the 1930s was not artificially low. Such an argument challenges the idea of 'postponement' and of 'catching up' of pregnancies.

\section{Plan of the dissertation}

This dissertation examines the social reproduction behaviour of Quebecois women from the 1960s to the early 2000s. Using a comparative perspective, drawing on contemporary economic history of Quebec, I examine the conditions under which fertility trends have fluctuated over the last five decades. Since individuals build their futures on the basis of the circumstances they are faced with, I examine how economic cycles, social policies, and changes in the timing of defining life events such as age at first birth, affect reproductive behaviours. I argue that the theory that is the most relevant for understanding changes in patterns of social reproduction is the gender equity theory developed by McDonald, which I redefine as the 'gender equality' theory. I show that in Quebec, when women have had new opportunities to be active in the labour market but the social institutions in place did not allow reconciling paid work with social reproduction activities, women reduced their fertility.

I use two entry points - simultaneously and in parallel - for my research. My first entry point is the examination of irregularities in fertility trends in Quebec, to make sure that disruptions experienced locally are not the outcomes of a set of new and broad norms that 
transcend geographical boundaries. The second entry point mirrors the first approach. Rather than identifying disruptive fertility trends, I analyse the various family-relevant policies offered by the federal and the provincial governments to question whether these measures have had an impact on the demotherization of care work, theorized as one important indicator of gender equality within the caregiving structure of families. The starting point of the analysis is 1964 , when women in Quebec were granted full legal and property rights. The core of my policy analysis, however, is focused on the 1988 and 1997 family policy packages. In 1987, history was made when the Government of Quebec adopted its first family policy statement and created a Secrétariat and a Conseil de la famille (Government of Quebec, 2008). The following year, Quebec announced different family policy measures, including a family allowance for all children under 18 years of age and an additional allowance for children under the age of six. The most popular of these measures was indisputably the family 'allowance for newborn children' (ANC), otherwise known as the baby bonus. Less than 10 years after the introduction of the baby bonus, Quebec proposed a whole new family policy package, with an integrated child benefit for low-income families, universal and good quality childcare at low cost, and the promise of a longer, and better paid parental leave.

Family-relevant initiatives are assessed using the concepts of equality and equity. Thus, I try to reconcile fertility trends with changes in the economic cycles, different indicators of the 'deinstitutionalization' of the family, and the characteristics of family-relevant policies offered by both levels of government. That said, chapters 1,2 and 3 are foundational 
chapters in which I introduce the object under study - the social determinants of Quebec's fertility regime. In chapter 2 , I argue that the existence of the intergenerational social policies and the distinctive Quebecois culture are under threat, precisely because Quebec has below-replacement fertility rates. In chapter 3, I discuss previous attempts to explain fertility behaviours in the light of economic and sociological theories. I show the limited relevance of the theories developed by Gary S. Becker, Richard Easterlin, Louis Roussel and Catherine Hakim to explain patterns of social reproduction in Quebec. I also introduce McDonald's gender equity theory, as a point of departure to theorise my approach to study social reproduction.

In chapter 4, 5 and 6, I locate Quebec within the international and Canadian worlds of welfare capitalism and I develop my institutional approach to the study of fertility. In chapter 4, I show that while Quebec belongs to a liberal welfare regime, family-relevant policies in this province are closer to those found in social-democratic countries. I also discuss the concepts of defamilialization and demotherization and I introduce a new typology of fertility regimes, with four types of familialism, 'implicit', 'gendered', 'institutional' and 'de-gendered/generational'. In chapters 5 and 6, I discuss the institutional approach, which begins with the assumption that at the macro level, states, markets and families, create an environment that is more or less favourable to maternity. In chapter 5, I report on the effect of the structure of the labour market and of the deinstitutionalization of the family on social reproduction. I show that economic slowdowns are typically associated with lower fertility, especially in the Southern European countries, in Scandinavia and in 
Sweden, while 'flexible' labour markets lead to higher fertility, most notably in the United States. I also address the paradoxes between on the one hand, marriage, divorce, age at first births and births out-of-wedlock, and, on the other hand, fertility outcomes in developed countries. Chapter 6 presents an extensive literature review on the possible tempo and quantum effects of family policies on fertility. While the effect of policies is complex and often contradictory, I show that three specific policies - parental leaves, the availability of childcare (in various forms) and the income-tax system - are the most likely to affect the quantum of births. The periodization of Quebec's fertility regimes is also presented in chapter 6.

Chapters 7, 8 and 9 investigate Quebec's fertility regime. A recurrent theme that cut across these chapters is the lack of initiatives regarding the development of family-relevant policies at the federal level, from the 1960s on. Though the federal government has put in place measures that allowed a certain level of economic defamilialization, social policies continued to favour the motherization of care work. In contrast, between 1960 and 2010, Quebec moved from a fertility regime that supported 'gendered familialism', where mothers were assumed to be ready, willing and able to perform childcare activities, to a policy architecture that encouraged de-gendered/generational familialism in which men actively contribute to caregiving chores.

In chapter 7, I show that between the early 1960s and the mid/late 1980s, though women were faced with new opportunities in education and the labour market, Ottawa and Quebec 
continued to support equity over equality through policies that continued to assume gendered familialism. Declining fertility was the result of both of deinstitutionalization of the family and of women's difficulty of combining earning and caring tasks. Quebec's first family policy is discussed in chapter 8 . In the late 1980s, though motherhood and labour market activity continued in many ways to be difficult to reconcile, yet because of the good economic context, women did not have to make difficult choice between productive and reproductive work. The 1988 pronatalist policy did not demotherize care work and did not challenge the gendered division of labour. As a result, new family-relevant measures introduced in the 1980 s - including the baby bonus- did not have a long-term positive effect on births. In contrast, the 1997 policy, discussed in chapter 9, put in place new structures that took on a significant part of child caregiving activities, making it easier for women to work and to have the number of children they desired. Quebec's new parental insurance program that became effective in 2006 also challenged the gendered division of labour with its 'take-it or leave-it' father's quotas. Since then, both women's labour market activity and fertility levels have remained relatively high. 


\section{CHAPTER 2}

\section{WHY SHOULD WE CARE ABOUT LOW FERTILITY IN QUEBEC?}

Population aging, the process by which older individuals become a proportionally larger share of the total population, affects most industrialised countries. Canada is among these countries, where seniors make up the fastest-growing age group (Statistics Canada, 2010). While the median age of the Canadian population was 26.2 in 1971, it went up to 39.9 years in 2011. Population aging has important consequences and implications for all facets of human life. Among other things, the decreasing ratio of working population to elderly raises concerns for the long-term sustainability of the social support systems. In Quebec, below-replacement fertility is an issue for both politicians and intellectuals. In Quebec, as in other industrialised countries, low fertility affects economic growth. Moreover, the survival of the distinct Quebecois culture, values and language are threatened by two phenomena: the decreasing demographic weight of the province within Canada and the increasing proportion of the Quebec population whose mother tongue is not French. ${ }^{3}$ Finally - and perhaps most importantly - longitudinal studies carried out both in Quebec and abroad show that there is a persistent gap between fertility intention and fertility realization. In other words, women are not giving birth to the number of children they desire.

\footnotetext{
3 The objective here is obviously not to give up to an apocalyptic scenario about the disappearance of Quebec's distinctive culture, nor is it to build a patriotic argument that focuses on women's duties of citizenship to save Quebec's nation through their reproductive potentials.
} 


\section{The aging population in numbers}

The Population Division of the United Nations reports that population aging is unprecedented and that by 2050 , for the first time in history, the number of older people in the world will exceed the number of young (United Nations, 2002). In absolute terms, the number of older people has tripled over the last 50 years and will triple again over the next 50 years; in relative terms, this means that globally the older people's share of the population is projected to more than double during the same period (United Nations, 2002: $33)$.

Population aging is not only the result of rising life expectancy and an increasing proportion of elderly people; it also stems from declining fertility. A declining fertility rate increases the average age of the population by changing the balance of young people to older generations. Of these two forces - rising life expectancy and decreasing fertility - the latter is the dominant contributor to population aging (United Nations, 2002; Weil, 1997). A third factor affecting the age distribution of populations is migration. Nevertheless, the role of migration in changing age structure has been far less important than that of fertility and mortality (United Nations, 2002). Even in Canada, one of the countries with the highest immigration rate, ${ }^{4}$ the number of newcomers is not high enough to significantly affect the age composition of the country (Anderson and Hussey, 2000).

\footnotetext{
${ }^{4}$ Anderson and Hussey (2000) reports that among the eight countries they studied -Australia, Canada, France, Germany, Japan, New Zealand, the United Kingdom and the United States- Canada and Australia had the highest immigration rates.
} 
The three figures presented below eloquently illustrate the need to be concerned about Quebec's aging population. Figure 1 illustrates the proportion of the population 65 years and older in all provinces in 2006 and projected for 2031. While in comparison to other Canadian provinces, Quebec's population is relatively young - only in Alberta, Newfoundland and Ontario was the proportion of elderly lower in 2006 - demographic trends imply that, in less than 20 years, Quebec will rank among the oldest populations. By 2031 only the Atlantic provinces will have a higher proportion of elderly people. Figures 2 and 3 illustrate the age pyramid of the province of Quebec in 2008 and in 2031. The obvious conclusion is that the age distribution in the province looks more and more like a reverse pyramid. What may not be obvious from the figures, however, is the fact that the median age, which separates the population into two equal parts, is predicted to rise from 41 in 2008 , to 47 in 2031. 
Figure 1 - Population 65 years and over, Canada and provinces, 2006 and projected 2031

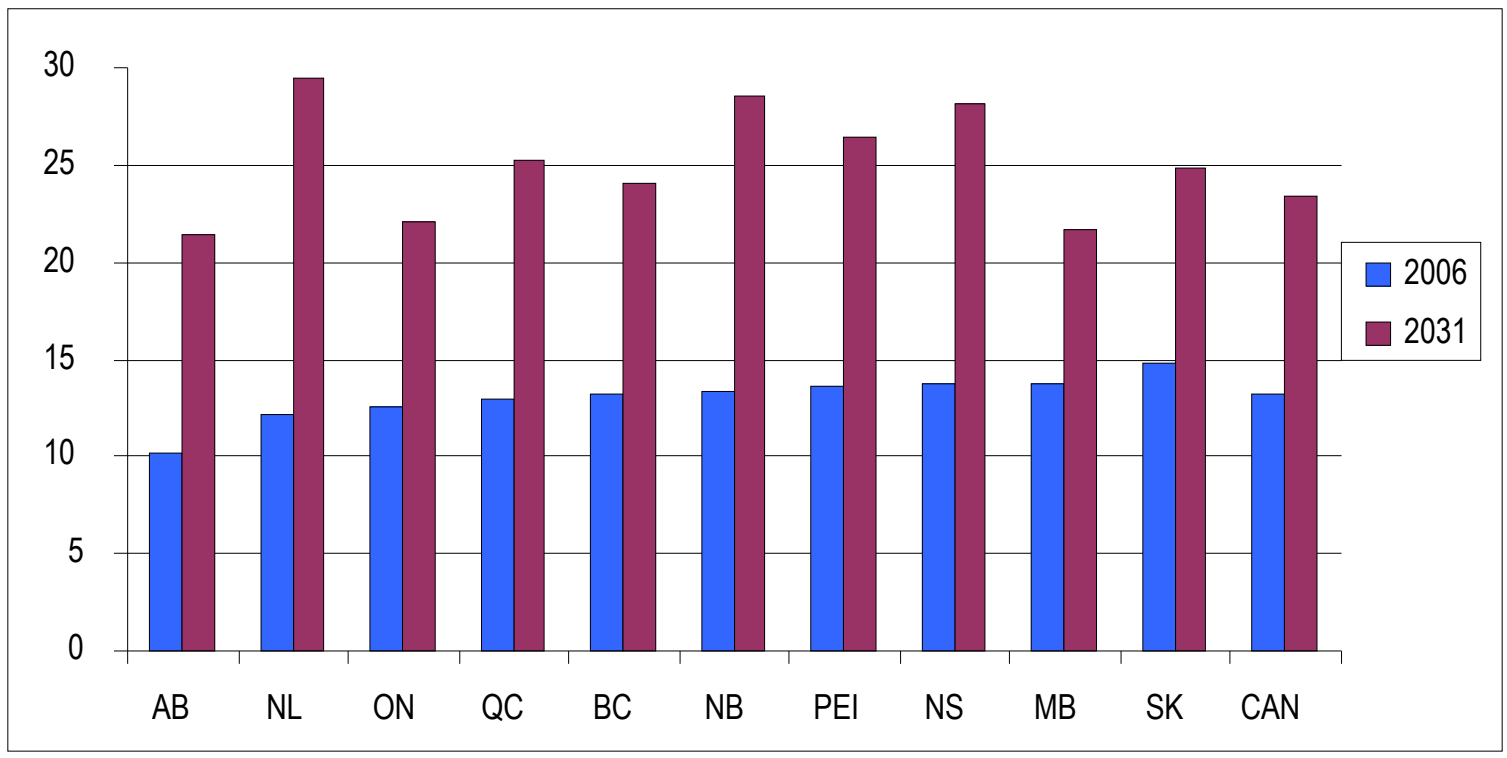

Source: Statistics Canada (2013a), and Statistics Canada (2005).

Figure 2 - Age Pyramid of the population of Quebec, 2008

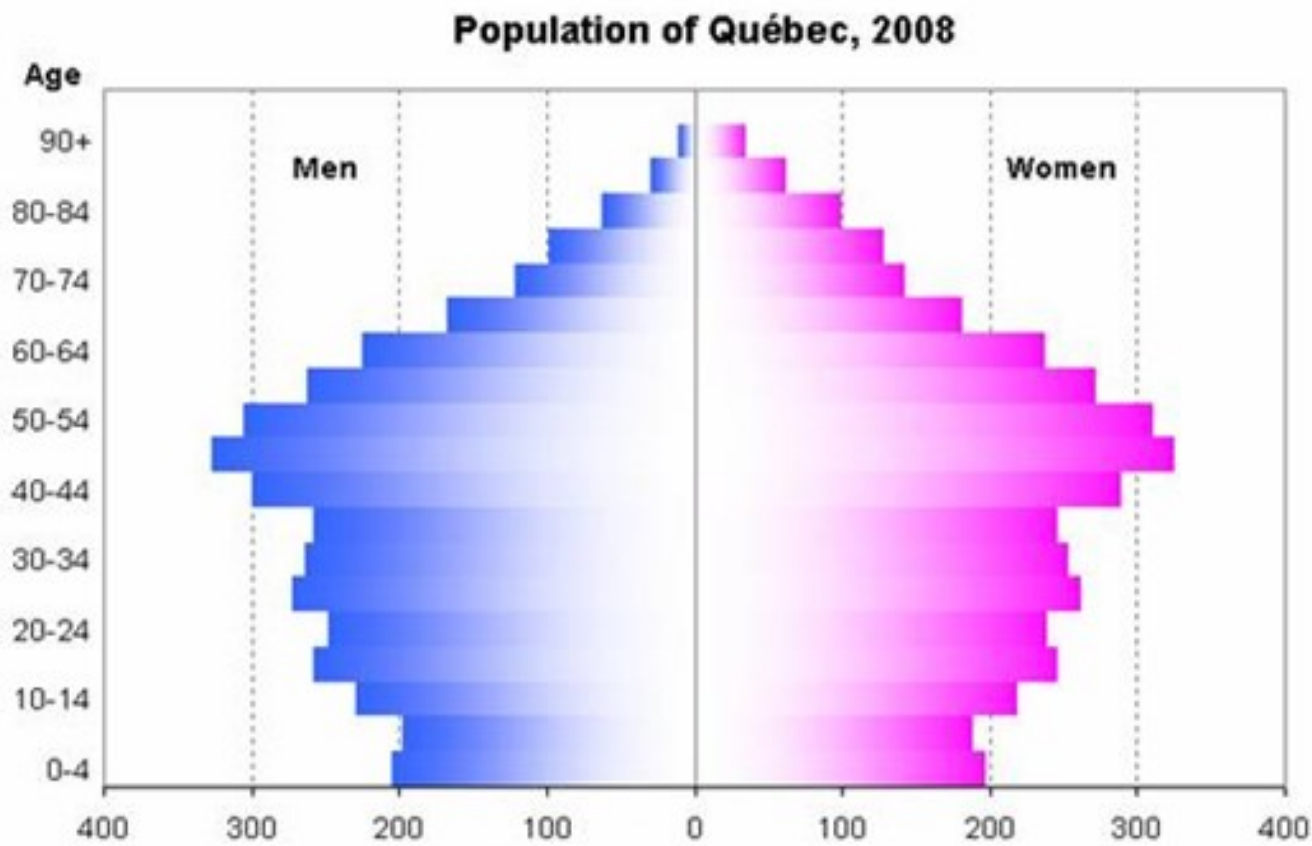

Source : ISQ (2013). 
Figure 3 - Age pyramid of the population of Quebec, 2031

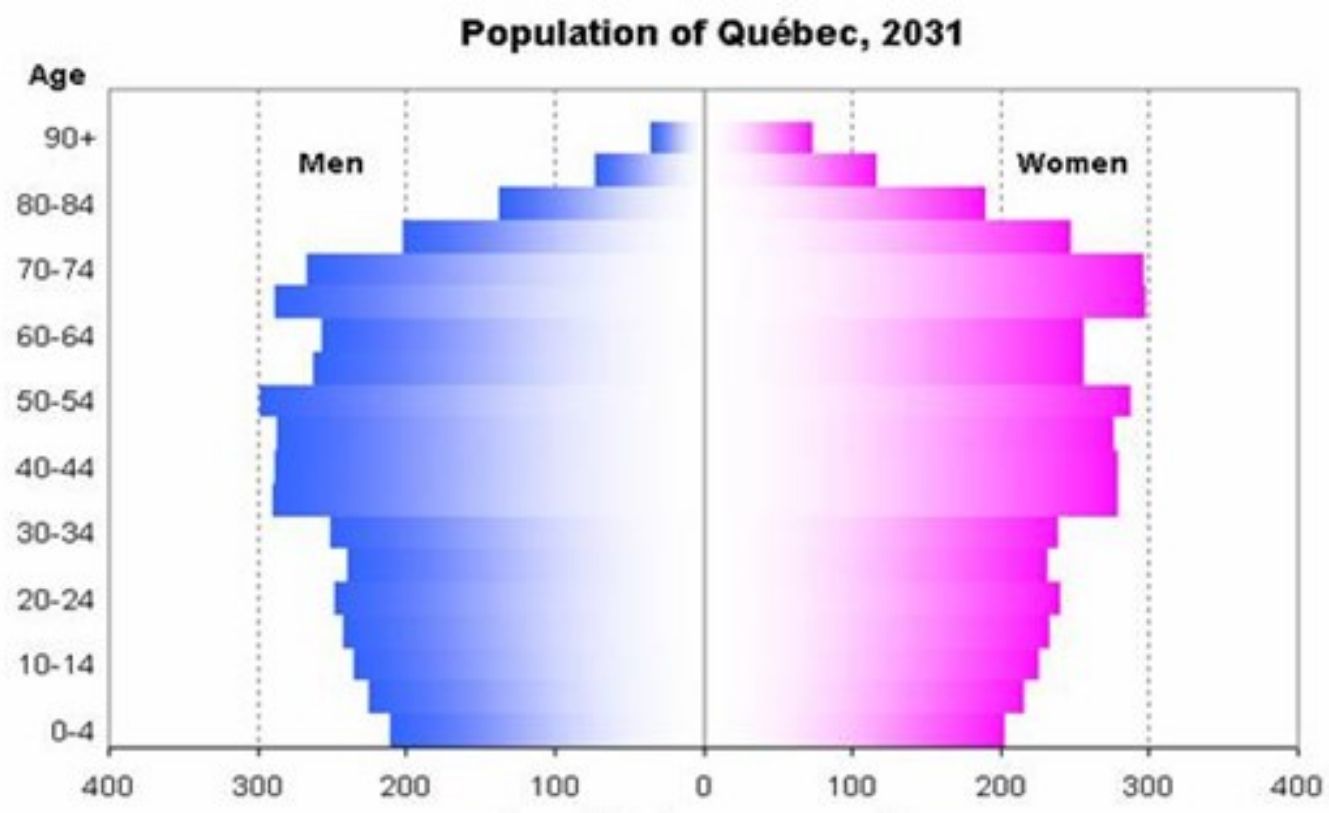

Source: ISQ (2013).

\section{From economic growth to the survival of the culture}

Despite considerable disagreement about the causes of low fertility and the severity of its effects, there has been a general consensus that developed countries will be facing a crisis of low fertility that will affect economic growth. There are several mechanisms through which a high proportion of young adults in a society lead to more rapid economic growth than one with a high proportion of older people. Most obviously, a high number of elderly combined with smaller birth cohorts could create an unsustainable scenario for economic well-being (Bloom et al., 2010; Werding, 2011). If a larger fraction of the population is of working-age ${ }^{5}$ and employed, each individual bears a lighter share of the financial burden

\footnotetext{
${ }^{5}$ The contentious issue here is obviously to define 'working age'. While most seniors retire by age 65 , many continue to work beyond this traditional milestone. In Canada, policy changes that have eliminated the
} 
entailed by an aging population. Unless the activity rates of specific groups such as women, young people and elderly significantly increase, reductions of the working age population may imply reduction in labour supply (Werding, 2011).

There are at least two other reasons to be particularly worried about Quebec's aging population. First, Quebec is the only French-speaking nation in North America. The history of Quebec has been one of struggles for the survival of the French language and, more broadly, French culture. Quebec's history since the loss of the Battle of the Plains of Abraham in 1759 has been punctuated with tensions between the English-speaking majority and the French-speaking minority. ${ }^{6}$ From Lord Durham, who openly claimed the need to assimilate French-Canadians, to the 'night of the long knives' of 1981, many Quebecois came to the conclusion that English speakers - and more broadly non-Francophones - were a threat to the distinctive Quebec culture. More recently, tensions over the integration of immigrants culminated in the launching of a large-scale commission on what came to be known as accomodements raisonnables ${ }^{7}$ ('reasonable accommodations'). The BouchardTaylor Commission Report ${ }^{8}$ revealed that many Quebecois had strong feelings of insecurity regarding the survival of their culture and that they feared losing their values, language,

mandatory age of retirement, improved education levels and health status over time have created conditions for people to work longer. As a result, in 2006, about 1 in 10 seniors participated in the labour market (Uppal, 2010).

${ }^{6}$ The reader will note that it was only during the Quiet Revolution that the French-Canadians living in the province of Quebec began to refer to themselves as Quebecois.

${ }^{7}$ A reasonable accommodation is an approach to deal with ethno-cultural diversity in Quebec. This approach proposes to make compromises in various areas of social life to take into account the special needs of some religious and ethnic minorities.

${ }^{8}$ Gérard Bouchard and Charles Taylor were the two commissioners mandated to study the crisis of the reasonable accommodations. 
tradition and customs and even eventually disappearing entirely as a French-speaking minority in North America. In 2010, the debate over the survival of the French language was directed again towards the fear of Anglicization of future generations. In 1977, the Charter of the French Language, also known as Bill 101, defined French as the only official language of Quebec. Bill 101 also made French the language of instruction from kindergarten to secondary school. Access to English schools was thus limited to children whose either parent had been educated in a public English-school in Quebec. Bill 115 passed in October 2010, changed this rule. For the first time since 1977, it made access to English-only schools easier for all children, which caused many French-speaking Quebecois to worry about the Anglicisation of the province. ${ }^{9}$ The Parti Québecois in power from 2012 to 2014 promised to abolish Bill 115, but it failed to do so.

The fear of assimilation or of the 'louisianization'10 of Quebec is to some extent justified. According to Termotte $(1999,2003)$, although the majority of the Quebecois will be French-speakers in the mid-2000s, only 43.5 per cent of the people living in Montreal will be Francophones by 2041. The rest will be Allophones (37 per cent) and Anglophones (19 per cent). ${ }^{11}$ While fertility rates among Francophones are below the replacement rate, Allophones have high fertility (close to or above the replacement rates), and a lower

\footnotetext{
${ }^{9}$ Bill 115 grants students access to the English public school system after spending three years in a private non-subsidized English school, otherwise referred to as "bridging schools". The purchase of three years of private education has been as a quick way to gain access to English education for a child, and subsequently all of their siblings.

${ }^{10}$ 'Louisianization' is the term to refer to the Anglicization of French Louisiana in the United States.

${ }^{11}$ Using data from the 2006 Canada census, Leclerc (2010) reports that French was the mother-tongue of only 48.8 per cent of Montreal's population.
} 
mortality rate, which contributes to their rising demographic weight in the province (Termotte, 2003).

Yet another reason to be concerned with Quebec's aging population relates to the demographic weight of the province within Canada and North America. ${ }^{12}$ Demographers estimate that the Canadian and American population will have a 1 per cent growth over the next 15 years, compared to 0.6 per cent in Quebec (Government of Quebec, 2009). Moreover, for the first time of its history, the demographic weight of Quebec within Canada has fallen below 24 per cent (Desgagné, 2007; Shields, 2007), following a long and steady decreasing trend (Langlois, 2004). ${ }^{13}$ The decreasing demographic weight of Quebec will soon affect the political weight the French-speaking province within the Canadian federation. In December 2011, the federal Conservative government led by Stephen Harper announced that 30 seats were to be added to the House of Commons, expanding the number of ridings from 308 to 338. Of these Quebec got three seats, keeping its share of seats precisely equal to its 23.1 per cent. ${ }^{14}$ From the 2015 election, the political power of Quebec within the Canadian confederation will diminish. This is not without consequences for the province of Quebec, whose population strongly rejects some of the recent changes in Canadian legislation celebrated by the Conservative Party. ${ }^{15}$

\footnotetext{
${ }^{12}$ It is not the number of Quebecois per se that matters, as much as the proportion of French-speaking Quebecois within Canada.

${ }^{13}$ Langlois (2004) reports that in 1961, the population of Quebec represented 28.8 per cent of the Canadian population. Two decades later, this proportion was at 25.2 per cent and by 2001 , it had fallen to around 23.8 per cent.

${ }_{15}^{14}$ Under current seat distribution, Quebec has 75 seats or $23.28 \%$ of seats in the Commons.

${ }^{15}$ The most obvious examples are the restoration of the word 'royal' to the Canadian military, the rejection of the Kyoto Protocol and the Bill to kill the gun registry.
} 
As mentioned above, the increase of older age groups in Quebec's population, both in absolute terms and in relation to the working-age population, has a direct bearing on the intergenerational equity and solidarity that are the foundations of the society. By the end of the 1960s, at a time of dynamic economic and demographic growth, federal and provincial governments had put into place pensions plans based on a pact between generations: pension plans were set to be financed through contributions from workers. ${ }^{16}$ With an aging population, this type of arrangement becomes difficult for the working population, who are less numerous, to bear the costs of a larger number of pensions. In Quebec, the ratio of people aged 20-64 to people entitled to receive pensions (people aged 65 and older) dropped from 10 to 1 in 1941 , to 3.6 to 1 in 2001 and by 2021 it would be around 2 for 1 (Légaré, 2003: 188). ${ }^{17}$ As more people live longer, retirement, pensions and other social benefits tend to extend over longer periods of time. An aging population places a heavy financial burden on younger generations to maintain existing social welfare programs aimed at accommodating the elderly.

Thus Quebec's aging population - which mainly results from below-replacement fertility brings along a variety of issues, from concerns about the overall economic growth, to the rising costs of pensions and services to support and accommodate the elderly, to the need for more immigrants and the fear of the decreasing importance of the French language and

\footnotetext{
${ }^{16}$ The Quebec Pension Plan also provides survivor's and disability benefits.

${ }^{17}$ Assuming retirement remains 65. Other countries such as Sweden have raised retirement ages to 67.
} 
culture that come with a higher proportion of newcomers ${ }^{18}$. Several kinds of solutions have been suggested to cope with these issues. In Europe, Bloom and al. (2010) have suggested that government and policy makers encourage higher labour force participation to prevent the potential negative economic effects of demographic changes related to low fertility. Changing social policy and childcare support could in that regard encourage people to remain in, or to re-enter, the workforce. In Quebec, services, programs and laws have been put in place to facilitate the integration of immigrants. Bill 101 and francisation measures such as the 1,000 hours of free French lessons - are the two most notable examples.

In conjunction with new policies such as increased immigration and francisation measures, one alternative is to encourage women who wish to have more children to do so. ${ }^{19}$ In other words, part of the solution to the demographic problem Quebec faces could be to better support women to enable them to bear the number of children they desire. The idea, if not framed or understood appropriately, may seem controversial. Let me thus first explain what it is I am not suggesting.

First I am not suggesting that women should be encouraged to increase their fertility through explicit pro-natalist initiatives (such as baby bonuses). Such an approach would

\footnotetext{
${ }^{18}$ In Quebec however, the proportion of newcomers that claim to be able to speak French is rising. Between 1993 and 1997, 34.8\% of immigrants pretended they could speak French; this proportion rose to $63 \%$ between 2008 and 2012 (ISQ website, 2013).

${ }^{19}$ I am not suggesting increased fertility will resolve all the concerns associated with an aging population. For example, if fertility was to dramatically increase among Anglophones and Allophones, but not Frenchspeaking women, the survival of the French culture in Quebec would be threaten. Thus, increased fertility, for women who wish to have more children, is one avenue among a menu of solution to cope with Quebec's aging population.
} 
create two classes of women, one of perennial mothers - typically less educated women who devote their lives to motherhood and social reproduction, and another, perhaps bettereducated group of women, who work full time and are free of childcare responsibilities. The idea is not to encourage women to return to their traditional role, nor to withdraw from the labour market.

I agree with Neyer's (2010) controversial argument ${ }^{20}$ that governments should not use gender equality policy instrumentally to raise fertility. Gender equality is a value per se, and it not a panacea against low fertility. That being said, gender equality policies have the double advantage of helping women to overcome inequalities they meet in the labour market (low pay or precarious work) and in the family (by regulating the conditions of entry and exit from marital unions), but also by allowing women to be mothers and to have the number of children they wish to have.

Second, I am not suggesting that giving birth should be anything less than a decision women make freely: access to contraception and abortion should not be restricted. Nor do I suggest women should sacrifice their professional or personal dreams and ambitions to accomplish what could be seen as their duties of citizenship. Although giving birth is a gift women make to society by reproducing and raising future workers and taxpayers, childbearing remains to a large extent a personal decision, framed by opportunities and

\footnotetext{
${ }^{20}$ Neyer's paper is based on a debate held at the Max Planck Institute for Demographic Research in Rostock in February 2006 at which participants were asked to bring forth arguments for and against the following proposition: "should governments in Europe be more aggressive in pushing for gender equality to raise fertility?". Neyer argued against the proposal.
} 
limiting conditions. Finally, the point here is not to find solutions to low fertility as much as to understand how gender equality, women's fertility realizations and female labour force participation are related to different types of structural arrangements.

\section{Fertility intention and fertility realization: a persistent gap}

Research both abroad and in Quebec has shown that women desire to have more children than they actually bear. Family size preferences have been gathered as part of many surveys for several decades in Europe. Many factors have been found to increase (or decrease) the gap between fertility preferences and fertility realization. Demographic analysis of these preferences link fertility intentions to individual socio-demographic characteristics, such as women's age, marital and employment status. The effects of key life transitions in the lifecourse such the timing of union formation also explain part of the disjunction between fertility intentions and behaviour (Edmonston et al., 2010; Morgan and Rackin, 2010). Finally, ideational factors (such as religious affiliation, and family and gender values), norms (the two-child norm) and institutional structures (such as parental leaves and childcare availability) all have a pivotal effect on realised fertility (Beaujot and Muhammad, 2006; Coenen-Huthier, 2005; Goldstein et al., 2003; Lyngstad et al., 2010; Quesnel-Vallée and Morgan, 2003; Ryser et al., 2010; Testa and Toulemon, 2006; Van Peer, 2002). Although the effects of individual characteristics on realised fertility produce mixed results across countries, ${ }^{21}$ there is a general agreement in the literature on the

\footnotetext{
${ }^{21}$ The type of union, for instance, affects fertility differently across developed countries. Drawing on previous studies on the gap between fertility intentions and subsequent realization, Régnier-Loilier and Vignoli (2010) report that Schoen et al. (1999) and Quesnel-Vallée and Morgan (2003) found that married couples were more
} 
existence of a gap between fertility ideals and completed fertility. At the empirical level, research has shown that levels of ideal family size are typically well below respondents' desires and intentions. Chesnais (1998) even reports that in the European Union in the late $1990 \mathrm{~s}$, the total fertility rate was 1.4 whereas the desired number of children was 2.1 (Chesnais, 1998), a finding that Bongaarts (2001) concurred. In the words of Chesnais (1998: 94):

$[\ldots]$ the main point is that the desired family size is usually close to the replacement level, whatever the member country of the EU-15 considered; young couples predominantly still wish to have two children (the preference of this model varies from one-half to twothirds of them) and sometimes three children (second choice). Of course, the reality is far from this wish in countries like Italy and Spain where the obstacles to childbearing are enormous and the economic sacrifices made by mothers are viewed as unbearable.

The relationship between fertility intentions and actual fertility is therefore complex and cannot always be explained by a causal model (Toulemon and Testa, 2005). Two countries that have similar ideational fertility patterns may have very different fertility rates. For example, the vast majority of French and Italian women still want two children, and the profiles of women who do not desire the two-child family norm are also very similar in France and Italy. Nonetheless, France and Italy are at the two extremes with regards to fertility, with the former holding the European record for persistent and high fertility while the latter is one of the industrialised countries with the lowest average number of children per women (Régnier-Loilier and Vignoli, 2010; Vignoli and Régnier-Loilier, 2009).

likely to realise their intentions of having (another) child in the United States, while Toulemon and Testa (2005) showed that in France the type of union did not have any significant influence on subsequent fertility behaviours. 
The only study that found an empirical indication of decreased fertility intention is Goldstein's et al. (2004) study of ideal family size preferences in the German-speaking parts of Europe. Goldstein et al. (2004) argue that the average family size ideals in Austria and Germany have fallen well below replacement rates. This decline does not seem to apply to other European countries. Their analysis, however, fails to acknowledge that women may adjust their ideal preferences in the light of their experience. It has been argued that Germany and Austria have had institutional arrangements that favoured a traditional division of work between men and women (Esping-Andersen, 1990, 1999; Mathieu, 2003; Stier et al., 2001). Women may thus have adjusted their fertility ideal when they realised the institutional constraints associated with maternity.

The gap between fertility intention and fertility realization has also been studied in North America. The same conclusion concerning the disjunction between fertility ideal and fertility realization applies there as well. Indeed, research has shown a correspondence between fertility intentions and behaviour in the United States (Hagewen and Morgan, 2005; Morgan and Rackin, 2010; Quesnel-Vallée and Morgan, 2003), but for a great majority of individuals this is not due to high congruence between ideal family size and family realization. Rather, a substantial proportion of individuals have had more children than they had originally intended, and these individuals contributed to 40 per cent of the births, although they constituted less than a fourth of the sample (Morgan and Rackin, 2010: 117). Thus, the observed total fertility rate in the United States is raised relative to intentions by factors such as unwanted fertility, and attenuated by fertility postponement 
including infertility and competition with other activities (Hagewen and Morgan, 2005). The dominant American ideal is for two or three children and this preference has persisted for the last three decades.

As for Canada, Edmonston et al. (2010) have examined trends in fertility intentions based on an analysis from four national household surveys. Their study shows relative stability with regards to fertility intentions of Canadian women over the past 16 years, moving from a narrow range of 2.11 to 2.29 children. The mean intended fertility for women in married or cohabiting unions has consistently been above the 2.1 replacement rate: it even rose from 2.19 in 1990 to 2.21 in 1995 , and 2.29 in 2001 , before declining to 2.11 in 2006 . The distribution of fertility intentions, according to Edmonston et al. (2010), has not changed greatly and has centered on two children for about half of Canadian women. The second most common intention (for 23 per cent of women) is to have three children. Childless intentions remained stabled with about 7 per cent of women intending to have no children. While Edmonston's et al. study focuses on Canada as a whole, they show that compared to the reference category of women who speak English only at home, women who speak French only reported statistically significant lower fertility for 2001. Moreover, using Ontario as the reference category, differences in intended fertility for the other provinces were not statistically significant. Thus, the analysis did not reveal any strong or consistent provincial differences in intended fertility. To put it differently, like other women in Canada, Quebecois women have higher fertility expectations than fertility realization. 
Finally, there have been very few studies to explain the link between fertility intention and fertility realization in Quebec. Using data compiled in the early and mid-1970s on fertility intentions, Evelyne Lapierre-Adamcyk (1981) finds no sign of decreased popularity for the two children family in Quebec. The proportion of adults who reported wanting only one child did not significantly increase in the 1970s, while the proportion of respondents who wished to have three children did not decrease substantially. Two decades later, LapierreAdamcyk (2001) and Lapierre-Adamcyk and Lussier (2003) reached a conclusion similar to that of European and American researchers: the fertility wishes of Quebecois women were higher than their actual fertility rates. In 1971 and 1977, women and men wished to have 2.5 and 2.4 children respectively (Lapierre-Adamcyk and Lussier, 2004). LapierreAdamcyk and Lussier (2003) concluded that fertility intentions tended to decrease as women and couples were faced with the reality and the responsibilities that having children entailed.

\section{Conclusion}

The process of population aging is the result of both increased longevity and fertility decline. Decreasing fertility has a stronger impact than life expectancy on the age structure of the population. Quebec's population is aging because women are not having enough children to replace the population. International, Canadian and Quebecois research however, has shown that Quebec's low fertility does not result from a significant change in ideal family size. Empirical studies across developed countries and in Quebec clearly show that women do not have as many children as they wish. It has been hypothesised that when 
women are faced with the daily work and constraints that come with raising a family, they reduce their fertility intentions. Studies show that if women realised their fertility wishes, fertility rates would be above replacement.

These observations raise many questions. Why have women not been able to realise their fertility intentions? Why in the past five decades have fertility rates dropped and fluctuated so much? While the steep fertility decline of the mid 1960s is partly the result of the commercialization of the pill and of the decriminalization of abortion, other forces have had an impact on women's fertility since then. It would be overly deterministic to argue that fertility rates dropped only as a result of new body rights. The discussion of the gap between fertility aspirations and fertility realization suggests that women and couples not only act with reference to their values and their preferences, but also with respect to the institutional environment that structures their day-to-day life opportunities and constraints. Childbearing can indeed be viewed in terms of the desires people have, but it can be also viewed in terms of the constraints under which they operate (Beaujot and Muhammad, 2006). For women, these constraints include the challenge of finding a suitable partner and the difficulty of reconciling professional and childbearing ambitions. Different theories have been formulated to explain the fertility drop that occurred in industrial countries over the last five decades. I introduce and discuss these theories in the next chapter. 


\section{CHAPTER 3}

\section{EXPLANING THE DROP IN FERTILITY: FROM ECONOMIC THEORIES TO THE GENDER EQUITY THEORY}

The determinants of women's reproductive decisions have been examined by different fields of scholarly work. On the one hand, demographers have focused on the importance of tempo effects, ${ }^{22}$ notably delayed childbearing, as an explanation for low period fertility rates. There is a broad agreement among these scholars that the era of lowest-low fertility emerged as a direct consequence of fertility postponement (Goldstein et al., 2009; Kohler et al., 2002). Though demographers have developed important indicators to measure births, their analyses of fertility have tended to remain descriptive and few developed theories to explain the causal mechanisms of the fertility decline. ${ }^{23}$ Economists and sociologists on the other hand have developed numerous - and often contradictory - theories. Among the economists, Gary S. Becker (1960, 1981) and Richard Easterlin (1961, 1968, 1973, 1978), have arguably produced the most important theoretical and empirical work. Their theoretical models are nonetheless inadequate to explain social reproduction in Quebec. At least two sociologists, Louis Roussel $(1987,1989)$ and Catherine Hakim $(2000,2003)$, have offered theoretical models to explain fertility behaviour. In the French literature, Roussel $(1987,1989)$ has received a great deal of attention by linking the overall fertility drop in industrialised countries to the 'deinstitutionalization of the family'. In Quebec, however,

\footnotetext{
${ }^{22}$ The tempo effect is due to changes in the timing of births. I discuss this phenomenon extensively in chapter 6.

${ }^{23}$ In that regard, Schofield and Coleman (1986:1) write: "Any subject which finds it necessary, or indeed possible; to consider its material divorced from an appropriate body of theory must be in trouble. This seems to be the case with demography at present" (cited in de Bruijn, 2002: 407). According to de Bruijn, this opinion has been shared by a number of scholars in the past few decades.
} 
reproductive trends cannot be easily linked to marriage and divorce trends. Hakim's Preference theory $(2000,2003)$ has emphasised the importance of women's heterogeneous preferences with regards to fertility, but has failed to take into account the opportunities and constraints women face when they make their reproductive choices. The sociological literature on the determinants of fertility is obviously not limited to Roussel's and Hakim's work. Women make reproductive decisions within a specific institutional context that either challenges or emphasizes androcentrism and a traditional gendered division of care work. Social policies, the structure of the economy and new norms pertaining to cohabitation and the transition into motherhood all have an impact on social reproduction. The literature on the effect of the differentiated arrangements of states, markets and families on fertility is briefly discussed in this chapter, but it is examined in greater detail in chapters 4, 5 and 6 .

There is at least one other macro-sociological theory that explains women's changing fertility behaviour: the gender equity theory recently developed by the Australian demographer Peter McDonald (2000a, 2000b, 2000c, 2002, 2006, 2013). In essence, this theory suggests that the loss of gender equity entailed by the birth of a child negatively affects women's reproductive decision. The gender equity theory has the singular advantage of taking into account the effects of institutional factors on reproductive decisions. 


\section{The economic theories: Easterlin and Becker}

Economists have developed two primary models to explain how fertility reacts to economic factors as opposed to changes in preferences or the social context as explanatory factors. First, Gary S. Becker's New Home Economics model $(1960,1981)$ is based on the theory of consumer choice. Becker's microeconomic approach includes the usual variables of income and expenditure and the quality of children and constraints in terms of time and opportunity costs. Becker establishes a link between the decisions taken on questions of fertility and those concerning the other activities of the household, such as labour force participation and consumption. Simply put, the model assumes that people have varying tastes for goods and services, and children are considered as one such good. If the cost of a good - in this context represented by the costs of childbearing and childrearing - increases, then people demand less of the good. Thus, according to Becker's model, any reduction in the cost of children (as a result of public subsidy) or any increase in income (as a result of transfer payment) is expected to increase the demand for children (Gauthier and Hatzius, 1997). There is a distinction to be made, Becker argues, between the quantity and the quality of children demanded: any increase in income is expected to result in either a higher number of children or in children of higher quality. In this case, the quality of children does not mean morally better; rather, the quality of children is directly related to the amount spent on them. 
Becker's economic theory has and continues to be foundational theory in many empirical studies evaluating the impact of economic and political factors on fertility. ${ }^{24}$ The theory, however, has also been strongly questioned. De Bruijn (1999) has argued that the New Home Economic model was too static as it did not allow for changes in preferences over a lifetime (De Bruijn, 1999). Gauthier (2001) points out that the neoclassical underpinnings of this model are that individuals have full information on the cost and benefits of various alternatives, and that the decision to have a child is the result of an economically rational decision.

Recent empirical trends have also plagued Becker's theory (Jacobs, 2009). The theory was relatively successful in explaining the fertility transition of the 1960s through the end of the 1980s (Jacobs, 2009). At the time, female labour market participation and female education rates increased throughout developed countries, thereby increasing the opportunity cost of childrearing. As Becker's theory would predict, fertility rates dropped steeply over that period. Nevertheless, over the past three decades, the correlation between women's labour force participation and total fertility has been positive. Quebec has been no exception in this regard.

The second economic model, The Relative Income Theory, was developed by Richard Easterlin $(1961,1968,1973,1980)$. Easlerlin completed the strictly demand-oriented model of Becker's New Home Economics by incorporating some notions from sociology. Unlike

${ }^{24}$ For a discussion of these studies, see Jacobs (2009). 
Becker, who had developed a framework in which the demand for children could be treated as analogous to the demand by producers or consumers, Easterlin based his theory on the notion of 'shifting preferences': preferences (that is, material aspirations) which changed systematically as a function of the same variables used to predict fertility - income and prices (Macunovich, 1998). Easterlin argued that the relative size of one's birth cohort has a major impact on one's overall life chances. Central to Easterlin's thesis is the idea that fertility patterns follow cycles, with large cohorts producing small cohorts and vice-versa. The number of young adults entering the work force heavily depends on the number of births in that generation, provided that the effects of mortality and migration do not differ from one generation to the next.

For Easterlin, cohort size was the key determinant of both income potential and the expected standard of living. There were definite advantages to being born in a relatively small cohort. There is a direct relationship between the number of births and the number of people reaching working age. Thus, babies born in the 1930s who entered the work force in the 1950s found a favourable labour market when young workers were in short supply. This resulted in low levels of unemployment, in rapid career advancement and in high relative incomes. Babies born in the 1950s, however, were in abundance and met unfavourable labour market conditions when they entered the labour force in the 1970s. As they were from a high fertility generation, these individuals found a much less favourable labour market with higher levels of unemployment, stronger competition for jobs, fewer opportunities for promotion and lower real wages. 
What ties Easterlin's argument together is his notion of a couple's 'relative income', defined as the ratio of their earnings potential to their material aspirations. The key word here is 'relative', which must not be confused with 'absolute' or 'real' income. For Easterlin, relative income is critical in determining the behaviour of young adults. In Easterlin's words (1989: 38-9):

...both the postwar baby boom and the subsequent baby bust were in large part the products of swings in generation size that affected the economic circumstances of young adults. Because of their exceptionally favourable economic situation, those from the small generation of the 1930s tended to marry earlier and have more children; the relatively unfavourable economic situation of the large generation of the 1950s made for later marriage and reduced childbearing.

Easterlin based his argument on the American experience where his model seems to fit the data very well but he went on to argue that his explanation should apply to other industrialised nations that have completed their demographic transitions. Further research conducted by Easterlin and Condran (1976) confirmed that the movements in relative cohort size and the total fertility corresponded closely in Australia, Belgium, Canada, England and Wales, New Zealand and the United States.

A number of studies, however, have shown the limited relevance of the Easterlin hypothesis in explaining fertility in Canada and more specifically in Quebec. Wright and Maxim (1987) have demonstrated that larger Canadian cohorts have had higher fertility rates than smaller cohorts, and consequently, that fertility in Canada has not fluctuated in accordance with the Easterlin hypothesis. Wright and Maxim (1987) explained the failure 
of the Easterlin model in Canada in terms of the social security net which has insulated Canadians from the full impact of the variations in the overall economy. Similarly, Pampel and Peters (1995) have argued that the modest welfare state of the United States was a precondition for the relative cohort size and that the Easterlin effect emerged during periods of relative economic stability and restrained immigration, such as after World War II.

Mathews (1984) has shown that the Easterlin hypothesis did not correspond with the timing of the booms and busts in Quebec's fertility rates. Between 1960 and 1972, the relative income of young families decreased by 9 per cent, while fertility dropped by 45 per cent. Between 1972 and 1978, the relative income of potential parents plummeted by 19 per cent while fertility rates diminished by only 11 per cent. The timing of the steepest drop in fertility thus did not correspond with the timing of the most acute deterioration of the relative well-being of young adults. Mathews also questioned how the evolution of the relative income of young adults could predict the fertility of individuals from every social class.

Easterlin's theory presumes a gendered division of labour in the family and in the labour market (Pampel and Peters, 1995). Consequently the theory can only explain the fertility pattern seen in Quebec (and in Canada) up to the 1980s, when the effect of female employment was relatively low. Easterlin's reasoning is problematic because it misses the impact of women's changing economic roles: As long as women's labour force participation was limited, fertility was more likely to vary in response to the mechanism 
posited by Easterlin (Oppenheimer, 1973: 43). Entrance of women in the labour market may compensate for the low-income of males in large cohorts (Pampel and Peters, 1995). Easterlin's theory implies that women enter the labour market only when men's income is insufficient. His model thus fails to explain the trends from the 1980 s on when female labour market participation consistently increased (Brown and Norville, 2001).

Overall, the Easterlin model is more comprehensive than the pure economic model of Becker due to its inclusion of sociological factors. However, given its exclusion of institutional considerations, the model still has shortcomings. Most obviously, it does not address the impact of social policy on women's reproductive decision. ${ }^{25}$

\section{Sociological theories}

Louis Roussel $(1987,1989)$ has been highly critical of economic theories of fertility, in particular the Easterlin model. First, Roussel argued that changes in fertility and divorce rates preceded the economic crisis by many years. Easterlin had predicted growing fertility rates in the 1980s as a result of a growing scarcity of young adults in the labour markets. However, as Roussel (1987) reminded, 1984 came and went with almost no change in fertility. ${ }^{26}$ Consequently, the link between the decreasing relative income and falling fertility rates is ahistorical. Second, the size of a cohort has not been the only factor that has affected economic cycles. Employment and unemployment rates are influenced by more

${ }^{25}$ The effect of various social policies on fertility is discussed extensively in chapter 6 .

${ }^{26}$ Easterlin had generated interest among many social scientists in 1978 when in presenting his inaugural presidential address to the Population Association of America, he provided his answer to the question "What Will 1984 be Like" (Macunovitch, 1987). 
determinants. In addition, human behaviour is not entirely determined by economic forces, let alone reproductive behaviours. Third, and similarly to Gauthier's argument (2001) discussed above, Roussel rejected the idea that the decision to have a child was simply the result of a calculated and rational choice.

Roussel accused Easterlin of not linking fertility trends to other demographic changes. According to Roussel, decreasing fertility should be understood in the wider context of the 'deinstitutionalization of the family', that is of the weakening of the family as an institution. Decreasing marriage, increasing cohabitation and births out of wedlock, as well as rising divorce rates led Roussel to argue that young adults hesitate to make a life-long commitment to a partner. In that context, how could they choose to raise two or three children for 20 or 25 years?

Roussel's argument, while compelling, does not readily explain some of the fertility trends in Quebec as the subsequent chapters illustrate. In the 1960s, Quebec experienced its steepest drop in fertility between 1965 and 1966 while marriage rates were increasing and while divorce law made it difficult for couples to terminate their marriage. Moreover, in the early 2000s fertility increased in the context of Quebec's lowest-low marriage rates and higher-high extra marital births.

Catherine Hakim's (2000, 2003) Preference Theory is a relatively new approach to explaining current and future patterns of employment and fertility among women in modern 
societies. The Preference Theory considers lifestyle preferences and values to be the main determinants of women's fertility choices and outcomes. It emphasises the importance of cultural aspects as determining factors behind the recent changes in family and fertility that have occurred in all developed countries. According to Hakim, women have had heterogeneous preferences within and across industrialised countries and such differences need to be taken into account when explaining their behaviour and designing public policies. Hakim distinguished between three idealised preferences: 1) family-oriented preferences for women who regard family life and children as their main priority in life (about 20 per cent of women); 2) work-centered choices for career-oriented women who strive for a high level of education and who devote their life to work preferences (about 20 per cent of women), and 3) adaptive preferences for women who are fully engaged in the trade-off between work and family (about 60 per cent of women). Adaptive women are the women researchers usually referred to when they assume that women in a given society form a homogeneous group.

Hakim's analysis has many features which make it more attractive than the economists' or Roussel's accounts. It takes into consideration personal values and decision making at the micro-level. It proposes a person-centered analysis which challenges the assumption that people were homogeneous in their responses to social influences. It also proposes a 'thick' analysis, because it insists on a case-by-case analysis of countries (Clement, 2004), and "substantive differences between countries or time periods [were] not reduced to variations on a series of variables that measure fragments of social reality" (Hakim, 2003: 352). 
Finally, the Preference Theory specifies that historical values became important predictors of behaviour. According to Hakim, there have been five historical social changes which have created a new scenario for women and their work choice: the contraceptive revolution, the equal opportunity revolution, the expansion of the white-collar occupations, the creation of new jobs for secondary earners and finally, the increasing attention paid to personal values and preferences when making individual choices.

The Preference Theory is also flawed however. The main criticism concerns the causality link, that is, whether heterogeneous preferences are causing heterogeneous behaviour. It could be the case, as Vitali et al. (2009) suggest, that the causality nexus acts the other way around and that person-specific circumstances and background are decisive for a person's orientation in life and thus determine decisions. Actual fertility sometimes triggers changes in values and preferences: thus motherhood could be the root of family-oriented preferences. McRae (2003) also underlined that the Preference Theory did not take into account the situational, structural and normative constraints in which social reproduction decisions are being made. McRae showed that women with similar preferences - but differing capacities for overcoming constraints - have different labour market trajectories. McRae's longitudinal analysis failed to support the idea that women in Britain and North American had genuine unconstrained choices about their careers. Instead, McRae suggested that a thorough explanation of mothers' labour market choice depended on understanding the constraints and opportunities women faced in their mix of employment and family responsibilities. 
Obviously, the sociological literature on social reproductive is much broader than the literature that causally examines the social determinants of fertility. It is also more diverse than Roussel's theorization of the deinstitutionalization of the family and Hakim's Preference Theory. Canadian feminist sociologists (Cohen and Pulkingham 2009; Luxton, 2006; Bezanson and Luxton, 2006; McDaniel, 2002, 2009) have made connections between social policies and the way women live their lives. Although these sociologists have not studied the causal link between specific social policy and fertility, they offer insight into how policy impacts on women's opportunities and constraints, notably in regard to child bearing and child rearing. McDaniel (2009) for instance notes that the timing of major life events such as entry into parenthood, completion of childbearing and experiencing the 'empty nest' has changed drastically over generations and has become far less uniform.

Different generations of women also lived through different models of the combination between earning and caring, as supported by social policies. In an earlier publication, McDaniel (2002) argued that states have different focal points and make different gender assumptions. States can enable women's caregiving role or women's paid work. In France, the state supports the duality of women's lives as breadwinners and caregivers but it overlooks men's roles. In North America, the focus on the need to achieve gender equality in labour market participation and earnings has made productive and reproductive work difficult to reconcile. Thus, in North America and in France, the assumptions about the gendered division of labour have not been adequately challenged. Though care work does not fully define women, women's caregiving role remains essential for families' well- 
being. The gender structure of paid work in many countries tends to support androcentrism, by making men the archetype for the design of social policy (Fraser, 1994, 1997; Cohen and Pulkingham 2009; McDaniel, 2002). Any attempt to move beyond the traditional sexual of paid and unpaid work toward a more 'universal care giver model' (Fraser, 1994) would require that men follow life course trajectories similar to those of women, rather than the other way around. Thus, the connections between social policies and social reproduction seem to be mediated by the effect of policies on gender inequalities experienced with the family and in the labour market.

\section{The gender equity theory}

In the late 1990 s and early 2000 s, two demographers working on separate continents, Peter McDonald (2000a, 2000b, 2000c, 2002, 2006, 2013) and Shigemi Kono (1996), found a connection between gender-friendly policies and high fertility. Meanwhile, sociological and economic studies showed that fertility rates and female employment had become positively correlated across developed countries (see for instance, Adsera, 2004; Ahn and Mira, 1999; Castles, 2003; Rindfuss et al., 2004).

The gender equity theory was primarily developed by McDonald to explain patterns of reproductive behaviours in developed countries (McDonald, 1999, 2000a, 2000b, 2000c, 2002, 2006, 2013). The theory stated that the conflict between high levels of gender equity in individual-oriented institutions and low levels of gender equity in family-oriented institutions was responsible for lower fertility in advanced industrialised economies. In 
other words, and in terms similar to those expressed by Chesnais (1998), when women feel they are provided with opportunities nearly equivalent to those of men in education and market employment (whether this is accurate or not), as long as these opportunities are vulnerable to a woman's decision to have children, fertility rates inevitably remain low. To be clear, McDonald does not argue that women actually have similar opportunities in any of the developed countries he is studying. Rather, McDonald argues that it is women's perception of fairness that matters, and that influences fertility outcomes.

For McDonald (2006), the lack of correspondence between actual fertility and women's ideal preferences reflected the socio-institutional setting in which women made their reproductive decisions. Women's preferences are unrealised because of countervailing forces. The emergence of low fertility is associated with two waves of social change that have had profound effects upon reproductive behaviours in the past four decades: social liberalism and new capitalism. From the 1960s to the 1980 s, social liberalism partially fulfilled women's claims for a greater level of gender equity through paid employment. Structures that discriminated against women in the workplace were gradually dismantled and young women were encouraged to improve their employment prospects by increased education. Beginning in the 1980s, and consolidated in the 1990s, however, new capitalism meant that regulations and restrictions were reduced so as to allow capital to flow more easily. While social liberalism provided women with new opportunities outside the household, new capitalism has meant a wider variation in earnings, career stability and progression. 
The movement towards greater gender equity, according to McDonald, focused upon individual-oriented institutions. As individuals, women were able to seize new opportunities in paid employment. ${ }^{27}$ Family-related institutions, however, continued to be characterised by gender inequity. In an early article (2000b) McDonald argued that among the social and economic institutions which affected fertility rates, the most important was the family unit itself. For McDonald, the rising tides of social liberalism and new capitalism did not sweep aside the values related to the family. By the time women consider forming a family, they have already become aware that the gender equity they have thus far gained will inevitably be compromised by such a decision. This is especially true where there are no measures in place to reconcile work and family responsibilities. Accordingly, very low fertility is the product of the combination of high gender equity in individualoriented institutions combined with the persistence of the male-breadwinner model of the family as the foundation of family-oriented institutions. ${ }^{28}$ Low fertility is therefore an unintended rather than a deliberate outcome of changing social and economic institutions.

\footnotetext{
${ }^{27}$ These 'new opportunities' do not systematically lead to higher gender equality. Even in the most genderegalitarian countries such as the Nordic countries, women are still segregated into traditional female-type occupations (see among others Mandels and Semyonov, 2006).

${ }^{28}$ For McDonald (2000b: 6), the reproductive behaviours of Greeks and Italians in Australia provide an example of the importance of family organisation and idealized morality in the determination of fertility rates. Over the past two decades, the fertility rates of first and second generations of these immigrants followed the fertility trends in Greece and Italy respectively. In the mid-1970s, their fertility rates were above those of Australian of British-Irish origin and fertility occurred at relatively young ages. In recent years, their fertility rates have been very low, and their age patterns of fertility, the same as those in Italy and Greece (and older than that of Australians of British-Irish origin). Australians of Greek and Italian origin continue to adhere to conservative attitudes towards the family and to patriarchy. As large groups in a multicultural society, ItalianAustralians and Greek-Australians have been able to maintain significant features of their culture: the incidence of divorce, birth out of wedlock and relationships alternative to marriage for example have been much lower than they have been in the dominant culture. At the same time, young women of Italian and Greek origins in Australia, now mainly of the second generation, have had the same opportunities and achievements as other Australians in education and in market employment. Conditions which apply to other Australians' institutions related to family, such as family services, tax and social security and industrial relations obviously have also applied to Italian and Greek Australians in the same way. Yet, family
} 
For McDonald, "the solution to low fertility therefore lies in providing a greater sense of assurance to young women and young men that if they marry and have children, they will be supported by the society in this socially and individual important decision" (2006: 495). Hence, although the family remains the institution that affects fertility rates the most, public policies can also have an impact on women's reproductive decisions.

The gender equity theory has received support in the literature. ${ }^{29}$ Research has shown the existence of a strong correlation between attitudes towards traditional gender roles in a society and birth rates (OECD, 2005). The results of an opinion poll on attitudes towards gender equality conducted by the United Nations ${ }^{30}$ showed that the countries with the most traditional family structures - Germany, Japan, Italy and Spain - faced chronically low birth rates. Conversely, in the Scandinavia, the United States and Canada, countries for which the data indicated strongly or moderately favourable attitudes toward gender equality, the birth rate was comparatively high or rising.

The gendered division of labour within families has been shown to be inversely related to fertility. Some studies have even drawn parallels between fertility decisions and the take-up

organizations and/or morality modify use or access to these conditions. For example, among Southern Europeans in Australia, care of dependent members is considered to be the responsibility of the family and more especially that of its female members. As a consequence, family support services provided by government, by voluntary organisations or by the market, while available, have only be used as a last resort by such families. According to McDonald, in this 'social experiment' in which all except the nature of family organisation is controlled, fertility rates were very low for groups whose family organisation remained more faithful to the conservative male-breadwinner model.

${ }^{29}$ The next two paragraphs draw on Oláh's argument (2011) for the need to be more aggressive in pushing for gender equality to raise fertility.

${ }^{30}$ People were asked whether they agreed with the statement: "A man's job is to earn money, a woman's job is to look after the home and family"(OECD, 2005). 
of paternity leaves and father's quotas. ${ }^{31}$ In a study based on data extracted from the Swedish Family and Fertility Survey covering the period between the 1970s and early 1990s, Oláh (2003) showed that the propensity to have a second child was 15 per cent higher in families in which the father took parental leave with the first child than in families in which only the mother used the leave. In line with these findings, Duvander and Andersson (2006) found that in Sweden the father's uptake of parental leave was positively related to continued childbearing. Couples where the father took some leave had higher second and third-birth propensities than couples where the father took no leave at all. Thus, considering fathers' parental leave use as a direct measure of gender equality, these two studies suggest that a higher level of gender equality in couple relationships may positively influence fertility.

In addition, Mills et al. (2008) have tested the gender equity theory by examining whether the unequal division of household labour led to lower fertility intentions of women in Italy and the Netherlands. They demonstrated that an unequal division of labour within the household was positioned as a central link in understanding women's reduced fertility intentions. Their study, however, was conducted around fertility intentions rather than behaviour. Rosenbluth (2007) argued that low levels of fertility in Japan were not the result of women's free choice, but rather that they reflected how hard it was for women to work in the market and to care for their families at the same time. She showed that fertility tended

\footnotetext{
31 'Paternity leaves' are short leave of one or two weeks in connection with the birth of child. Father's quotas are periods of parental leave based on' use-it-or-lose-it' principles. In the latter case, if the father does not take up his allocated period of leave, the leave is lost to the family and the full leave period is consequently shorted (Haas and Rostgaard, 2011).
} 
to decrease where vested interests impeded female access to the workforce and to increase where easy labour market accessibility and childcare support made it easier for women to balance family and career (Rosenbluth, 2007: 4). According to Rosenbluth, when high levels of gender inequality are experienced in the labour market such as in Japan, instead of going home and having babies, women expend more effort - sometimes foregoing childbearing in the process - to find a job, to keep it and to struggle against glass ceilings.

Rosenbluth's (2007) underlying assumption that women actually wish to work outside of the home is one of the underlying assumption of which this dissertation is built. Very few people would question that the average man wants to have both a job and a family. As Rosenbluth explains, the argument is less that women like working in the market (although my view is that in Quebec most women do) than the labour market provides them with a source of economic independence. Women's paid work also provides the family with a second income. The new norm in Quebec has been for women to simultaneously combine both productive and reproductive work. The pact of complementary gender roles with differential supports has largely ended (McDaniel, 2002). In its place is the expectation that women will manage family care together with paid work. In addition, high rates of conjugal breakdown mean that women are at risk of experiencing poverty if they are not financially autonomous. An outside source of income therefore constitutes a buffer against life precariousness (Clement et al., 2009). 
The gender equity theory: two clarifications

McDonald (2013) has recently clarified some of his theory's specifications. First, McDonald draws a distinction between equity and equality. Gender equality is a straightforward matter, as it can be measured simply by comparing outcomes for men and women in various areas such as education, employment, income, etc. Gender equity is a more subtle concept that allows for different outcomes between genders. Indeed, the notion of gender equity captures the perception of fairness and opportunity rather than strict equality of outcome. Thus, according to the gender equity theory, it is the perception of unfairness that leads to low fertility. While the notion of gender equality refers to the idea of treating both sexes equally, the concept of gender equity is concerned with the recognition of the specific attributes of each gender. ${ }^{32}$

The case of the Netherlands is particularly illustrative of the difference between equity and equality. In the Netherlands, part-time work is common for mothers of young children and engagement in part-time work is not linked to a feeling of unfairness. The Netherlands is not gender equal in that a high proportion of mothers work part-time, while fathers work full-time; yet, gender equality defined by equal hours of work does not lead to very low levels of fertility in this country. In the Netherlands, gender equity is high, as the different attributes of women are recognised and supported. As a result, women perceive their position in the labour market as being fair, and fertility has not fallen to lowest-low levels.

\footnotetext{
${ }^{32}$ The tension between gender equity and gender equality is best captured by the 'Wollstonecraft's dilemma', discussed in the next chapter.
} 
In other contexts, where part-time work may be perceived as being second-rate work with low-wages and little opportunity for advancement, fertility is more likely to drop.

In Quebec however, the notion of equity has not been picked up by the feminist movement and the political arena. Modern feminism in Quebec originated in 1965-1966 ${ }^{33}$ with the founding of two major organizations devoted to upholding women's legal and economic rights and fighting for equality: the Fédération des Femmes du Québec (the FFQ) and the Association Féminine pour l'Éducation et l'Action Sociale (the AFEAS). ${ }^{34}$ Together these two movements marked the inception of the 'second wave' of liberal feminism, a feminism that claimed the need to make reforms so that women could benefit from all the rights and advantages enjoyed by men. The feminist themes of the time were autonomy, selfdefinition and equality between the sexes. Many people thought sexual equality was achieved after the passing of the law on the legal capacity of married women in $1964,{ }^{35}$ but the new feminism exposed such equality for what it was: women had been granted formal rights, but there was no real equality. The 1970 s were marked by the rise of 'radical'

\footnotetext{
${ }^{33}$ It is not my intention to discuss into details the history of the feminist movement in Quebec. Readers interested in that topic should refer to chapter 15 of the Collective Clio (1987) and chapter 42 of Linteau et al. (1986).

${ }^{34}$ The FFQ quickly became one of the major feminist organizations in Quebec. The FFQ was nondenominational and ethnically mixed. It brought together about twenty women's groups and a few hundred individual members, mostly lawyers, trade unionists and social workers. It saw itself as a tool for promoting women's interests and as a pressure group lobbying for reforms and legislation that might improve women's well-being (Linteau et al., 1986: 449). The AFEAS, born from the merger of the Union Catholique des Femmes rurales and the Cercles d'Économie Domestique, was apolitical and denominational. While less visible than the FFQ, it was based mainly in the countryside and small towns and was closer to women from ordinary backgrounds

${ }^{35}$ I discuss the law on the legal capacity of married women in chapter 7.
} 
feminism, ${ }^{36}$ radical because it aimed to abolish the domination of women by men in sexual relationships, the family, the labour market, and the media.

The dominant feminist voices of the 1960s and the 1970s thus claimed the need for better equality. The difference between women and men had only been stressed by the feminist movement in the fight for female suffrage in the first half of the $20^{\text {th }}$ century. At the time, an important strand of the movement argued that women needed to be granted the right to vote, not because they were equal to men, but because mothers' traditional social role had to offer a new vision of society and this could only be beneficial to all.

More recently, the introduction of low cost childcare, the centres de la petite enfance (CPE) in 1997, also reflects a concern for gender equality. One criticism of the CPE was that it favoured a 'one size fits all' solution. That model was for women to be full-time workers, just like men. In the past three provincial elections, only one party has suggested introducing a new policy that favoured gender equity. In its 2007 electoral platform, the Action démocratique du Québec (ADQ), proposed to offer $\$ 100$ per week for each child who did not use a subsidised space in childcare. In other words, stay-at-home mothers were to receive $\$ 5,200$ per year for each child they kept home. The ADQ argued that this policy was to give families more options and to compensate stay-at-home mothers. ${ }^{37}$ Its

\footnotetext{
${ }^{36}$ This branch of feminism did not replace or eliminate the first- reformist- wave of feminism. Throughout the 1970s, the reform movement remained strong, and may even have been larger than the radical groups (Linteau et al., 1986).

${ }^{37}$ It has been argued that the allowance offered to stay at home mothers favoured inequality (see Mathieu, 2008).
} 
proposition, however, disappeared when the ADQ merged with the Coalition pour l'Avenir du Québec (CAQ), a new party that entered the political arena in 2011.

While keeping in mind that equity and equality are two different concepts, the gender equity theory, as it is applied to study social reproduction in Quebec, is really about gender equality. The fact that no political party in Quebec offers measures to support stay-at-home mothers, and the wide popularity of the CPE suggests that equality, rather than equity, remains a societal concern. Thus, all things considered, this dissertation shows that when gender equality is threatened by motherhood, women restrain their fertility. Moreover, as McDonald (2013) points out, it is no simple matter to test whether or not social institutions are perceived by women as offering them a fair opportunity to pursue their preferred combination of work and family. Questions related to the measurement of perception of fairness are not straightforward. Perhaps extensive interviews would be required to produce data that reflect women's perception of gender equity. While interviewing women to understand their awareness of the opportunities and constraints entailed by motherhood when making reproductive decisions could be an interesting project for future research, it goes beyond the scope of this dissertation.

The second clarification concerning McDonald's gender equity theory concerns the appropriate unit of analysis. McDonald (2013) specifies that the gender equity theory can only be tested across contexts, thus across different countries. In McDonald's words (2013: 985-986): 
[...] fertility will be lower in Country A than in Country B if a higher proportion of women in Country A, either alone or jointly with their partner, decide not to have a child or an additional child because of the adverse effect that the additional child will have upon their lives.

Although in most advanced societies, young women are more highly educated then young men (OECD, 2013), pregnancy, childbirth, breastfeeding and the nurturing role of the mother affect the capacity of women to compete with men in the market employment. The issue is whether the individual woman considers this impact to be acceptable or not. McDonald argues that more women will consider the impact to be unacceptable in countries where social institutions do not provide strong support to the combination of work and family. The theory is therefore inherently comparative and it was not developed to investigate fertility across individuals within a single context.

McDonald's perspective has nonetheless shown its relevance to explain fertility trends in singular countries such as France and Scandinavia. The assumption here is that the theory will also prove to be useful to explain social reproduction in Quebec. Moreover, the comparative component inherent to the gender equity theory is not ignored, though it focuses more on time than place for the purpose of this research. The periodization of Quebec's fertility regime indeed stretches between 1960 and 2010. Quebec's patterns of social reproduction are also compared with those of other developed countries, most specifically with nations that have similar types of institutional arrangements. Accordingly, the next chapter locates Quebec within different types of welfare and gender regimes. 


\section{CHAPTER 4}

\section{BETWEEN WELFARE AND FERTILITY REGIME: LOCATING QUEBEC WITHIN THE WORLDS OF WELFARE CAPITALISM}

The comparative literature on social policies has sought to illuminate the effects of states, markets and families on the structure of inequalities in developed countries. The concepts of welfare regimes and gender regimes, developed in the $1990 \mathrm{~s}$, have played an important role in this regard. ${ }^{38}$ In his 1990 seminal work The Three Worlds of Welfare Capitalism, Gøsta Esping-Andersen $(1990,1999)$ identified three welfare regimes (liberal, conservative and social-democrat). Subsequent feminist work challenged his theoretical framework, arguing that the typology did not account for gender inequalities. Some sought to remedy this by introducing the concept of gender regime (Walby, 2001). Using these conceptual lenses, comparative research on welfare and gender regimes has located Canada within the world of liberal countries, where class inequalities are high but gender inequalities are not as acute as is other countries (Mathieu, 2003; O'Connor et al., 1999). Both policy analysis and empirical work have since the 1990s shown the existence of intra-regime variations within the Canadian welfare state, Quebec sharing with the social-democratic regime a number of social and political attributes.

This chapter draws on the conceptual tools developed in the 1990s - notably the concepts of decommodification and defamilialization - to discuss class and gender inequalities within the regime literatures. The idea of decommodification refers to the degree of

\footnotetext{
${ }^{38}$ Though the literature discussed in this chapter mostly dates from the 1990s, it should not be considered outdated, as Quebec's and Canada's position within different types welfare and gender regimes have been stable since then.
} 
independence by individuals from the market, while the notion of defamilialization pertains to the degree of independence by individuals from the family. Though the concept of defamilialization offers some insight, it does not go far enough to explain the social division of care work. From a gender equality perspective, the key is not so much defamilialization, but rather demotherization. This new concept refers to the degree of independence mothers enjoy from the necessity of performing care work. Although the family remains the most important agent of care provision within all developed countries, the extent to which fathers and other family members step in to perform caregiving duties affects the context of social reproduction and fertility outcomes. The combination of motherization/demotherization and familialization/defamilialization yields four types of familialism: 'implicit', 'gendered', 'institutional' and 'de-gendered/generational'. The concept of demotherization will be used in further chapters to characterise the various fertility regimes experienced in Quebec and in the ROC since the 1960s.

\section{From welfare regimes to gender regimes}

As noted above, the concept of welfare regimes, associated with the work of EspingAndersen $(1990,1999)$, refers to the way welfare is produced and distributed by the three main pillars of developed countries: states, markets and households. In the 1990s, the literature on welfare regimes was dominated by the search for an appropriate classification of advanced societies into types that would reflect the major emphasis of their social policies. Esping-Andersen's work clustered countries into three types of regimes - socialdemocratic, conservative, liberal - based on two dimensions of welfare statism: 1) 
decommodification, or the ability of individuals to obtain services and income without having to turn exclusively to the market, and 2) the kind of class stratification and solidarities promoted by social policies (Esping-Andersen, 1990, 1999).

The liberal regime emphasizes individualism and the primacy of the market. This welfare regime is characterized by a low level of decommodification as citizens must rely to a large extent on the market to meet their needs. As a consequence a liberal regime "erects an order of stratification that is a blend of a relative equality of poverty among state-welfare recipients, market-differentiated welfare among the majorities, and a class-political dualism between the two" (Esping-Andersen, 1990: 27). In conservative welfare regimes, social solidarity networks are erected on the basis of families and professional groups. In these countries, social insurance provides certain benefits, which depend on previous contributions and thus on work and employment. The process of decommodification is therefore restricted to those who work or those who belong to the family circle of the worker. Hence, the spheres of solidarity remains narrow and the family becomes the key actor in the provision of welfare. Social policies also perpetuate the traditional model of the male breadwinner model. Finally, the socio-democratic regime has the highest level of decommodification, with social programs designed to apply to all citizens, irrespective of individual contribution. The ideology behind the socio-democratic model is equality in the name of citizenship rights. Rather than allowing a dualism between the state and the market or between men and women, the state acts as the main pillar of welfare to promote equality between social classes and genders. 
Several authors have developed alternative classifications or added more types to existing typologies for better empirical refinement (Arts and Gelissen, 2002). One set of criticisms came from authors who disagreed with the labelling of the Antipodean welfare states Australia and New Zealand - as belonging to the liberal model (Castles, 1998; Castles and Mitchells, 1993). Others criticised Esping-Andersen for not systematically including the Mediterranean countries of Greece, Spain and Portugal. Bonoli (1997), Ferrara (1996) and Leibfried (1993) added a new type - the Latin - to describe the Southern European countries (Spain, France, Portugal, Italy and Greece). According to these scholars, the latter countries share a particular institutional arrangement: they are characterized by rudimentary social policies as well as an important Christian tradition that influences political choices and that complicate adaptation to globalisation. Like the conservative regime - but even more so the family represents the main pillar of welfare in Latin countries.

The empirical work of Saint-Arnaud and Bernard (2003) and Bernard and Saint-Arnaud (2004) echoed some of these criticisms. Using a set of 36 quantitative indicators and hierarchical cluster analysis, Saint-Arnaud and Bernard (2003) confirmed the existence of four welfare regimes - the three originally found by Esping-Andersen, to which they added the existence of a fourth familialistic one. In their analysis, Canada belonged to the liberal welfare regime, an unsurprising finding for Saint-Arnaud and Bernard, given the geographical proximity and the intensity of the economic exchange between Canada and the United States. Further research by Bernard and Saint-Arnaud (2004) shed light on important intra-regime variations among the four largest provinces of Alberta, British 
Columbia, Ontario and Quebec. According to their research Alberta most resembled the 'ultra-liberal' United States, while Quebec leaned in the direction of Europe, and to some extent, social democracy. Their analysis revealed that Quebec had higher expenditure than other Canadian provinces. Quebec also had a higher proportion of civil servants and a particularly low level of infant mortality, which are features of socio-democratic countries.

\section{Between gendered welfare states and gender regimes}

The most important criticism of Esping-Andersen's 1990 work came from feminist researchers, who argued that the analysis was limited to male workers since it failed to take into account the family in the provision of welfare to individuals (Lewis, 1992; O'Connor, 1996; Orloff, 1993). According to this line of critique, Esping-Andersen had given too much credit to states and markets in the production of resources and downplayed the importance of women and families in the distribution of welfare. To remedy this imbalance, feminist scholars began to 'gender' typologies of welfare regimes by adding new concepts to document the influence of state policies on women and on gender relations. Orloff (1993) and O'Connor $(1993,1996)$ were among the first to question the relevance of the decommodification process for women, for whom access to paid work - or the commodification process - can be emancipatory. Orloff (1993) suggested that the decommodification concept be complemented with two new analytical dimensions: 1) access to paid work to capture the extent to which women are to be economically active, and 2) the capacity to form and maintain an autonomous household - or the extent to which welfare states provide women freedom from the compulsion to enter a partnership to 
obtain financial support. Similarly, O'Connor's $(1993,1996)$ concept of personal autonomy stressed the importance of women's capacity to survive without men's assistance.

Around the same time, Lister (1994) and McLaughlin and Glendinning (1994) developed a concept to parallel the decommodification dimension which, they argued, did not account for the fact that paid and unpaid responsibilities were articulated differently for men and women. The idea behind the one of defamilialization was to highlight the linkages between women's family caring responsibilities and their participation in gainful employment. Lister (1994) defined defamilialization as the "capacity for individual adults to uphold a socially acceptable standard of living independently of family relationships, either through paid work, or social security provisions" (Lister, 1994: 27). In other words, the idea of defamilialization captured the degree to which people were freed from dependence upon the family unit, by either bringing care outside the family or by paying family members to care for dependents.

These concepts - access to paid work, the capacity to form and maintain an autonomous household, autonomy and defamilialization - all led to the unveiling of the effects of social provisions on gender relations. Yet, although gender was incorporated into the examination of the various regimes of welfare capitalism, the analysis remained confined within the boundaries of the welfare triad of states, markets and households. It was only in the end of the 1990s and in the early 2000s, that the idea of gendered welfare states became too narrow for the weight of analysis being placed upon it and it was gradually replaced by the 
broader and more differentiated concept of gender regime in which the welfare state was only one component domain among several others.

Although they did not specifically use the term gender regime, O’Connor et al. (1999) developed an analytical framework for analysing gender relations in industrialized countries that went beyond the idea of the gendered welfare states. Their framework not only included labour markets and state social provision but also reproduction, as reflected in the regulation of abortion. They argued that although abortion regulation was distinct from the 'welfare proper', state legislation of biological reproduction was influenced by some of the same factors that shaped support for the reproduction of populations more broadly, including the cash transfers and services received by families. O'Connor et al. (1999) felt that these areas represented the most significant sites of gender politics in developed countries. ${ }^{39}$

Sylvia Walby was among the first in 2001 to theorize gender regimes as such. Walby argued that sexuality was a domain of gender relations with profound consequences for people's lives as well as a venue for political struggle, especially in its intersections with

\footnotetext{
${ }^{39}$ In addition to developing a new analytical framework O'Connor et al. (1999) addressed the issue of intraregime variation within countries that represented the 'liberal' world of welfare capitalism: Australia, Canada, Great Britain and the United States. They suggested that Australia was the most distinctive of the four countries, since women were treated as independent citizens, though caregiving responsibilities remained a basis for claims. In both the United States and Canada, there was a considerable emphasis on the market, as a source of income and service; strong assumptions of gender sameness also prevailed in these countries, though in Canada there was a greater tradition of state involvement and a greater recognition of the connections between labour market and caregiving activities. Finally, Britain emphasised the more traditional 'breadwinner' model of the family. This was made obvious in both the income support system and policies related to labour market participation. The relatively strong commitment to social rights has been under threat since the 1980s, although the levels of income support continued to more effectively buffer British single mothers from poverty than those in the other countries.
} 
fertility and bodily integrity issues such as abortion, rape and contraception. Unlike O'Connor et al. (1999), Walby believed that adding reproduction to the welfare trinity of state-market-family was not sufficient. She argued for the need to replace the notion of 'gendered welfare state' with the one of 'gender regime'. For Walby, a complete examination of gender relations needed to include at least three other untheorized domains of state intervention: 1) the regulation of marriage and divorce, 2) the state regulation of labour market through equal opportunity legislations that reduced the impact of discrimination against women, and 3 ) the regulations and the punishments surrounding violence against women.

While the contribution of the feminist scholars was welcomed, empirical work on the classification of developed countries into different types of gender regimes did not significantly differ from the work of Esping-Andersen. Following the work of SaintArnaud and Bernard (2003) and using 32 indicators that pertained to the welfare of women and gender equality in developed countries in the early 2000 s, I conducted cluster analysis to see whether models of gender regimes could be found across developed countries (Mathieu, 2003). I unveiled the existence of four clusters of countries similar to those found by Saint-Arnaud and Bernard (2003). The first group, labelled the 'familialistic regime' included Spain, Greece and Italy. Social roles played by each partner in these countries could not be exchanged or combined: men were breadwinners and women were carers. Women in these countries encountered difficulties in trying to penetrate the market arena, which was due, to some extent, to the scarcity of social care services for children and 
elderly that could defamilialize care work. Unable to combine breadwinning and caring responsibilities and pressured into taking care of the dependents, the trade-off that once pushed Southern European women into housewifery was now pushing them to forego maternity.

The 'famialistic' regime was followed by the regime of 'limited employment', which resembled Esping-Andersen's conservative regime. This regime was composed of Belgium, Switzerland, the Netherlands, Austria, Germany, France, Portugal and Ireland. Although defamilialization was high in most of these countries, family policies were aimed at keeping women (albeit sometimes only momentarily) out of the labour force. In some of these countries, this was done by providing women with extensive maternity leaves, and 'child-rearing leaves' in order for them to stay at home to look after their children. At the same time, since childcare services remained rare (except in France), mothers either worked part-time or withdrew completely from the labour market until their children got older. This illustrates the fact that women in these countries could sequentially - but not simultaneously - be carers and workers (the exceptions here are France and Belgium). The third model the 'dual earner and carer' regime, was found in Finland and the Scandinavian countries. In the early 2000s, this model was the most egalitarian gender regime. Although these countries had high fertility rates and offered some time off to look after their children, Scandinavian and Finnish women were massively active in the labour market. This was the result of generous defamilialization and conciliation policies that allowed them - as well as their partners - to take time for dependent care, without risk of losing their employment. 
The liberal gender regime was the one of 'superwomen', where Canada and its four largest provinces were located. Anglo-Saxon countries typically offered a limited choice of family policies to reconcile family responsibilities with employment. State interventions to correct class and gender inequalities were scarce and therefore, families had primarily to rely on the market to acquire the resources necessary for their survival. Both men and women whether they had caring responsibilities or not - were forced to sell their labour power on the market, and the state did not offer policies that would facilitate the conciliation between the earning and caring responsibilities. Women were thus burdened with the double day and expected to be superwomen. Within Canada, the most distinctive cases of gender regimes were Quebec and Alberta (Mahon, 2009; Mathieu, 2003).

\section{A new concept: the 'demotherization' of care work}

The dominant concepts in comparative social policy analysis of welfare and gender regime - decommodification and defamilialization - are not easily separable. Defamilializing policies might encourage women into the workforce if the market, or the state, can take care of the family risks, and yet those same policies might lead employees to leave the labour market to perform care work (Woods, 2006). In his 1999 book, Esping-Andersen (1999) added a concept originally suggested by feminists, that of familialism and nonfamilialism. A familialistic regime is one in which public policy assumes - and even insists - that households are responsible for their members' welfare. Conversely, a defamilializing regime is one in which policies unburden the household by diminishing individual's welfare dependence on kinship (Esping-Andersen, 1999: 51). Defamilialization, according 
to Esping-Andersen, can occur through state-provision, such as in the social-democratic regime, or through the market, typically in the liberal welfare regime.

As noted above, one major advantage of the concept of defamilialization is that it allows for a parallel to Esping-Andersen's scale of decommodification. While decommodified workers in Esping-Andersen's typology gain power vis-à-vis their prospective employers, the degree to which women gain independence from their family through the provision of family-relevant policies is more difficult to grasp (Saxonberg, 2013). Literally, one could conclude that the goal of defamilializing policies would be to enable parents to put their children into formal childcare as soon as possible since responsibility for childcare would come away from the family (Saxonberg, 2013). In that sense, defamilialization is really about moving care work outside of the family unit, to allow women to be economically active in the market. In Lister's (1994) much accepted definition of defamilialization however, any policies that allow individuals to uphold an acceptable standard of living independently of family relations are defamilializing. In that sense, the idea of defamilialization remains ambivalent regarding the interpretation of parental leaves (Saxonberg, 2013). On the one hand, paternity leaves and fathers' quotas could be argued to be defamilializing, because they make it easier for women to return to the labour market and become economically independent, while their partner cares for their child. Paternity leaves and father's quotas make gender relations more equal. On the other hand, maternalist policies that would pay mothers to stay at home could also enable women to remain financially independent, yet the differences in gender roles- and most likely 
inequalities- would be strengthened (Saxonberg, 2013). Thus, defamilialization can be interpreted in at least two different ways: 1) as the transfer from care giving responsibilities of the family to other institutions and 2) as the economic collectivization of the costs entailed by raising a family.

Three further critical remarks should be made about the concept of defamilialization. First, the provision of care services in the market makes defamilialization a class-biased issue since only the better-off can afford to buy the services: in other words, the quality of defamilialization varies across social classes (Leitner, 2003). This applies particularly to the case of the United States, where paid maternity leaves are non-existent and where childcare is offered in the market. Second, even in Scandinavia, the family remains the most important agent of care provision. Defamilialization is therefore not only about providing services outside the family, but also about unburdening the family from the economic costs entailed by raising children. There is a distinction to be made between economic and social defamilialization, and between care giver and care receiver (Leitner and Lessenich, 2005). Social defamilialization occurs when the care giver is unburdened from the obligation to care and the care receiver is socially autonomous from his/her relatives (Leitner and Lessenich, 2005). Accordingly, defamilialization is about the social relationship between the care giver and the care receiver, and is possible through the collectivisation of caring tasks (Esping-Andersen, 1999; Leitner and Lessenich, 2005). Economic defamilialization refers to the degree of financial autonomy for care givers and receivers (Leitner and Lessenich, 2005). From the perspective of the care giver, individualised social rights such 
as the right to be paid for care increase the economic autonomy from other household members (Leitner and Lessenich, 2005) and thus, economic defamilialization can occur through a familialization of care work.

Third, when Esping-Andersen defines defamilialization as “policies that lessen individuals' reliance on the family" (1999: 45), what is truly meant by 'individuals' are 'women' or even more precisely, 'mothers'. The concept of defamilialization has been used to document the degree of independence mothers, more than individuals, enjoy from the necessity to perform unpaid care work. Yet, international research shows that women can be unburdened from care work without using policies that shift care outside the family unit.

Most obviously, fathers share with their partner caring responsibilities. Many countries, especially in Northern Europe, offer paternity leaves and father's quotas. Father's right to paid leave facilitate men's taking solo care of young children when their partners return to work (Hass and Rostgaard, 2011). Not only is the involvement of fathers in caregiving responsibilities linked to a better gendered division of care work (Haas and Rostgaard, 2011), it also has a positive impact on reproductive decisions. The implementation of fathers' quotas in the parental leave systems of Norway and Sweden was intended to reduce the gender imbalance of childrearing in the family (Duvander et al., 2010). The father's take up of the quotas in these countries has been associated with continued childbearing (Duvander et al., 2010). New preliminary research on causal effects between the father's quotas and fertility rates in these countries show that in Sweden, families where the father 
use the quotas more often have a third child (Duvander et al., 2013). In all of these situations, care work is performed by family members - and thus familialized - without burdening women.

Extended family members can also be involved in providing childcare. In Alberta, the involvement of relatives in childcare is even supported through the Kin Child Care program (KCC) that offers subsidies for eligible parents ${ }^{40}$ who use a non-custodial relative to care for their child (Friendly et al., 2013). Extended family members are often willing and available to look after dependent children. In Europe in the early 2000s, it was estimated that 58 per cent of grandmothers and 49 per cent of grandfathers took care of at least one of the grandchildren below the age of 15 (Hank and Buber, 2008). The involvement of grandparents influences reproductive decisions. Sear and Coall (2011) found that European countries with a higher proportion of grandparents involved in childcare such as the Netherlands, France and Denmark had higher fertility rates than countries where grandparents were not involved. ${ }^{41}$ This observation was confirmed by at least two other studies that showed that in the Netherlands, involvement of grandparents increases the likelihood of additional childbirths in couples with at least one child (Kaptijn et al., 2010; Thomese and Lietbroer, 2013). In Italy, the impact of grandparents' help appears to be even more important than the availability of formal childcare in the probability of having

\footnotetext{
${ }^{40}$ To be eligible for the program, parents must be working, seeking work, attend school, have a special need or a child with special need. The funding - up to $\$ 400$ per month for children below 7 not yet attending Grade 1 and $\$ 200$ per month for school-aged children- is available for low and middle income families.

${ }^{41}$ The correlation between the involvement of grandparents and fertility outcomes became negative in countries where a high proportion of grandparents provided daily care. This reflected, according to the authors, the inadequate provision of institutional childcare and support for women to return to work, after having a family in countries such as Greece and Italy.
} 
children (Del Boca, 2002). These findings imply that care provided by grandparent "may not only be instrumental by easing the combination of paid employment and raising children but may also be an important resource for these children to realize their [fertility] ambitions" (Thomese and Lietbroer, 2013: 416).

Thus, fertility behaviours are not only influenced by policies that defamilialize the economic and social costs of family raising. The extent to which women are freed from care work is not just affected by the distribution of care work between states, markets and families, but as importantly by the division of work within the household - and more broadly between members of the extended family - a nuance the concept of defamilialization fails to capture. Conversely, even policies that defamilialize the economic costs of raising children do not always relieve mothers from care work. Child-rearing leaves, maternity leaves and family allowances - all policies that allow economic defamilialization - do not challenge the gendered division of care work within families. In contrast, childcare, whether it is offered in the public or the private sectors, brings the social costs of caring outside the family unit, and allows mothers to be active in the labour market. For all these reasons, the concept of defamilialization needs to be supplemented by a new concept, the demotherization of care work, to convey the extent to which mothers are relieved from caring tasks. 
Table 1 presents four types of familialism that emerge from different degrees of motherization-demotherization and familialization-defamilialization. ${ }^{42}$ The four types of familialism are more evocative of different family services and benefits than regime types, although it is possible to give examples of countries that fit each model.

\section{Table 1- The four types of familialism}

\section{Strong motherization $\quad$ Demotherization}

Defamilialization

Familialization
Implicit familialism

Gendered familialism
Institutional defamilialism

De-gendered/generational

familialism

First, the implicit familialism occurs when mothers are being offered time and money to look after dependants. Defamilialization occurs when the economic costs of care work are collectivized. Child-rearing leaves and maternity leaves are examples of policies that favour implicit familialism. In countries where implicit familialism prevails, the gendered division is not challenged and there is a broad social understanding that women are to perform the bulk of the care work. In contrast to implicit familialism, the model of institutional defamililalism favors the shift of care work from the family unit to institutions (childcare for children and nursing homes for elders or home helps). Men and women do not struggle over who takes care of the children and the elderly. While this type of arrangement allows both partners to be freed of caring activities, it has been described as being a 'cold-modern'

${ }^{42}$ Leitner (2003) offers a similar classification of types of familialism in her classification, based on a combination of strong/weak familialization and strong/weak defamilialization. 
solution (Hochschild, 1995) because it presses for maximum hours of institutional control. Third, in the gendered familialism model, mothers are perceived as being able and willing to meet the care needs of their family members. As a result, people in need of care also depend on their family. This is the dominant pattern in the Southern European countries, where the mothers are considered to be the best suited to look after dependents. Policies and services that could help women to combine earning and caring activities are scarce and the financial and social costs of raising a family are borne by the families. In that model, the caring role of mothers is enforced. Finally, in the model of de-gendered/generational familialism, the family still holds an important caring function, yet fathers and other family members relieve mothers from caring responsibilities.

Pervading the idea of defamilialization and demotherization are the notions of gender equality - treating women and men alike - and gender equity - recognizing and embracing the specific attributes of each gender (Cohen and Pulkingham, 2009; Lister, 1994. McDaniel, 2002). This dilemma was first referred as the 'Wollstonecraft's dilemma. ${ }^{43}$ The dilemma is that the two routes towards citizenship that women have pursued are impossible to achieve. On the one hand, women have demanded that the ideal of citizenship be extended to them, and the liberal-feminist agenda for a 'gender-neutral' social world is the

\footnotetext{
${ }^{43}$ It was Carole Pateman, in her 1988 essay on "The Patriarchal Welfare State" that first referred to the problem of women and citizenship as the 'Mary Wollstonecraft's dilemma'. Mary Wollstonecraft was an English writer who lived between 1759 and 1797. During the period of intense debates following the French Revolution, Wollstonecraft wrote one of the first feminist works, A Vindication of the Rights of Woman with Strictures on Political and Moral Subjects (1792), in which she argued, in contrast with feminists of her time, that women's specific attributes had to be recognized by law.
} 
logical conclusion of one form of this demand. Thus, if women are to achieve citizenship rights, they must become like men.

On the other hand, women have also insisted, often simultaneously, that their specificities be taken into account and that the expression of their citizenship be differentiated from that of men. Wollstonecraft argued that the unpaid work performed by women was the equivalent of men's paid work and that both roles were essential to society. Accordingly, men and women both had to be granted citizenship rights.

The notion of equality and equity should be understood as being part of the same continuum. High level of gender equality is almost systematically achieved at the cost of lower gender equity and vice-versa. The promotion of women's activity is understood to be the best means of increasing gender equality, the objective being to enable women to support themselves and their families through their own earnings. This 'universal breadwinner model' (Lister, 1994) scores poorly on Fraser's anti-androcentrism scale as social policies valorize men's traditional spheres while trying to help women fit in. Care work is not accorded social value. Programs that help to achieve this model are mainly childcare centers and reforms that aim at removing equal-opportunity obstacles (Lister, 1994). In Fraser's 'caregiver parity model', the objective is to enable women to support themselves and their families either through care work alone or through care work and parttime paid work. Accordingly, programs such as caregiver allowances to compensate child raising favour higher equity, but they reinforce the association of caregiving with 
femininity. The third alternative is obviously to shift the focus of analysis, by trying to achieve equality not only in the paid work, but also in caregiving responsibilities (Lister, 1994; McDaniel, 2002).

Table 2 differentiates the four types of familialism on whether they create equity or equality. First, policies that defamilialize the economic costs of raising a family by paying women and thus by encouraging a motherization of care work, recognize the nurturing abilities of women. These policies score high on the equity ladder, yet poorly on equality, because women are not available on the labour market to the same extent as their male partners. Conversely, strong equality occurs when defamilialization and demotherization are high. As mentioned above, this occurs when care work is performed outside the family (or at least by other family members than the mother) through market or state-funded institutions. This model allows women to have their work fully commodified, because they are largely relieved from care work, but it has the disadvantage of using men as the typical and ideal worker. Third, the addition of high familialization and strong motherization of care work leads to high gender inequalities. In such a context, gender equity is also low because it is implicitly assumed that mothers are responsible for the family well-being, yet they are denied social or economic defamilialization and their care work remains unrecognised. Women who live in countries where care work is strongly familialized and motherized experience the most acute forms of inequality. 
Table 2 - The four scenarios of gender equity and gender equality

\begin{tabular}{lll}
\hline & Strong motherization & Demotherization \\
\hline Defamilialization & Strong equity & Strong equality \\
Familialization & $\begin{array}{l}\text { Low equity/strong } \\
\text { inequality }\end{array}$ & Post-modern compromise \\
\hline
\end{tabular}

Finally, when care work is performed inside the family unit by other family members than the mother, a post-modern compromise is achieved. Although women are never entirely relieved from care work - it is virtually impossible to pretend that women will never have to cook a meal, do laundry, or drive their kids to school - when fathers perform care work, or when a large part of the care work is taken outside the family unit, the family remains the main provider of welfare and both partners can earn and care simultaneously. Thus, higher equality in the labour market can be achieved, though not systematically at the cost of equity, because men are encouraged to follow life course trajectories similar to those of women. The post-modern compromise scores high on equality and on equity. It also leads, as the next chapters show, to higher fertility. Before making this demonstration, the next two chapters introduced a macro-structural institutional approach to the study of Quebec's fertility regimes. 


\section{CHAPTER 5}

\section{THE INSTITUTIONAL APPROACH TO FERTILITY: STATE, MARKET AND FERTILITY}

Jobs in the industrial and postindustrial worlds do not always permit women to simultaneously perform both care work and paid work. Until the 1980s, female labour market participation and fertility were negatively related in advanced societies. At the time, the relationship between market activities and childbearing was articulated in terms of a trade-off between work and maternity. The contradictory demands of working life and motherhood were seen as restricting the capacity of working women to have children and of mothers to be employed (Castles, 2003). Since the 1980s however, the relationship between fertility and women's employment has completely reversed in industrialised countries (see among others, Ahn and Mira, 1999; Brewster and Rindfuss, 2000; Castles, 2003; McDonald, 2000a, 2000b, 2002; Rindfuss et al., 2004). As countries with low female labour force participation saw their fertility rates plummeting, others kept relatively high fertility with high female activity.

In line with the gender equity theory, and through an extensive literature review, the institutional approach developed in this chapter and chapter 6 provides a macro-structural perspective to address these changes in patterns of social reproduction. While some scholars emphasise the role of changes in the labour market as the main cause for new patterns of social reproduction, others search for explanations in the social policy regime that allows family responsibilities to be reconciled with participation in paid work. What is clear is that women's reproductive decisions are made within specific institutional contexts 
that pose opportunities and constraints on their ability to earn and to care. Thus, the institutional approach starts with the assumption that at the macro-level, the structure of the three pillar institutions of advanced societies - states, markets and families - creates an environment that is more or less favourable to motherhood.

Together with chapter 6 , this chapter draws a broad picture of the economic, political and cultural context that leads to specific fertility outcomes across different types of fertility regimes. This chapter opens with a discussion of the effect of the structure of the labour market on fertility. Studies tend to confirm that economic slowdown is typically linked to lower fertility, at least in the Southern European countries and in Scandinavia. Other determinants that negatively affect fertility include the shortage of part-time jobs and the difficulty of finding employment. On the positive side, flexible working hours, ${ }^{44}$ prosperous economies and women's attachment to the labour market all lead to higher fertility. Then the articulation between various indicators pertaining to the deinstitutionalization of the family, new norms regarding formation and fertility outcomes is addressed. While all developed countries seem to be making the same shifts towards less homogeneous patterns of family and living arrangements, the relationship between marriage, divorce, age at first birth, births out-of-wedlock and fertility is often paradoxical. Chapter 6 focuses on the abundant literature on the effect of public policies on fertility.

\footnotetext{
${ }^{44}$ Obviously, the extent to which flexible working hours help workers balance work and family life is determined by the extent to which workers have control over their schedule. In practice, flexible working schemes are often designed to address employer needs in the production process (OECD, 2012).
} 


\section{The structure of the labour market and fertility}

There is a broad consensus among social scientists on the effects of the structural changes in the labour market on new fertility trends. The idea that fertility reacts positively to economic prosperity and falls in times of crisis has been explored for centuries (Sobotka et al. 2010). ${ }^{45}$ As early as 1776 , Adam Smith linked the rate of economic development and growth to the 'multiplications of species' (Spengler, 1976: 173). As we saw in chapter 3, Becker $(1960,1981)$ compared children to durable goods, demand for which would increase with a rise in couple's income and with a decline of their 'price'. In the 1960s and 1970s, Easterlin $(1961,1968,1973,1978)$ modified this classical economic argument, emphasising the role of income relative to economic aspirations of the couple. Easterlin felt that fertility varied with the relative affluence of the younger cohorts, which is gauged against the childhood experiences of their parents' household. Conversely, Butz and Ward (1979) suggested that fertility trends were likely to become countercyclical with women's rising employment. They argued that the baby bust of the 1960 s was due to increases in female wages and income. While an increase in the wage of an employed woman adds to family income, it simultaneously increases the price of children since the opportunity costs of childrearing rise at the same time. Whereas Butz's and Ward's conclusion found support for their analysis in U.S. data pertaining to the first half of the 1970s, later research by Macunovitch (1996) suggested that the U.S. fertility remained 'pro-cyclical'. According to Macunovitch (1996: 251), periods of high unemployment had a stronger effect in disrupting

\footnotetext{
${ }^{45}$ The first two paragraphs heavily draw from Sobotka's et al. (2010) literature review on the impact of economic recession on fertility in the developed world.
} 
women's expectations regarding future income streams than they have in providing ‘windows of opportunity' for pregnancy.

While the evidence is not unanimous, many studies found that fertility tended to be procyclical and to react to the ups and downs of the business cycle. Goldstein et al. (2009) showed that unemployment rate and economic growth were statistically significant predictors of the total fertility rates across 27 OECD countries ${ }^{46}$ between 1995 and 2008, a finding corroborated by Sobotka et al. (2010). To put it simply, difficult economic conditions tended to lead to low fertility while improved economic conditions were associated with increased fertility. Most of the time, the economic cycle waves were minor and of relatively short duration; consequently, they could be overshadowed by long term secular trends in fertility.

In the Southern European countries, the availability of jobs - especially for women - and a foreseeable stable income seems to have exerted a determining impact on fertility behaviour. A high incidence of unemployment makes it hard for working women to decide to have children. The strong probability that they will lose their job and the difficulty of finding another after giving birth has meant that women abandon, or at least postpone, their plans to have a child (Bagavos and Martin, 2000). Kohler et al. (2005) showed that the three lowest-low fertility countries in Southern Europe - Italy, Greece and Spain - had the

\footnotetext{
${ }^{46}$ These countries are Australia, Austria, Belgium, Canada, Czech Republic, Denmark, Finland, France, Germany, Greece, Hungary, Iceland, Ireland, Italy, Japan, Korea, Luxembourg, Mexico, Netherlands, New Zealand, Norway, Poland, Portugal, Slovakia, Spain, Sweden, Switzerland, Turkey, United Kingdom and United States.
} 
highest youth unemployment rates in the European Union in 1999, and this situation had remained essentially unchanged since 1989. The link between unemployment and low fertility was also supported by the observation that the only Southern European country with relatively high fertility has been Portugal, with considerably lower unemployment rates than its Mediterranean counterparts (Kohler et al., 2005). Similarly, Adsera (2005) showed that maternity postponement was acute in countries with high and persistent unemployment, such as in Greece, Italy and Spain. For a similar level of employment, however, fertility varied as a function of country-specific institutional arrangements. Public sector jobs which provided security and benefits led to faster transition to motherhood. Wide access to part-time employment has also been associated with faster transitions to second and third births in the three Mediterranean countries.

Surprisingly, Del Boca et al. (2005) argued that if Italian women had access to the same number of part-time positions as women in the United Kingdom, the national fertility rate would decrease. This finding is in contradiction with other studies that have shown that the availability of flexible working hours and part-time positions were important dimensions affecting fertility behaviours (see for instance Engelhardt and Prskawetz, 2002). In Italy, the structure of the labour market acts to discourage fertility, as young workers encounter difficulties in finding entry positions and there is a scarcity of part-time jobs. The fact that part-time employment has been rare in Italy is an important factor in accounting for the low employment rates of married women, particularly those with children (Del Boca, 2002; Del Boca et al., 2005). If the Italian labour market offered more part-time jobs, female labour 
force participation would increase, at the cost, however, of lower fertility. According to Del Boca et al. (2005), in a country where women are accustomed to choose between no work or full-time work, the growth of the availability of a third option - working part-time would change the choice set available with ambiguous results on fertility. If non-working women chose to work part-time, their fertility would probably decline, while if full-time working women chose to reduce their working schedule, their fertility would increase. Thus, the net effect on fertility would depend on the size of these two flows. The link between the scarcity of part-time work and fertility is still open to debate.

In the social-democratic regime, conflict between employment and family has been relatively low, due to the institutional support for working mothers (Matysiak and Vignoli, 2008). There is a strong agreement among scholars, however, that the deterioration of the Swedish economy during the 1990s was largely responsible for the drop in the fertility rate. Hoem (2000) reported that the first-birth rates of women under 25 were cut in half between 1990 and 1997 and that the birth rates of older childless women moved in parallel, albeit with a different pattern. Similarly, Santow and Bracher's (2001) showed that unemployment affected first births trends in Sweden between 1966 and 1992. The rise of unemployment rate to 5-9 per cent in the same age group as the respondent's age category indeed decreased the likelihood of birth conception by 21 per cent, while the rise of unemployment above 10 per cent resulted in a decline in first conception by one half (table II in Santow and Bracher, 2001, discussed in Sobotka et al., 2010). In Norway, the 0.08 
reduction in total fertility rates was associated with a peak in unemployment rates experienced in 1993 (Kravdal, 2002).

Perhaps, women in the Scandinavian countries have responded to precarious economic contexts by enrolling in education as one way of improving their chances in the labour market, and as a consequence they have delayed family formation (Dribe and Stanfors, 2005, 2009; Hoem, 2000). While education is a key factor determining the transition to parenthood for both men and women, there have been differences in the effect according to gender (Dribe and Stanfors, 2009). In Sweden, education attainment has delayed the entry into parenthood only for women, which indicates a conflict between higher education and childbearing; educational enrollment however, is incompatible with childbearing for both women and men (Dribe and Stanfors, 2009). In Sweden, labour market attachment is an important determinant of the transition to parenthood for both men and women. Hence, women enrolled in education and women with relatively low level of earned incomes have had lower birth risks than others (Andersson, 2001); it is the increase in the number of women with such characteristics that resulted in fewer births in the 1990s. In Sweden, being employed has indeed been highly conductive to childbearing for both men and women (Dribe and Stanfors, 2009). This is due to the income-replacement character of the generous parental-leave system in this country, which provides strong incentives for women to have a firm footing in the labour market before they start having children (Andersson, 2001; Dribe and Stanfors, 2009; Hoem, 2000; Vitak, 2004). The income-base benefits are much more generous than the flat rate benefit that is given to people with 
insufficient work experience. The positive effect of employment has been shown to affect men and women, irrespective of the sector they work in. In relation to other forms of employment, however, women who work in the public sector have had higher chances of childbearing (Dribe and Stanfors, 2009).

In the Scandinavian countries, the pronounced swings in fertility rates have been associated with the ups and downs of the business cycle, supporting a notion of 'pro-cyclical fertility' or, as Hoem and Hoem (1996) term it, a 'roller-coaster fertility'. Business cycles reflect the degree of confidence in the course of the economy: while in prosperous times, Swedish adults start families even when they are unemployed, they have tended to defer childbearing in times of economic slowdowns even when being employed (Dribe and Stanfors, 2009). Not only is women's economic activity positively correlated to entry to motherhood, but it is also correlated to earnings. Indeed, predictions from standard economic theory, which say that women with a higher income normally show a lower propensity to give birth, are not valid in Finland (Vitak, 2004). In that country, the earnings of 20 to 30 year old women have had a strong positive effect on their propensity to become mothers, even after controlling for the level of education. Among women over age 30, controlling for activity and level of education, the high-income earners still displayed a 38 per cent higher risk to experience a first birth than women in the lowest third of the income distribution. 
The negative relationship between unemployment and fertility rates that has prevailed in Scandinavia and the Southern European does not hold in Continental Europe. Kurz et al. (2005) pointed out that in Germany the effect of unemployment on the transition to parenthood differed between men and women. While unemployed men have been less likely to become fathers, an insecure position has not had a negative impact on women's decision to start a family. Quite the contrary: in Germany, positions of insecurity seem to have promoted the transition to motherhood. Studying the impact of unemployment on the transition to first-parenthood, Schmitt (2008) demonstrated the existence of a positive effect on the transition to family formation in the United Kingdom, Germany and Finland; only in France did unemployment correlate to lower fertility. According to Schmitt (2008) unemployment was positively correlated with family formation in the United Kingdom and Germany for both men and women. For German women, even short-term unemployment (up to six months) increased the probability of undergoing the transition to family formation, while for German men the effect became significant for long-term unemployment. The causal relation between unemployment and the probability of having a child could be mediated by social class (Kreyendeld, 2009): while women with low levels of education often respond to these situations by becoming mothers, highly educated women postpone parenthood when subject to employment uncertainties. Parenthood is then a strategy for disadvantaged women to structure their otherwise uncertain life course.

Finally, in the liberal countries high fertility has been explained in the light of the availability of numerous jobs that both make the returning to employment after giving birth 
easier and that compensate in part for the lack of public support for parents (Adsera, 2004, 2005; Kohler et al. 2005; Lattimore and Pobke, 2008; Matysiak and Vignoli, 2008). In the United States, although immigrants and minority groups have had fertility levels above the national average, racial and ethnic diversity explained only part of the relatively high fertility rates (Kohler et al., 2005). Indeed, the total fertility rate of non-Hispanic White women exceeds the national rates for most other high income countries. Hence the heterogeneity of the American population is one factor that has contributed to the relatively high levels of fertility in the United States; it does not however constitute the primary explanation (Kohler et al. 2005). ${ }^{47}$ In Australia, the strength of the labour market has reduced the costs of leaving a job in order to have children as prospects of getting another job in the future are bright. Very low unemployment rates and shorter durations of unemployment in the mid-2000s were likely to have created these conditions (Lattimore and Pobke, 2008).

To summarise, in the Southern European countries - and more specifically Greece, Italy and Spain - the scarcity of employment, the moderate size of the public sector and the stickiness of unemployment have brought about a dual market with unstable labour contracts for young workers. All these institutional factors have had a depressing effect on fertility. Research has also shown that although the scarcity of part-time employment had a

\footnotetext{
47 This argument should be nuanced in the light of class analysis. In the United States, the lack of family policies may make it hard for women who have invested in their career to find equivalent employment after giving birth. The flexibility of the U.S. labour market is probably more positive for women who are relatively undemanding with respect to their paid work (Bagavos and Martin, 2000).
} 
negative effect on fertility in Italy, an increase in part-time job opportunities could further decrease fertility rates. As in the Mediterranean countries, fertility trends have been associated with economic cycles in Scandinavia and Sweden. The literature points to the existence of a Scandinavian pattern of family formation, in which there is a positive relationship between a woman's position in the labour market, both in terms of her labour market attachment and her earnings - and the risk of giving birth for the first time. This relationship contradicts the notion that women who command a higher wage have lower childbearing risks because of the high opportunity cost of childbearing, at the heart of the New Home Economics model. Yet in continental Europe, and especially in Germany, the New Home Economics model has found some relevance as a causal relation - albeit mediated by social class - between unemployment and the probability of having a child was found: positions of insecurity sometimes promoted parenthood. The exception to the rule here was France. Finally, in the Anglo-Saxon countries, the availability of numerous jobs and the low unemployment rates have created an institutional context that eased women's return to economic activity after giving birth.

\section{Is low fertility the result of the deinstitutionalization of the family?}

Prioux (2003) has presented a clear-cut example of an inverse relationship between youth unemployment and the rate of first union formation in France, indicating that difficulties experienced in the labour market caused a postponement of marriage and entry into cohabitation. There are connections between the situation individuals experience in the labour market and other life-course transitions that lead to family formation. Although 
family and living arrangements are currently heterogeneous across Europe and North America, all countries seem to be making the same shifts towards new norms. These include the decline of marriage and the growth of cohabitation, the postponement of union formation and childbearing, the rise of union instability and an increase in the proportion of children born out-of-wedlock (Sobotka and Toulemon, 2008). According to Roussel (1987, 1989), these emerging norms were linked to the deinstitutionalization of the family and have strong depressing effects on fertility.

The evidence presented below however shows that the links between indicators of the deinstitutionalization of the family and fertility are complex and that they often challenge common sense. The first trend pertains to the causal relationship between marriage and fertility. From a time series point of view, one could argue that marriage has been a valid proximate determinant of fertility behaviours since the overall decline in total fertility rate was accompanied by a decline in total first marriage rates (Engelhardt and Prskawetz, 2002). Table 3 however shows that from a cross sectional view, marriage is no longer positively correlated to fertility and that the emergence of lowest-low fertility in the 1990s was associated with fundamental shifts in the relationships between these two variables (Billari and Kohler, 2002; Engelhardt and Prskawetz, 2002; Kohler et al. 2005). Even though marriage has been the main context of childbearing in Europe, countries with low marriage rates such as the Nordic countries and France have not had the lowest fertility (Hobson et al., 2004). In the Southern European countries, long-term partnership commitments- symbolised by relatively high prevalence of marriage and a low incidence of 
divorce - even seem to have represented an obstacle for the progression to (relatively) high fertility levels (Billari and Kohler, 2002; Kohler et al., 2005). In the early 2000s, four of the five countries with the lowest fertility rate -Portugal, Spain, Italy and Greece - also had the highest proportion of married people (table 3).

Table 3 - Prevalence of marriage ${ }^{48}$ and fertility rates in selected OECD countries

\begin{tabular}{lcc}
\hline & Prevalence of marriage $^{49}$ & Total fertility rate (in 2009) \\
\hline Australia & 51.2 & 1.90 \\
Canada & 39.3 & 1.66 \\
Denmark & 40.8 & 1.84 \\
Finland & 43.6 & 1.86 \\
France & 44.6 & 1.99 \\
Germany & 47.5 & 1.36 \\
Greece & 56.4 & 1.53 \\
Italy & 53.9 & 1.41 \\
Netherlands & 48.1 & 1.79 \\
Norway & 44.1 & 1.98 \\
Portugal & 56.5 & 1.32 \\
Spain & 53.6 & 1.40 \\
Sweden & N.A. & N.A. \\
United Kingdom & 47.3 & 1.94 \\
United States & 52.9 & 2.01 \\
\hline
\end{tabular}

Source: OECD family database (2011).

${ }^{48}$ The prevalence of marriage refers to the proportion of the population, aged 20 and over, that is legally married.

${ }^{49}$ Data refer to 2000 in Finland and the United States, 2001 in Denmark, Greece, Italy, the Netherlands, Norway, Portugal, Spain and the United Kingdom, 2006 for Australia and Canada, 2007 for France. 
Due to a combination of marriage decline and marriage postponement, the proportion of married people decreased rapidly between 1960 and 2000 across Europe, especially among men and women under age 30 (Sabotka and Toulemon, 2008). Today the sequence of 'cohabitation, first-birth, and marriage' is now the norm in some countries and many couples with children do not marry at all (Sabotka and Toulemon, 2008). In Sweden where most young people enter their first union through cohabitation, new standards of behaviour have been emerging: first marriage takes place on average almost three years later than the birth of a first child (Oláh and Bernhardt, 2008; Sabotka and Toulemon, 2008). This observation led Elzinga and Liefbroer (2007) to argue that the decrease in variation in family-life trajectories in Sweden (and to a lesser extent in the Netherlands) brought a process of re-standardization of family behaviours.

A second trend concerns the correlation between divorce and fertility. Again, from a time series point of view, the decline in total fertility rates went hand in hand with an increase of divorce rates. But the cross-country relationship between partnership dissolution and fertility has also been reversed in the late 1990s (Engelhardt and Prskawetz, 2002; Kohler et al., 2005). In 1975, a higher level of divorce in European countries was associated with lower levels of fertility in cross-sectional comparisons. This correlation became weak in the late 1990s, and if a systematic relationship exists at all between the total divorce rate and the total fertility rate, the sign of the correlation has changed: countries with higher total divorce rates have had higher fertility levels (Billari and Kohler, 2002). In the late 2000s, the two countries with the lowest divorce rate, Italy and Greece, also had very low fertility; 
conversely, in the United Kingdom and the United States, high divorce rates did not have a negative impact on fertility. Finally, as shown in figure 4 while a low level of family dissolution does not seem to increase fertility by itself, a high level of extramarital childbearing has not been associated with low fertility. Both in the Nordic and the AngloSaxon countries, births out of wedlock have been positively correlated with high fertility, while in the Southern European countries, the low prevalence of births outside marriage has been linked to low fertility.

Figure 4 - Cross-country relationship between the share of births out of wedlock and the fertility rate, selected OECD countries, 2008

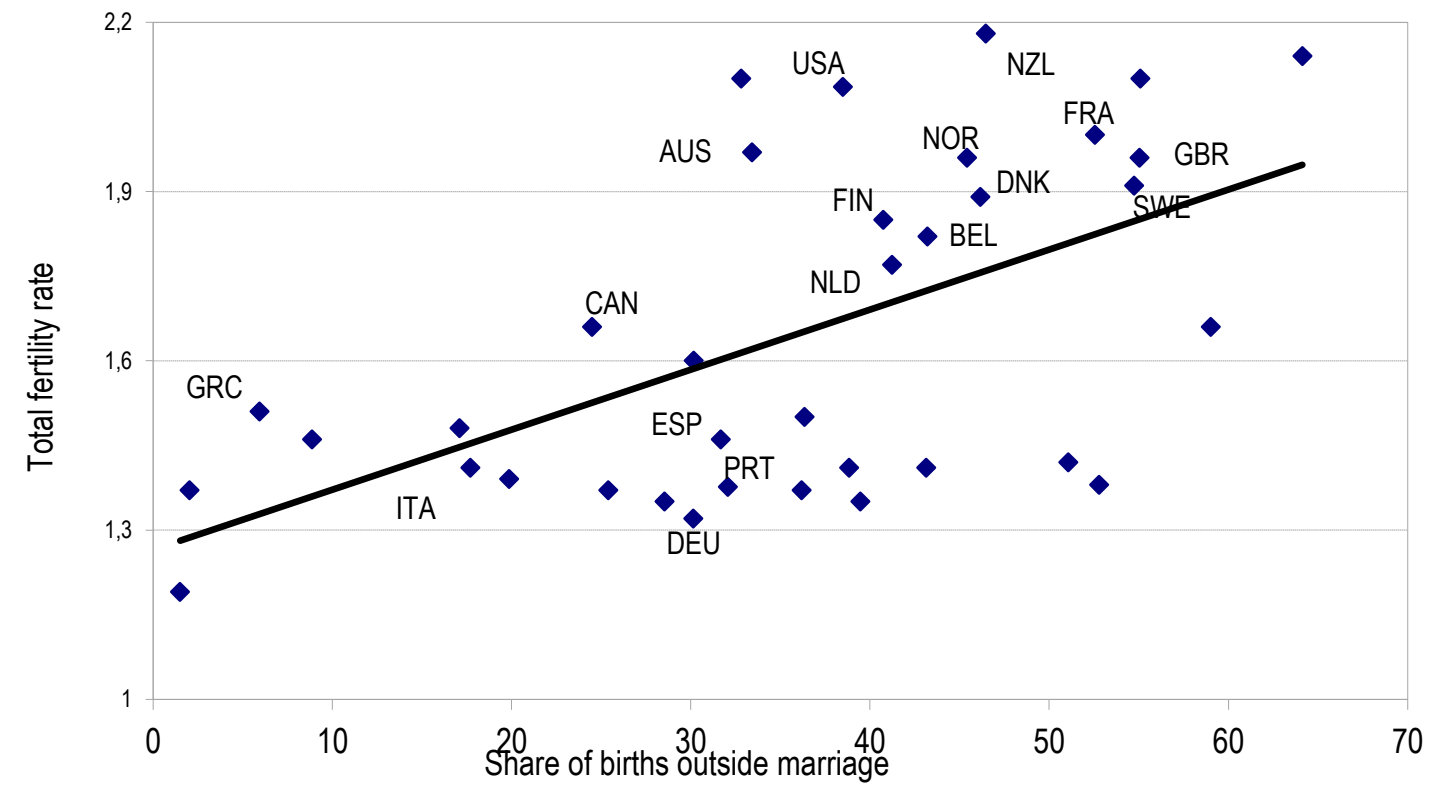

Source: OECD Family Database (2011).

The increasing proportion of children born outside marriage ${ }^{50}$ does not imply a similar increase in the frequency of single motherhood, as extramarital births are often taking place in the context of stable cohabiting partnership (Oláh and Bernhardt 2008; Sabotka and

${ }^{50}$ Commenting statistics published by Eurostat (2006), Sabotka and Toulemon (2008) report that one-third of all births in the EU-25 occurred outside marriage in 2005. 
Toulemon, 2008). The case of Sweden is striking in that regard. While the proportion of extramarital births in Sweden has been among the highest in Europe for decades, the share of births to single mothers has remained at around 10 per cent, except for the mid 1990s (Oláh and Bernhardt, 2008). Similarly, in the Netherlands, most births to unmarried women today occur within a relationship, usually to a couple in their late 20 s or early 30 s who made a conscious decision (Fokkema et al., 2008: 756). Thus, the correlation between extramarital fertility and the women's marital status is also far from being straightforward, not only because of the different combination between these two dimensions, but also because countries with differential structural arrangements of states, markets and families are often brought together in an unusual manner. On the more commonsensical side, a low prevalence of premarital cohabitation has been associated with low rates of extramarital fertility in the Mediterranean countries. A low incidence of cohabitation, however, can also be associated to high rates of children out of wedlock; this has not only been the case in Eastern European countries, but also in Portugal, Ireland, the United Kingdom and the United States (Lesthaeghe and Morrs, 2002). Similarly, high rates of cohabitation can be combined with low non-marital fertility, as in the more conservative nations of Switzerland, Belgium, the Netherlands and Germany, but it can also occur in a context of parenthood such as in the Scandinavian countries, France and Canada (Lesthaeghe and Morrs, 2002). Another puzzle regards the age at which women start having a family. The emergence of lowest-low fertility in Europe is associated with a delay in childbearing. During the 1990s the mean age at first birth increased by more than 1.5 years in Italy, Spain, Hungary and the Czech Republic (Billari and Kohler, 2002). It would be misleading, however, to conclude 
that a marked postponement automatically leads to very low levels of fertility. In the United Kingdom, France, the Netherlands and Sweden, for instance, countries in which women have tended to delay first births beyond age 28 , fertility has not been exceptionally low, quite the contrary (Hobson et al., 2004; Fokkema et al., 2008; OECD, 2011; Toulemon et al., 2008).

This observation invalidates one common explanation of low fertility: demographic trends in these countries have not followed the suggested pattern that delaying entry into parenthood has a negative influence on fertility. The key to this puzzle is in the differential degree of recuperation of women passed age 30 in various developed countries (Lesthaeghe and Moors, 2000). The trend towards later childbearing has contributed to the decline in period fertility rates, as they have been negatively affected by changes in the timing of childbearing. Delayed births are often being recuperated, especially among childless women.

The extent of recuperation nonetheless differs by country and region (Frejka and Sobotka, 2008). Thus Western and Northern European countries, joined by Japan, all progressed much further along the postponement trend, but they split into two groups (Frejka and Sobotka, 2008; Lesthaeghe and Moors, 2000). The first group -composed of the Nordic countries, the United Kingdom, France and the Netherlands - has had a relatively strong recuperation after age 30 and has been able to maintain or to reach total fertility rates above 1.70. The extent of recuperation has been notably smaller in the second group, formed by 
the Mediterranean countries and German-speaking countries (Frejka and Sobotka, 2008; Lesthaeghe and Moors, 2000, Nishioka, 2003). ${ }^{51}$ Lowest-low fertility is also not inevitably associated with a rapid delay of childbearing.

The delay in family formation can be partially explained by the prolonging of adult children in their parent's home (Billari and Kohler, 2002; De Rose et al., 2008; Dribe and Stanfors, 2005; Kohler et al., 2005; Lesthaeghe and Morrs, 2000; Sabotka and Toulemon, 2008). Leaving home is one of the crucial moments in the life course and a central event in early adulthood; it implies the formation of a new household and greater autonomy for young people. Home-leaving constitutes a central correlate of fertility and union formation in Europe and other industrialized countries. The timing, the sequencing and the synchronisation of leaving home with the formation of a first union and of childbearing are rather heterogeneous in Europe. In Southern Europe, the 'latest-late pattern' (Billari, 2004) dominates: home leaving has taken place late, especially for men who often reside with their parents after the age of 30 (Sabotka and Toulemon, 2008). Furthermore, Mediterranean populations have been reluctant to adopt an intermediate phase of home leaving (Lesthaeghe and Moors, 2000), where young adults leave the parental home to live as a single person or cohabiting, without starting a new family for a period of time. As a result, in Italy, more than 80 per cent of men aged 18-30 lived with their parents in the early 2000s (Manacorda and Moretti, 2006), and a clear postponement of marriage and motherhood have been visible (Elzinga and Liefbroer, 2007). Cohabitation is a normal good

${ }^{51}$ Insufficient recuperation is also noted for other Western European countries such as Belgium, and Switzerland (Lesthaeghe and Moors, 2000). 
for Italian parents and parental preferences might contribute to explain the remarkably high rate of cohabitation between Italian adult children and their parents (Manacorda and Moretti, 2006). In Italy and in Spain young adults often prefer to stay in their parent's home, even when they are economically independent. In these countries, greater freedom of movement enjoyed by adult children as a result of quasi-democratic relationships with their parents and growing household welfare and the social differentiation between sexuality and procreation, have weakened the pressures for leaving the parental home at an early age. At the same time, the generalized use of family planning has lightened social pressures to form a family (Delgano et al., 2008: 1086).

The Nordic countries have had the opposite pattern of entry into adulthood with the earliest-early age at home-leaving, the highest proportion of young adults leaving home before union formation and the lowest connection between home-leaving and marriage (Billari, 2004; Billari et al., 2001). In these countries, procreation has been detached from the precondition of marriage. Still, cohabitation - and even more so marriage - positively affects the risk of conception in Sweden (Dribe and Stanfors, 2005). More precisely, married men and married women are about 12 and 7.3 times more likely to experience a conception leading to a first birth than are never married men or women respectively. Although for cohabiting men and women, the corresponding effects are similar - but are less - (Dribe and Stanfors, 2005), birth intensities in Sweden have been higher for married women than for cohabiting women, at least up to the third child (Oláh, and Bernhardt, 2008). 
The discussion of the effect of the deinstitutionalization of the family on fertility showed that the once normative order of key life transition of 'direct' marriage without cohabitation followed by childbearing has been increasingly replaced by a number of alternative pathways. The dominance of one type of family trajectory characterised by early marriage and motherhood decreased across all the Western world and family-life trajectories of young adult women have become more diverse (Elzinga and Liefbroer, 2007). In the socialdemocratic, liberal and conservative welfare regimes, the course of traditional family formation characterised by early marriage and motherhood dropped in popularity. In the Southern European countries, although cohabitation has become an option new generations seem to consider (Rosina and Fraboni, 2004), and even if the proportion of young adult women who enter motherhood later in their life course is increasing (Elzinga and Liefbroer, 2007), marriage continues to be a popular choice. Thus, aggregate cross-country relationship between partnership formation/dissolution and levels of fertility became indeterminate in the late $1990 \mathrm{~s}$, which was markedly different from the strong relations between fertility and union formation and dissolution that prevailed two decades earlier (Billari and Kohler, 2002; Kohler, et al., 2005).

To summarize, the three foundational pillars of fertility regimes - labour markets, family structures and family-relevant policies - are key determinants of reproductive behaviour. The effect of these three pillars, however, is not straightforward. The last building block of the institutional approach concerns the effect of public policies on fertility. This issue is addressed in the next chapter. 


\section{CHAPTER 6}

\section{BETWEEN THE TEMPO AND THE $Q U A N T U M$ OF BIRTHS: THE EFFECT OF FAMILY POLICIES ON FERTILITY ${ }^{52}$}

"It might be said that developing fertility policy is a bit like shooting at a target in a pitch black room. Actually this metaphor is too optimistic. Developing fertility policy is like trying to hit a target while standing in a pitch black room without even knowing whether the target is there" (Sanderson, Warren, 2011: 75).

Public policies shape the institutional context in which women combine earning and caregiving duties and make reproductive decisions. Among other things, policies regulate the terms of employment, they set eligibility conditions to welfare programs such as parental and child-rearing leaves and benefits, they define sharing of care work between parents, the market and the state, and they favour or challenge the traditional gendered division of labour. The influence of specific policies on fertility outcomes nonetheless remains open to debate. Demographers have been concerned with two possible effects of policies on fertility. The first one, the tempo effect, is due to changes in the timing of births. Thus while a tendency towards a younger age at birth increases total fertility rate, a deferral of births leads to a decrease in the observed rate. Changes merely in the timing of births however have no effect on the level of fertility and completed fertility remains unchanged (Philipov and Kohler, 1999). The second possible effect of policies on fertility affects the quantum - or the number- of births. The quantum changes when the number of children

\footnotetext{
${ }^{52}$ A modified French version of this chapter was published under the title «Entre l'effet tempo et l'effet quantum: une analyse de l'effet des politiques familiales sur la fécondité dans les pays avancés ", in Sociologie et sociétiés, 25 (1), 255-276, 2013.
} 
born to a woman over her entire reproductive period fluctuates, rather than the age at which these births occur.

Taking into account both tempo and quantum effects, the literature has shown that social policies could influence fertility in three distinctive ways. First, it has been argued that the effect of specific policies could only be only temporary - thus creating a calendar effect - by bringing forward births parents would have had later in life. The tempo effect could be particularly important when parents are concerned that a generous policy measure may only be in place for a short period of time (Lattimore and Pobke, 2008). The Australian baby bonus, the Swedish 'speed premium' and the Austrian parental leave have all been suspected of influencing the timing of births, rather than completed fertility. A second possibility is that policies - or more accurately the lack thereof - have a negative influence on fertility. In Germany, Spain and Italy, the difficulty for women to find suitable childcare has had a negative impact on both female activity rates and fertility. The opposite scenario appears as plausible: social policies could have a positive impact on fertility, by demotherizing part of the economic and social costs entailed by the birth of a child. In France and in the Scandinavian countries, policies have allowed mothers to stay active in the labour market even when they have young children by offering childcare services and generous parental leaves. More broadly, it has been argued that these countries created an institutional setting that favoured parenthood. 
There is yet another possibility regarding the causality between policies and fertility. This chapter shows that the effect of specific policies varies depending upon the welfare and gender regimes in which they are embedded. Thus, fertility is theorised as the outcome of broad attributes such as the extent of family friendliness characterizing a society. This chapter demonstrates the contradictory findings of empirical strategies that examine the influence of policies in isolation, instead of taking into account the context in which policies are being introduced. Accordingly, the effect of similar policies on reproductive behaviour changes depending on the policy constellation.

The chapter begins with a brief discussion of previous studies that have concluded that policies have a weak yet positive impact on fertility. The bulk of the analysis is in the second part of the chapter. Since family policies are an integral part of welfare policies, I draw on the welfare and gender regimes literatures to discuss the effect of various policies such as parental and child-rearing leaves, childcare subsidies and centers, the income-tax system, cash benefits and baby bonus on fertility. I show that the effect of policies on fertility is complex and sometimes contradictory, yet that parental leaves, the availability of childcare (in various forms) and the income-tax system are the policies most likely to affect fertility. In the third section of the paper, I discuss the difficulties inherent in an examination of the influence of policies on fertility. I suggest that policies that promote gender equality by allowing care work to be demotherized are the most likely to positively affect fertility outcomes. The chapter ends with the introduction of the methodological approach and the periodization of the different fertility regimes in Quebec. 


\section{Previous literature reviews and comparative studies}

Previous literature reviews and comparative studies in developed countries have tended to demonstrate the existence of a positive, albeit limited effect of family policies on fertility (Gauthier and Hatzius, 1997; Gauthier, 2007; OECD, 2011; Sleebos, 2003; Sobotka, 2011; Thévenon and Gauthier, 2011). Three policies have been the object of specific academic attention. First, family cash benefits have been shown to have a weak but positive influence on reproductive decisions. Gauthier and Hatzius (1997) estimated that a 25 per cent increase in family allowances would result in an increase of the total fertility rate of 0.07 children per woman in the long run in 22 developed countries. Luci-Greulich and Thévenon (2013) showed that cash benefits covering childhood after the year of childbirth had a stronger quantum effect than benefits granted around childbirth. Conversely, Thévenon and Gauthier (2011) argued that cash transfers had a positive effect on the tempo of births. These findings were contradicted by Kalwij's (2010) comparative study of 16 Western European countries. According to Kalwij, an increase in family allowance's program would not have a significant effect on the timing or the completed fertility. With regard to workrelated policies such as parental leave, Kalwij (2010) argued that a 10 per cent increase in maternity and parental benefits would only result in a reduction of 3.2 per cent in childlessness at age 36-40; yet, parental leaves would have no effect on completed fertility. Surprisingly, d'Addio and d'Ercole (2005) found that a longer parental leave lowers fertility rates in developed countries. 
The only policy that has consistently been found to have a positive impact on fertility within the comparative literature is the availability of childcare, either in the form of a subsidy (Kalwij, 2010; Sleebos, 2003) or through provision of institutional services (Castles, 2003, Apps and Rees, 2004), especially for children under 3 (Luci-Greulich and Thévenon, 2013). More broadly, Castles (2003) found a strong association between fertility and the composite index of work/family reconciliation, an observation later supported by several other studies (OECD, 2011; Sobotka, 2011; Thévenon and Gauthier, 2011). As we will see below however, country specific analyses of the effect of childcare on fertility have produced more complex results.

\section{Public policies and fertility in the worlds of welfare capitalism}

Using Esping-Andersen's $(1990,1999)$ three worlds of welfare capitalism with the addition of a fourth - Latin model - I show that the effect of policies on reproductive behaviour is not straightforward across different countries. While numerous empirical studies have investigated the effect of singular policies on fertility in the Scandinavian and Anglo-Saxon countries, scholars who have studied fertility in Continental and Southern European countries have used a more holistic approach, showing that fertility increased when the institutional context and the societal attitudes favoured the reconciliation of paid work and care for young children (under 3 years of age). Overall, child-contingent cash support (whether provided through cash benefits, in-work tax credits or income tax deductions) were found to be associated with higher fertility in Scandinavia, in Anglo-Saxon countries, in Finland and in Spain, supporting the hypothesis of a positive effect of policies on 
reproductive behaviour. The provision of parental leave has been shown to have a positive influence in the socio-democratic countries, but ambiguous effects in Anglo-Saxon countries, in Germany and Austria. Finally, the availability of childcare has been associated with increased fertility in Norway and Spain, but it does not seem to influence fertility decisions in Sweden and Germany.

\section{The Nordic countries}

The Nordic welfare states have a long tradition of extensive and generous social policies to support families, designed around concerns for the general well-being of children and their families (Rønsen, 2004a, 2004b). The Nordic countries have also succeeded in maintaining a high rate of female activity, without reducing fertility to low levels (Datta Gupta et al., 2006; Ellingsaeter, 2009). Among the Nordic countries, Norway has the most ambiguous family policies, giving incentives both to gender equality and childrearing at home. Since 1998, Norway has offered childcare cash benefits to couples with children aged between 12 and 36 months. The benefit is available as long as state-subsidized childcare facilities are not used. Through this scheme the government aims to provide a cash payment to parents who either prefer to care for their children at home or to compensate those who are not offered external state-subsidized childcare (Aassve and Lappergård, 2009; Lappergård, 2010). It has been argued that the new policy encouraged (some) women to stay at home with their children. Aassve and Lappergård (2009) showed that couples where the mother had low education attainment and lower earnings were most likely to take the cash benefits. The take-up of the benefit was also positively associated with fertility timing: couples who 
took the cash benefit were quicker in progressing onto subsequent childbearing. Since timing is often correlated with completed fertility the authors argue that there is every possibility that the take-up of the cash benefit policy increases fertility. Lappergård (2010) showed that the introduction of the benefit had a stronger positive effect on third births than on second births. ${ }^{53}$

Maternal and parental leaves in the Nordic countries have a history of more than 100 years (Datta Guta et al., 2006). Current Nordic paid parental leave arrangements share several similarities, most notably with regards to their high wage compensation levels. ${ }^{54}$ Examining the effect of the generous Norwegian parental leaves on fertility outcomes, Lappergård (2010) has shown that couples in which at least the mother used the leave had higher second-birth intensities than couples in which neither parent used any leave. The correlation between parental leave and third-order births, however, turned out to be reversed. No parental leave was positively related with third-birth rates: the more the leave taken by the father, the higher the birth rate.

With the exception of Denmark, all Nordic countries offer 'daddy's quota' - periods of parental leave based on use-it-or-lose-it principles. The length of the daddy quota varies significantly, between two weeks and three months. At the lower end of the spectrum,

${ }^{53}$ As for Finland, Vitak (2004) argues that women who make use of extended childcare leave related to the child home allowance (HCA) have a higher propensity to have a third child- most probably because women who are family oriented opt for HCA as part of their plan to have a third child. Vitak's study, however did not explicitly test whether the introduction of the HCA had an effect on fertility.

${ }^{54}$ Denmark and Sweden have the highest compensation rates, $90 \%$ and $100 \%$ respectively, while Finland has the lowest level of compensation (70\%). Wages are usually compensated up to a ceiling (see Ellingsaeter, (2009) for further discussion of the leave policy in the Nordic countries). 
Finnish men are entitled to take one daddy month if they use the last two weeks of the parental leave. The most generous fathers' quota is in Iceland, where since 2003, fathers are entitled to three months of daddy quotas (along with three months leave for the mother and three months of parental leave). Since 2002, Sweden offers two months of non-transferable daddy quota. Though the causal effect of daddy quotas on fertility has only been examined recently (Duvander et al., 2013), the father's take up of the quotas in Norway and Sweden has been associated with continued childbearing. Couples where the father used the quota had a second and third child more often than couples in which the father did not use the leave at all (Duvander et al., 2010). In addition, a report written for the Ministry of Social Affairs and Centre for Gender Equality is eager to suggest that fertility has increased in the wake of the 2000 legislative change in Iceland, that introduced the parental leave system currently in place (Gíslason, 2007).

For the most part, fertility trends in Norway and in Sweden have been synchronised; in Sweden, however, a distinct birth-spacing behaviour occurred during the 1980s that appeared to be related to the introduction of a new benefit (Andersson, 2004). In Sweden, parents received a parental leave allowance at 80 per cent of earnings prior to childbirth. A specific component of the parental-leave system, the so-called 'speed premium' was introduced in the 1980 s to create incentives for women to have their children at relatively short birth intervals. When women spaced their birth sufficiently closely, ${ }^{55}$ they were guaranteed to avoid any reduction in allowance from one parental leave to another. This

\footnotetext{
${ }^{55}$ In 1980, the spacing between the births was set to 24 months, and in 1986 it was extended to 30 months.
} 
constituted a premium if the parent on leave earned a lower income or had no income in the period between the two births (Andersson et al., 2006). There is evidence of a causal effect of this policy change on childbearing behaviour: cross-country comparison of fertility behaviour in Sweden, Norway and Denmark showed that the introduction of the speed premium had a positive effect on the tempo of childbearing in Sweden and that it contributed to the increase in fertility during the 1980s (Andersson, 2004). Moreover, the effect was experienced across all social classes, an observation that "fits rather well with the stereotype of Swedish society as having a large degree of homogeneity in terms of social dynamics" (Andersson et al., 2006: 65).

The effect of childcare on the fertility of Nordic women is equivocal. While Lappergård (2010) found no significant association between the availability of formal childcare and fertility in Norway, others (Rindfuss et al., 2007; Rindfuss et al., 2010) shed light on the positive effects of childcare availability on the transition to motherhood. In their 2010 study, Rindfuss et al. showed that moving from having no childcare available for preschool age children to having space available for 60 per cent of pre-school children led the average Norwegian woman to have between 0.5 and 0.7 more children. In Sweden, while Andersson et al. (2004), argued that variations in formal childcare availability did not affect fertility rates, Mörk et al., (2009) demonstrated that fertility increased over an 18-month period by about 5 per cent when total childcare cost for the average family was reduced. 
To summarize, socio-democratic countries offer four types of explicit family-relevant policies: childcare cash benefits, formal childcare, parental leaves (including daddy quotas) and the Swedish speed premium. All of these measures have had a positive effect on fertility outcomes, though this effect remains hard to qualify or to quantify. The Norwegian cash benefits and the Swedish speed premium seem to have had a positive effect on the tempo of birth, though the possibility of a quantum effect cannot be ruled out. Studies on the effect of childcare on fertility have produced mixed results, especially in Norway. While the availability of childcare sometimes affected the transition to motherhood, a reduction in childcare costs can also trigger a quantum effect. Finally, research showed that in the Nordic countries, parental leaves were associated with increased fertility. Both in Norway and Finland, maternity leaves had a positive impact on fertility (especially for higher order births), while in Iceland, Norway and Sweden, preliminary research indicates that the father's uptake of the daddy quotas is associated with higher fertility.

\section{The Anglo-Saxon countries}

Studies of the effect of family policies on fertility are not as abundant in liberal countries. This observation reflects the fact that in Anglo-Saxon countries, the development of policies that help families to reconcile earning and caring tasks has not been a priority. ${ }^{56}$ One area of concern in these countries is whether the introduction of new tax credits creates unintended effects on the childbearing decisions of low-income families. In that regard,

\footnotetext{
${ }^{56}$ In that context, it is not surprising to find studies that examine the impact of unpaid leave on reproductive behaviour. Jacobs (2009) for instance showed that in Canada, unpaid-job protected leave has had a slight positive effect on fertility.
} 
studies show that tax-transfer programs had a (involuntary) positive effect on fertility. In the United States, the expansion of the Earned Income Tax Credit (EITC) in the 1990s was associated with an increase in first birth rates among married women, and especially nonWhites. Eligibility for, and the value of, the EITC changed in the 1990s. Initially the credit was only available to tax units with qualifying children, but its value did not differ by number of children in a family. From 1991, the maximum credit value for families with two or more children was set higher than the credit for those with just one child. Between 1990 and 1999 , the maximum credit available to an individual with one child grew from $\$ 953$ to $\$ 2,312$ and the incremental credit for a second child grew from $\$ 0$ to $\$ 1,504$ (Baughman and Dickert-Conlin, 2003: 247).

In the United Kingdom, the introduction of a similar reform, the Working Families Tax Credit (WFTC) also raised the probability of births for couples, although studies produced contradictory results on whether the effect of the reform was greatest for entry to motherhood (Brewer et al., 2007) or for subsequent births (Ohinata, 2008). In the United Kingdom, the Labour government initiated a series of policy reforms in 1997 drawing on the experience of welfare-to-work programmes in North America. A key element in these changes was to 'make work pay', by providing incentives for families with children. Alongside this, the government increased the generosity of means-tested income support payments to families with children (Brewer et al., 2007). Child benefit, a cash benefit available to all families with children regardless of income, increased in the amount paid in respect of the first child. Overall, the combined set of welfare reforms amounted to a big 
increase in the total package of child-contingent cash support (whether provided through cash benefits, in-work tax credits or income tax deductions), especially for low-income families.

Parental leaves are usually of short duration in Anglo-Saxon countries, are not well paid, and are typically conditional on being active in the labour market. Their effect on fertility has also been variable. In the United States, the Family Medical and Leave Act that was introduced in 1993 provides 12 weeks of unpaid leave for employers who work in a business of over 50 workers. Although no evidence was found that working women who desired children self-selected into firms offering maternity leave, the availability of leave substantially increased the probability of birth. The transition to motherhood, however, was not found to be affected by the possibility to take a leave (Averett and Whittington, 2001). Conversely, in Great Britain, the introduction of maternity leave increased rates of transition to first birth for women who had acquired a sufficient amount of tenure to qualify (Zabel, 2009). When maternity leaves were introduced in 1976, they were conditional on having worked full-time (16 or more hours a week) for two years for the same employer. Women who then did not qualify to receive the leave did not have transition rates to motherhood as high as women who qualified. In Australia, up until the 2011 reform, while the period of unpaid leave was relatively generous, it fell short of international standards for the provision of paid maternity leave; legal entitlement to paid leave was indeed restricted to public sector employees. In that country, young women (under 25) were 
positively influenced by the availability of paid or unpaid leave, while women between 25 and 35 years old were positively affected by the availability of unpaid leave (Risse, 2006).

Only in Canada has the availability of maternity leaves not been shown to influence fertility rates, at least in the late 1980s/early 1990s (Phipps, 2000). In Canada, maternity and parental benefits are provided through the Employment Insurance (EI) program (previously Unemployment Insurance- UI). Using micro data from the late 1980s, Phipps (2000) showed that fertility behaviour was not affected by the benefits and that women did not adjust their behaviour to gain access to benefits under the former UI system (which was in operation in the late 1980s). These observations, however, did not apply to Quebec. In Quebec, changes in the structure of parental leave in the early 2000s increased both the birth rate and the labour force participation of women (Ang, 2009; Lapierre-Adamcyk, 2011).

In Australia and in Quebec, the introduction of baby bonuses (in 2004 and 1988 respectively) and their effect on fertility has been the object of much academic interest. While Australia and Quebec have both been categorised as belonging to the liberal world of welfare capitalism, the effect of the baby bonus has not been the same. In Australia, the 2004 Maternity Payment, whereby mothers received an amount starting at $\mathrm{A} \$ 3,000$ per new child as of July $1^{\text {st }}$ of that year, ${ }^{57}$ was introduced as a tool to increase fertility. ${ }^{58}$ Different

${ }^{57}$ The Maternity Benefit effective from July 2004 was a universal flat rate payment to parents of newborn children of A $\$ 3,000$ initially, with major increases scheduled for July 1st 2006 (to A $\$ 4,000$ ) and July 1st 2008 (to $\mathrm{A} \$ 5,000)$. 
studies have tried to establish the magnitude of the effect of the baby bonus on fertility, the underlying assumption being that the benefit lowered the private costs of children and that, as a consequence fertility would increase. In Australia, most studies showed a modest - if any - effect of the baby bonus on fertility. Drago et al. (2009) and Lain et al. (2009) argued that the baby bonus exerted a small though positive and significant effect on fertility, especially for second and subsequent births, but Parr and Guest (2011) found the effect of the bonus to lack significance. Similarly, Day and Dowrick (2010) showed that a rise in a lump sum baby bonus had an ambiguous effect on fertility; baby bonuses increased fertility only if the amount paid rose faster than income per capita. This finding was to be expected since the increase in family benefits represented only a small subsidy of the lifetime costs of an additional child (Parr and Guest, 2011). Gans and Leigh (2009) demonstrated that announcement of the introduction of a baby bonus in Australia caused an introduction effect' whereby about 1,000 births were moved as to ensure that their parents were eligible to receive the benefit. Thus around 6 per cent of the babies who would have been born in the month before the introduction of the bonus were postponed. ${ }^{59}$ Surprisingly, the concern about the possibility that the bonus would increase the fertility of those households who could least afford another child did not seem to be founded. According to Lain et al. (2009), the greatest increase in fertility following the introduction of the baby bonus was among women residing in the highest socio economic areas.

\footnotetext{
${ }^{58}$ The objective of the baby bonus was to recognise the cost of having a baby rather than assist those with financial needs. This was most evident with the absence of any mean test for the bonus until the introduction of a relatively high family income threshold in the 2008 budget (Lattimore and Pobke, 2008).

${ }^{59}$ Gans and Leigh (2009) analysed a subsample of birth record data; these indicated that the babies born in early-July were significantly more likely to be of high birth weight than babies born in late-June. According to Gans and Leigh, these findings suggest that the shift in birth timing observed in the aggregate data was a real phenomenon, and not merely due to the misreporting of birth dates.
} 
The pronatalist policy in Quebec has also stimulated the interest of several researchers, typically economists. In its May 1988 budget, the Quebec government introduced a baby bonus called the Allowance for New Born Children (ANC). Initially, families received $\$ 500$ on the birth of their first child, $\$ 500$ for their second child, and the first of 8 quarterly payments of $\$ 375$ (totalling \$3000) when a third or subsequent child joined the household. For the most part, economists have argued that the baby bonus had a positive impact on women's reproductive behaviour. ${ }^{60}$ Milligan $(2002,2005)$ claimed that the baby bonus introduced in 1988 had a positive and significant impact on fertility. While the total fertility rates of Quebec and the other provinces diverged through the 1980s, the spread between the TFRs in Quebec and the ROC shrank dramatically from 1989. Between 1989 and 1996, the gap closed by 86 per cent, from 0.29 to 0.041 children per woman, which led Milligan (2002, 2005) to conclude that the responsiveness of fertility to a birth subsidy was large. ${ }^{61}$ Preceding Milligan et al., (2001) argued that generous family benefits had an effect on fertility rates, in particular providing strong incentives to give birth to a third child in Quebec. Using data on the transition rates for the first, second and third child, Kearns (1996) suggested that the much higher benefits for third births in Quebec countered their steady decline, a finding Duclos (2000) supported. Recently, Lapierre-Adamcyk (2011) showed that the historical progression of Quebec's family policy led to a quantum effect on births. While Lapierre-Adamcyk felt that the baby bonus had a positive effect on fertility,

\footnotetext{
${ }^{60}$ Bélanger and Dumas (1998) failed to show a significant increase in third-order birth in Quebec. They stated however, that "it may not be valid to conclude from these findings that the program was ineffective, since the sample was small and the period covered was short. It is also impossible to say what the third-order fertility of women in Quebec would have been if the program had not existed" (1998: 61).

${ }^{61}$ In chapter 9, I refute Milligan's argument and I offer a different interpretation of the effect of the ANC on fertility.
} 
she also argued that women who benefited from Quebec's recent initiatives regarding the implementation of universal low-cost childcare and the new parental insurance plan had even higher fertility rates than in the 1980 s.

To summarise, in Anglo-Saxon countries, tax credits, parental leaves and baby bonuses had a positive effect on births, though once again this effect is difficult to quantify. The various tax reforms that were introduced to increase activity rates in Anglo-Saxon countries unintentionally increased the fertility of married women and of low-income families. The effect of maternity leave on reproductive behaviour remains ambiguously positive and varies along different variables such birth order, the age of women and employment tenure. What is clear, however, is that mothers who experience the most precarious life situation (Clement et al., 2009) - teenaged mothers, those with little education and those with atypical job s- are much less likely to either work in a firm that offers maternity leave (in the US) or to qualify to receive benefits (in Canada). Regarding the baby bonus, research has been unable to capture whether the increase in the number of births represented an increase in family size, and/or a change in the timing of births. All things considered, both the possibility of a tempo and a quantum effects are plausible in Anglo-Saxon countries: while the provision of maternity leaves generally had a positive impact on births, there is a strong probability that the baby bonus only affected the calendar of births. 


\section{The Continental European countries}

Esping-Andersen classified Germany, Italy and France as corporatist regimes, with a high level of state support and a system of family benefits based on patriarchal assumptions. In other typologies however, these three countries appeared in different categories (see among others Gornick et al., 1997; Hantrais, 2004; Mathieu, 2003; Thévenon, 2011b). Gornick et al. (1997) grouped France along with the Nordic countries, while Germany was clustered with the Netherlands and Italy, because family policies are designed around the assumption that women are willing to leave the labour force until their children go to school. Similarly, Hantrais (2004) identified three models of family policies: a Nordic model - in which France is included and where care is strongly defamilialized; an English and German model, where care is partially familialized; and the Southern model, where care is almost exclusively familialized.

The fertility level of French women has been among the highest in Europe and across OECD countries. This high level is somewhat puzzling because most of the trends emerging from Western countries since the 1970s - and that are linked to delayed transitions in the life-course and to the deinstitutionalization of the family - are also seen in France. As in the rest of Western Europe, sexual relations and reproduction have increasingly occurred outside of marriage, medical contraception has spread, marriage has declined in popularity and divorce rates have been on the rise. The fertility of French women, however, has remained at a relatively high level when compared to other Continental or Southern European countries. French women are significantly indeed less 
frequently childless and the proportion of families with three children or more still remains higher in France than in most European countries (Thévenon, 2011a). Yet, as in other developed countries, young people have increased their educational investment, delayed their entry in the labour market and postponed childbearing (Thévenon, 2011a; Toulemon et al., 2008). This observation invalidates one typical explanation of low fertility: demographic trends in France do not follow the suggested pattern that delaying entry into parenthood results in lower fertility.

One explanation for France's relatively high fertility is its longstanding family policy. ${ }^{62}$ Although French family policies were originally shaped to support the traditional male breadwinner model (Letablier, 2003) since the 1970s, policies evolved to accommodate the growing participation of women in the labour force. ${ }^{63}$ First, France has a complex system of allowances aimed at supporting families. The basic family allowance is a universal cash benefit provided for families with at least two children, up to age of 20 . These allowances are tax-free, and the benefit level rises in relation to the number of children. A variety of pre- and post-birth completes this. Transfers to families also occur through tax breaks granted by the quotient familial mechanism (a 'family ratio' dependents' allowance) introduced in the income tax system in 1945. This mechanism was designed to reduce the

\footnotetext{
${ }^{62}$ Referring to the work of Toulemon (2006), Toulemon et al. (2008) explain that the assumption that the high level of fertility in France is due to the immigrant population is not valid. According to Toulemon (2006) the overall level of fertility in France in the 1990s would be a mere 0.07 child per woman less if it were based only on women born in France.

${ }^{63}$ The discussion of family policy in France draws heavily on Toulemon et al., (2008) and Thévenon (2011a).
} 
cost of raising children and has provided tax reductions that are particularly important to families with three children or more (Thévenon, 2011a).

Second, the early socialization of children through crèches and écoles maternelles is encouraged. Childcare in France begins at a young age with the crèches, a type of childcare made available after the end of maternity leave, from when the baby is two or three months old. The école maternelle is a specifically French institution available from the age of two and is free of charge. As childcare facilities are expensive and in order to create employment, private systems that are more individualised, such as subsidised childminders, allowances and tax deductions have become new tools of the French family policy. Since 1980, an allowance has been introduced for families with children under 3 (and then 6) who are cared for at the home of a registered childminders; in 1986, another allowance was introduced for families who hired nannies to care for their children at home.

In the 1980s, the Allocation Parentale d'Éducation (APE) was introduced, and was reformed in the following decade. This new measure was implemented in a context of high unemployment and strong budgetary restrictions, which led some authors to argue that family policy was gradually shaped as an instrument of employment policies (Fagnani, 2002; Toulemon et al., 2003). When the APE was created in 1985, it allowed one parent (in practice, mothers) to leave the labour market for childrearing for a period of three years after a third or subsequent birth. In 1994, this benefit was extended to mothers with two children. The 2004 family policy reform unified all existing infancy benefits into a single 
one: the Prestation d'accueil du jeune enfant (PAJE). The APE was then replaced by the Complément libre de choix d'activité (CLCA), which can be granted after the birth of a first child for a limited period of 6 months. ${ }^{64}$

Most analysts of the French family policy system have already highlighted its complexity. Accordingly, very few studies have examined the effect of any singular policy on reproductive behaviour. French family policy contains about 30 different measures that help parents at the time of a birth or to support them later in childrearing. Breton and Prioux (2005) showed that the measures targeting the third child have had a visible impact on the timing of birth. These measures may even have contributed to the stability of the slight increase in the probability of having a third child, especially with the APE as it was originally introduced (Breton and Prioux, 2005). This probability decreased as policy support moved from focusing on the third birth to the second. The changes in the rules concerning the APE, particularly its extension to parents of two children in 1994, may be viewed as a sort of a natural experiment on the impact of such allowance on fertility and women's professional activity (Piketty, 2003). Though the effects of the APE on fertility are hard to quantify, Piketty argued that the extension of the APE would not have explained more than 20-30 per cent of the increase in the total number of births observed from 1994 to 2002 .

\footnotetext{
${ }^{64}$ Other measures were introduced in 2004 and since then such as the Complément de Mode de Garde (CMG), and the Complément Optionnel de Libre Choix d'Activité (COLCA). It is beyond the scope of this chapter to discuss into detail all the French family-friendly measures.
} 
In spite of the difficulty of assessing the impact of each of these policies on fertility, French family policy seems to have been successful in creating an environment favourable to children and family life (Letablier, 2003). The cultural norms with respect to the demotherization of care work, in the form of childcare outside the home, as well as the attitudes towards working mothers favoured women's labour force activity and fertility (Fagnani, 2002, 2007; Salles et al., 2010). Conversely, in the former West Germany, the majority of women feel that children under 3 should be cared for by their mother (Fagnani, 2002, 2007; Salles et al., 2010). ${ }^{65}$ In (West) Germany, the provision of childcare has been limited, especially for infants and toddlers (Hank and Kreyenfeld, 2003). Perhaps, this explains why Germany is one of the few countries where the provision of public childcare does not seem to influence women's reproductive decisions. For the availability of childcare to be a significant parameter that couples take into account in their reproductive decisions, the provision of care for children must be high enough so that parents perceive they have a realistic chance of finding a slot for their child in a public childcare. This was not the case in the old West Germany, where Hank and Kreyenfeld (2003) estimated that childcare spaces were available for less than $10 \%$ of children aged 0 to 3 in the 1990s. Public childcare in Germany was primarily designed to provide high-quality care that contributes to children's early education - not to foster the compatibility of the mother and worker roles or to promote the demotherization of care work. Thus, opening hours are so

\footnotetext{
${ }^{65}$ The German reunification in 1990 merged two contrasting models of family policy. In East Germany, the dual-earner model predominated, with expectations that mothers and fathers worked full-time. In West Germany, family policy was based on ideas of different, but equal and complementary gender roles, supporting a male breadwinner model (Letiner and Schmitt, 2008).
} 
rigid that mothers sometimes cannot even engage in 'mini-jobs' (Hank and Kreyenfeld, 2003; Weinkopf, 2009).

Yet even when German mothers have access to childcare, they have preferred to care for their children themselves, which indicates that the availability of external childcare is not enough to explain use or non-use (Salles et al., 2010). Thus, the limited availability of childcare is consistent with other German family policies that reflect the predominance of the male breadwinner model. In that context, while offering more subsidised childcare in Germany would increase the labour supply of all women, only the fertility rates of the childless and highly educated women would increase (Haan and Wrohlich, 2011).

German parental leave, which until the 2007 reform provided 84 months of child-rearing leave, has not been associated with increased fertility. New changes in the parental leave legislation in 2007 contributed to move away from the male breadwinner policy model (Erler, 2009), but they were not related to an increase in fertility. Salles et al. (2010) report that the number of births increased by only 1.8 per cent that year, and even decreased by 1.1 per cent in 2008 , while the total fertility rate progressed only slightly (Salles et al., 2010). In contrast, in Austria, the parental leave extension in mid-1990s led many women to increase the tempo of their childbearing (Hoem et al., 2001; Lalive and Zweimüller, 2005). In 1990, the maximum duration of parental leave was extended from the child's first to the child's second birthday. As parental leave benefits can be automatically renewed when a new mother is still on leave from a previous child, this created strong incentives to 
bunch a given number of planned children and the associated time off work. In Austria, a decrease in the spacing of births also led to an increase in fertility: over a ten year period, women who benefited from the parental leave had 3.9 percentage points higher probability to have an additional child (Lalive and Zweimüller, 2005).

All things considered, the French APE in its initial form, which offered a cash benefit to parents who left the labour market after the birth of their third child to perform care work, had a quantum effect on births, until the program was reformed in 1994. In Germany, social attitudes towards the demotherization of care work performed outside the household impede on the possibility for this service to affect reproductive behaviour. As a result, childcare has only had a positive effect on fertility of two restricted groups of women. Finally, parental leaves have had no effect- whether tempo or quantum- on births in Germany, while the opposite holds true in Austria.

\section{The Southern European countries}

In the Southern European countries women are either care givers or workers, but rarely both simultaneously. In these countries, the family serves as a focal point of social protection and is considered to be at the center of the distribution of welfare. In Greece, the normative institutional framework of the family is even embodied in the national constitution, which recognises the family as a social institution founded on marriage (Sarikaki, 2001). State intervention to support the family has been relatively important, but to the extent it encourages the familialization and the motherization of care work. On the 
one hand, parental leaves in Greece are generous by international standards. Public-sector employees receive five months of paid maternity leave, three days of paternity leave, two years of parental leave (for each parent) and nine months of child-care leave (Ray, 2008). In total, families are entitled to about five years of leave. This led Ray et al. (2009) to argue that with regard to parental leave, Greece has among the strongest policies on both generosity and gender equality across developed countries, along with Finland, Norway and Sweden. On the other hand, childcare centers have been rare and most infants are being cared for by their mother, even beyond the duration of the maternity leaves. According to Karamessini (2008), only 10 per cent of the children aged 0-2 were covered by childcare services provided by public or private crèches and nurseries. This was partly due to the fact that families were unfavourable to the demotherization of care for children aged less than 3 years. Consequently, limited availability of care services for young children cannot be only explained by the lack of responsiveness of policy-makers to changing needs but equally by unfavourable social attitudes (Karamessini, 2008). Research on the effect of specific Greek family-friendly, whether parental leave or childcare services on fertility is non-existent.

Likewise, very few studies have examined the impact of singular family policies on reproductive behaviour in Spain and in Italy. Two policies have been the object of research studies: income tax and the provision of childcare. In Spain, the government introduced a reform in 2003 to the income tax system as a means of countering the dual problem of low fertility and low female life activity. The tax reduction for households with children was substantially increased; additionally, a supplement for each child less than 3 years old was 
offered. As a result, fertility is estimated to have increased by between 5 and 6 births per 1,000 women, with a stronger effect among lower-educated women (Azmat and González, 2009).

In both Spain and Italy, the demotherization of childcare is associated with higher fertility. In Spain, dual earner couples that pay for childcare are more likely to have another child (Cooke, 2008); accordingly, for each percent increase in the proportion of children in childcare, there has been an increase in the relative risk of fertility by 5 per cent (Baizán, 2009). To be clear, it is not the availability of institutional childcare per se that influence fertility decisions. In Italy, there are few public childcare services for children under 3 years old: only 6 per cent of children that age are able to attend formal childcare (Nishioka, 2003: 278). The centers are unevenly distributed and concentrated in the central and northern regions and in larger cities. Consequently, the utilization ratio varies and needs have not been met. Private childcare centers are scarce and expensive. Thus, many working mothers with infants rely on their own mothers to care for their children (Nishioka, 2003). Grandparents' help increases the probability of having children and this effect appears to be more important than the impact of formal childcare availability (Del Boca, 2002; Del Boca et al, 2005).

While studies that examine the effect of specific policies on the fertility of Southern European countries are rare, the large consensus in the literature is that lowest-low fertility emerged in Italy, Spain and Greece because of the strong familialist attitudes (see for 
instance Billari, 2008; Castles, 2003; Neyer, 2003). It is believed in these countries that welfare should not 'crowd out' family relationships. Accordingly, there has been a low level of gender equality in households. Thus, the lack of policies that favour the compatibility of work and family, especially for women, has been identified as a causal factor that depressed the probability to meet fertility intentions (Billari, 2008; Castles, 2003). In that sense, the lack of policies that allow the reconciliation of earning and caring responsibilities has a negative influence on fertility. That being said, the 2003 Spanish tax reform had a positive effect on fertility, while the availability of formal or informal childcare was also associated with increasing births.

\section{Higher fertility as an outcome of better gender equality?}

This chapter has argued that the effect of various family-relevant policies changed in different contexts. There are numerous challenges and difficulties when trying to study the effect of policies on fertility. First, the effect of similar policies sometimes varies both across and within welfare regimes types. The effects of childcare services are typical in that respect. While in Germany, no statistically significant effect of formal institutional childcare on fertility was found (Hank and Kreyenfeld, 2003), the availability of childcare was related to higher probability of entry to motherhood in Norway (Rindfuss et al., 2007). Spanish mothers using childcare services were also more likely to have another child (Baizán, 2009). These inconsistent findings cannot be the result of the differentiated arrangements of states, markets and families that prevailed in Germany, Norway and Spain. Indeed, within the Nordic regime type, two studies found a positive effect of childcare on 
fertility (Rindfuss et al., 2007; Rindfuss et al., 2010), while two others found no effect (Andersson et al., 2004; Lappergård, 2010). Distinct measures implemented in two welfare regime types to respond to different problematic can also have similar outcomes. The extension of the Austrian parental leave introduced in the mid-1990s led many women to increase the tempo of their childbearing in order to benefit from the changes in regulations for higher-order births, which is reminiscent of the reproductive behaviour of the Swedish women following the introduction of the 'speed premium' in the 1980s (Hoem et al., 2001). The motivations underlying the introduction of these two family policies were nonetheless very different. In Austria, the law was changed partly to prolong women's stay at home and to reinforce the separation between childbearing and labour-force participation. In Sweden, the speed premium was implemented to create incentives for women to have their children at relatively short birth intervals.

Causal ordering between policies and outcomes is difficult to assess (Castles, 2003). It is not counterintuitive to assume that childcare and other services to families will, ceteris paribus, be higher where the population is most youthful. Family policies could thus be an outcome rather than a determinant of fertility. Similarly, insofar as governments see specific policies as potential tools to increase fertility, they could use these measures when fertility is low, again reversing the order of causality (Bradshaw and Attar-Schwartz, 2011; Castles, 2003). Another possibility is that the effect of policies on fertility may not be linear (Gauthier, 2007): it is possible that fertility is subject to a threshold that requires benefits to reach a certain minimum level before having an effect. Accordingly, the impact of the 
benefit could reach a plateau or even be negative beyond a certain point. Parental leaves for example, allow women to maintain employment status while performing childcare, and could be argued to contribute to gender equality and consequently to increase fertility. Yet, a longer parental leave has been found to lower fertility (D'Addio and d'Ercole, 2005). Perhaps, the effect of this policy varies depending on the duration of the leave.

There are also important methodological differences across studies on the effect of policies on fertility. Empirical studies have used different methods of analysis such as regression, bi-variate correlations, binomial probit models, multi-level analysis, discrete-time hazard model, qualitative interviews and event-history analysis. Different methods change what we are able to see (Wheaton, 2003), and make comparison between the findings even more complex. Moreover, studies are sometimes too variable in data sources and data period to draw some definite conclusions. While some datasets refer to individuals and are longitudinal, others refer to aggregate data and are cross-sectional. Both the dependant and the independent variables of interest also vary. It is one thing to argue that childcare influences fertility; it is another to show that it is the provision of subsidised childcare for children under 3 that matters. Similarly, dependant variables are diverse and range from total fertility rates, to the transition to motherhood, to the probability of a second birth or third birth, etc.

Do public policies influence fertility? Of course, fertility is the systemic result stemming from attributes that are more exhaustive than the sum of family policies. Depending upon 
the policy constellation, economic trends can interact closely with family policies in influencing fertility. By extension, reproductive behaviours are often explained by developments in areas well beyond those in the realm of core family policies, such as housing policies, school opening hours, etc. That being said, this literature review has shown that the effect of a given policy may be strongly dependent upon the social context in which it is implemented. Previous studies have almost unanimously concluded that demotherization measures, such as the availability of formal childcare (in various forms) had a positive quantum effect on births (with the exception of Germany and Austria). Parental leaves also seemed to have a quantum effect, mostly only in socio-democratic countries, while tax reforms increased births in the Anglo-Saxon countries and in Spain. Finally, baby bonuses had more of a tempo than a quantum effect on births.

This chapter, along with the previous one, has given strong evidence that a specific policy cannot be completely studied in isolation, and that in another context its impact might turn out to be completely different from that where it was first introduced (Andersson, 2008; Hoem, 2008). Accordingly, the strategy I propose for the next chapters is to consider the whole package of policies in context. Thus, when we compare patterns of family policies, it appears clear that countries that have provided a positive institutional setting to motherhood such as Scandinavia and France have retained relatively high fertility rates. Conversely, in Germany and in the Southern European countries, where public provision of childcare is rare and where societal attitudes and beliefs concerning the need for familialized childcare 
prevent women of young children to be economically active, fertility has reached lowestlow levels.

\section{Linking policies and outcomes: methodological approach and periodization}

Given that policy changes and fertility outcomes are rarely attuned, and that the effect of similar policies differs across different institutional settings, explaining patterns of social reproduction is a complex task. Building on the findings discussed above, the methodological approach introduced in this section suggests the need to move beyond causal models that examine the effect of specific policies on fertility. After defining the contours of what is meant by 'fertility regimes', the periodization of the examination of social reproduction in Quebec is presented.

\section{Defining fertility regimes}

The notion of 'regime' has been used extensively in the literature on social policies in the developed countries, often without being defined beyond the notion that it captured the articulation of states, markets and families. Accordingly, in the 1990s, welfare regimes were understood to be the "combined, inter-dependent way in which welfare is produced and allocated between state, market and family" (Esping-Andersen, 1999: 34-5). Thus, the premise of regime analysis is that people are constrained and enabled by macro social structures. These structures have a significant influence over people's welfare, typically measured in terms of economic wellbeing or gender equality. In welfare regime analysis, the outcomes of these different arrangements have been measured in terms of the degree of 
decommodification made possible by social policies, as well as by the structure of class inequalities. In gender regimes, the focus of the analysis was placed upon gender relations and gender inequalities, theorised as an outcome not only of welfare proper, but also of other domains such as body rights and defamilialization policies. In other words, the outcome of interest in research on gender regimes was the nature and the type of inequalities women experienced vis-à-vis men. Finally, in fertility regimes, the attention is drawn towards the extent to which care work is defamilialized and demotherized to create a socio-institutional environment that is more or less favorable to gender equality. The outcomes of interest are the conditions surrounding social reproduction and actual birth and fertility rates.

Researchers interested in conducting regime analyses are confronted with different methodological choices and various points of contention. The first regards the choice between doing a 'thin' comparative inquiry where countries are treated as variables and where the outcome of interest is the formulation of a typology, or doing a 'thicker' investigation where countries are treated as case studies. While the two options are valuable, they are likely to reveal and conceal different realities. Thin analyses allow for greater analytical parsimony. To borrow Esping-Andersen's (1990: 5) metaphor, they help to see the forest rather than the myriad of trees. Another advantage of thin inquiries is that they facilitate cross-national and cross-temporal comparisons. The downside of typologies and the benefit of conducting thicker analysis - is that parsimony is bought at the expense of nuance, and the forest that is unveiled may indeed bear little resemblance to reality. If 
typologies allow one to see the forest, case studies allow an examination of the roots of individual trees, as well as how leaves are connected to the branches.

The second issue concerns the causal links between policies and outcomes. The direction of the causality between specific policies and social outcomes is indeed often difficult to determine in regime analysis. In addition, the effects of specific policies on fertility sometimes interact with the economic context. Thus, the effect of generous parental leaves on fertility changes as unemployment rates increase. Similarly, a generous parental leave, followed by subsidised childcare, may encourage women to have more children, while a generous parental leave in a context of familialized childcare can trigger the opposite effect.

Regime analysis cannot be limited to the examination of national policies and outcomes. The political context, predominant ideologies and disturbing historical events that are not typically accounted for in the state-market-family trilogy are likely to affect reproductive behaviour. Thus, a third point of contention has to do with the appropriate unit of analysis. Regime analysis typically examines the welfare of individuals within their national context. History has taught that international events or innovations find local echoes. The postWorld War II baby-boom was experienced both locally in Quebec and across other developed countries. The increase in fertility and birth rates between the mid-1940s through the early 1960s in Quebec was not due to the introduction of new policies, but rather to new patterns of reproductive behaviour as women from different generations more or less simultaneously had babies. 
The last point of contention concerns the differentiated outcomes created by similar policies for individuals with different social characteristics. Upper class women do not experience the same type of inequalities as working-class women; similarly, patterns of social reproduction are likely to vary across different ethnic groups. This is where the literature on intersectionalities becomes relevant. While class, gender and race are considered the most salient social divisors of the $20^{\text {th }}$ century others - such as religion, language, citizenship (Siltanen, 2006; Stasiulis and Bakan, 2003) - sometimes acquire a greater significance. The difficulty of doing intersectional analysis is often linked to the lack of relevant data. This is certainly the case in this research. This does not mean that the researcher assumes similar outcomes for individuals with different social characteristics.

In order to address these points of contention, three inter-related strategies are used to theorise the links between family policies and outcomes. While each of these steps is insufficient in itself to theorise fertility regimes, together they form a coherent methodological approach. The first entry point into the analysis is to locate Quebec's patterns of social reproduction within 1) the Canadian context and within 2) the liberal and the social-democratic regimes. As observed, there is a possibility that patterns of social reproduction are influenced by forces that transcend geographical territories. Most obviously, the Canadian government passes legislation that can directly impact the wellbeing of Quebec's families. Such legislation might include family allowances, tax credits, unemployment eligibility criteria and parental leave and benefits (until 2006). Quebec also shares with the socio-democratic countries patterns of family formation, which sometimes 
reflect similar normative behaviour rather than family-relevant policies pertaining to union formation or the timing of key life transitions.

The second and third entry points into the analysis aim to verify the existence of a doublesided connection between fertility and changes in the menu of family-relevant policies. Fertility indicators are thus used as point of departure for investigation, rather than as an outcome of policies. Accordingly, rather than questioning whether the introduction of a particular policy caused disruptive trends in reproductive behaviours, irregularities in fertility patterns are theorised as being the result of economic restructuring and/or new norms in the sequence of life-transitions.

Thus, the third entry point is similar to the classical approach in the effect of policies on fertility, described in the previous chapter. Using the conceptual tool of demotherization, the objective is to ask whether the introduction of new policies caused changes in the type of familialism, from explicit to de-gendered/generational. Rather than identifying disruptive periods in fertility trends, the effect of the introduction of family-relevant measures on gender equality is examined, arguing that higher equality has helped women to achieve their fertility intentions. The starting point of the analysis is 1964, the year Bill 16 gave Quebec women full legal and property rights. The core of the policy analysis in Quebec centered on the 1988 and 1997 family policy packages. 
Between the Quiet Revolution and the early 2000s

The focus of the analysis spans five decades, from the 1960s through 2010. The 1960s are the starting point. In the Western world, that decade corresponded to a period of profound changes in social attitudes and practices, including the so-called 'sexual revolution' that challenged traditional codes of sexual behaviors. The sexual revolution was in turn facilitated by the development and the commercialization of the contraceptive pill, and by the increased economic independence of women. In Quebec, the 1960s witnessed the beginning of the Quiet Revolution, a period of deep social changes and of wide secularization of public institutions that lasted until the 1980s, and during which the influence of the Catholic Church shattered, medical contraception spread and new patterns of social reproduction erupted. The 1960 s are significant because many of the changes in sexual norms that emerged in this period have since become mainstream in Quebec and in other developed countries.

Two additional reasons justify using the period between 1960 and 2010. First, as observed by McDonald (2010), the gender equity theory was not framed to investigate fertility within a single country. While this study locates Quebec within the Canadian context and the worlds of welfare capitalism, a long periodization allows comparison across time between different types of fertility regimes within the province. Second, the time frame needs to cover the years when new family policy programs were introduced, thus the 1980 s and the 1990s. The early 2000s also witnessed important changes in the menu of family policies 
when in 2006 the last portion of the 1997 policy, the promise of a new parental leave program, became effective.

Figure 5 gives a broad picture of fertility rates in Quebec and the ROC since the 1960s. The decline in fertility rates in Quebec and other provinces was particularly stark in the 1960s and 1970s. Conversely, the decline in fertility rates has been much less pronounced since the beginning of the 2000s. Although women continued to have fewer children by the end of the 1990s, the new millennium saw birth rates remaining stable, and even increasing slightly. In addition, the gap between the fertility rates of Quebecois women and other Canadian women was particularly high in the early 1970s; it then decreased from the mid1970s through 1980, and it increased again from 1980 to 1986. In 1987, the gap began to close, but it was only in 2006 that women in Quebec began to have higher fertility than women in the ROC.

The next three chapters are organized around the following periodization. Chapter 7 covers almost three decades, between the 1960s and the eve of Quebec's first family policy. Chapter 8 discusses the introduction of the 1988 policy package. The point of departure for analysis in this chapter is 1986 to have a picture of the socio-institutional environment before the implementation of new benefits. Following the same strategy, chapter 9 stretches from 1995 to 2010 . 
Figure 5 - Fertility rates in the ROC and in Quebec, 1960- 2010

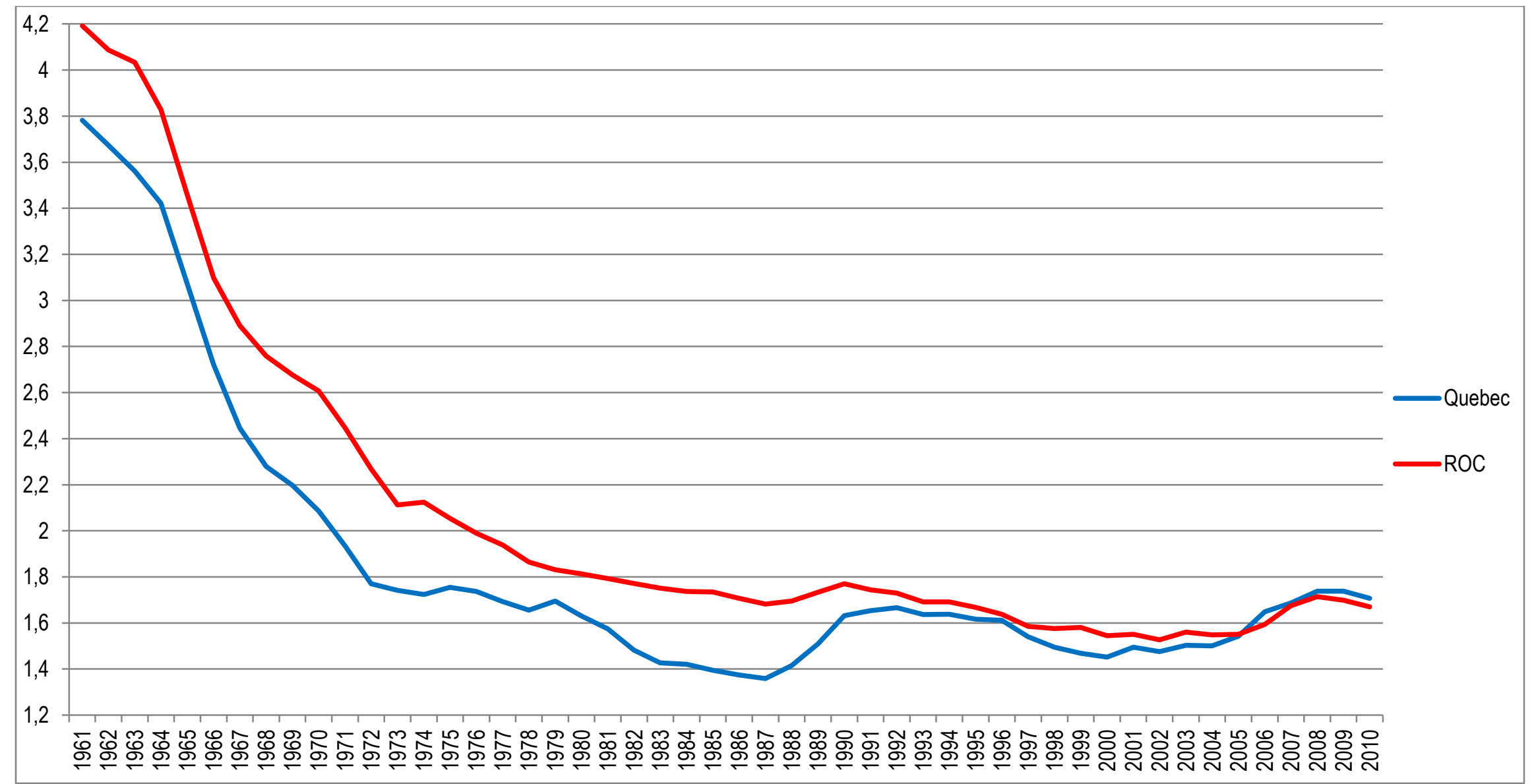

Source: For Quebec, ISQ (2013). For the ROC, from 1961 to 1970, Statistics Canada, Health Indicators 1999 CD-ROM; from 1971 to 1992 : Verma et al (1996).; from 1993 to 1996, Statistics Canada, (2006); from 1997 to 2005, Statistics Canada (2008a); from 2006 to 2010, Statistics Canada (2008b). For the ROC, the calculations were all made by the author and they exclude Yukon, the Northwest Territories and Nunavut. 


\section{CHAPTER 7}

\section{BETWEEN THE QUIET REVOLUTION AND QUEBEC'S FIRST FAMILY POLICY}

The 1960s and the 1970s were decades of major importance to the framing of Quebec's welfare architecture. As in all Western capitalist countries postwar expansion allowed Quebecois to enjoy unparalleled prosperity. The 1960s also marked the end of the Grande Noirceur (Great Darkness) ${ }^{66}$ and the blossoming of the Quiet Revolution, a period characterised by the rapid growth of public investment that led to deep political, economic and cultural changes in the province. With the Quiet Revolution, the French Canadian province went from opposing state intervention to fully embracing it (Gagnon and Montcalm, 1990). Accordingly, a large and professional state bureaucracy was established over the course of the 1960s and 1970s, and many new government departments and agencies were formed. In practical terms, this implied that the state took responsibility for institutions that had hitherto been dominated by the private sector and by the Roman Catholic Church.

Although it is difficult to clearly periodize the beginning and the end of the Quiet Revolution ${ }^{67}$ the expression is often used to refer to the period between 1960 and 1980 when, despite frequent changes of government, the conduct of public affairs was marked by

\footnotetext{
${ }^{66}$ The Grande Noirceur was the historical period that was named after Maurice's Duplessis reign.

${ }^{67}$ In that regard, although many date the beginning of the Quiet Revolution in 1960, some trace the beginning of this period to a slightly earlier year- the death of Duplessis in 1959 and his replacement with Paul Sauvé (Lacoursière, 1996; Linteau et al., 1991). The end of the Revolution is even more difficult to periodize. In the strict sense, it ended in 1966 with the election of the Unionist government of Daniel Johnson, although some writers identify 1964 as the year when the pace of reform began to slow.
} 
remarkable continuity (Linteau et al., 1991). This periodization is loosely used in this chapter to discuss social reproduction between 1960 and 1988, the year Quebec's first family policy was introduced.

Between 1960 and 1988, women were awakening to new possibilities. For the first time, they were granted rights that allowed them to control birth and to leave an unhappy marriage. As Quebec began to modernize, secondary education became more accessible to girls, and women were no longer forced to choose between getting married, becoming a nun or being an 'old maid'. Young women could opt for both a family and a career and indeed, though women had children at a young age in the $1960 \mathrm{~s}$, an increasing proportion of them chose to be economically active. Meanwhile, marital unions became more fragile, as fewer individuals chose to marry and more decided to divorce. Undeniably, these changes, along with the introduction of family planning, had a negative effect on births. At the same time, conservative attitudes regarding the gendered division of care work that prevailed in the society made it difficult for women to combine breadwinning and caring responsibilities. This was mainly due to the fact that both levels of government persisted in supporting equity over equality through family-relevant policies that encouraged gendered familialism. The design of the main policies implemented during that period, maternity leaves, family allowances, the provision of funding for childcare through the Canada Assistance Plan (CAP) and the childcare tax deduction did not support the defamilialization of care work, let alone demotherization. Thus, when the economic recession of the $1980 \mathrm{~s}$ 
hit Quebec, women chose to abstain from having children, although a relatively large proportion of them became unemployed and could have had the time to perform care work.

\section{Fertility and social reproduction in Quebec in the 1960s and beyond: more adults, and less babies}

Scientists could have easily predicted that fertility rates were to increase in the 1960s and the 1970s. The context seemed to be favorable to births. Indeed, more adults were becoming available for parenthood than in the preceding decades. In the early 1960s, recruitment of priests and religious (nuns and monks) seemed to be drying up. By the middle of the decade, a rapid exodus from the priesthood had begun and later spread to communities of women; membership in religious communities also fell (Linteau et al., 1991). Meanwhile, the proportion of childless women declined for the generation born between 1941 and 1946 (and thus who were 20 in the early 1960s) in comparison to previous decades (Lapierre-Adamcyk and Lussier, 2003). The postwar prosperity and the establishment of the welfare state also signified the introduction of new measures aimed at supporting families. These included, among others, the 1966 Canada Assistance Plan (CAP), the 1967 provincial family allowances, the 1971 federal maternity leave and the 1972 federal childcare tax deduction.

Analysts who would have predicted an increase in fertility could not have been more wrong. As table 4 and figure 6 show, for most of the period between 1960 and 1988 , fertility dropped. Between 1960 and 1972, births and fertility rates in Quebec declined one 
year after another. The baby bust was at its most acute in the mid-1960s, when fertility rates went from 3.42 in 1964 to 2.45 in 1967 . These are not minor declines: in the $20^{\text {th }}$ century, only between 1918 and 1919, 1922 and 1923 and 1925 and 1926 had fertility rates dropped more abruptly. Table 4 also shows that birth diminished in the early 1980s, when an important recession hit the country. The early 1980s also corresponds to the period when Quebec hit its lowest fertility rates in history. At the time, Quebec's low fertility became the object of academic and political attention, leading to the implementation of a pronatalist family policy designed to reverse the downward trend. 
Table 4 - Birth and fertility rates in Quebec, 1968-1988

\begin{tabular}{|c|c|c|c|c|}
\hline & Birth rate & Difference & Fertility rate & Difference \\
\hline 1960 & 27.5 & & 3.86 & \\
\hline 1961 & 26.6 & -0.9 & 3.78 & -0.08 \\
\hline 1962 & 25.7 & -0.90 & 3.67 & -0.11 \\
\hline 1963 & 24.9 & -0.80 & 3.56 & -0.11 \\
\hline 1964 & 24.00 & -0.90 & 3.42 & -0.14 \\
\hline 1965 & 21.70 & -2.30 & 3.07 & -0.35 \\
\hline 1966 & 19.50 & -2.20 & 2.72 & -0.35 \\
\hline 1967 & 17.90 & -1.60 & 2.45 & -0.27 \\
\hline 1968 & 17 & -0.90 & 2.28 & -0.17 \\
\hline 1969 & 16.6 & -0.4 & 2.20 & -0.08 \\
\hline 1970 & 16.1 & -0.5 & 2.09 & -0.11 \\
\hline 1971 & 15.3 & -0.8 & 1.94 & -0.15 \\
\hline 1972 & 14.3 & -1 & 1.77 & -0.17 \\
\hline 1973 & 14.4 & 0.1 & 1.74 & -0.03 \\
\hline 1974 & 14.6 & 0.2 & 1.72 & -0.02 \\
\hline 1975 & 15.2 & 0.6 & 1.75 & 0.03 \\
\hline 1976 & 15.3 & 0.1 & 1.74 & -0.02 \\
\hline 1977 & 15.1 & -0.2 & 1.69 & -0.04 \\
\hline 1978 & 14.9 & -0.2 & 1.66 & -0.04 \\
\hline 1979 & 15.4 & 0.5 & 1.70 & 0.04 \\
\hline 1980 & 15 & -0.4 & 1.63 & -0.06 \\
\hline 1981 & 14.5 & -0.5 & 1.57 & -0.06 \\
\hline 1982 & 13.8 & -0.7 & 1.48 & -0.09 \\
\hline 1983 & 13.3 & -0.5 & 1.43 & -0.05 \\
\hline 1984 & 13.2 & -0.1 & 1.42 & -0.01 \\
\hline 1985 & 12.9 & -0.3 & 1.39 & -0.03 \\
\hline 1986 & 12.6 & -0.3 & 1.37 & -0.02 \\
\hline 1987 & 12.3 & -0.3 & 1.36 & -0.02 \\
\hline 1988 & 12.6 & 0.3 & 1.42 & 0.06 \\
\hline
\end{tabular}

Source: ISQ (2013).

Decreasing fertility was not a phenomenon peculiar to the province of Quebec; it was also experienced in the ROC, though during the 28 year period, Quebec's fertility rates remained lower than that of other provinces (figure 6). The mid-1960s and the 1970s were 
also associated with decreasing fertility in all developed countries, even those that belonged to the more conservative worlds of welfare capitalism. Austria, France, the Netherlands, Italy, Portugal and Spain for instance, were no exception to the important fall in the birth rate. From the end of the 1970s through 1988, fertility rates across many developed countries remained more stable. This can be seen most clearly in the Scandinavian and the Anglo-Saxon countries, represented here by Denmark, Sweden, the United Kingdom and the United States (figure 7). Developed countries, especially those that shared with Quebec the same type of arrangements of states, markets and families, underwent similar changes in fertility rates, which suggest that social forces other than national policies may have caused fertility to plummet.

Figure 6 - Fertility rates in Quebec and the ROC, 1961-1998 ${ }^{68}$

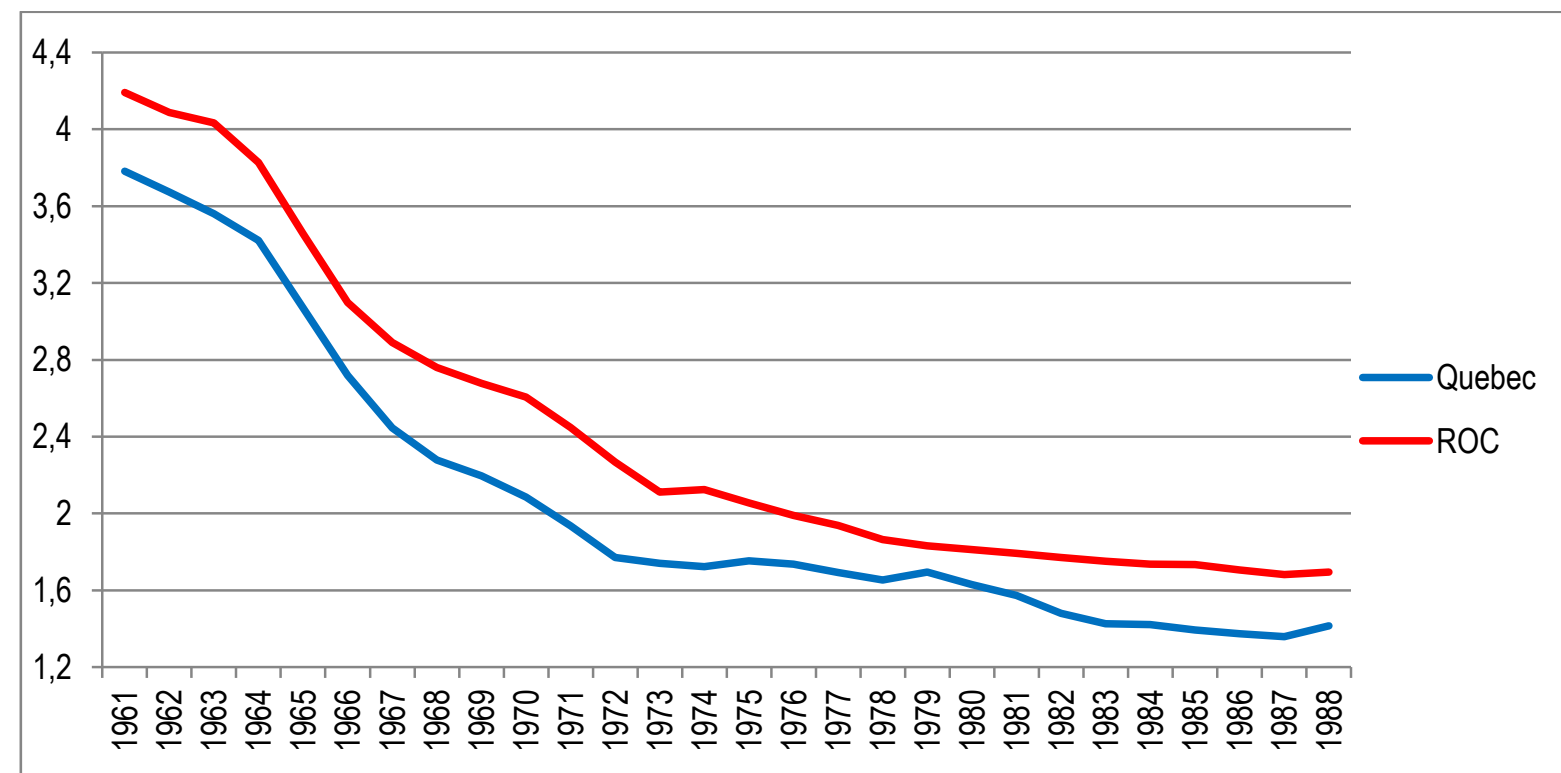

Source : For Quebec, ISQ (2013). For the 1970, Statistics Canada, Health Indicators 1999 CD-ROM; from 1971 to 1988, Verma et al. (1996). For the ROC, the calculations were all made by the author and they exclude Yukon, the Northwest Territories and Nunavut.

${ }^{68}$ The data were not available for 1960. 
Figure 7 - Fertility rates in selected Nordic and Anglo-Saxon countries and Quebec, 1960-1988

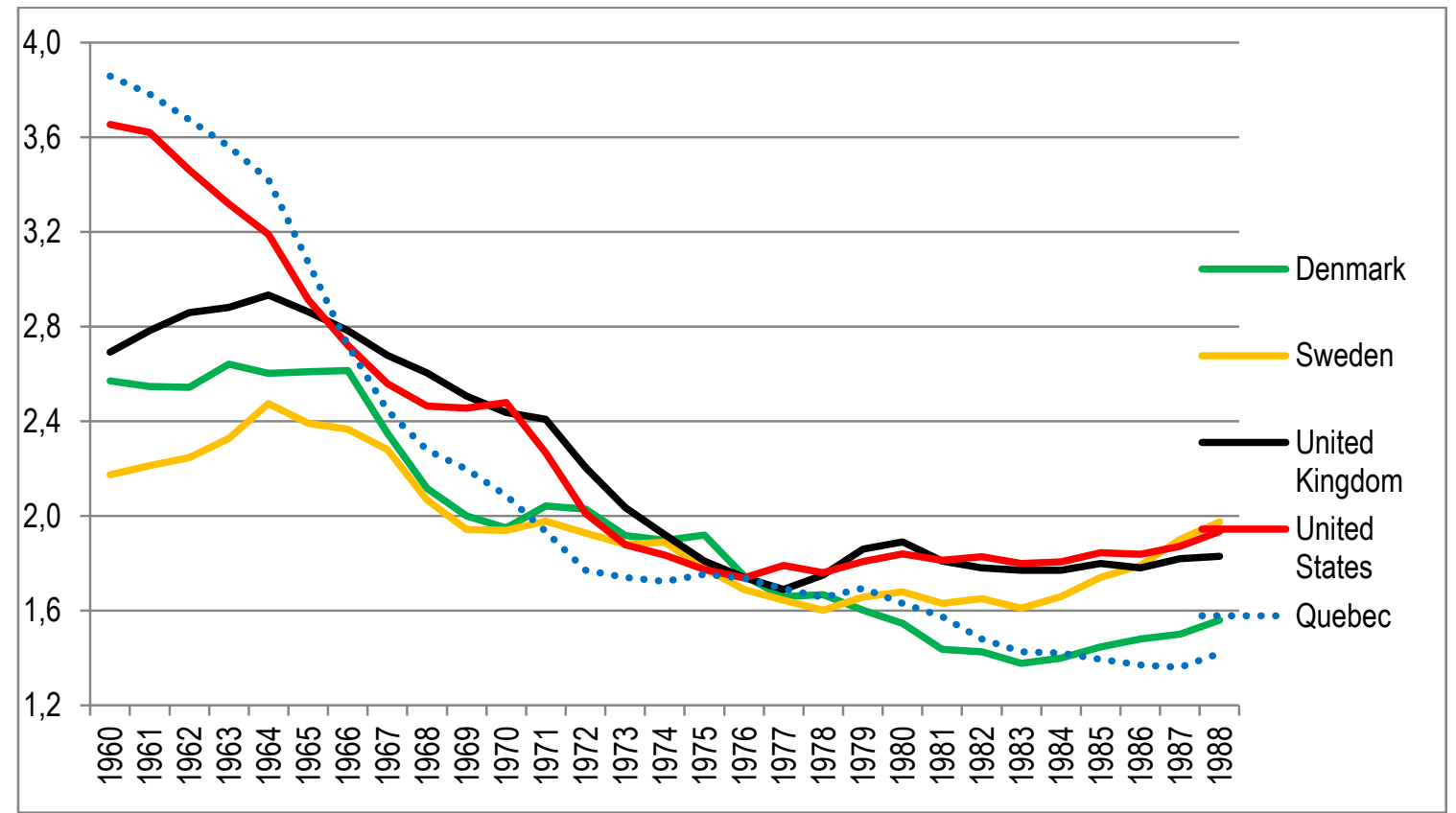

Source: ISQ (2013) and Worldbank (2012).

Of course, the difficult question to address is the effect of Quebec's unique institutional context on reproductive decisions. In that regard, the trade-offs between economic activity and fertility in Quebec are to some extent, paradoxical. On the one hand, women's increased presence in the labour market in the 1960s and the 1970s had a negative effect on births. From the little data available, ${ }^{69}$ it is clear that women's activity rates increased dramatically in Quebec at the time of the most acute drop in fertility rates. In 1960, 26.5 per cent of women were active in the labour market (figure 8), and they counted for 26.2 per cent of the employed population (Annuaire du Québec, 1974). Ten years later, 33.1 per

\footnotetext{
${ }^{69}$ Women's activity rates in the 1960s and 1970s are rarely discussed in typical account of the correlation between women's activity and fertility in Canada. This is due to the difficulty of documenting women's status in the labour market at the time. Although the Labour Force Survey is most often used by social scientists as a source of information for trends in employment, it has only been compiling data since 1971. Thus, annual data on women's status on the labour market are difficult- if not impossible- to find.
} 
cent of women held a job, and they represented 33.3 per cent of all workers (Annuaire du Québec, 1974).

Figure 8 -Women's activity rate in Quebec, 1960-1970

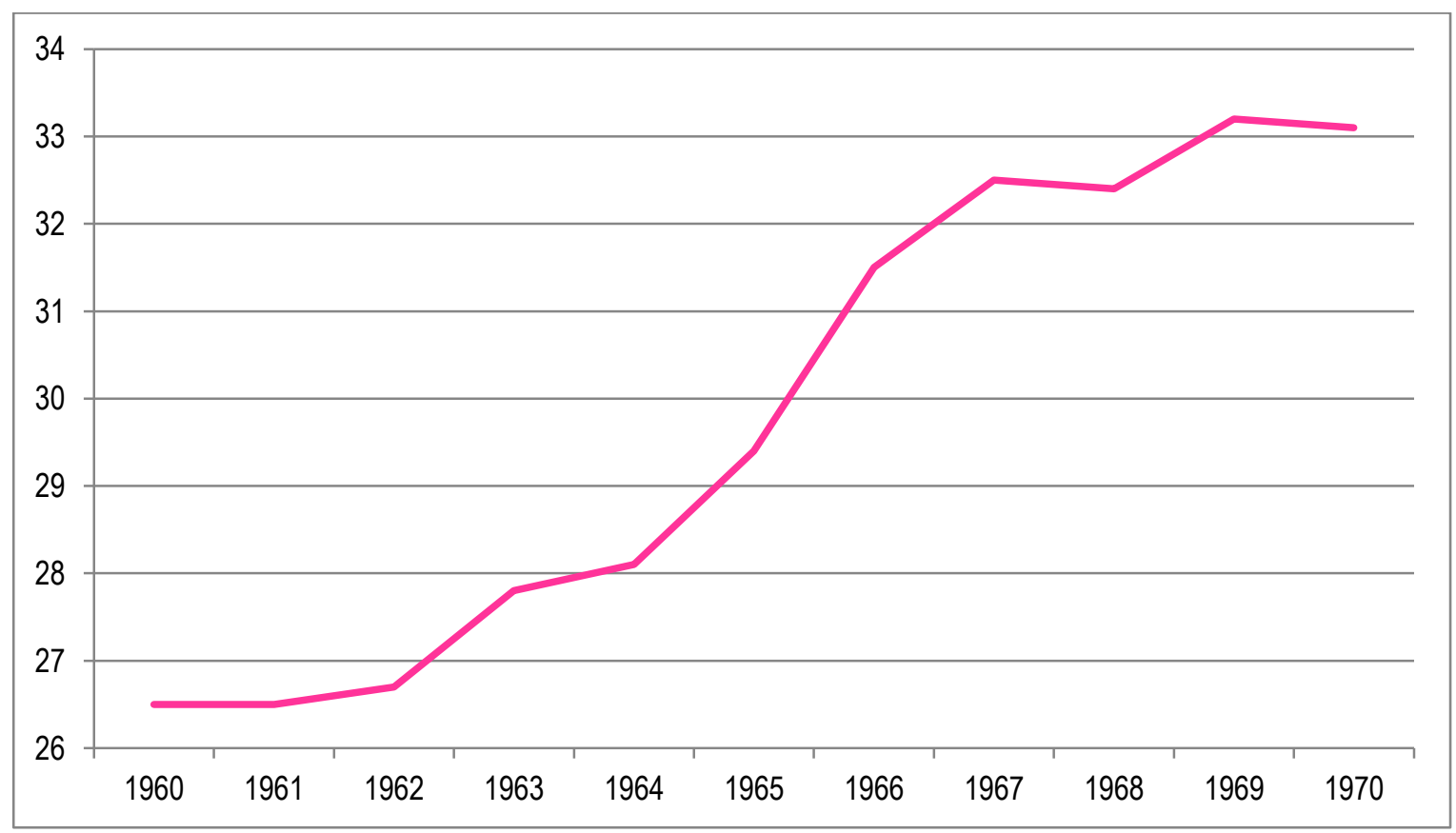

Source: Annuaire du Québec, 1974.

In addition, between 1976 and 1988, ${ }^{70}$ women of prime child-rearing age ${ }^{71}$ increased their presence in the labour market (with the only exception of 1982) in tandem with a declining proportion of births. Figure 9 shows an inverse relationship between fertility and young women's activity. As in other industrialised countries, fertility and labour market participation for women seemed to be incompatible activities in Quebec between the early 1960 s and the late 1980 s.

\footnotetext{
${ }^{70}$ Statistics Canada (2013b). The data were not available for years prior to 1976.

${ }^{71}$ Individuals of child-rearing age are defined as those between 25 and 34. Indeed, women's mean age at the birth of their child ranged between 25.04 in 1975 to 25.9 in 1988, while women's mean age at the birth of their third child varied between 30.21 to 30.22 respectively. Thus, the data presented here were compiled using two age group categories: $25-29$ and 30-34.
} 
Figure 9 - Relationship between the activity rates of women aged 25-34 and fertility rates in Quebec, 1976-1988

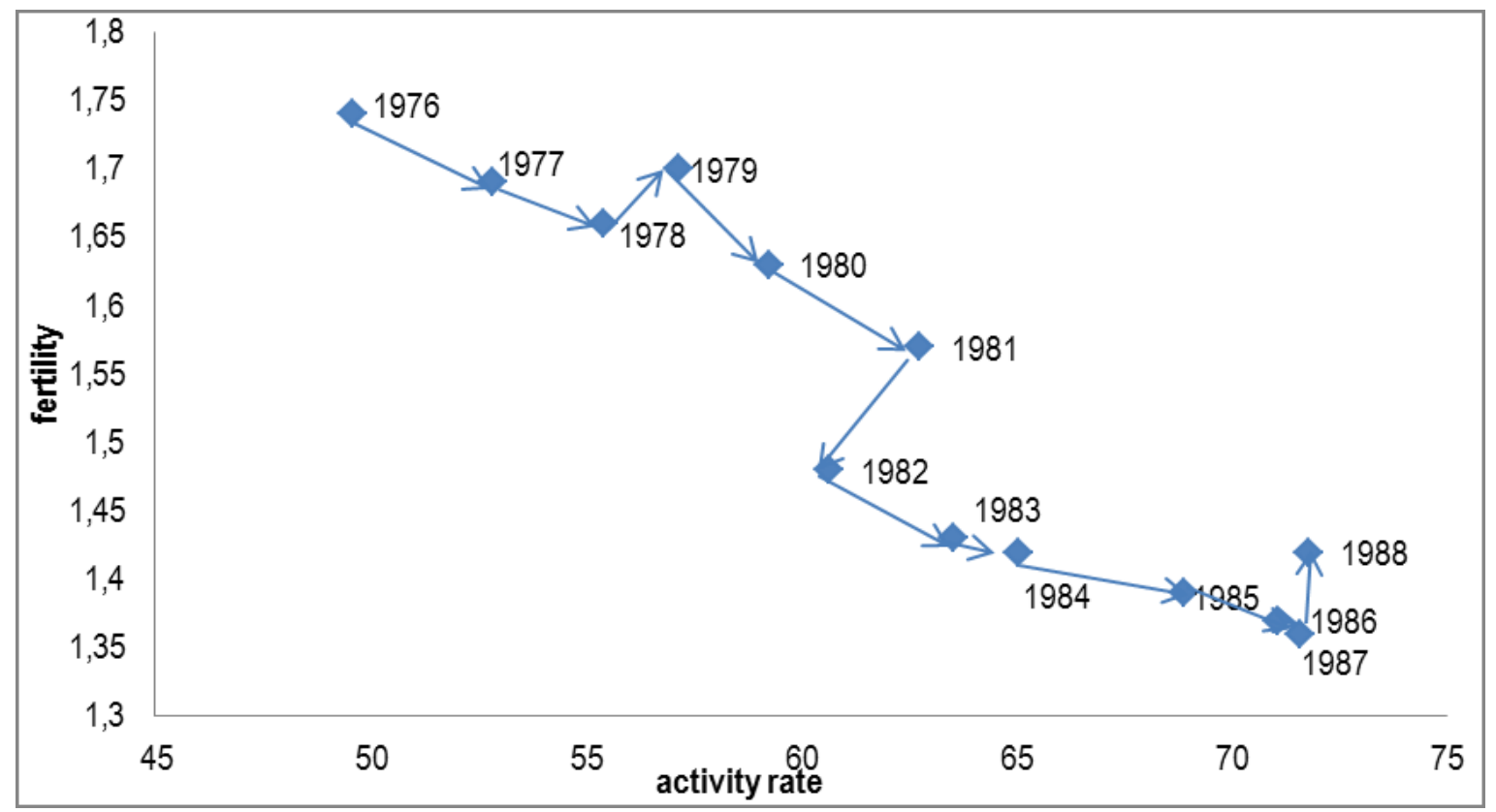

Source: ISQ (2013) and Statistics Canada (2013b). The data on activity rates were not available for years prior to 1976 . The data were compiled by the author and are the average activity rates of women aged 25-29 and 30-34.

While women's increased presence in the labour market seemed to have a negative effect on births, women's withdrawal from the labour market in the early 1980s did not have a positive effect on fertility. While there seems to be a consensus in the literature on the positive effect of a strong economy on fertility rates, it has also been argued that unemployment could be positively correlated with family formation (Kurz et al., 2005; Schmitt, 2008). The connections between economic activity and reproductive decisions are not systematically straightforward in developed countries.

In Quebec however, there are parallels to be drawn between economic slowdown and decreased fertility. Quebec's economic performance, and more specifically activity and 
employment rates, have been below many of the other provinces from the 1960s through 1988- (Boyer, 2008; Migué, 1998; Paquet, 1999)..$^{72}$ Interestingly, fertility also remained lower in Quebec during this entire period. Second, the effects of the early 1980s recession, the longest and deepest decline in total production since the 1930s (Yalnizyan, 2009), were more strongly felt in Quebec than in the ROC (Fortin, 2001) and fertility rates also fell more steeply in Quebec than in the other provinces. The connections between economic activity and births in Quebec are further demonstrated in the light of figure 10, which provides unemployment rates for men and women of prime child-rearing age. Between 1982 and 1984 youth unemployment peaked. Thus, while women's activity and childrearing seemed to be incompatible tasks between the early 1960s and 1988, women's unemployment did not have a positive effect on reproductive decisions either.

72 These three economists have argued that Quebec's economy was doing rather well before the Quiet Revolution, and has since gone through a period of stagnation and decline. 
Figure 10 - Unemployment rates of men and women, aged 25-34 in Quebec, 1976-1988

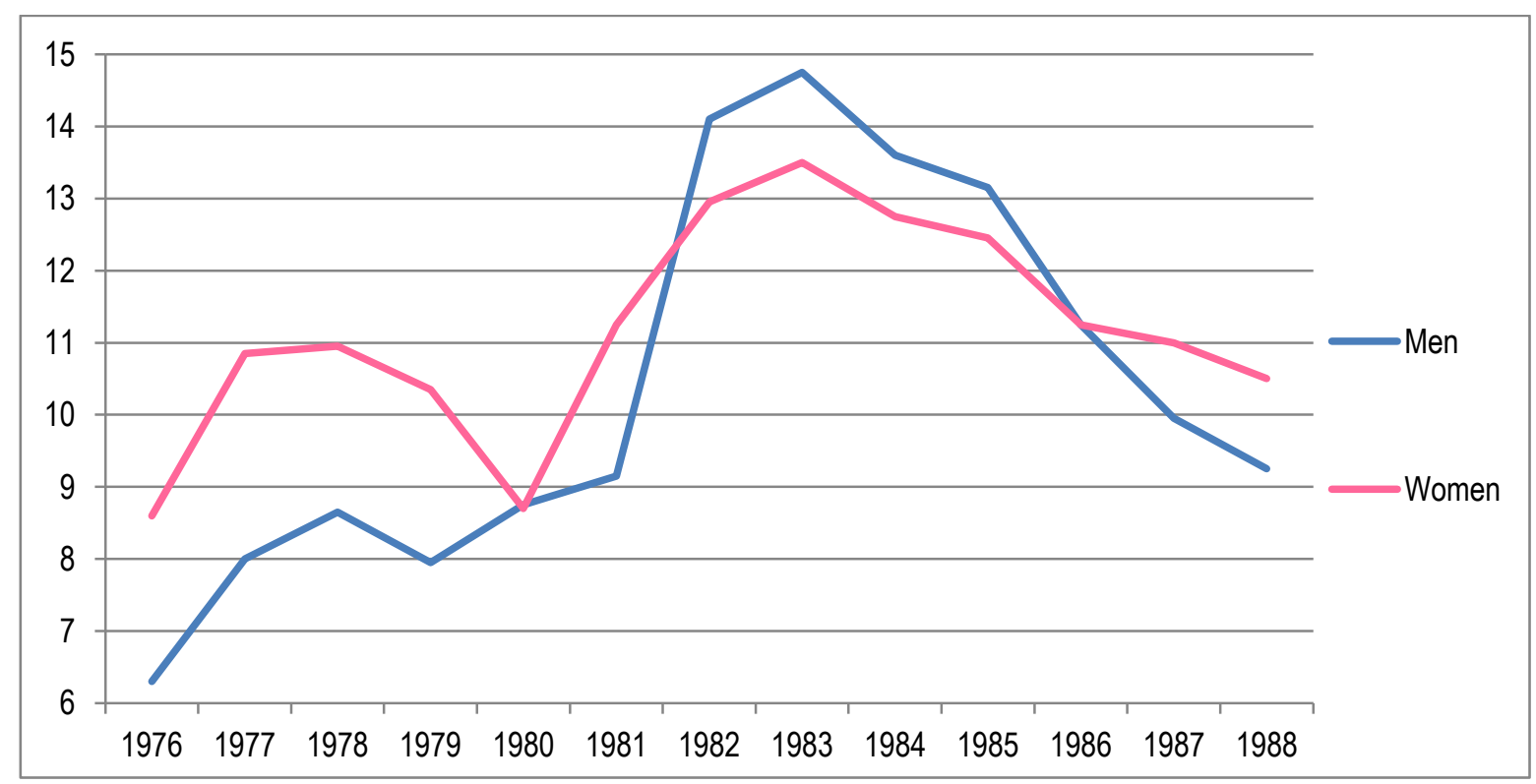

Source: Statistics Canada (2013b). The data were compiled by the author and are the average unemployment rates of men and women aged 25-29 and 30-34.

Perhaps one of effects of the economic slowdown and of women's increased activity was the postponement of the transition into parenthood. The connections between the timing of the transition into motherhood and total fertility nonetheless remain difficult to establish from the 1960s through 1988. The connections between the tempo and the quantum effects are sometimes even counterintuitive. In the 1960s, having children at a younger age did not systematically mean having more children, as the average age women gave birth decreased between 1960 and $1976 .^{73}$ Women had their children in the 1960 s over a longer time span than in any other decade under study (figure 11). While women aged 20-24 had birth rates almost as high as women aged 25-29, it was also during that decade that women aged 40-44 had their highest birth rates. Moreover, in the 1980s, shorter intervals between the first two

\footnotetext{
${ }^{73}$ This is not to be confused with the mean age of women at the birth of their first child, for which the data are not available between 1960 and 1975.
} 
pregnancies did not lead to an overall increase in fertility. Women waited an average of 2.48 years before they had a second baby in 1987, down from 2.82 years in 1975 (ISQ, 2013).

Figure 11 - Birth rates of women of different age groups, Quebec, 1960-1988

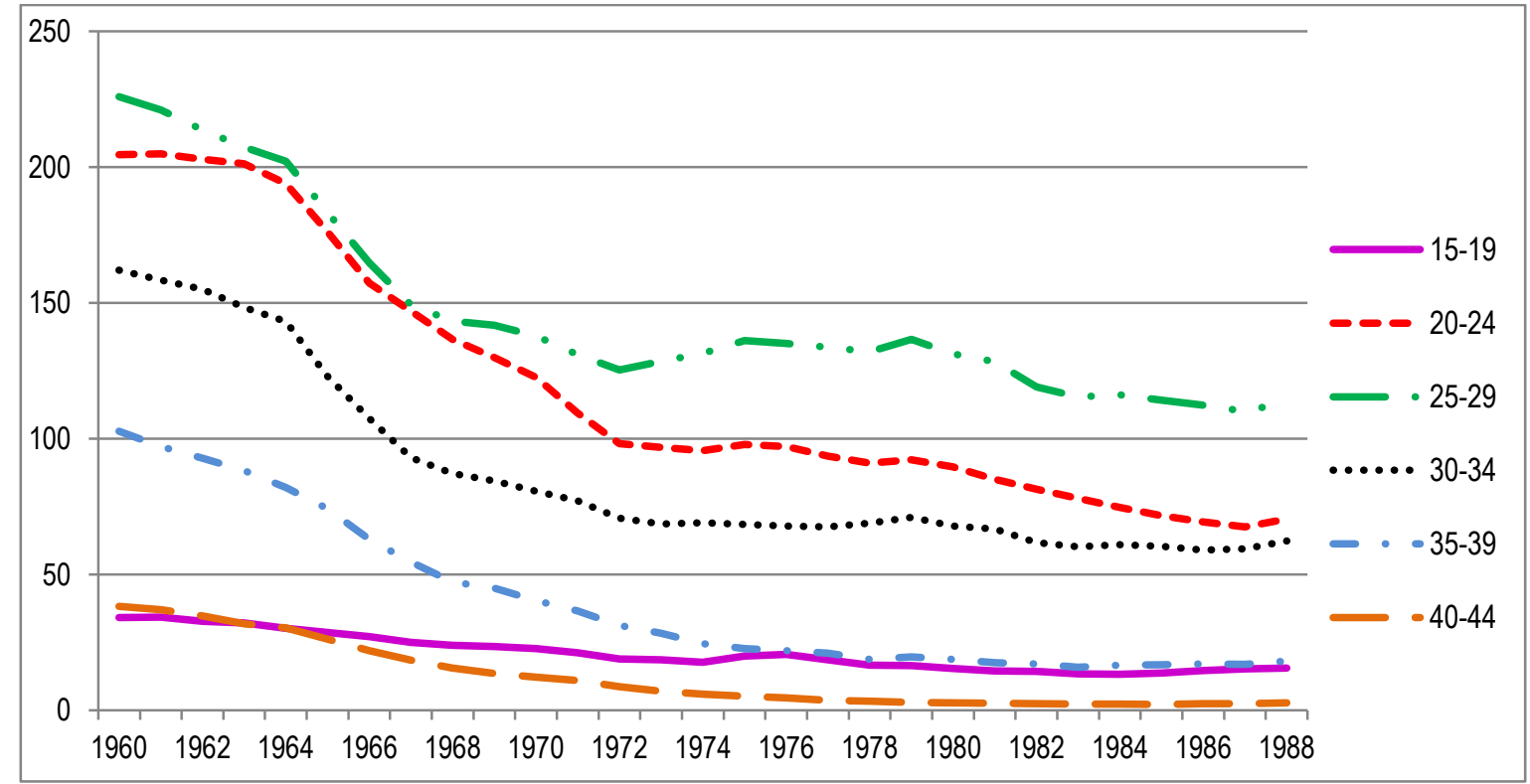

Source: ISQ (2013).

As more women entered the labour market, they also seemed to be less attached to marital life. For the most part, Roussel's $(1987,1989)$ prediction about the articulation between fertility trends and key variables pertaining to the deinstitutionalization of the family held between 1960 and 1988. From a time series point of view, the decline in birth and fertility rates in Quebec went hand in hand with the overall decreasing popularity of marriage. While 924.2 men and women per 1000 individuals married in 1960, that number went down to 444.35 in 1988 (ISQ, 2013). Marriage rates dropped the most between 1980 and 1981 (from 616.65 to 553.55), followed by the period between 1972 and 1973 (from 905.25 to 849.7 ) (ISQ, 2013). The declining popularity of marriage was almost perfectly in sync 
with the rise of marital dissolution. Divorce rates increased at three key points: between 1973 and 1974, between 1980 and 1981, and between 1985 and $1987 .{ }^{74}$ To some extent, this increase is not surprising. The first two periods correspond almost perfectly to the most important drop in marriage rates. As discussed later in the text, though women were granted the right to divorce in 1968, ending an unhappy marriage became much easier after 1985 . Thus, what is somewhat unexpected from the examination of divorce trend is the fact that the most significant rise in marital dissolution occurred before the 1985 Divorce Act. This suggests that the growing prevalence of divorce was not exclusively the result of a change in marital laws and that marital unions became more fragile in the 1970s, even when divorce was relatively difficult to obtain.

Lower marriage rates also led more parents to have children out of wedlock. In Quebec, extramarital births were nonetheless typically taking place in a context of a stable union throughout the period under study, as no more than 5.3 per cent of children were born from undeclared fathers (ISQ, 2013). Finally, the prevalence of abortions increased dramatically after its decriminalization in 1969, from 1.4 interrupted pregnancies for 100 births in 1971 to 19.8 in 1988 .

While to a large extent the argument about the connection between the deinstitutionalization of the family and low fertility is relevant between 1960 and 1988 ,

\footnotetext{
${ }^{74}$ Between 1973 and 1974 divorce rates rose from 21.5 to 32.1 divorces per 100 married individual, while between 1980 and 1981 and between 1985 and 1987, the rates increased from 31.7 to 43.5 and from 35.8 to 435 respectively (ISQ, 2013).
} 
smaller variations in fertility trends observed in a short period of time cannot be explained by Roussel's thesis. In the 1960s, the steepest drop in fertility rates was recorded between 1965 and 1966, precisely when marriage rates were increasing and divorce rates remained low. Similarly, the timing of an increase in marriage rates between 1971 and 1972 (along with a decrease in the age at first marriage ${ }^{75}$ ) corresponded with a sharp decrease in birth and fertility rates. Finally, between 1973 and 1976, as marriage rates plummeted and divorce rates increased dramatically in Quebec, birth rates went up and fertility rates remained relatively stable.

\section{New opportunities...}

In parallel with their rising economic activity and their increasing reluctance to marry, women gained new sets of rights in the 1960s and 1970s. These rights pertained, among other things, to access to education and to family planning. While women were being offered new opportunities in individual-oriented instituted such as the labour market, the idea of specific gender roles within the family and broader society persisted. Women's traditional role as care givers was encouraged through an institutional context that favoured gendered familialism.

In 1964, amendment to the Civil Code gave married women full legal and property rights. Until then, Quebec's Civil Code had maintained the inequality of rights between spouses: married women were treated like minors and could not sign a contract or carry out any legal

\footnotetext{
${ }^{75}$ The average age for men and women at the time of their first marriage indeed went from 24.52 in 1971 to 24.31 in 1972 (ISQ, 2013).
} 
transactions without obtaining their husbands' consent. Bill 16 recognised the equality of spouses in marriage and women's independence. Legislative changes in family laws were also made by the end of the 1960 s that gave women the ability to decide whether they wanted to stay in an unhappy marriage. Prior to 1968 there was no federal divorce law in Canada. In Quebec (and in Newfoundland), where there was no provincial divorce legislation and individuals had to seek the passage of a private Act of Parliament in order to end their marriage. In the 1968 Divorce Act, the grounds for divorce became equally available to husbands and wives, thus removing the double standard that had previously existed, making divorce easier to obtain for men than for women. ${ }^{76}$ The Act allowed divorce on both fault and no-fault grounds. The fault grounds were widened from only adultery to include mental or physical cruelty, desertion, rape or another sexual offence such as homosexual act. The no-fault ground only applied if there was a permanent breakdown of marriage.

Reproductive rights were broadened in the same period, and gave women more sexual freedom. In 1960, the marketing of the first contraceptive pill was authorized to regulate menstrual cycles and relieve pain. Doctors nonetheless sometimes prescribed the pill as a means to control births (Gauvreau et al., 2007), though contraceptive use and abortion

\footnotetext{
${ }^{76}$ Before 1968, in most other jurisdictions in Canada, a husband could obtain a divorce on the grounds of his wife's adultery; in order for a wife to do the same she had to demonstrate that her husband had committed incestuous adultery, rape, sodomy, bestiality, bigamy, or adultery along with cruelty or desertion. Wives who had committed adultery were not entitled to spousal support; husbands had no right to apply for support in any circumstances. Some provinces enacted legislation allowing either spouse to seek a divorce on the basis of adultery.
} 
remained illegal until 1969. ${ }^{77}$ That year, Ottawa adopted Bill C-150, which eliminated the prohibition on the distribution and the sale of contraceptives. Sections of the Criminal Code on abortion were also amended to stipulate that abortion could be performed under limited circumstances. $^{78}$

Finally, since the end of the 1950s, a revolution in girl's education had begun with the introduction of a full-fledged public secondary education system across the province, the disappearance of domestic-science schools and the creation of classical colleges (Clio Collective, 1987). In addition, the 1964 Parent Report proposed that girls have the right to the same education as boys, that classes be mixed and the education be free.

The influence of these changes on women's position in the larger society should not be overestimated. Thus, although married women's formal status had changed with Bill 16, social practices did not evolve at the same pace, and women who decided to transact daily business still met some resistance. Bank managers, notaries and department store credit departments took their time in recognizing women's rights and continued for some time to demand a husband's signature (Clio Collective, 1987). With regards to the possibility of ending an unhappy marriage, divorce still proved relatively difficult to obtain. The no-fault grounds on which the breakdown of marriage could be demonstrated remained specific and

\footnotetext{
77 This does not mean women did not voluntarily interrupt unwanted pregnancies: in 1862, the Dominion Bureau of Statistics noted that 57,617 hospitalizations were due to abortion-related complications and in 1966, abortion was the main cause of hospitalization for Canadian women (Pépin, 2006).

${ }^{78}$ Abortion remained a criminal act, unless conducted by an accredited hospital under the authority of a therapeutic abortion committee composed of three doctors. Furthermore, abortion could only be performed if the pregnancy endangered the mental, emotional or physical well-being of the mother. Abortion legislation in Canada was further liberalized in 1988.
} 
limited. Divorce could be obtained if the parties had been living separate and apart for three years, a period during which women were not free to remarry. In the 1960s and 1970s, a large proportion of women were financially dependent on their husband, and the prospect of living three years without a male-breadwinner may have deterred some women from seeking divorce. ${ }^{79}$ The situation was especially difficult for women whose husband had deserted them, as they had to wait five years before they could initiate divorce proceedings. Finally, though the Parent Commission seemed to propose structural reforms that would significantly change the school system, a closer reading of the report reveals that the idea of a specifically female education persisted. The aim was still to develop for girls a predisposition for their future role as mistresses of the house, wives and mothers (Clio Collective, 1987).

Most importantly, women's new sets of rights and opportunities were not paralleled with new sets of defamilializing or demotherizing policies that went above and beyond the idea of formal equality and that could have changed their social role within Quebec's society. Though Ottawa and Quebec both expressed interest in the well-being of families, this interest was not associated with the desire to implement new structural arrangements designed to better support dual-earner families. Nor was this interest related to the welfare of mothers, now increasingly active in the labour market. In the postwar era, the male breadwinner remained the archetype for the design of social policy and indeed social policy was built on principles that women would be dependent on males on most circumstances

\footnotetext{
${ }^{79}$ Women whose husband had been imprisoned for more than two years were entitled to divorce.
} 
(Cohen and Pulkingham, 2009). The discourse around the introduction of family measures, whether it was maternity leaves, family allowances or childcare services, reflected different concerns, none of which were framed in terms of gender equality, or in terms of easing the reconciliation between work and family.

Thus when in 1971 the federal government decided to offer 15 weeks of maternity leave to working women across the country, the benefits were made available through existing institutional structures, via the Unemployment Insurance (UI) program. Access to the UI system was designed around the characteristics of work normally associated with male labour force participation (full-time, full-year) (Cohen and Pulkingham, 2009; Porter, 2003). In fact, the debate on the maternity leave program revealed a concern that some women would enter the labour force once pregnant in order to obtain benefits (Phipps, 2006; Porter, 2003). To guard against this possibility, women were explicitly disqualified from receiving regular UI for six weeks before, and six weeks after, the expected date of their confinement. Maternity claimants had to demonstrate a 'major attachment' to the labour force by having worked twenty weeks of insured employment during the previous fifty-two, compared to the eight required by those applying for regular benefits. In addition, to ensure that women were working at the time of conception, the 'magic-ten' specified that a minimum of ten of the weeks worked had to be between the thirty-first and the fiftieth weeks before the expected date of birth. ${ }^{80}$

\footnotetext{
${ }^{80}$ In 1984, new amendments were introduced to the UI maternity provisions. These amendments eliminated the magic-ten rule, and allowed benefits to be paid at any time during a 25 -week period.
} 
The regulations inscribed in the maternity leave program not only reflected a concern to prevent 'abuse', but also an interest in health. Policy makers were not the least concerned with the issue of work and family reconciliation; rather, the initial rationale for maternity benefits was related to the mother's physical incapacity to be active in the labour market in the weeks surrounding the birth or in the immediate postpartum period. Accordingly, a larger share of the leave ( 8 weeks) had to be taken before, instead of after, giving birth.

The motivations that led the federal and the provincial governments to introduce family allowances did not echo women's new role as breadwinners either. At the federal level, the main rationale behind the implementation of the federal allowances in 1945 was to thwart the rise of the left. ${ }^{81}$ Faced with an apparent interest in social security, the federal government promised "a national minimum of social security and human welfare", which included family allowances (Guest, 1997: 119). At the provincial level, it was in 1961 that the government paid its first benefits to parents with dependent children. The school allowance was a monthly benefit of $\$ 10$ paid for teenagers aged 16 and 17 who were attending school or who were physically or mentally disabled. The allowance was thus designed to support the welfare of children, not women. In 1967, in light of the federal government's failure to keep the family allowance program in step with the rising cost of living, Quebec established its own provincial family benefits. Again, the program was designed to implicitly support fertility as the amount of the benefits, which added to the

\footnotetext{
${ }^{81}$ In 1943, a Gallup Poll had reported that the Co-Operative Commonwealth Federation (CCF) had overtaken the Liberal Party in popularity in Canada, then in power.
} 
amount received from the federal government, was based on the number of children in the family.

As with maternity leaves and family allowances, the discourse around the need for childcare did challenge women's role as the main caregiver (Finkel, 2006; Mahon, 2000). Under Canada's Constitution, though the right to implement public childcare programs falls under provincial jurisdiction, the federal government can play an indirect role through the use of its constitutional spending powers. In 1966, childcare services became a cost-shared program funded by the federal and the provincial governments through the CAP. Federal monies were made available to expand social assistance in Canada, the objective being to support individuals in finding work and getting off social assistance. Childcare was one initiative among others to encourage individuals to enter the labour force, and from the start, the federal government insisted that only the 'needy' would be covered by CAP. According to Mahon (2000), the fact that childcare was included in the welfare services for cost-sharing was more a by-product of negotiations between federal and provincial officials, than a deliberate strategy. Childcare was not introduced as a service to support the increasing number of dual-earner families, but as a tool to improve social assistance.

Indeed, it was generally argued in the 1950s that mothers of young children were best at home (Finkel, 2006; Mahon, 2000). Those who broke this taboo, working-class and immigrant women who had to work, were identified as being 'needy' of childcare services so their children would be financially and morally saved (Mahon, 2000). Though the 
dominant discourse on women's work did not identify childcare as a way to achieve greater gender equality until the $1970 \mathrm{~s},{ }^{82}$ it was increasingly recognised that some working-class women had to work and that they had a right to claim state aid for childcare during hours where there was no parent in the home. Childcare thus initially formed part of an antipoverty strategy (Mahon, 2000). Furthermore, while childcare had once been attacked as the culprit in juvenile delinquency, it now came to be seen as a preventive measure for social problems (Finkel, 2006). It followed that childcare policy should target the working poor, and those on social assistance.

Women with higher family earnings could afford proper childcare, and indeed they did (Mahon, 2006). In addition, these women soon received additional support for childcare through measures introduced via the tax system. First, the Child Care Expense Deduction $(\mathrm{CCED})^{83}$ introduced in 1972 by the federal government, made it possible for parents to deduct part of their childcare expenses from their tax report. However, the childcare expense deduction was only available for women with earned income, ${ }^{84}$ and receipts had to be supplied in order to receive the deduction. The CCED favored a limited level of economic defamilialization in the sense that the deduction was restricted to $\$ 2,000$ per child

\footnotetext{
${ }^{82}$ In the 1970s, the discourse on childcare changed, becoming part of larger agenda aimed at gender equality. It was then understood that even White middle-class women would take advantage of a publicly subsidized childcare network. Yet, the struggle for a universal childcare strategy became part of a 'never-ending story' (Mahon, 2000), as various concerns erupted such as costs, the federal intervention in an area under provincial jurisdiction and an overall move away from the principle of universality (see Finkel, 2006 and Mahon, 2000).

${ }_{83}$ Tax deductions and credits are two different canals that have an impact on taxes. A tax deduction reduces taxable income, on which federal tax is calculated. Thus, as long as one pays some taxes, a deduction is worth more when the income is higher. A tax credit directly reduces the amount of tax payable. If the credit is refundable, the person may receive a refund from the government if no tax is owed (Baker, 1995).

${ }^{84}$ Men could also claim the deduction if they were widowers, divorced, or separated (and also, starting in 1974, never married) or if the children's mother was incapable of caring for the children (Gagné, 2001).
} 
under age 14 , subject to a maximum of $\$ 8,000$ per family. Furthermore, given that the majority of unlicensed caregivers did not provide the required receipts (Mahon and Phillips, 2002), a large proportion of families were not entitled to the deduction.

The other childcare initiatives - also implemented via the tax system - clearly supported traditional families. At the federal level, the deduction for a dependent spouse - the married credit - recognised that some families chose parental care. Since 1918, a tax deduction had been made available for employees with dependent wives. The federal government thus explicitly supported women's traditional role as care givers. The deduction rose sporadically with the cost of living and was converted in 1988 into a non-refundable credit. Similarly, Quebec introduced in 1982 an availability allowance for families who did not use childcare. The allowance was a non-taxable grant designed primarily to benefit mothers who stayed at home with their young children (below the age of 6) and who did not claim deductions for childcare costs. Ironically, gendered familialism was supported the most via these childcare initiatives.

The availability allowance generated anxiety in the community of childcare centers, because it encouraged women to stay out of the labour market and, by the same token, to stop using their services (Lalonde-Graton, 2002). The allowance not only reflected a conservative view of women's proper role, but also pronatalist ambitions. At first, the amounts offered were $\$ 300$ for the first child, $\$ 500$ for two children and $\$ 100$ for each 
additional child (Schwartz, 1982; RRQ, 2003). ${ }^{85}$ In 1988, the amounts offered were changed to signal Quebec's willingness to move toward family-relevant measures designed with pronatalist objectives: the benefit was thus decreased for the first two children $(\$ 100$ and $\$ 200$ respectively), while it was raised to $\$ 500$ for the third and subsequent children.

Thus, the policies put in place by both levels of government favored equity over equality, by recognizing and encouraging men's role as breadwinner and women's role as care givers. Family-relevant measures introduced by Ottawa and Quebec scored poorly on the demotherization index. The designs of the maternity leave, of the family allowance programs and the limited offer of childcare did not help to move care work away from the mother's hands. To be fair, these programs did allow care work to be partially defamilialized, but only for a limited number of families. For instance, the inclusion of maternity benefits as part of the UI program meant that the benefits were tied to an insurance program based on notions of a particular type of male worker: as a result, it excluded women who were not in the labour force, or who were not able to find a job that was stable enough for them to qualify. Arguably, women with the most precarious labour market situation were thus the least protected by the program. The extent of defamilialization thus varied along the characteristics of the families. Likewise, though the provincial family allowances were universal, the amount of the benefit varied depending on the number of children, from $\$ 15$ for one child to $\$ 142.50$ for six children.

\footnotetext{
${ }^{85}$ Working parents who paid childcare costs either could deduct those costs from their income or claim the availability allowance. The two could not be combined.
} 
The lack of vision for the development of institutional structures to support families on the part of both governments, the prevailing suspicions of working women who wished to secure their job in the labour market after giving birth, the difficulty of obtaining a deduction when using childcare services, the incentives that encouraged women to care for their children, and the pronatalist flavour to Quebec's allowances sent a somewhat paradoxical message to women. Though women now had gained formal equality within the institution of marriage, both levels of government seemed to be committed to gendered familialism, where women's role is mostly defined in terms of caring obligations. As women were being defined as having 'various roles', from breadwinners to caregivers, it was generally assumed that they needed to remain principally responsible for raising the children and maintaining the household (Finkel, 2006).

\section{...or failed promises?}

The Quiet Revolution brought with it new promises and opportunities for women, who now had the option to remain single, to pursue an education, to be economically active and to control their fertility. New patterns of social reproduction emerged during that period, as women reduced the number of pregnancies though in the 1960s they gave birth at an earlier age. Quebec's baby-bust must be contextualised and understood in the light of similar fertility trends, experienced in developed countries, especially the Nordic and the AngloSaxon nations. The commercialization of the pill and a better access to abortion also had a negative effect on reproductive decisions. Though more adults became available for 
parenthood, and while a decreasing proportion of women remained childless, fertility was bound to decline.

In light of new opportunities that were offered to them in school and in the labour market, women were faced with difficult decisions. During that period, being active in the labour market was perceived as incompatible with social reproduction. Entitlement to maternity benefits proved difficult to obtain and in the best case scenario, women could only enjoy 15 weeks of paid leave at 66 percent of their past wages (60 per cent after 1978). Public support for childcare also remained limited. Despite the government's reluctance to facilitate the reconciliation between earning and caring responsibilities, women were not ready to choose motherhood over economic activity, and they steadily increased their presence in the labour market. When the economic recession hit the province in the 1980s, women did not massively withdraw from the labour market to devote themselves to social reproductive work, and fertility rates decreased. The context of high unemployment for young women was not understood to be the opportunity to conceive.

Though both Ottawa and Quebec introduced family-relevant policies that supported implicit familialism, it was in the 1970s and 1980s that the two levels of government developed their distinctive approaches to supporting families. On the one hand, in Quebec, the government's commitment to universality was signalled with the introduction of two benefits. In 1974, the Quebec family allowance plan replaced the school allowance and the family allowance. The new plan provided for a monthly allowance that was paid to the 
mother of any children under 18. Three years later, the province introduced the Quebec Maternity Allowance Program (QMAP) and became the only province to supplement the federal maternity allocation, by paying the first two weeks of maternity leave not financed by the federal government.

On the other hand, Ottawa seemed determined to put a cap on spending on family-relevant policies. In 1978, maternity benefits were reduced from 66 per cent of past wages to 60 per cent. In addition, when the Canadian family allowance was first paid in 1945, it was worth about 4.7 per cent of the average family income. This declined to 1.8 per cent in 1971 (Baker, 1995). Though the benefits were increased in 1973, the program was cut back in 1978 to finance a refundable Child Tax Credit (CTC) based on family income, the objective being to target assistance for families in need of governmental support. Ottawa thus also started to introduce targeting principles in its family-relevant initiatives. Accordingly, the credit was income-tested and varied according to the number of children in a family (Baker, 1995, 2006; Lefebvre and Merrigan, 2003). This credit provided the maximum benefit to low-income families, a declining amount to middle-income families and no benefit to wealthy families. Upon the creation of the CTC, FA benefits were reduced from an average of $\$ 25.68$ per month (which would have increased to $\$ 28$ with indexing) to an average of \$20 per month. In 1986, the FA benefit, which still existed in its reduced form, was partially de-indexed meaning there were no increase in benefit levels until inflation reached 3 per cent. Consequently, the value of the FA would lessen over time. Except in Quebec, the FA was treated as taxable income, and up to 40 per cent of the value of the benefit 
could be taxed back from higher-income earners. By 1989, the tax-back rate reached 100 per cent for families with net incomes over $\$ 50,000$. This was the end of FA as a universal program in all but name.

It would probably be an exaggeration to view these changes as the signaling the end of universality in Ottawa's policies (Battle, 2008): despite the introduction of targeting principles, child benefits, under the form of family allowances, remained universal in reach. A clearer commitment to targeting principles was made obvious in the $1980 \mathrm{~s}$ and throughout the 1990s, when the children's tax exemption was reduced in 1987 and converted into a non-refundable child tax credit in 1988 as part of the federal tax reforms. Accordingly, the dualism between Ottawa's targeting family-relevant measures and Quebec's universal family policies will further be discussed in the next two chapters. 


\section{CHAPTER 8}

\section{FERTILITY AND SOCIAL REPRODUCTION IN THE LATE 1980S: FROM OTTAWA'S TARGETING MEASURES TO QUEBEC'S UNIVERSAL ALLOWANCES}

How can one account for the increase in fertility rates experienced in Quebec in the late 1980s? Was the increase the result of a return to traditional patterns of family formation, of the introduction of the baby bonus in 1988, or something else? This chapter addresses these questions and shows that the small baby boom of the late 1980s was the result of a complex articulation between the economic context, the postponement of motherhood and the introduction of provincial policy incentives. While in Quebec, marital status has not had a significant, if any, impact on fertility decisions since the 1970s, the effect of the economic health of the province on reproductive decisions is not straightforward. Indeed, although the timing of the economic boom matched that of increasing fertility, the effect of economic slowdown on reproductive decisions remains difficult to establish.

The discussion of Quebec's fertility regime between 1988 and 1997 is roughly divided into two periods. First, between 1988 and 1990, births rose significantly in a context of low unemployment and as women of childbearing age were increasing their presence in the labour market. At the time, fertility trends were in sync with the economic cycle. The combination of good activity rates for men and women and increasing fertility took place in a context of new norms such as delayed motherhood and the rising popularity of births out of wedlock. This period also corresponded with the introduction of Quebec's first family policy, which contained incentives for couples to have children. The articulation between 
economic activity, family policies and fertility trends became more blurry after 1990. In the early 1990s, as the province entered a period of economic slowdown, birth and fertility rates peaked. After 1993, fertility and birth rates fell while unemployment rates fluctuated. Thus, the timing of the recession and of low fertility did not easily correspond. At the same time, women's age at the birth of each of child continued to increase. Furthermore, a change in the tempo of births after the early 1990s did not lead to a change in the quantum of births: although women spaced their pregnancies more closely after 1992, fertility rates declined.

These tendencies are explained in light of the menu of family-relevant policies implemented by Ottawa and Quebec, which supported implicit familialism. As in the previous decades, the two levels of government refrained from developing benefits and services that would have transferred the social costs entailed by family-raising from the mother to other instances, and the socio institutional context did not favor the demotherization of care work. The first modern national childcare initiative occurred in 1984, when Ottawa ordered a Task Force on Childcare that eventually recommended a universal, publicly funded non-profit childcare system, as well as improved parental leaves. By the time the Cooke report was released in 1986 however, a federal election had brought a new government into power and another federal group was set up by the new government to study childcare, and none of the major recommendations of the Report were acted upon. To be sure, both levels of government nevertheless offered benefits that permitted economic defamilialization. In that regard, the federal government implemented a 
confusing mix of measures to support families that included a tax deduction for childcare expenses, and the new Child Tax Benefit (CTB). These measures shared two characteristics: they targeted the most needy and, as in the previous decade, they were implemented within the institutional structures in place. Conversely, Quebec chose to introduce a universal package of family allowances, with a new set of family allowances, including a baby bonus. In doing so, the provincial government showed its commitment to the pursuit of pronatalist objectives. After discussing the details of Quebec's family policy, the arguments about the positive effect of the baby bonus on the quantum of births are refuted, mainly because this measure did not support social reproduction and did not allow women to combine productive and reproductive work.

\section{Fertility and labour markets in Quebec and abroad}

Figures 12 and 13 and table 5 illustrate birth and fertility rates in Quebec and the ROC between 1986 and 1997. The figures show that fertility was lower in Quebec than in the ROC throughout the period under study. As observed, while birth rates may sometimes be affected by variations due to the age structure of the population, it does not explain the higher rates observed in the ROC. This is made obvious by the fact that fertility rates were also higher in the ROC. The figures illustrate that the biggest gap in birth and fertility rates between Quebec and the ROC was experienced in 1986, while the narrowest gap was observed in 1992-1993 and 1996 respectively. Of particular interest is the fact that fertility and birth rates in Quebec started to increase in 1988, the year Quebec's first family policy 
was implemented. Table 5 also demonstrates that the highest increase in fertility occurred between 1988 and 1990.

Figure 12 - Birth rate in Quebec and the Rest-of-Canada, 1986-1997

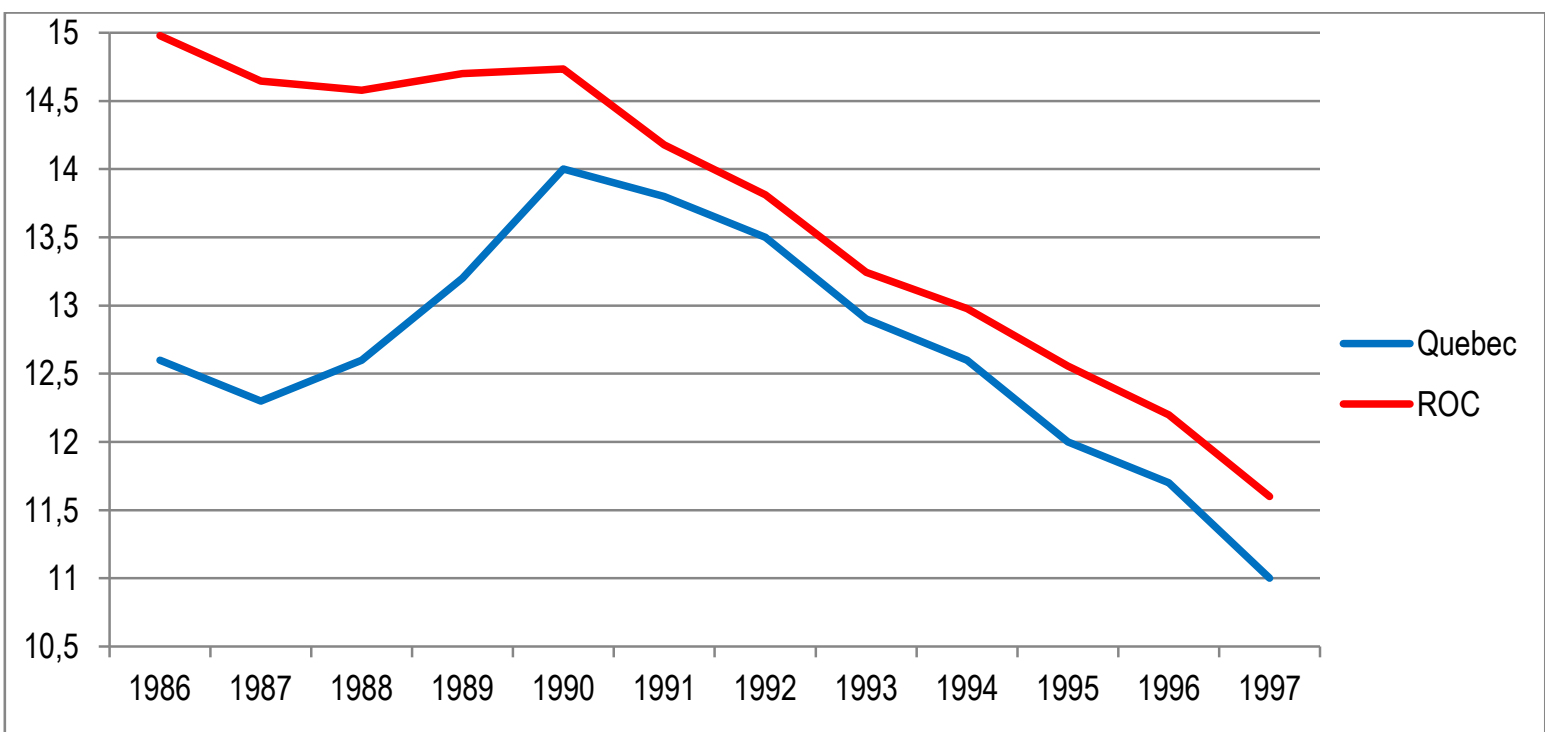

Source: ISQ (2013) and Statistics Canada, Health Statistics Division, Vital Statistics and Demography Division, demographic estimates. For the ROC, the calculations were all made by the author and they exclude Yukon, the Northwest Territories and Nunavut.

Figure 13 - Fertility rates in Quebec and in the Rest-of-Canada, 1986-1997

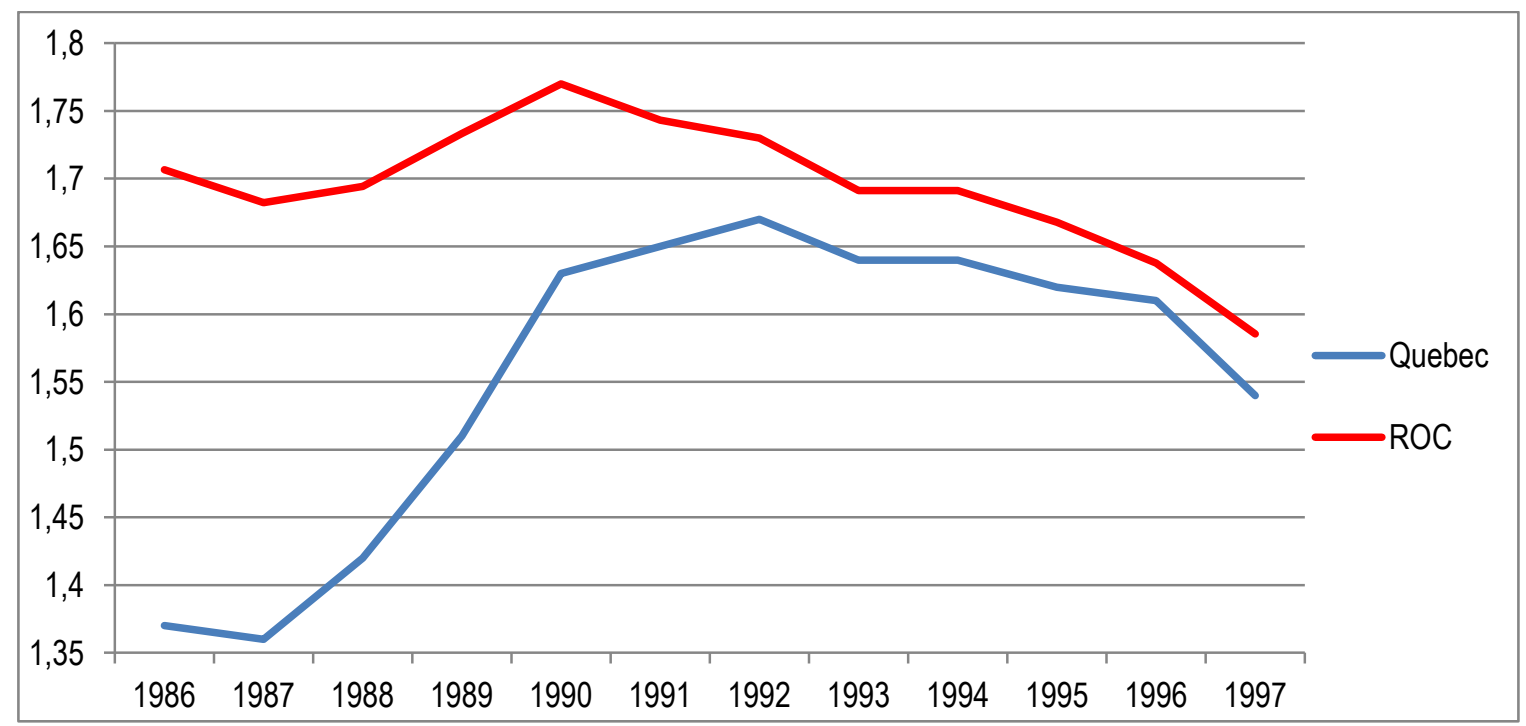

Source: For Quebec, ISQ (2013). For the ROC, from 1986 to 1992 Verma et al. (1996); from 1993 to 1996, Statistics Canada, (2006); for 1997, Statistics Canada (2008a). 
Table 5 - Birth and fertility rates in Quebec, 1986-1997

\begin{tabular}{lcccc}
\hline & Birth rate & Difference & Fertility rate & Difference \\
$\mathbf{1 9 8 6}$ & 12.6 & -0.3 & 1.37 & -0.02 \\
$\mathbf{1 9 8 7}$ & 12.3 & -0.3 & 1.36 & -0.02 \\
$\mathbf{1 9 8 8}$ & 12.6 & 0.3 & 1.42 & 0.06 \\
$\mathbf{1 9 8 9}$ & 13.2 & 0.6 & 1.51 & 0.09 \\
$\mathbf{1 9 9 0}$ & 14 & 0.8 & 1.63 & 0.12 \\
$\mathbf{1 9 9 1}$ & 13.8 & -0.2 & 1.65 & 0.02 \\
$\mathbf{1 9 9 2}$ & 13.5 & -0.3 & 1.67 & 0.01 \\
$\mathbf{1 9 9 3}$ & 12.9 & -0.6 & 1.64 & -0.03 \\
$\mathbf{1 9 9 4}$ & 12.6 & -0.3 & 1.64 & 0.00 \\
$\mathbf{1 9 9 5}$ & 12.1 & -0.5 & 1.62 & -0.02 \\
$\mathbf{1 9 9 6}$ & 11.7 & -0.4 & 1.61 & -0.01 \\
$\mathbf{1 9 9 7}$ & 11 & -0.7 & 1.54 & -0.07 \\
\hline
\end{tabular}

Source: ISQ (2013).

Comparisons between the fertility trends of Quebec and other developed countries confirm that Quebec's fertility trends were similar to those found in the Nordic and the AngloSaxon countries (Roy and Bernier, 2006). In the Nordic countries, fertility gradually increased from 1988, and between 1987 and 1995, similar trends could be observed in Norway, Sweden and Quebec (figure 14). ${ }^{86}$ In the 1990s, fertility in Quebec peaked in 1992, when it reached 1.67; from 1993, fertility started to go down before it stabilized for one year (in 1994). In the Anglo-Saxon countries, fertility rates peaked two years prior to Quebec, in 1990. Fertility trends between Quebec, New Zealand and the United States were nevertheless very similar between 1987 and 1990. When fertility began to decrease in Quebec in 1993, it also declined in these liberal countries. Thus, as observed in the previous

\footnotetext{
${ }^{86}$ The exception here is 1991, when fertility rose in Quebec, but decreased in the two Nordic countries.
} 
chapter, precisely because fertility trends were similar between Quebec and other countries, there are high probabilities that social reproduction was not only being affected by national social policies, but also by other social forces that surpassed territorial boundaries. Of course, the context in which women chose to give birth in these countries may have been very different, yet the social outcome remained similar.

Figure 14 - Fertility rates in selected Nordic and Anglo-Saxon countries and Quebec, 1986-1997

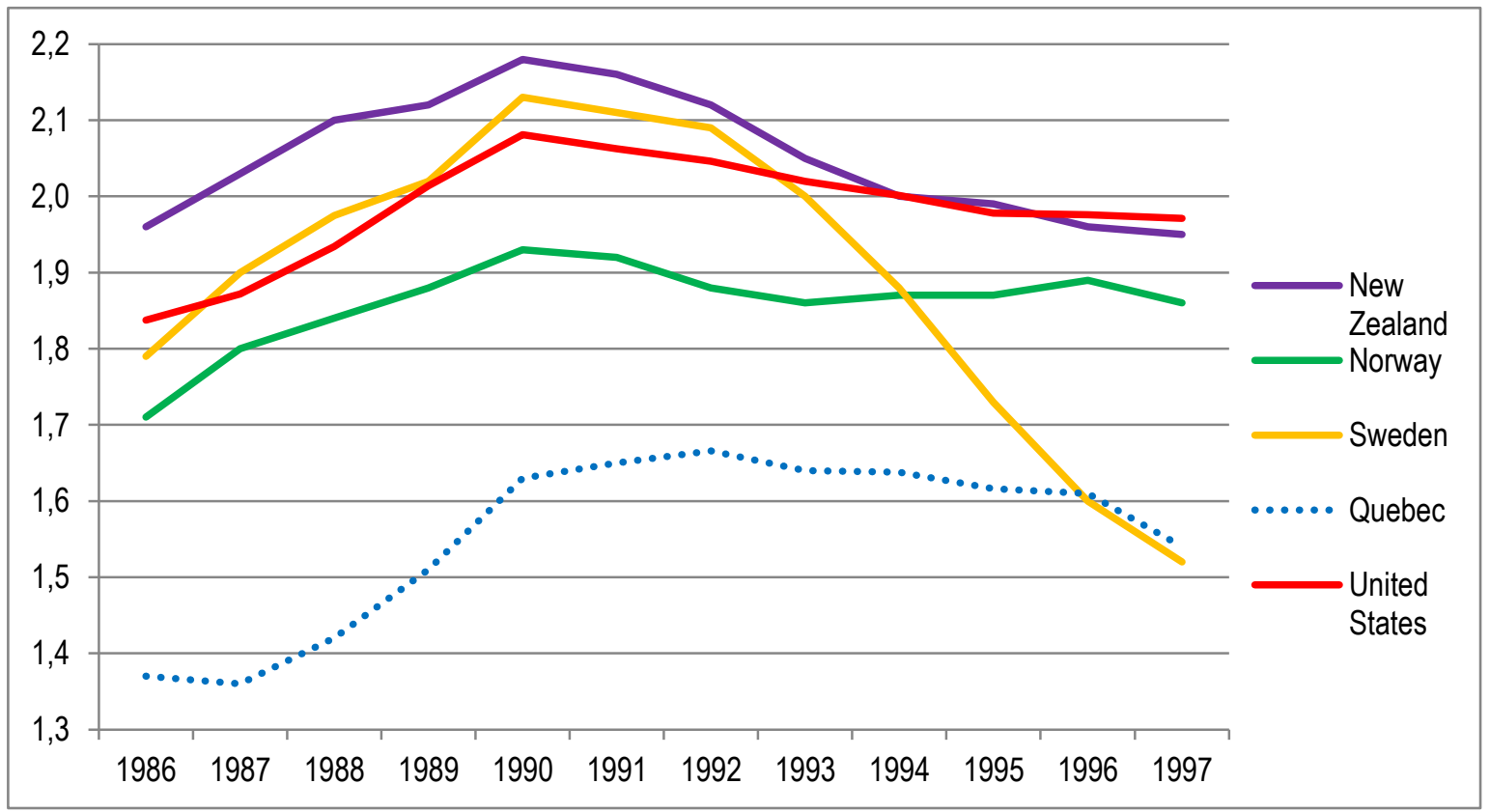

Source: ISQ (2013) and Worldbank (2012).

As in most developed countries, the timing of the economic boom in Quebec was synchronized with the timing of a fertility rise. From the late 1980s through the early 1990s, women's presence in the labour market was increasingly felt. Fertility rates were also increasing at the time. Between 1987 and 1990, there was even a positive correlation 
between fertility and young women's activity (figure 15). ${ }^{87}$ Between 1991 and 1994 however, as fertility rates reached their highest point, the activity rates of women of childbearing $^{88}$ age began to decrease. This observation could mean that the reconciliation between productive and reproductive activities was more difficult at the time; it could also mean, that in the light of an economic slowdown, a significant proportion of women withdrew from the labour market to devote themselves to social reproductive work.

\section{Figure 15 - Relationship between the activity rates of women aged 25-34 and fertility} rates in Quebec, 1986-1997

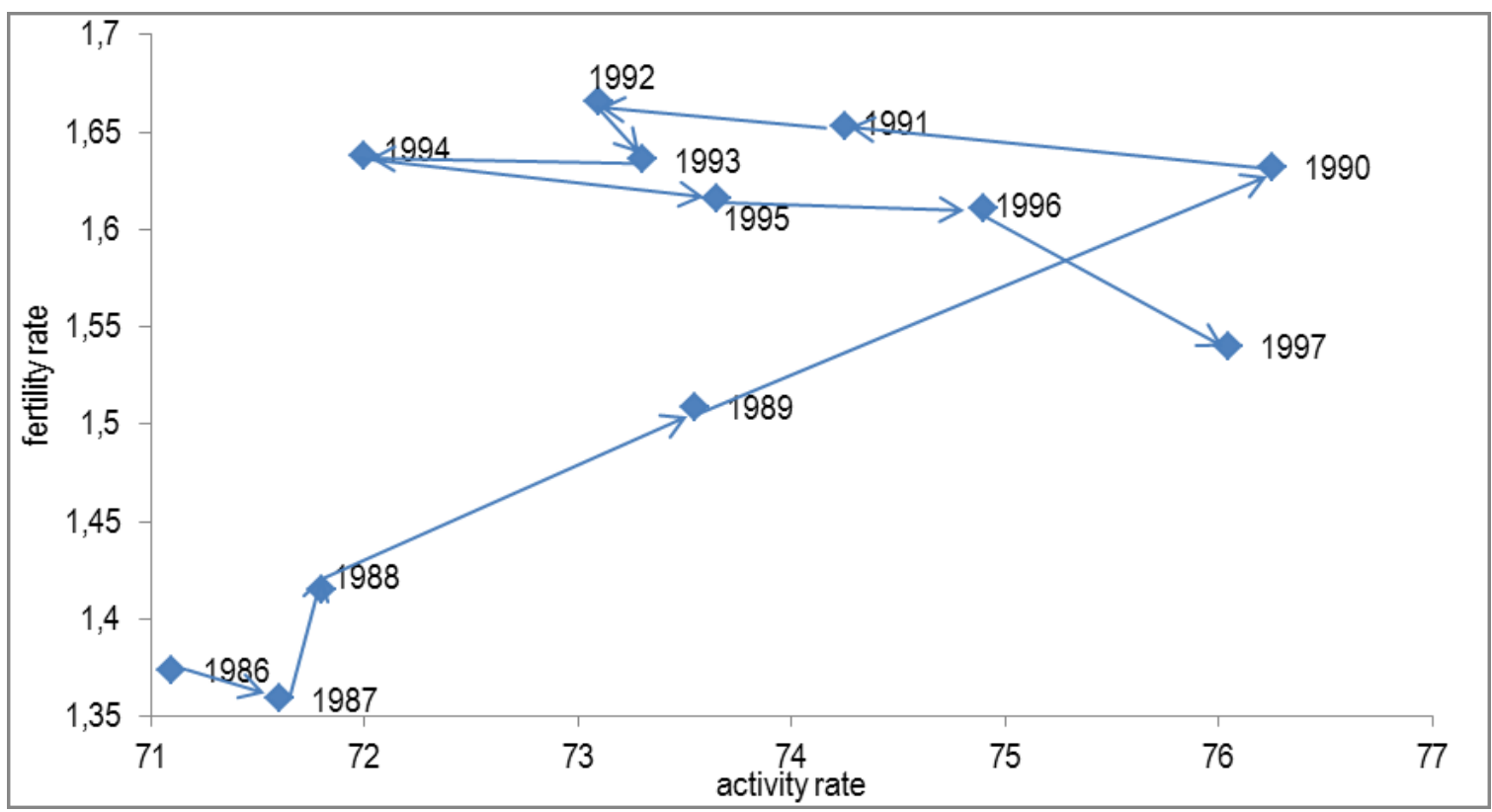

Source: ISQ (2013) and Statistics Canada (2013b). The data were compiled by the author and are the average activity rates of women aged 25-29 and 30-34.

\footnotetext{
${ }^{87}$ This does not mean, to be clear, that women who had children these years were automatically active in the job market. The data do not allow us to make such a precise remark.

${ }^{88}$ Women of childbearing age are defined here as women aged between 25 and 34 . Women's mean age at the birth of their child ranges between 25.8 in 1986 to 26.6 in 1997, while women's mean age at the birth of their third child ranges between 30.3 and 30.4 respectively. Thus, the data presented here were compiled using two age group categories: $25-29$ and 30-34.
} 
Thus, while the economic recession of the early 1980s seemed to have had a negative impact on births, the effect of the early 1990s economic slowdown remains unclear. Between 1990 and 1992, Quebec's labour market became unstable and adults of prime child-rearing age were faced with high unemployment rates. As discussed previously, high rates of youth unemployment can keep adult children in the parental home, postponing union formation, and ultimately, births.

Indeed, it seems like the early 1990s economic recession had a tempo effect on social reproductive decision. Though women continued to experience maternity at an older age in the 1980 s and the 1990 s, the transition to motherhood was more acutely postponed between 1990 and $1992{ }^{89}$ While younger women seemed to stay away from motherhood, older women had rising birth rates: as of 1992 women aged 30-34 - instead of women aged 2024- started to have the second highest birth rates, behind women aged 25-29 (figure 16). Despite the the postponement of births, women chose to space their pregnancies more closely in the early 1990s than previously. Between 1986 and 1991, women waited 2.54 years on average between the birth of their first two children; between 1992 and 1997, that number went down to 2.49 (ISQ, 2013). ${ }^{90}$ Thus, in the 1990-1992 period, the connections between tempo and quantum effects are complex. Perhaps, the context of the economic slowdown influenced women into postponing the transition into motherhood. Once they

\footnotetext{
${ }^{89}$ Between 1990 and 1992, the mean age of women at the birth of their first child increased by 0.2 years. In comparison, between 1987 and 1990, women's age only increased by 0.11 (ISQ, 2013).

${ }^{90}$ With regards to the interval between the second and the third child, women waited on average 1.51 years between 1992 and 1997, down from 1.79 years prior to 1992 (ISQ, 2013).
} 
had a child, and in the light of the difficulty to find a job, an important proportion of women withdrew from the labour market and had another baby.

Figure 16 - Birth rates of women of different age groups in Quebec, 1986-1997

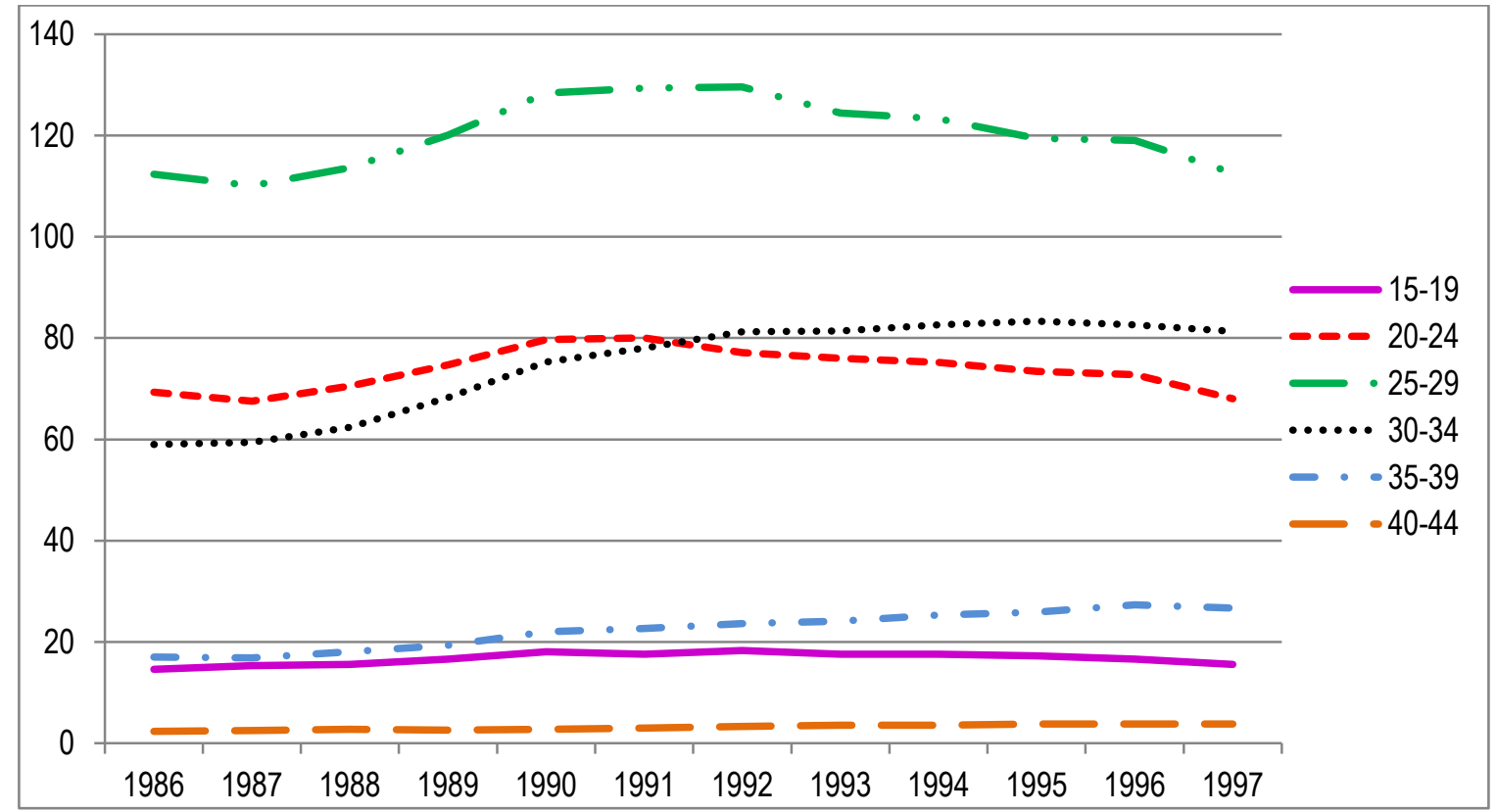

Source: ISQ (2013).

Patterns of social reproduction in Quebec from the 1980s on cannot be explained by an increasing deinstitutionalization of the family. The connections between the proportion of children born out of wedlock, marriage, divorce, and fertility rates are sometimes intriguing, if not paradoxical. For instance, the two most significant rises in the proportion of births to unwed parents occurred between 1986 and 1988, when fertility rates were increasing, and between 1991 and 1994, when fertility rates were decreasing! In Quebec, extramarital births continued to be the choice of a growing proportion of parents between 1986 and 1997 . While only 8 per cent of children were born out of wedlock in 1970 that proportion rose to 13.9 per cent in 1980 and to 54.3 per cent in 1997 (ISQ, 2013). Despite 
the high popularity of extramarital births, the proportion of children born to undeclared fathers fluctuated very little, from 4.3 per cent to 5.3 per cent, between 1986 and 1997 . Rising births outside of wedlock is inevitably associated with the declining population of marriage. Since the 1970s, marriage has not been a precondition to family formation in Quebec. Surprisingly, between 1987 and 1988, the number of marriage for 1000 individuals aged 50 and less, increased from 409.3 to 421.6 (ISQ, 2013). This is unexpected, given that in the proportion of births outside marriage also increased at the time. After 1988 however, the decreasing popularity of marriage was accompanied by an unprecedented augmentation of divorce rates. Between 1985 and 1987, divorce rates rose from 35.8 to 51.2 (ISQ, 2013), probably as a result of the new Divorce Act which made the dissolution of marital unions easier to obtain.

\section{Family policies in Quebec and in Ottawa in the late 1980s: two branches of the same tree?}

On the whole, in the 1960s and the 1970s, Ottawa and Quebec both encouraged gendered familialism through their limited menu of family-relevant policies, as neither government felt the need to assist families through the development of new institutional structures that would have made demotherization possible. The early 1980s started in a promising way: the issue of childcare was placed squarely on the federal government's agenda by the Abella Commission $^{91}$ on Employment Equality and the Cooke Task Force ${ }^{92}$ on Childcare

\footnotetext{
${ }^{91}$ In 1983 Ottawa established the Royal Commission on Equality in Employment, headed by Judge Rosalie Abella. The Commission released its report in 1984. Its main conclusions were that the demographic, social and economic patterns of Canadian society were changing and that women and minorities would form increasingly large segments of the labour force in Canada's future.
} 
(Jenson et al., 2003; Mahon and Phillips, 2002), and all three national party leaders pledged themselves to a national childcare program during the 1984 election campaign. Following the election however, the new government in place became more concerned with reducing the national debt than extending social programs and though it did not openly oppose the right of mothers to be economically active, it stressed that this was a decision to be made by individuals (Finkel, 2006). The new Conservative government ignored the request for publicly funded childcare in favour of for profit childcare centers and tax deductions. In 1987, Ottawa released a report that contradicted the Cooke Report and drafted Bill C-44, the Canada Child Care Act (CCCA). The CCCA proposed tax deductions to benefit forprofit childcare centers, but was mute on the establishment of national childcare standards. Unlike CAP moreover, the new bill put a ceiling on federal contradictions. Opponents mobilised against the bill, and the government let the draft die when it called the 1988 election (Friendly and Prentice; 2009; Jenson et al., 2003).

In the end, childcare retained its residual character and deductions to cover childcare costs were linked to the taxation system. Similarly, maternity benefits proved difficult to obtain and remained connected to the UI program. In a sense, the situation did not change much in the 1980s and the 1990s, as the different benefits introduced during that period did not challenge the gendered division of labour. The implicit assumption remained that it was 'natural' and even desirable that mothers raise the next generation of workers, without pay or financial aid (Finkel, 2006).

${ }^{92}$ Dr. Katie Cooke led the Cooke Task Force, along with three other experts. Cooke was a sociologist with a background in women's issues. 
The 1980s and 1990s nonetheless witnessed the introduction of new measures that supported the early stages of social reproduction, and that marked a transition from gendered, to implicit, familialism. The motherization of care work continued to prevail as neither governments initiated the development of state-funded, universally accessible childcare facilities. Government commitment to budgetary austerity reinforced Ottawa's preference for targeting the most needy as it converted three of its former child benefits under one program, the Child Tax Benefit (CTB), to help cushion the financial costs entailed by social reproductive work. The CTB, however, was only offered to low- income and middle-class families and upper-income families were left without any benefit. The CTB, along with the extended parental leave allowed an improved - yet still modest - level of economic defamilialization. The federal government also implemented policies that rewarded labour market attachment, but it did not put in place policies that helped parents to reconcile earning and caring work.

Though the provincial government did not offer measures that could have challenged the division of caregiving work, Quebec chose a different path by developing a coherent structure of benefits. Quebec made the choice to support the early stages of social reproduction with a set of universal allowances, the most popular being the allowance for newborn children (ANC). While designed with the objective of raising fertility, the ANC nonetheless mirrored the governments' effort to help new parents with the economic costs of the early stages of family-raising. 
Federal initiatives: between confusion and targeting

In the 1970s, while Ottawa had not completely eliminated the universality principle from child benefits, targeting principles began to emerge slowly. The full blossoming of these principles occurred in the late 1980s/early 1990s when Ottawa's concern with the national deficit combined with the campaign to reduce child poverty led the government to redirect resources to those 'in need'. As a result of this dual preoccupation, the patchwork of targeted allowances, credits and deductions introduced by the federal government during that time did not reflect a concern for the defamilialization and the demotherization of care work.

The late 1980s indeed witnessed a series of tax reforms that led to a new configuration of family-related credits and deductions. When the Income Tax Act was first introduced in 1918, a deduction for taxpayers with children under sixteen was built into the system. In 1987, the children's tax deduction was reduced and in the following year it was converted into a non-refundable child tax credit as part of the federal government's income tax reforms. Like the former children's tax exemption, the non-refundable child tax credit excluded poor families below the taxpaying threshold. In 1989, Ottawa announced the imminent demise of universal family allowances by requiring upper-income families defined as those whose earnings exceeded $\$ 50,000$ - to repay all of their benefit through the income tax (Baker, 1995, 2006; Lefebvre and Merrigan, 2003). Thus, from 1988 to 1993 , 
Canada retained both refundable ${ }^{93}$ and non-refundable tax credits for dependent children and a non-refundable credit for dependent spouses. Ottawa also retained the Child Care Expense Deduction (CCED) that was introduced in 1972.

In the end, the 1988 tax reform changes led to a confusing mix of allowances, credits and deductions: family allowances were now subject to a claw back (since 1973), the refundable child tax credit (introduced in 1978) remained in place (yet excluding upperincome families), the non-refundable child tax credit replaced the children's tax deduction and the CCED was raised. ${ }^{94}$ In practical terms, this meant that a large segment of the population received very little - if any - defamilializing benefits. Poor families with income below the taxpaying threshold were excluded from the non-refundable child tax credit, while well-off families did not receive the refundable child tax credit. Families not considered 'in need' or 'in danger of becoming in need' under CAP, who either chose to care for their children at home, or who could not provide receipts from their care providers, were not entitled to any type of federal support that would have defamilialize the economic costs of caregiving responsibilities. Upper-income families with earnings above $\$ 50,000$ no longer received family allowances. In a nutshell, Ottawa did not have a coherent menu of family-relevant policies that supported either social reproduction or fertility.

\footnotetext{
${ }^{93}$ As discussed in chapter 7, the refundable child credit was initiated in 1978, and it delivered its maximum amount to low-income families, a smaller payment to middle-income and nothing to the well-off.

${ }^{94}$ Ottawa raised the maximum tax deductions in 1988 from $\$ 2,000$ per child under seven (with a family maximum of $\$ 8,000)$ to $\$ 4,000$ a year for children under seven and $\$ 2,000$ for children seven to fourteen. These amounts were raised again for the 1993 tax year to $\$ 5,000$ and $\$ 3,000$ (Baker, 1995, 2006).
} 
The 1993 election brought new hopes with regards to development of childcare across Canada. The newly elected Liberal government had promised to dramatically expand childcare. This new opportunity for a pan-Canadian childcare program however never materialized (Friendly and Prentice, 2009; Mahon and Phillips, 2002; Mahon, 2009). Following a long period when childcare was off the federal political agenda, new steps towards the implementation of a national childcare program was announced. The 2003 Social Security Review (SSR), designed to reduce child poverty and to encourage people to stay off social assistance by offering them support, gave childcare a particular status. Childcare was viewed as having a double benefit: it supported the employment of lone mothers and it fought child poverty as quality care was presented as an important investment in early child development. Thus, the federal government shifted the discourse around childcare from the provision of quality childcare as a tool to help parents enter the labour market, or as a way to achieve better gender equality, to being an instrument of early childhood development (Jenson et al., 2003).

The early 1990s signalled a formal break with universality with a shift to a wholly incometested federal child benefit system (Battle, 2008). In 1993, Ottawa changed its benefit package to families with dependent children. The three programs designed to provide support for families with children - family allowances, the non-refundable amount (credit) for dependent children and the refundable child tax credit - were replaced with a single Child Tax Benefit (CTB). In order to finance this benefit, the government combined money from the former family allowance and the child tax credits into a new - and targeted- 
benefit for families with middle or lower incomes. The CTB was to offer limited resources to families with the greatest needs. In 1993, the maximum monthly payment was $\$ 85$ per child under eighteen and was paid to families with a net income of $\$ 25,921$ or less; families with income up to $\$ 70,981$ received partial benefits, while those with incomes over that amount did not receive any benefit (Baker, 1995, 2006).

Basing benefits on family income and targeting benefits to low and modest-income families was vindicated in terms of fairness, with a precise concern with negative labour market incentives. The objective of higher efficiency justified the introduction of a Work Income Supplement (WIS) designed to reinforce the incentives for low-income parents to participate in the labour market. In addition to the monthly benefit, an annual supplement of \$500 per family was paid to the 'working poor', regardless of the number of children. This amount was not extended to welfare recipients because, the federal government argued, working poor families had greater expenses than those not in the labour force.

The move away from universality left some parents without benefits, and thus without any type of social recognition of their contribution to society as parents. Indeed, before the introduction of the CTB, out of the four forms of family assistance measures, two were 'theoretically' universal: 1) the federal family allowances (though families earning $\$ 50,000$ and over repaid their entire benefit through the income tax) and 2) the non-refundable child tax credit (though families with income below the taxpaying threshold were excluded from credit). On the other hand, the non-refundable child tax credit was targeted toward low- 
income families, while the CCED was only offered to working parents (or full-time students) who could show receipts for payment. With the introduction of the CTB, the federal family allowances and the non-refundable child tax were blended into one program. As a result, the goal of vertical redistribution completely replaced that of horizontal redistribution.

Perhaps, the complexity of the reform made it not immediately obvious for many Canadian families how the different components of the reform interacted, and whether as a result, they ended up in a better or worse financial position. What stood out in the 1988 and the 1993 reforms, however, was the idea of a social institutional context that encouraged labour market participation and that supported economic defamilialization for a limited number of families. Accordingly, not only were governmental benefits increasingly targeted towards low- income households, they were also designed to support 'active' families. Thus, the WIS was only made available to families who had some form of attachment to the labour market. Similarly, the CCED, the most 'universal' instrument to support families with their childcare expenses, was only offered to parents who worked on the market or who pursued an education.

This preoccupation with labour market activity was not accompanied by the development of policy instruments that favoured a redistribution of care work between the state, mothers and other family members. This is made obvious not only by the lack of affordable, universally accessible and publicly funded childcare services, but also by the absence of a 
coherent program of parental leave and benefits. Since its implementation in 1971, the Canadian parental leave has been linked to the Unemployment Insurance (UI) program, thus making it difficult for some women to qualify. In 1990, the Parental Benefit Program (PBP) introduced 10 weeks of paid leave available for sharing by qualifying parents. Neither a daddy month or even paternity leaves were not part of the equation. For many families, parental leave was welcomed as an extension of the existing maternity leave. With the introduction of the PBP, both parents had to serve the two-week waiting periods. Replacement rates for both maternity and parental benefits matched those for regular UI benefits. While these were initially set at 60 percent in 1990, replacement rates for regular and special benefits were reduced to 57 percent in 1993 and to 55 percent in 1994 . That year, claimants with low earnings (less than 50 percent of maximum insurable earnings) and those supporting dependants became eligible for special 'dependency rate' of 60 percent.

\section{Quebec's first family policy: between pronatalism and universalism}

In December 1987, the Quebec government issued a statement of direction on family policies that provided the basis for increasing the budget allocated to families. In the light of the alarmist demographic discourse shared by politicians and demographers about Quebec's historically low fertility, the government of Quebec introduced a coherent threepronged family policy that pursued clear pronatalist objectives (LeBourdais, 1989; Maroney, 1992). The preoccupation with the need to increase births was not shared by the federal government. As opposed to the patchwork of (targeted) family-related measures 
introduced by Ottawa, in Quebec, most of the measures offered were universal despite the shared concern with budgetary austerity. As a result, every family was presented with the same opportunities to benefit from defamilializing measures.

Quebec's family policy contained three types of allowances. The first, the allowance for newborn children (ANC), granted women $\$ 500$ for the birth of each of their first two children and $\$ 3,000$ for the third and subsequent births. For the first child, the allowance was paid at birth; for the second child, it was paid in two annual installments of $\$ 500$, and for the third child and following children, the benefit was paid in quarterly installments of \$400. The allowance for each additional child for a family that already had two children was thereafter increased every year, reaching $\$ 8,000$ in $1992 .{ }^{95}$ The ANC was unique in the sense that it recognized that the costs associated with the birth of a second or a third child were greater than the economies of scale resulting from an increasing in family size. Although a second child is usually less costly than the first in terms of commodities (the second child can use the same crib as the first, play with the same toys and ride in the same stroller) the birth of a second child increases the parental burden in the sense that one parent might leave the labour market for an extended period, or the couple might resort more frequently to outside help for domestic tasks (Baril et al., 2000).

The province also provided two provincial allowances to every family with young children: the Quebec Family Allowance (QFA) paid to all children under 18 (implemented in 1974)

\footnotetext{
${ }^{95}$ From 1993 on, none of these amounts were indexed, so that fiscal benefits and transfers were reduced due to inflation, though inflation remained low at the time (Duclos et al., 2001).
} 
and the Allowance for Young Children (AYC), ${ }^{96}$ introduced in 1989 as a non-taxable child allowance that acknowledged that young children of preschool age had specific needs that involved additional costs. The two allowances, paid in addition to the federal benefits, varied according to the child's rank in the family. Along with the baby bonus, these allowances were universal.

Table 6 - Allowance for newborn children, family allowance and allowance for young children, annual amount in dollars per child, Quebec

\begin{tabular}{|lccc|}
\hline $\begin{array}{l}\text { Child's } \\
\text { rank }\end{array}$ & $\begin{array}{c}\text { Newborn child } \\
\text { allowance }\end{array}$ & Family allowance & $\begin{array}{c}\text { Allowance for young } \\
\text { children }\end{array}$ \\
\hline $1^{\text {st }}$ & 500 & 130.92 & 117.24 \\
\hline $2^{\text {nd }}$ & 1,000 & 174.48 & 234.36 \\
\hline $3^{\text {rd }}$ & 8,000 & 218.16 & 585.96 \\
\hline $\begin{array}{l}4^{\text {th }} \text { and } \\
\text { subsequent }\end{array}$ & 8,000 & 261.32 & 585.96 \\
\hline Source: Baril et al., $(2000)$. & & \\
\hline
\end{tabular}

While recognising that all families had similar needs regardless of income, the allowances supported the early stages of child development through measures that allowed economic defamilialization. In addition to these allowances, the provincial government offered three other measures to support families: ${ }^{97}$ 1) income tax assistance; 2) child-care assistance; and 3) as part of its strategy to reduce poverty, a social safety net for the poorest families as well as the Parental Wage Assistance (PWA) program. With regard to income tax assistance, families could claim a non-refundable tax credit for dependent children equal to 20 per cent of the amount of the recognized essential needs, evaluated at $\$ 2,600$ for the first

\footnotetext{
96 The AYC replaced the former 1982 Availability Allowance (AA).

${ }^{97}$ The next three paragraphs draw heavily on Baril et al., 2000.
} 
child and $\$ 2,400$ for the second. A specific tax credit was also offered to single parent families and to the parents of children pursing post-secondary education (Baril et al., 2000).

Childcare assistance was presented in the form of a refundable child tax credit for childcare expenses that compensated for a portion of the childcare expenses. The tax credit rate varied across income levels, from 75 per cent for low-income families to 26.4 per cent for families with income above $\$ 48,000$. Financial assistance for childcare was also offered indirectly though the Office des services de garde à l'enfance (OSGE), a government agency mandated to determine childcare needs and to ensure childcare quality. The OSGE granted subsidies directly to childcare centers for their operations. It also offered a program of financial relief and assistance to low- income families (Baril et al., 2000; Tougas, 2002).

The government assisted families in financial need for their basic necessities, providing them with a safety net in the form of a guaranteed minimum income. In conjunction with the family allowances and federal CTB, social assistance programs financed the essential needs of children in cases where family resources were insufficient. In addition, the PWA supplemented the income of low-income earners who had at least one dependent child. It provided benefits to working low-income families to compensate for their loss of social assistance benefits. Once they no longer received social assistance, families could benefit from a work-income supplement to boost their income (Baril et al., 2000). 
In total, the cost of the Quebec government's family assistance measures was estimated at \$2.7 billion in 1995 (Baril et al., 2000). Despite those impressive numbers, Quebec's family policy did not allow demotherization of care work, as the government adopted a passive attitude regarding the use of childcare. While the Quebecois family policy package combined horizontal and vertical redistribution, it clearly favored the former, because of its universal character. The 1988 family policy recognized that each child had the same societal value and the same basic needs. Yet, the 1988 was myopic in the sense that it did not address the issue of the long-term process of child-rearing. Rather, the baby bonus component of the policy supported fertility, more than social reproduction. Doing so, it encouraged equity over equality and the motherization of care work through economic defamilialization. As a result, it did not have a positive long-term effect on births.

\section{The (improbable) effect of the baby bonus on fertility decisions in Quebec}

The literature on the possible effect of baby bonuses on fertility is abundant, but the conclusions are sometimes contradictory (see for instance, Day and Dowrick, 2010; Drago et al., 2009; Lain et al., 2009; Mathieu, 2013; Parr and Guest, 2011). There are at least two reasons why a program such as the baby bonus might affect the tempo, instead of the quantum of births (Parent, 2008). First, the existence of the bonus allows relieving some of the financial constraints entailed by the birth of a child. For instance, some couples who already have one child - and who wish to have more - might prefer to space their children closely, but because of the financial burden occasioned by the birth of another child, choose to postpone the timing of the second pregnancy. The baby bonus partly eliminates this 
constraint. Second, many couples may be worried that the program will not be offered for a long time and thus decide to have a child earlier than they would otherwise have.

There is yet another possibility regarding the effect of the bonus on fertility. It could be the case, as Daniel Parent (2008) has argued, that heterogeneous groups of women react differently to a specific policy such as the baby bonus. Some women may choose to never have children, independently of the extent of state support. Conversely, there are women who will have children, regardless of the menu of services and benefits offered to them. These two groups of women, according to Parent (2008) are not likely to respond to a pronatalist policy, such as the baby bonus. The third group of women might be influenced by the program in their decision to have more than two children. When examining the effect of the baby bonus on fertility outcomes, there is yet a fourth group of women, who may react to the policy, but not the way policy makers thought they would. These women may not have more children because of the policy, but will change the tempo of their births.

In their 2001 study, Duclos et al. showed that the 1988 policy in Quebec had a positive effect on the transition to motherhood, but they could not determine whether the benefit accelerated the decisions about having children or if it had an impact fertility realization. The most vivid defence of the positive effect of the baby bonus on fertility in Quebec came from Kevin Milligan (2002, 2005), an economist from the University of British Columbia. In his 2005 study, Milligan implemented a quasi-experimental empirical strategy using vital statistics and micro-data derived from the public-use files of the Canadian Census. He 
then showed the existence of a "strong, positive, and robust effect of the policy on fertility" (Milligan, 2005: 540). Milligan estimated that the fertility of those eligible for the new program increased by 12 per cent on average, and by 25 per cent for those eligible for the maximum benefit (that is, after having a third or any subsequent child).

There are major drawbacks to Milligans's argument. Table 7 shows that births of rank 1 started to increase as early as 1986, and that births of rank 2 and over began to increase the very year the policy was implemented. Once we take into consideration the nine months of pregnancy in addition to a reasonable delay for the population to consider the advantage of the baby bonus, it seems improbable that the bonus caused fertility rates to increase in 1988. Similarly, Milligan did not account for the fact that birth rates began to decrease in Quebec before the abolition of the program in 1997. Between 1992 and 1997, births of rank 1 decreased steadily, while between 1993 and 1997, the same trend could be observed (with the exception of 1994) with second and third births. Thus, fertility rates began to decrease precisely when the baby bonus became the most generous, after 1992 . 
Table 7 - Fertility rates by birth order, Quebec, 1985-1989

\begin{tabular}{lcccc}
\hline Year & Rank 1 & Rank 2 & Rank 3 & Rank 4 and + \\
\hline $\mathbf{1 9 8 5}$ & 0.625 & 0.526 & 0.183 & 0.06 \\
$\mathbf{1 9 8 6}$ & 0.648 & 0.497 & 0.169 & 0.06 \\
$\mathbf{1 9 8 7}$ & 0.656 & 0.485 & 0.16 & 0.057 \\
$\mathbf{1 9 8 8}$ & 0.693 & 0.496 & 0.166 & 0.06 \\
$\mathbf{1 9 8 9}$ & 0.736 & 0.52 & 0.188 & 0.065 \\
\hline
\end{tabular}

Source: ISQ (2013).

Most importantly, Milligan's study did not address the issue of the calendar of births. In light of the 1982 economic recession, many women probably decided to postpone the timing of pregnancy but by the late 1980 s, as the province recovered from the economic slowdown, were ready to reconsider the option to give birth. Conversely, the unstable economic context of the early 1990s may have had a negative influence on fertility, as was the case in Scandinavia. Thus, there was the possibility of interaction effects between the economic context and the baby bonus. In a context of social conservatism, where women would have been faced with the irreconcilable choice between earning and caring, it is unlikely that the baby bonus would have substantially raised fertility. Another interaction effect could have occurred between the introduction of the baby bonus in 1988 and the CCED, the federal program intended to assist parents when purchasing childcare services. As observed, Ottawa raised the maximum tax deductions for the CCED in 1988, from $\$ 2,000$ per child under seven to $\$ 4,000$. It is difficult to determine whether couples reacted more to the baby bonus than to another policy implemented at the same time. 


\section{Discussion and conclusion}

The 1980s and the 1990s saw the emergence of two distinctive approaches to supporting families, and couples were faced with mixed messages from Ottawa and Quebec. While Ottawa favoured targeted measures, Quebec introduced a universal family policy. While Ottawa began to offer benefits that supported, albeit modestly, the reconciliation of work and family responsibilities (with the introduction of the parental leave and the increase in the CCED), Quebec pursued pronatalist objectives. While Ottawa made changes in existing family benefits within the institutional structures in place, Quebec put in place a system of allowances that was not tied to the taxation system.

This chapter opened by questioning the effect of the ANC on fertility in the late 1980s. Given that the Nordic and the Anglo-Saxon countries also witnessed a rising number of births at the time, we need to be cautious before concluding to the existence of causal links between the introduction of one specific policy and fertility outcomes. In addition, since fertility began to increase before 1988 and started to decrease as early as 1992, there are reasons to believe it was not the bonus that triggered the fertility increase of the late 1980s.

The baby bonus did not provide women with the necessary means to combine paid and caring responsibilities. Quebec directly encouraged fertility - more than social reproduction - by paying women to produce new citizens. The examination of data on women's labour market participation indicates that women were increasingly active in the labour market between the late 1980s and the mid-1990s. At the time, the relationship between labour 
market participation and fertility, at the macro level, had already been reversed: countries with relatively high fertility rates also had high women's activity rate. The three main measures introduced in Quebec's first family policy, the ANC and the two universal allowances, did not provide women with any measures to ease the reconciliation between earning and caring responsibilities. Thus, in answer to the question raised about the presumed correlation between the introduction of the baby bonus and the small baby boom of the late 1980s, this chapter concludes that the ANC was only one element, among others, to have encouraged women to give birth. 


\section{CHAPTER 9}

\section{ON THE ROAD TOWARDS BETTER GENDER EQUALITY: QUEBEC'S FERTILITY REGIME SINCE 1997}

The gender equity theory is especially helpful for explaining patterns of social reproduction in Quebec since the late 1990s. Though the federal government continued to lack vision for the development of a coherent family policy, Quebec chose to support the defamilialization and the demotherization of care work through a family policy that supported social reproduction. The combination of a dynamic labour market and new demotherizing measures made it possible for women to better realize their fertility intentions without sacrificing their careers. After the last segment of Quebec's second family policy became effective in 2006, young women continued to increase their presence in the labour market, and though they postponed maternity, they had more babies. The increasing number of births after 2005 was the result of both a change in the timing of births (because of the shorter intervals between births) and an increase in the total number of children born. More than anything, it was the result of a gender-egalitarian environment in which caregiving responsibilities became more equally shared between the state, mothers and fathers.

\section{From decreasing fertility in the mid-1990s to rising births after 2005}

Between 1995 and 2010, Quebec and Canada experienced u-shaped fertility trends (figure 17). In Quebec, birth decreased between 1995 and 2000, then plateaued and rose again from 2005 through 2009. In the other provinces, fertility rates steadily decreased between 1995 and 2002, plateaued between 2003 and 2005 and increased from 2006 through 2009. 
Fertility trends thus corresponded roughly in Quebec and in the ROC. In Quebec, the sharpest decline in fertility and birth rates (table 8) occurred between 1996 and 1998. Though this observation may seem surprising given the introduction of Quebec's new family policy in 1997, the last component of the policy, the new parental leave, was only put in place in 2006 and fertility rates in Quebec have been higher than in the other provinces since then. Other countries also experienced rising fertility in the early 2000 s. Among the socio-democratic and liberal countries, these include Norway, Sweden, New Zealand and the United Kingdom (figure 18). The u-shaped fertility curve was thus not singular to Quebec and Canada.

Figure 17- Fertility rates in Quebec and the Rest-of-Canada, 1995-2010

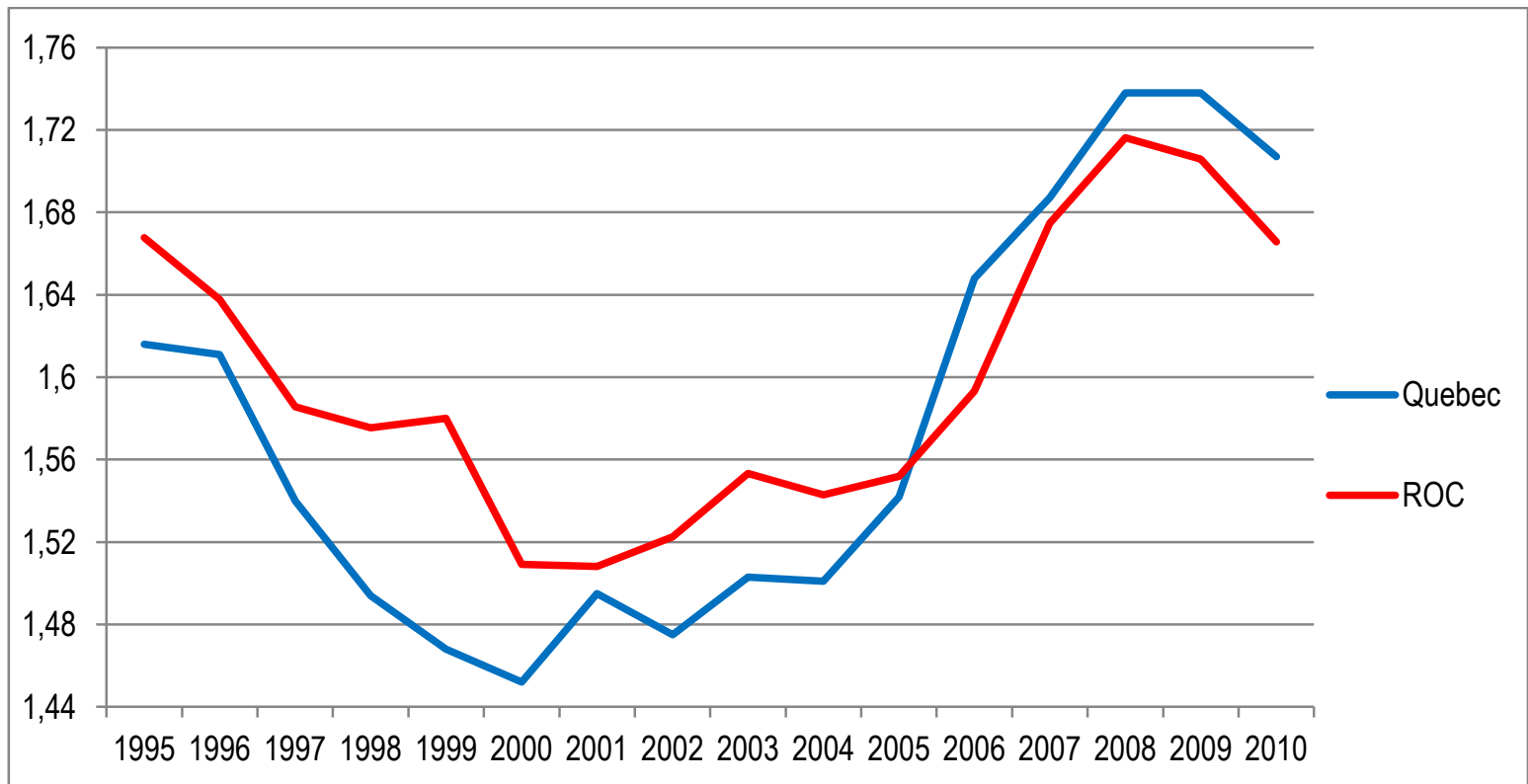

Sources: For Quebec, ISQ (2013). For the ROC, from 1995 to 1996, Statistics Canada, (2006); from 1997 to 1999, Statistics Canada (2008a); from 2000 to 2010, Statistics Canada (2008b). For the ROC, the calculations were all made by the author and they exclude Yukon, the Northwest Territories and Nunavut. 
Table 8 - Birth and fertility rates in Quebec, 1995-2010

\begin{tabular}{lcccc}
\hline & Birth rate & Difference & Fertility rate & Difference \\
$\mathbf{1 9 9 5}$ & 12.1 & & 1.62 & \\
$\mathbf{1 9 9 6}$ & 11.7 & -0.4 & 1.61 & -0.01 \\
$\mathbf{1 9 9 7}$ & 11 & -0.7 & 1.54 & -0.07 \\
$\mathbf{1 9 9 8}$ & 10.4 & -0.6 & 1.49 & -0.05 \\
$\mathbf{1 9 9 9}$ & 10.1 & 0.3 & 1.47 & -0.02 \\
$\mathbf{2 0 0 0}$ & 9.8 & -0.3 & 1.45 & -0.02 \\
$\mathbf{2 0 0 1}$ & 10 & 0.2 & 1.50 & 0.04 \\
$\mathbf{2 0 0 2}$ & 9.7 & -0.3 & 1.48 & -0.02 \\
$\mathbf{2 0 0 3}$ & 9.9 & 0.2 & 1.50 & 0.03 \\
$\mathbf{2 0 0 4}$ & 9.8 & -0.1 & 1.50 & 0.00 \\
$\mathbf{2 0 0 5}$ & 10.1 & 0.3 & 1.54 & 0.04 \\
$\mathbf{2 0 0 6}$ & 10.7 & 0.6 & 1.65 & 0.11 \\
$\mathbf{2 0 0 7}$ & 11 & 0.3 & 1.69 & 0.04 \\
$\mathbf{2 0 0 8}$ & 11.3 & 0.3 & 1.74 & 0.05 \\
$\mathbf{2 0 0 9}$ & 11.4 & 0.1 & 1.74 & 0.00 \\
$\mathbf{2 0 1 0}$ & 11.2 & -0.2 & 1.71 & -0.03 \\
\hline S0ur $:$ & & &
\end{tabular}

Source : ISQ (2013). 
Figure 18 - Fertility rates in selected Nordic and Anglo-Saxon countries and Quebec, 1995-2010

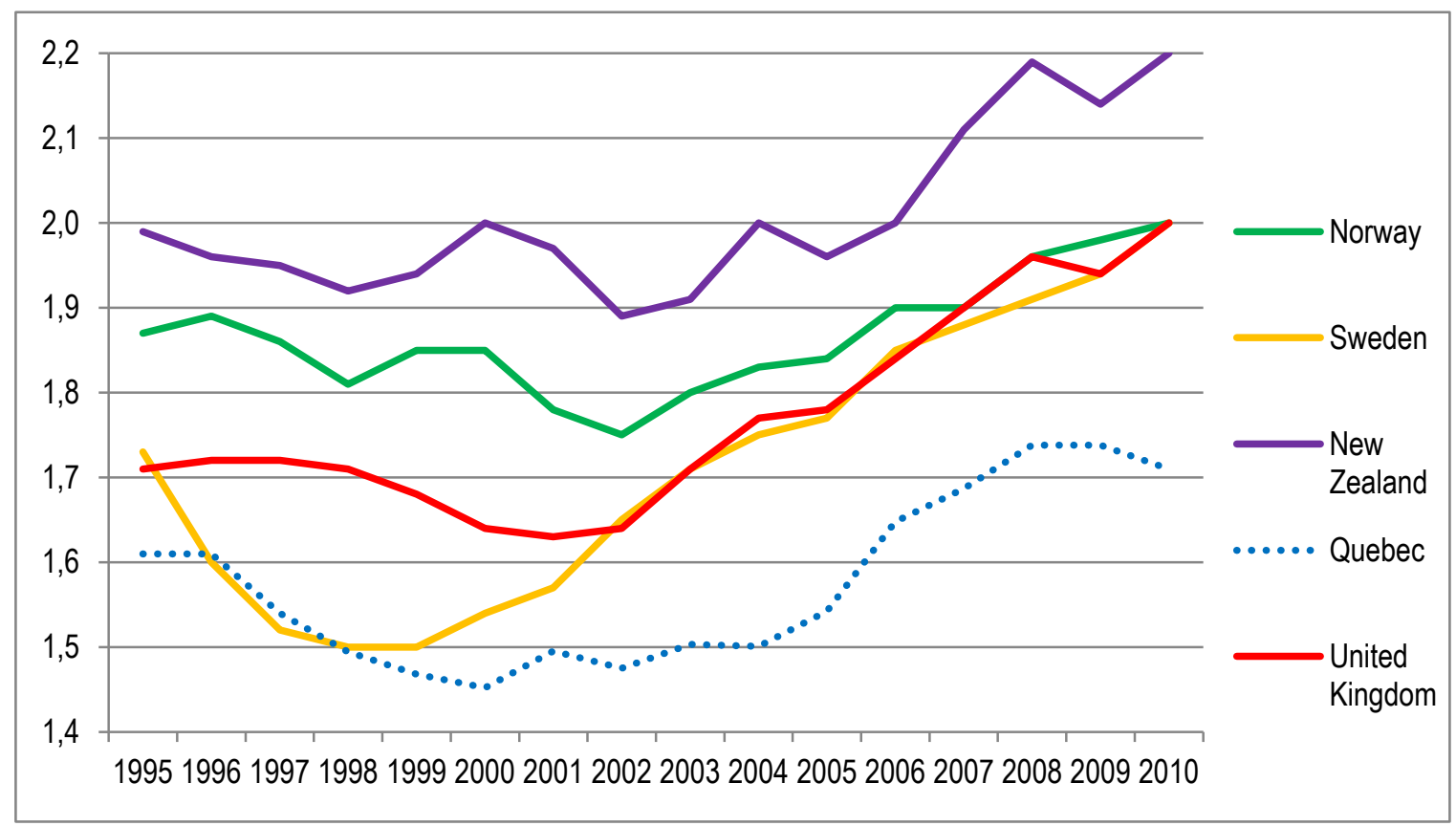

Source: ISQ, 2013 and Worldbank website, 2013.

The previous chapters unveiled the complexity of the connections between the economic context and fertility trends. Since the Quiet Revolution, unemployment has systematically been higher in Quebec than in the ROC, while fertility has remained lower. The economic recession of the 1980s seemed to put a damper on births, while the effects of the economic climate in the early 1990s remained unclear. Economic activity is obviously not the sole determinant of fertility decisions, but in some places, such as in Scandinavia, employment has been correlated with the transition to motherhood. In Quebec women's increased presence in the labour market from the mid-1990s through 2000 occurred in tandem with decreasing fertility (figure 19). At the outset, this observation seems to support the idea of incompatibility between productive and reproductive work. Perhaps this was the case in the 
late 1990s. Services that demotherized care work during the first few years of motherhood were relatively scarce at the time. Bushnik (2006) reports that only 44 per cent of children were in non-parental childcare in Quebec in 1994-1995. The fertility drop of the late 1990s could also reflect the overall instability of the labour market. Unemployment rates of adults of prime childbearing remained relatively high during that period (figure 20). As youth unemployment fell in the early 2000s, the number of births picked up (figure 19). In addition, the steady rise in fertility and birth rates that began in 2005 was not accompanied by a clear downward trend in young women's activity rate, at least between 2005 and 2007 , when birth and fertility rates rose the most.

Figure 19 -Relationship between the activity rate of women aged 25-34 and fertility rate in Quebec, 1995-2010

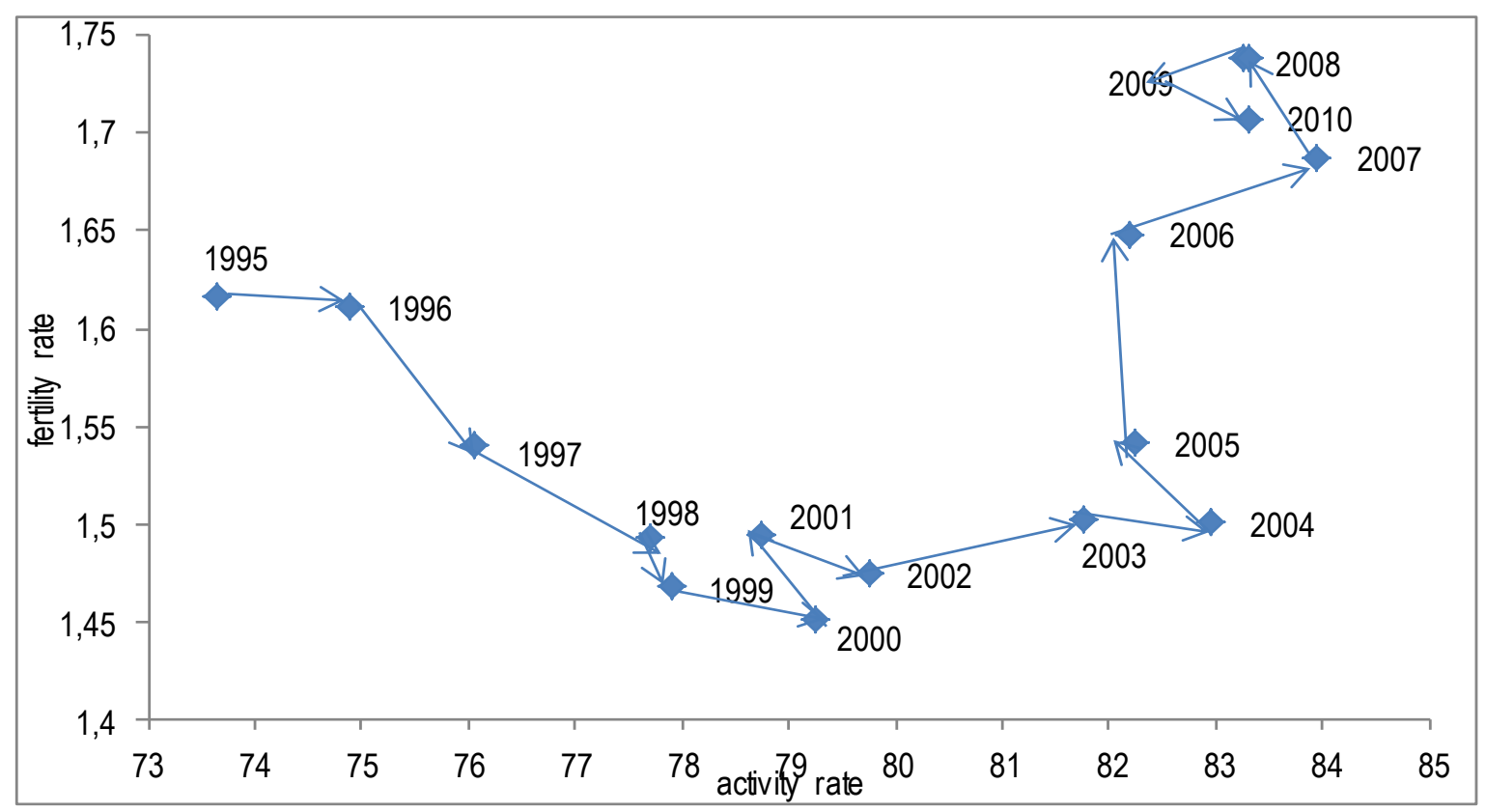

Source: ISQ, 2013 and Statistics Canada (2013b). The data were compiled by the author and are the average activity and employment rates of women aged 25-29 and 30-34 
Figure 20 - Unemployment rates of men and women in Quebec, aged 25-34, 1995-2010

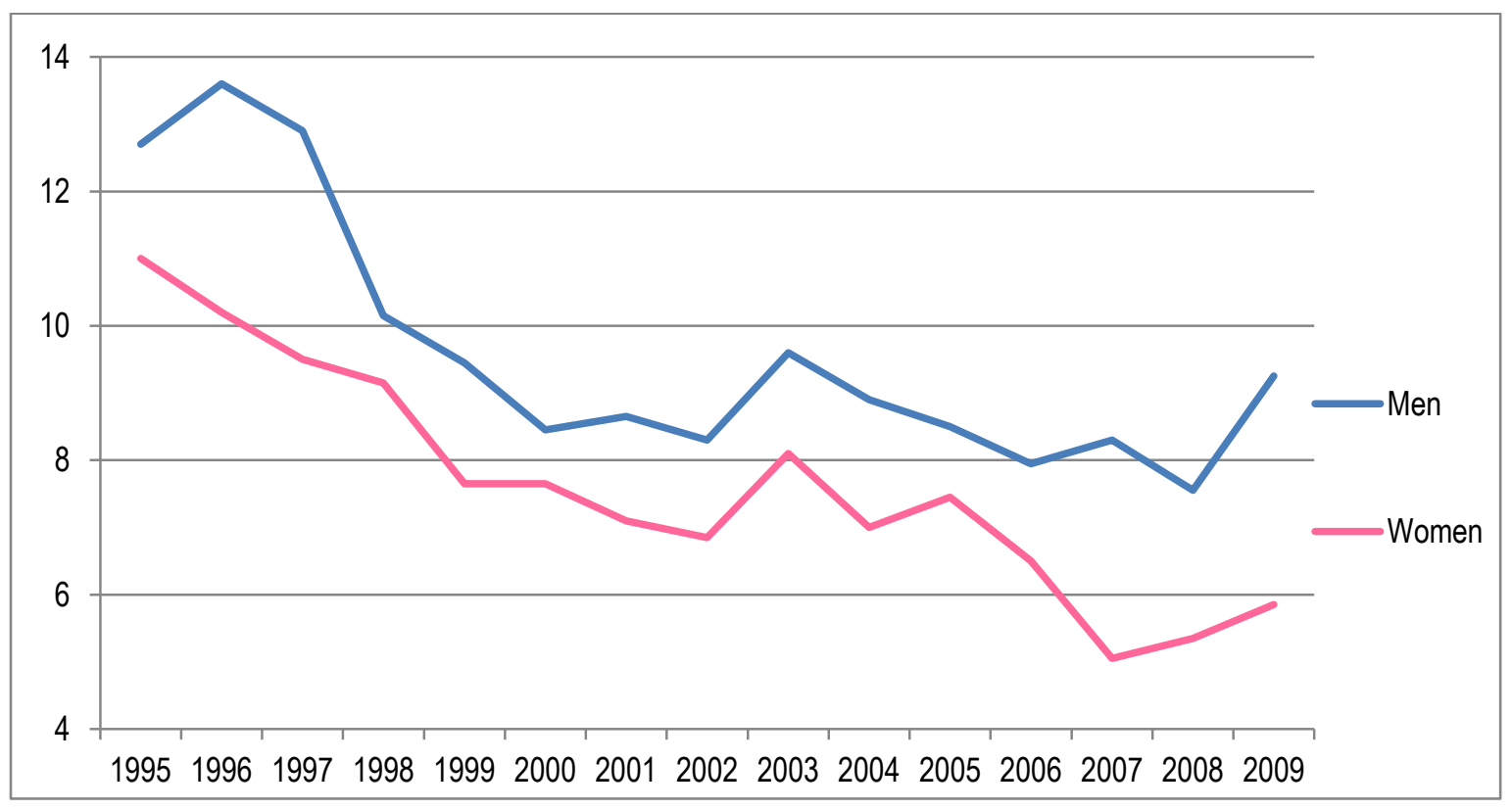

Source: Statistics Canada (2013b). The data were compiled by the author and are the average unemployment rates of men and women aged 25-29 and 30-34.

The complexity of the articulation between labour market activity and fertility is further reflected in the timing of family formation. While young women experienced growing employment rates, they continued to postpone the transition into motherhood. As noted in the previous chapter, only since the 1990s have women aged 30-34 been the group with the second highest birth rate. Furthermore, starting in 2000, births rates in the older age group (30-44) increased year after year. The fact that mature women have recently had a high number of births suggests the existence of new patterns of life-transition characterised by a postponement of motherhood, rather than a 'catching-up effect' for older women who wished to have children, but who considered the initial institutional context to be unfavorable to motherhood. 
Indeed, though women continued to postpone the transition to motherhood, more families chose to have a third child between 2005 and 2009 (figure 21). Rising fertility in that context can be explained by the decreasing intervals between births. Between 1995 and 2000, as total fertility decreased, intervals between births were relatively long and fewer women had third or fourth children. Conversely, between 2005 and 2009, shorter birth intervals led to the birth of more third and fourth children (figure 21). Hence, after 2005, the fertility increase was not solely the result of a calendar effect triggered by the shorter spacing of births.

Figure 21- Fertility rates by birth order, for children of rank 3 and over, Quebec, 1995-2010

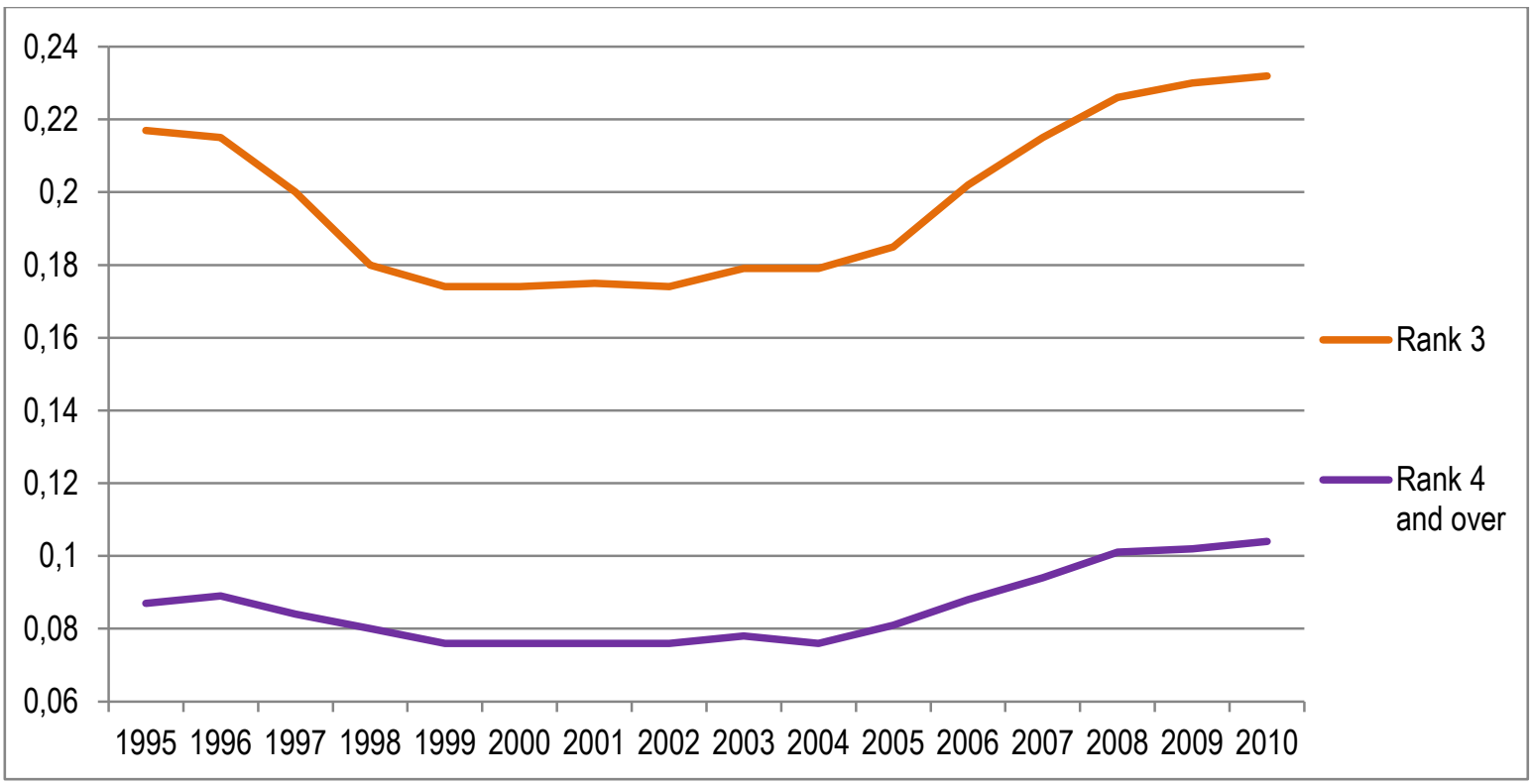

Source: ISQ (2013).

Marriage grew in popularity in year 2000 in Quebec, probably as a result of a millennium effect since marriage rates dropped again in 2001. Divorce peaked in 1995. Given the low 
prevalence of marriage in Quebec, the correlation between divorce and fertility is impossible to theorize: common-law partners obviously cannot divorce. Births out of wedlock continued to increase, while births from undeclared fathers remained low. Finally, there seems to be some symmetry between the highs and lows for abortion rates and fertility. For instance, abortion rates were very high between 1996 and 1998, at a time birth and fertility rates were decreasing; conversely, as abortion rates started to decline from 2004, births increased. Despite these observations, a higher number of abortions does not inherently mean women are having less children; it can also mean that a larger proportion of women are using abortion as their last contraceptive option. Moreover, an age-group analysis of fertility rates reveals that abortion rates for women aged 24 and under were at their lowest between 2008 and 2010, at the time these women had relatively low birth rates. Conversely, among older women, both abortion and fertility rates remained high after 2005 .

To summarize, the period between 1995 and 2010 was characterised by the predominance of two fertility regimes. On the one hand, between 1995 and 2000, women increased their presence in the labour market, while they reduced their fertility by having fewer third and fourth children and by waiting longer intervals between pregnancies. On the other hand, between 2005 and 2009, women of prime childbearing age secured their position in the labour market by maintaining high activity and low unemployment rates. Women also spaced their pregnancies more closely while choosing more often to have a third child. Finally, during both periods, an increasing proportion of children were born to unwed parents, as marriage decreased in popularity and divorce rates remained high. 


\section{Family-relevant policies in Canada and Quebec since 1995}

The difference in the design of family-relevant measures between Quebec and the federal government was particularly marked after the 1990 s. ${ }^{98}$ Ottawa's inability to develop a clear family policy ${ }^{99}$ meant that the federal government continued to offer a limited set of targeted family-relevant measures that supported implicit familialism. Conversely, Quebec's second family policy created a socio-institutional context that favoured the transition from implicit familialism to a hybrid model of institutional and degendered/generational familialisms. In the context of a prosperous economy and of increased gender equality, women maintained good activity rates, along with rising fertility. While not ignoring the difficulty of drawing correlations between the introduction of new policies and changes in fertility trends, these observations are in tune with the gender equity theory to suggest that the socio-institutional context in Quebec since the early 2000s has moved towards a 'universal care giver model' (Lister, 1994), where both partners share caregiving responsibilities.

\footnotetext{
${ }^{98}$ To be clear, I am not arguing that every provinces offer similar family-relevant policies. Programs like childcare are determined by the provinces and show substantial variation. As an example, within the ROC, Ontario is the only province that offers kindergarten for all four year olds (Friendly et al., 2013).

${ }_{99}$ During the 2004 federal election campaign, the Liberal Party promised to build a national universal childcare program, that they called the Foundations program. The Liberals even committed to spend about $\$ 1$ billion a year during the first phase of this program. The Liberals however, were elected with a minority. By the time the government fell in 2005, all the provinces had agreed to move forward and by January 2006 , Canada came close to having a national early childhood education and childcare system. Following the 2006 election, however, the newly elected Conservative government cancelled the Foundations program, arguing that that it would not provide 'choice' for parents.
} 
Ottawa's family relevant policies since 1995: different lyrics, same melody

Ottawa's initiative (or more accurately lack thereof) regarding the development of a panCanadian family policy is one of a repeating story. New agreements and policies implemented since the 1990s, ${ }^{100}$ from the National Children's Agenda (NCA) to the extension of the parental leave, have been developed within existing legislative structures. Each new family-relevant initiative has also been either embedded into - or intertwined with - other agendas. Accordingly, discussion around childcare has been tied to the broader issue of health. It has also been almost impossible to address child benefits and childcare services separately, outside of Quebec. The same observation applies to the parental leave programs. Even after 1997, when the UI program was transformed to become the Employment Insurance (EI), eligibility criteria for parental leave continued to be based on the premise of standard employment. As a result, part-timers, students, and precarious workers, among which women are disproportionately represented, have continued to be excluded from the program.

\footnotetext{
${ }^{100}$ While most of these policies reviewed in this section do not apply to Quebec, this discussion is nonetheless important. Obviously, Quebec is part of the Canadian confederation and an examination of Ottawa's initiatives, even when they do not directly affect the well-being of Quebecois, gives a snapshot of the sociopolitical pulse of the country. Furthermore, the discussion of Canada's policies gives ground for comparison between the Canadian and the Quebecois fertility.
} 
-The National Children's Agenda

In 1997, the federal and provincial governments concluded an agreement to work together to develop the National Children's Agenda (NCA) (Battle and Torjman, 2002), ${ }^{101}$ an umbrella concept that embodied a range of programs and benefits geared towards the broad goal of ensuring that children were healthy. In fact, as discussed above, the arguments for family-relevant policies, and more precisely childcare, were framed differently from the 1970s through the early 2000s, shifting from a focus on women's rights and gender equality to the need for 'investing' in children (see among others Amoroso, 2010; Jenson, 2000; Jenson, 2009). Though the NCA acknowledged the need to reform family-relevant policies, it did not provide the structural architecture to do so (Battle and Torjman, 2002; McKeen, 2007). The NCA concretized through three major policy initiatives: 1) the National Child Benefit (NCB)/ Canada Child Tax Benefit (CCTB); 2) two early childhood development agreements -the Early Childhood Development Agreement (ECDA) and the Multilateral Framework Agreement on Early Learning and Childcare (MFAELC); and 3) the expansion of the maximum length of parental benefits under EI, from six months to one year. While the intergovernmental agreements were federally initiated and orchestrated, the programs themselves fell under provincial/territorial jurisdiction, thus allowing a patchwork of benefits and services (Mahon, 2009; McKeen, 2007).

\footnotetext{
${ }^{101}$ Two years later, in 1999, the federal and the provincial/territorial governments (except for Quebec) agreed to the Social Union Framework Agreement (SUFA), which allowed both levels of government to work cooperatively to support the delivery of social programs and services.
} 
As part of the NCA, the National Child Benefit (NCB) was introduced in 1998. The new benefit reflected the government's recurrent concern with targeting and efficiency. The NCB pursued the objective of reducing the depth of child poverty, of promoting parental attachment to the labour market and of reducing overlap and duplication by harmonizing programs between Canadian and provincial programs. ${ }^{102}$ The NCB comprised a base benefit, the Canada Child Tax Benefit (CCTB) in replacement of the former Canada Tax Benefit (CTB), with the exact same parameters as those prevailing in 1993. In other words, rather than viewing child rearing as a benefit to society as a whole, the benefit retained the focus on child poverty and activation of those on social assistance (Mahon, 2009; Mahon and Phillips, 2002). The innovation was - and this is the second part of the NCB initiative that the amount of working income supplement was converted into an income-tested National Child Benefit Supplement (NCBS) independent of the source of income, paid work, or else. The Work Income Supplement (WIS) was thus replaced by the NCBS paid to all low-income families, as part of the CCTB. The provinces were invited to claw back the equivalent amount from payments to social assistance recipients. As a result, in most provinces, families receiving provincial social assistance saw no increase in their public financial support because child-related social assistance benefits were cut dollar for dollar with the amounts provided by the federal government. The provinces agreed to 'reinvest' the money freed up in provincial child benefits or services for children in low-income families: provinces were invited, but not forced, to invest the funds saved in social services for children.

${ }^{102}$ Commenting on that last objective, Lefebvre and Merrigan (2003) argued that the NCB actually added a layer of complexity- the coordination of federal and provincial support levels. 
Child benefits and childcare services were thus brought to the same mix in an unusual manner. Mahon and Phillips (2002) noted that in Ontario and in New Brunswick, the NCB funds were reinvested to expand unlicensed childcare. While tax credit could be devoted to childcare, it could also be used for other services or additional income support for the working poor or those on social assistance. The implementation of childcare service was thus a possibility, among others. No statement of intent was formulated either by the federal or the provincial/territorial governments to provide for a universally accessible childcare program.

The second agreement that was part of the NCA, the Early Childhood Development Agreement (ECDA), was signed in 2000 by Canada's First Ministers (again with the exception of Quebec). The agreement provided, in theory, a foundation for a national childcare strategy, but since it did not require investment in childcare, it did nothing in practice to move in this direction. The ECDA committed the federal government to transfer $\$ 2.2$ billion over the next five years, with the funds to be invested in any of four areas, one of which was childcare. ${ }^{103}$ The agreement aimed "to promote early childhood development so that, to their fullest potential, children will be physically and emotionally healthy, safe and secure, ready to learn, and socially engaged and responsible" (Treasury Board of Canada, 2013). As a result, childcare was subsumed under services for early childhood development. Three years later after the ECDA, the provincial and federal governments reached the Multilateral Framework Agreement on Early Learning and Childcare

\footnotetext{
${ }^{103}$ The other three areas are 1) healthy pregnancy, birth and infancy, 2) parenting and family supports and 3) community supports.
} 
(MFAELC), under which Ottawa was to provide new fund to help provincial governments improve access to affordable childcare programs and services. However, the program did not require the provinces/territories to invest matching funds, as they had been under the Canadian Assistance Plan (CAP), and they were free to select from a broad menu of early learning and care programs and funding models (Mahon, 2009).

In the early 2000s, Ottawa finally committed to invest $\$ 5$ billion to create a pan-Canadian ECEC system based on the QUAD principles (quality, universally inclusive, accessible, and developmental). ${ }^{104}$ The QUAD agreements had a number of serious flaws, however, one of which is that they made provision for any government to terminate its involvement with one year's notice. ${ }^{105}$ Following the election of the Harper Conservatives in 2006, Ottawa announced the termination of the agreements, arguing that parents should be entitled to choose for themselves the care arrangement they preferred for their children. The new government introduced Universal Child Care Benefit (UCCB), to replace the child care bilateral agreements. The UCCB provides $\$ 100$ per month per child for all families with children under the age of six, to support them with the costs of their childcare choices. ${ }^{106}$ Nevertheless, the money can just as well be used to buy whatever the parents want, not necessarily childcare services. For the second time, childcare services and childcare benefits were thrown into the same basket. Though the substitution of the QUAD

\footnotetext{
${ }^{104}$ Quebec agreed to participate to the QUAD agreement, which represented an important shift in CanadaQuebec relations as Quebec had refused to participate to the previous agreements (Mahon, 2009).

${ }_{105}$ Another flaw of the QUAD agreements was that it did not make any restriction for profit provision.

106 The federal government also delivered the Goods and Services Tax (GST) / Harmonized Sales Tax (HST) Credit, to help people living in low income offset the burden of consumptions taxes. The GST/HST Credit is paid quarterly to eligible low-income individuals and families. The amount of the credit depends on household income and province of residence.
} 
agreements by the UCCB permitted childcare costs to be collectivized - albeit very modestly, ${ }^{107}$ economic defamilialization was made possible through a further motherization of care work.

The last agreement that was part of the NCA was the 2000 extension of the parental benefit. As noted in previous chapters, since the introduction of maternity leave in 1971, benefits have been tied to the UI program, and at different times, have excluded various groups of individuals, such as 'inactive' women and individuals unable to find a job stable enough for them to qualify. Not only has the creation of a separate - and universal - maternity/parental program never been considered by the federal government since 1971, as noted above, replacement rates have been reduced at various occasions, from 66 per cent in 1971 to 60 percent in 1978, 57 percent in 1993 and 55 percent in 1994. The low and falling replacement rates reflect a lack of concern to entice fathers (usually those with the higher salaries) to take their share of the leave. This is in contrast to parental leave in Sweden which remained at a high rate even when the Social Democrats lowered the unemployment insurance replacement rate in the 1990s. Furthermore, following the replacement of UI by the Employment Insurance (EI) program in $1997,{ }^{108}$ a change in the eligibility criteria from weeks worked to hour works made it more difficult for parents to qualify. ${ }^{109}$

\footnotetext{
${ }^{107}$ The UCCB has been treated as a taxable income, and consequently, even if parents use the money to buy childcare services, the benefit is not generous enough to cover a substantial portion of childcare costs. In that sense, the UCCB does not have anything to do with childcare per se, but much more with family benefits.

${ }^{108}$ In 1995, amendments to the UI program were announced. The new program, introduced in 1997, explicitly aimed to remove the disincentive to work, as it was designed to move away from 'passive' income support towards a more active approach to help people finding new employment.

109 While the new legislation covered part-time work, the number of hours required to qualify increased: under the UI program, it had been necessary to have worked for 300 hours (fifteen hours per week, for twenty
} 
By 1999, parents who qualified to receive UI benefits had the option to take a paid leave for up to 25 weeks, as the parental leave was increased from 10 weeks to 15 weeks, which could be added to the 10 -week maternity period reserved for birth mothers. The NCA doubled the length of parental leaves, paid by the EI. Since 2001, parents can use up to 50 weeks of paid leave after the birth of a child. The first 15 of these weeks are considered a maternity leave, which birth mothers only are entitled to take, and the remaining 35 weeks of parental leave can be shared between the parents, or alternatively be taken only by one parent. Though the federal government did not consider offering father's quotas, as an incentive for parents to split the extended parental benefits entitlement, the two-week waiting period is no longer imposed on both claimants. This has represented a reduction in the cost to a father hoping to take just a few weeks of benefits. Yet, outside Quebec, only 11 per cent of recent fathers took or intended to take parental leave in 2011 (Statistics Canada, 2012); this represented a minor increase since 2004, when 9 per cent of fathers used the leave (Marshall, 2008). The NCA also changed the eligibility condition to the parental benefit program, from 700 to 600 hours, but again, this initiative did not adequately address the problems of those who still failed to qualify, precisely because it did not change the policy architecture of the leave (Battle and Torjman, 2002). Finally, while replacement rates and ceilings continued to match those for regular EI benefits, the

weeks), but with the EI changes, seven hundred hours (the equivalent of thirty-five hours a week for twenty weeks) were necessary. The replacement rate for claimants stayed at 55 percent of past earnings, with a cap of $\$ 413$ per week. In 2013 , the maximum insurable earnings amount was $\$ 47,400$, meaning that a new parent could receive a maximum of $\$ 501$ per week. The dependency rate for lower-income claimants with families was dropped in favour of the family supplement (FS), which served a similar purpose. EI claimants with low family income who received the CCTB were eligible to receive a top-up to their EI benefits equal to the weekly values of the child tax benefit. The value of the FS thus depended upon the number of children and of family income. As for other benefits, the value of the FS was highest when family income was lowest, disappearing altogether when net family income reached a certain threshold (\$25,921 in 2013). 
replacement rate of the FS for claimants from low-income families increased to 80 percent. This only alleviated the poverty of low-income families who met requirement criteria to qualify for EI.

Thus, between 1995 and 2010, Ottawa's support for families took the form of a limited yet not systematically targeted - assistance. Services that allowed defamilialization and/or demotherization of care work have only been offered to a narrow group of parents. ${ }^{110}$ Defamilialization was made possible for two categories of individuals: those who qualified to receive parental benefits ${ }^{111}$ and those who were poor enough to receive child tax benefits. With regards to parental benefits, government support through paid leave has been limited to individuals who met eligibility criteria. Although the improvement of the parental leave constituted a useful enhancement of an existing program, it did not change the policy architecture of the leave. Daddy quotas were also left out of the equation. The issue of gender equality as thus been secondary to the issue of poverty and the goal of vertical redistribution has replaced the one of horizontal redistribution.

In the end, federal social policies continued to favour implicit familialism. While some became entitled to a relatively long, yet not very generous, parental leave, in the absence of higher replacement rates and dedicated daddy months and/or of state-funded childcare

\footnotetext{
${ }^{110}$ Again though, the Liberal and the Conservative parties had two different visions about the way they should support families, the former emphasising the need for universal high quality childcare and the later arguing that such a program would not provide choice for parents and would be a 'one-size-fits-all' initiative with a massive bureaucracy (Friendly and Prentice, 2009).

${ }^{111}$ Following my earlier discussion of the concept of defamilialization, parental leaves can be argued to be defamilializing in the sense that they allow individuals to uphold an acceptable standard of living independently of family relation (Lister, 1994).
} 
facilities, care work remained in the mother's hands. In that context, the extent of demotherization became contingent upon the presence of grandparents willing to do care work, fathers' wish to go against the stream by using part of the parental leave, and income, as middle and upper-class households may choose to buy services that unburdened mothers.

Quebec's fertility regime since the mid-1990s: sitting between two chairs?

In many respects for the last two decades, Quebec's fertility regime has been quite distinctive. Even before Quebec's new family policy in 1997, the province had at least two family-relevant programs not available elsewhere in Canada: 1) the Quebec Maternity Allowance Program (QMAP), introduced in 1978 to cushion the first two weeks not covered by the parental insurance program, and 2) Quebec's 1995 universal alimony, under which an Alimony Fund could advance payment of up to three months ${ }^{112}$ if the payer defaulted on his or her responsibility. ${ }^{113}$

Given the targeting nature of these two programs, it may look like Quebec was not able to escape the Canadian tendency to move away from universalism. To some extent, that was the case, though this observation needs to be nuanced. In the 1980s, despite the concern with budgetary austerity, Quebec's first family policy offered a set of universal allowances. Quebec's second family policy should nonetheless be examined within the wider context of changes to the income security programs, the goal of which was to increase the benefits

\footnotetext{
${ }^{112}$ For a maximum of $\$ 1,000$.

${ }^{113}$ Although Canadian provinces have an enforcement program which serves to encourage compliance, the strategy in English Canada has been to focus on punishment of the payer at fault, rather than to provide some financial support to the creditor as is the case in Quebec
} 
provided to low-income workers relative to social assistance recipients (Baril et al., 2000; Jenson, 2002). The mid 1990s through 2010 were a time during which individual responsibility was emphasised and where labour market activity, even for adults with young children, was strongly encouraged. In that regard, the 1996 Green paper on income security reform, The Road to Labour Market Entry, Training and Employment, even suggested that persons presenting temporary limitations to employability should be redefined as individuals with children with children below aged two, instead of six. ${ }^{114}$

-Quebec's 1997 family policy

The publication of the 1997 White Paper, Les enfants au coeur de nos choix, provided the blueprint for the development of Quebec's new family policy that would be implemented in phases between 1997 and 2006. The goals of Quebec's second family policy were stated on January 1997, by Prime Minister Lucien Bouchard. According to Bouchard:

Les nouvelles dispositions de la politique familiale du gouvernement du Québec s'arriment à plusieurs des grands objectifs de l'État que sont la lutte à la pauvreté, l'égalité des chances, le développement de l'économie sociale, l'intégration au marché du travail des bénéficiaires de l'aide sociale et le support accru aux parents déjà en emploi. ${ }^{115}$

The objectives were to be met by means of three new provisions. The first was to ensure equity between families by providing greater assistance to low-income households in the form of a new Integrated Child Allowance (ICA). This program was in line with the

\footnotetext{
${ }^{114}$ When the Bill was enacted in 1998 however, the age of the child giving entitlements to the supplement was not changed and it has not been modified since.

${ }^{115}$ The new family policy aims to pursue broad objectives such as the fight against poverty, the equality of opportunities, the development of social economy, the activation of social assistance recipients and an increase support towards working parents.
} 
tendency, in a liberal welfare state, of targeting. The ICA replaced former family allowances and the allowance for newborn children. The change was significant. Until then, the allowance had been universal, whereas family benefits varied according to family income. Family benefits covered the essential needs of children under 18 in low-income families, taking into account the CCTB. As in other provinces, the first requirement to be eligible for family allowances was the presence of dependent children under 18 , and the amount of benefits increased with the number of children. What was unique to Quebec was that the benefits also depended on the number of adults living with the child. Accordingly, low-income single-parents families with two children received higher benefits than lowincome bi-parental families with the same number of children. The new family allowance combined with the new federal benefit assured a stable income in comparison with the previous situation, because the benefit was paid automatically. Thus, the new allowance allowed the government to reach its most precarious clientele, which was not the case under the Parental Wage Assistance (PWA) program, because only a small proportion of families applied for it. Since 2005, the new child assistance measures have replaced family allowances, along with the nonrefundable tax credit for dependent children and the tax reduction for families.

The second objective of the 1997 White paper was to promote child development and equal opportunities through the implementation of low costs educational services on two separate grounds. On school grounds, full-day kindergarten for 5 years old has been offered in Quebec since September 1997. While attendance has not been mandatory, enrolled children 
must attend class for the full school day and school week. Since the introduction of the new family policy, 98 per cent of all 5 year-old have attended full-day kindergarten, compared to 85 per cent before the policy change (Lefebvre et al., 2011). ${ }^{116}$ Starting in September 1998, the Department of Education began subsidizing before- and after-school day care. The School boards must offer these services on the school premises at the reduced contribution of $\$ 5$ per day per child ${ }^{117}$ for children in kindergarten and elementary school. The only requirement for a family to benefit from this low-fee service has been for the child to attend the school day care center for at least $2 \frac{1}{2}$ hours per day, for a minimum of three days per week.

Subsidised childcare spaces were also implemented for preschool children. Preschool subsidized childcare facilities - the centres de la petites enfance (CPE) - were created out of existing non-profit childcare centers to serve as organization nodes of the new system. Typically, the CPE attracted children older than two years old. Home-based care with a regulated provider has been another form of childcare, often used for children under the age of two. These home-based providers were organized as a network affiliated with a CPE.

On September 1997, the government of Quebec implemented accredited childcare facilities that offered subsidized childcare for all children four years and older. The government also promised to progressively decrease the age requirement for subsidies and to increase the

\footnotetext{
${ }^{116}$ In Canada, all provinces offer publicly provided free kindergarten for 5-years old children (with the exception of Ontario, where 4 years old have access to junior kindergarten), yet all programs are for half day ( 2 hours and 30 minutes) during the school year.

${ }^{117}$ Since January 2004 childcare costs $7 \$$ a-day.
} 
number of subsidised and regulated childcare spaces. On September 2000, all children aged less than 59 months were eligible for reduced contribution spaces. Access to childcare spaces in Quebec was not to be tied to the parents' professional status or income level (Jenson, 2002; Tougas, 2002), yet the low-fee spaces were not offered at the cost of lower quality. The 1997 policy emphasised the importance of the quality of care. Formal qualifications were raised for both CPE and home-based caregivers. ${ }^{118}$

The universal childcare program was nonetheless criticised on many levels. First, there has never been sufficient political will for the program to get the resources needed to meet growing demand. Despite the increases provided for and although childcare was defined as a universal right for all children in Quebec, access to spaces has been an issue since 1997 (Campbell, 2006; Jenson et al., 2003). ${ }^{119}$ As an alternative, families could turn to private providers of childcare services (non-subsidized and non-regulated spaces) and obtain a refundable tax credit for their childcare expenses.

In 1994, Quebec's childcare deduction was transformed into a refundable tax credit. The credit varied from 75 per cent to 26 per cent based on family income, and parents could even demand anticipated payments of the credit, to help them cover the cost of childcare.

\footnotetext{
${ }^{118}$ In that regard, two-thirds of staff must have a college diploma or university degree in early childhood education, as prior to the reform, it was only one-third. The government also provides financial support for the "éducatrices", (childcare providers, the overwhelming majority of whom are women) who are enrolled in college-level courses in early childhood education. Home-based childcare providers affiliated with a CPE faced increased training (24-45 hours) and annual professional development (6 hours) requirement (Baker et al., 2008).

${ }^{119}$ As Baker et al. (2008) and Lefebvre et al. (2011) note, excess demand is very hard to gauge since waiting lists may include children already in a subsidized spot but wanting to change centers and children's name may be on multiple waiting lists.
} 
As a tool to decrease the demand pressure on subsidized childcare spaces, the tax credit was improved twice, in 2008 and 2009. ${ }^{120}$ Second, the program was criticized for being designed on the basis of 'one size fits all'. Quebec's model of childcare services only served the needs of parents with stable 'typical' jobs with a rather standard working schedule, from morning to the late afternoon. Families - or more accurately mothers - who chose to care for their children themselves have not been treated equally in terms of public family support. While there is a generous provincial refundable tax credit based on family income for childcare expenses, it has not matched the subsidies offered to families using subsidized childcare. Finally, the policy has been shown to benefit the higher income families (Baker et al., 2008; Lefebvre and Merrigan, 2005, 2008). The change in childcare policy had different impacts on childcare costs depending on family-income. This is explained by the structure of the policy before the regime switch, where childcare expenses were reduced via a refundable tax credit that was substantially higher for low-income households (Lefebvre and Merrigan, 2005, 2008). While prior to 1996, families faced a nonlinear pricing curve, with higher price reductions for low-income families, the new policy set prices at $\$ 5.00$ for everyone, resulting in a larger price diminution for high and middle class families.

The third and final component of the 1997 new family policy was implemented in 2006, with the introduction of Quebec's Parental Insurance Program (QPIP). Since then, Quebec

\footnotetext{
${ }^{120}$ Thus, since 2008 , the maximum expense has been $\$ 9,000$ per child aged less than 7 , the credit rate table changed and family income enhanced to $\$ 125,000$ or over for the lowest rate, ${ }^{120}$ to reduce the net-cost difference between private and subsidized $\$ 7$ a day childcare (Lefebvre et al., 2011).
} 
has had the most generous parental leave in North America. The program eliminated the original two week waiting period for obtaining benefits. The eligibility criteria for parental benefits also changed: parental insurance has been available to any parent who had earned $\$ 2,000$ or more during the previous tax year. This represented an extension in coverage to persons not covered by the EI because eligibility was now based on flat-rate earnings rather than on the number of hours worked. Salaried workers, the self-employed and many students thus became entitled to receive benefits. A third feature of the parental leave program was that new parents had a choice between a larger income for a shorter leave or a smaller percentage of their usual income for a period of almost one year. ${ }^{121}$ In 2013 , the maximum insurable income taken into account for benefit calculation purposes was $\$ 67,500$. This income is indexed on January $1^{\text {st }}$ of each year. Finally, the new plan included a paid daddy quota of up to five weeks that was not transferable to the mother.

Since the introduction of the 1997 family policy, Quebec took other measures to support families, leading Rose (2008) to argue that Quebec's family policy has been simplified. One of these measures was the substitution of the Parental Wage Assistance (PWA) program by a Work Premium (WP). Unlike the PWA, the premium was made available to all workers with low incomes, independently on whether they had children or not. The premium was more generous for families than for singles. A second measure was the refundable child assistance implemented in 2005. This initiative replaced family benefits,

${ }^{121}$ With regards to maternity leaves, women have had a choice between being paid 15 weeks at 75 per cent of their income or 18 weeks at 70 per cent. The parental leave can be paid 25 weeks at 75 per cent of the income or 7 weeks at 70 per cent, followed by 25 weeks at 55 per cent. Finally, the paternity leave can be paid 3 weeks at 75 per cent of the income, or 5 weeks at 70 per cent. 
the non-refundable tax credit respecting dependent children and the tax reduction for families. This credit also exemplified Quebec's willingness to offer universal assistance to families, in the wider context of targeted financial support to the most needy. On the universality side, the credit has been offered to all eligible families with one or more dependent children under the age of 18 living with them; ${ }^{122}$ families did not even have to apply to receive child assistance payments, because children were automatically signed up when declared to the Registrar of Civil Status, following their birth. The benefit was thus not only universally accessible, but parents did not have to do anything to receive their quarterly payments. ${ }^{123}$ On the targeting side, the amount of the payment varied from one family to another. The amount was indeed determined on the basis of the number of dependent children, the number of children in shared custody, the number of parents and the family income. Beyond a certain threshold, the amount of the credit was diminished.

-Institutional defamilialism or de-gerended familialism?

As in the ROC, defamilialization in Quebec has to some extent been targeted towards lowincome households, the best examples being the child assistance programs. Since 2006, however, the government has universally supported defamilialization and demotherization measures through QPIP and the childcare program, made available for pre-school and

\footnotetext{
${ }^{122}$ The child assistance credit has two components: 1) the universal child assistance payment and 2) the supplement for handicapped children, to financially assist families with the care and education of a handicapped child. The physical or mental handicap must be serious and must significantly limit the child in carrying out daily activities for a period expected to last at least 1 year.

${ }^{123}$ The assistance payments are made on the 1 st working day of each quarter, that is, four times a year: 1) in July for July, August and September, 2) in October for October, November and December, 3) in January for January, February and March and 4) in April for April, May and June.
} 
school-aged children. Quebec's model of social reproduction has become a blend/hybrid of institutional defamilialism and de-gendered/generational familialism. The fact that a large proportion of children are in their main care arrangement 30 hours or more per week frees both partners from care work (table 9). The same observation applies with regard to the high number of hours children spend in childcare (table 9). Because that type of model presses for a maximum hours of institutional hours, it could run the risk of remaining a 'cold modern' (Hochschild, 1995) solution. While before 1997 the proportion of children in non-parental care was actually higher in the ROC than in Quebec (figure 22) after 1997 the proportion of Quebec children in non-parental childcare exploded, reaching 66.9 per cent in Quebec in 2002-2003, as compared to 47.5 per cent in the ROC. The rise in the proportion of children in non-parental care was very much linked to the growing proportion of children in the CPE. Figure 23 shows that between 1994 and 2003, the proportion of children in non-parental care, who were cared for in a childcare centre increased from 25.2 per cent to 51.9 per cent. 
Table 9 - Proportion of children who are in their main care arrangement full-time (30 or more hours per week) and weekly number of hours in main care arrangement, Quebec and ROC, 1994-2003

\begin{tabular}{lcccc}
\hline & \multicolumn{2}{c}{$\begin{array}{c}\text { Proportion of children in their } \\
\text { main care arrangement full- } \\
\text { time }\end{array}$} & $\begin{array}{c}\text { Average number of hours in main care } \\
\text { arrangement }\end{array}$ \\
\cline { 2 - 5 } & Quebec & ROC & Quebec & ROC \\
$\mathbf{1 9 9 4 - 1 9 9 5}$ & 52.4 & 47.6 & 28.5 & 26.7 \\
$\mathbf{1 9 9 6 - 1 9 9 7}$ & 54.8 & 46.2 & 28.6 & 26.1 \\
$\mathbf{1 9 9 8 - 1 9 9 9}$ & 54.5 & 47.1 & 28.8 & 26.4 \\
$\mathbf{2 0 0 0 - 2 0 0 1}$ & 57.9 & 46.2 & 29.2 & 26.0 \\
$\mathbf{2 0 0 2 - 2 0 0 3}$ & 60.3 & 43.4 & 29.3 & 24.6 \\
\hline
\end{tabular}

Source: adapted from Bushnik (2006).

Figure 22 -Proportion of children in non-parental childcare, Quebec and the ROC, 1994-2008

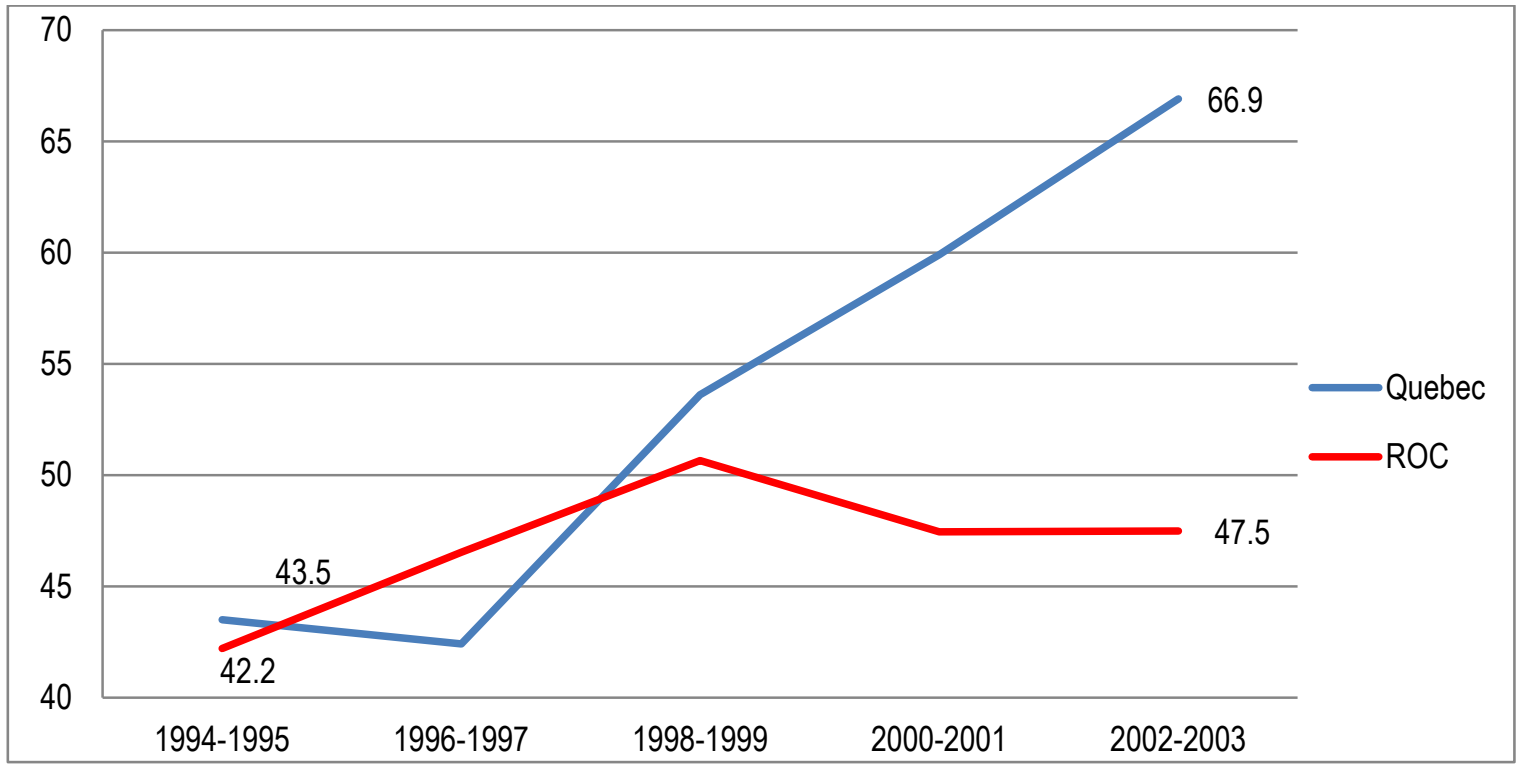

Source: Bushnik (2006). 
Figure 23 - Proportion of children in a childcare centre

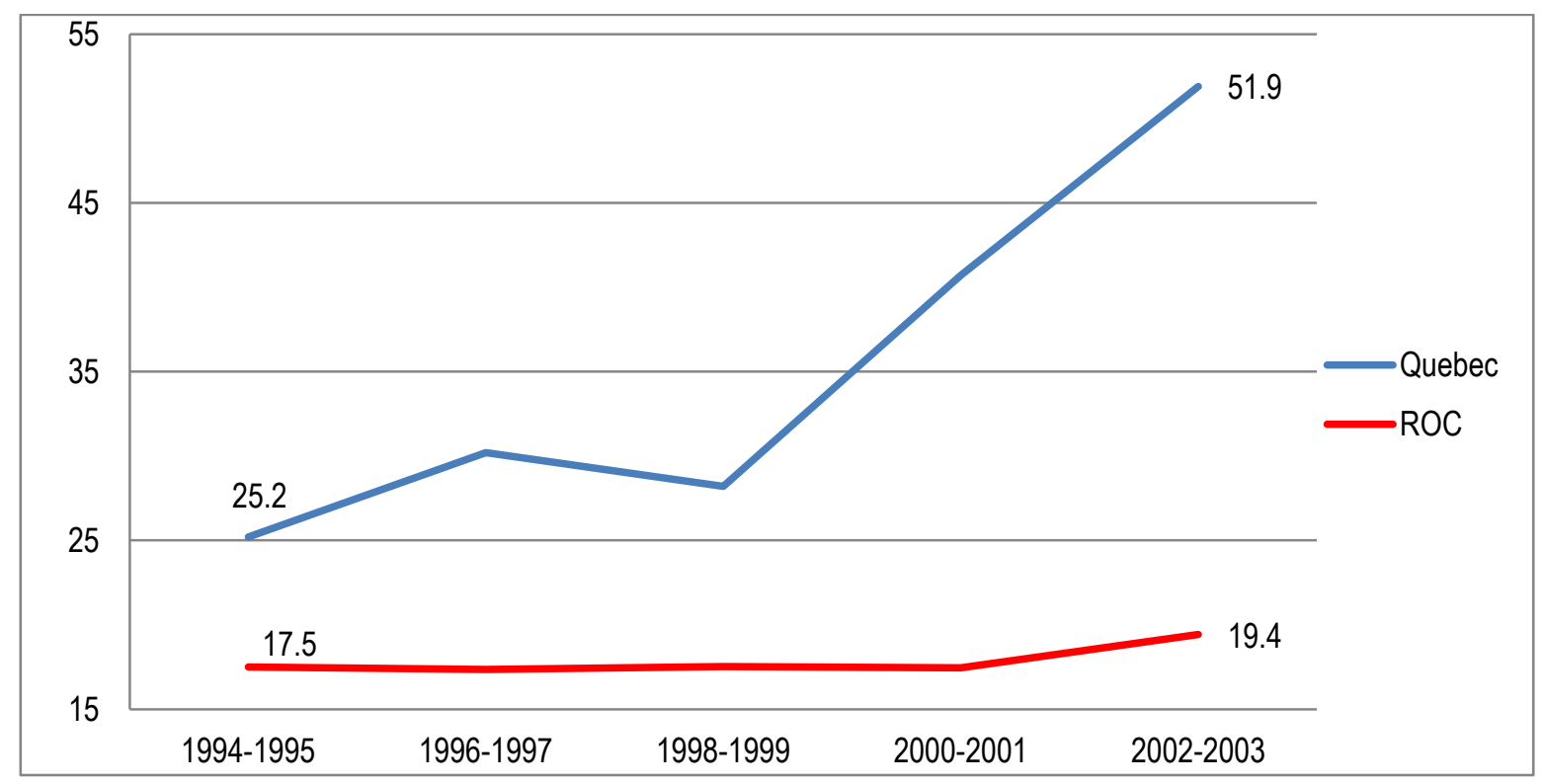

Source: Bushnik (2006).

Quebec's model of social reproduction, however, has not entirely been one of institutional defamilialism. Although the parental leave program was the same across Canada prior to 2006, Quebec had a consistently higher proportion of fathers claiming benefits, perhaps representing some cultural differences (Marshall, 2008). Of all Quebec fathers eligible for the program, 32 per claimed benefit in 2005, up from 22 per cent in 2004 (Marshall, 2008), while the participation rate for fathers outside Quebec remained steady over the same years, at around one in ten (Marshall, 2008). Quebec's introduction of daddy quotas encouraged the shifting of part of the care work from mothers to fathers, thus moving Quebec even closer to the model of de-gerendered familialism. The implementation of QPIP has been successfully welcomed by new fathers and a large proportion of Quebecois men have indeed 'mothered' (Doucet, 2006). Men have accounted for an increasing proportion of beneficiaries of Quebec's parental leave insurance plan (table 10). While in 2006, 37 per 
cent of all recipients were men, that proportion rose to 45.1 per cent in 2009. Similarly, men represented a growing proportion of beneficiaries of the parental leave, a finding that reflects Quebec's move towards a 'universal caregiving model' given that maternity leaves have remained relatively short, and that new mothers have had the option to use the parental leave to prolong their stay at home. This finding is unanticipated. Even in the Nordic countries, where the father's quota is popular, the shared leave entitlements fathers have with mothers is not (Laas and Rostgaard, 2011). In Denmark and Finland, which have no father quotas, fathers take only $6 \%$ of the parental leave days; in Iceland, and Norway, fathers also tend to not take a large share of the family entitlements. Although Sweden has the best record for fathers taking parental leave, in 2010 this meant that less than one-fourth of all parental leave days taken by parents were taken by fathers (Laas and Rostgaard, 2011).

Table 10 - Distribution of women and men among recipients of Quebec's parental insurance plan, 2006-2009

\begin{tabular}{llll}
\hline & Women & Men & Total \\
$\mathbf{2 0 0 6}$ & 63 & 37 & 100 \\
$\mathbf{2 0 0 7}$ & 56.1 & 43.9 & 100 \\
$\mathbf{2 0 0 8}$ & 55.5 & 44.5 & 100 \\
$\mathbf{2 0 0 9}$ & 54.9 & 45.1 & 100 \\
\hline
\end{tabular}

Source: Conseil de gestion de l'assurance parentale (Direction générale adjointe de la recherche, de l'évaluation et de la statistique, ministère de l'Emploi et de la Solidarité sociale), Statistiques officielles sur les prestataires du Régime québécois d'assurance parentale, décembre 2006, décembre 2007, décembre 2008 et décembre 2009 in Government of Quebec (2011). 
Table 11 - Distribution of women and men among recipients of parental benefits in Quebec, 2006-2009

\begin{tabular}{llll}
\hline & Women & Men & Total \\
$\mathbf{2 0 0 6}$ & 81.9 & 18.1 & 100 \\
$\mathbf{2 0 0 7}$ & 80.1 & 19.9 & 100 \\
$\mathbf{2 0 0 8}$ & 79.1 & 20.4 & 100 \\
$\mathbf{2 0 0 9}$ & 79.1 & 20.9 & 100 \\
\hline
\end{tabular}

Source: Conseil de gestion de l'assurance parentale (Direction générale adjointe de la recherche, de l'évaluation et de la statistique, ministère de l'Emploi et de la Solidarité sociale), Statistiques officielles sur les prestataires du Régime québécois d'assurance parentale, décembre 2006, décembre 2007, décembre 2008 et décembre 2009 in Government of Quebec (2011).

Quebec's post-modern compromise thus scored high on both the equity and the equality ladders. On the equity barometer, new rules of eligibility for QPIP have made it easier for a large proportion of women to qualify to receive maternity benefits. Not only has QPIP supported economic defamilialization, it has also recognised women's exclusive right to be compensated to be full-time mothers for at least 15 weeks. On the equality side, Quebec's family policy has supported a better division of care work between parents by offering men the opportunity to use a paid leave to look after their newborn (or adopted child). Since father's leave is a 'take-it or leave-it' opportunity, it cannot be used, as it is the case with the parental leave, by the mother. The daddy leave has thus allowed care work to be performed within the family unit, yet not by the mother. The growth in the proportion of men among beneficiaries of parental benefits was the consequence of an institutional environment that has favoured increased gender equality. ${ }^{124}$ While, at the outset, the change in the parental leave policy did not encourage men to use a larger part of the

\footnotetext{
${ }^{124}$ The observation, however, is contingent upon the assumption that men use their parental leave to perform care work, instead of hobbies or other activities. This has yet to be demonstrated.
} 
parental benefits, the implementation of the paternity leave had an effect on the take-up of parental leave for men. In other words, a different culture started to emerge for men, one that has allowed them to take time off to look after their children. Finally, care work has also been defamilialized and demotherized through the provision of the CPE, which have been universally accessible from the baby's first months to school age.

\section{Discussion and conclusion}

In the period between 1995 and 2010, Ottawa and Quebec set up policies and services with the broad objective of promoting attachment to the labour market. To some extent, both levels of government embraced the liberal ideology of targeting, by offering social policies that focused on vertical redistribution, rather than horizontal redistribution. Child benefits provide the most eloquent example of vertical redistribution. The Canada Child Tax Benefit (CCTB) implemented by Ottawa in 1998 only provided child benefits to low-income families; similarly the National Child Benefit Supplement (NCBS) paid monthly to lowincome and middle-income families was reduced by a percentage amount (which depended on the number of children) when family net income reached a certain threshold. Furthermore, in an effort to reduce overlap and duplication, provincial governments were invited to consider the NCBS as an income and to adjust social assistance payments dollar by dollar. Consequently, families receiving social assistance payments saw no increase in their benefit. 
In Quebec, the 1997 Integrated Child Allowance (ICA) was only offered to low-income families, again demonstrating the value of targeting resources towards the most needy. The introduction in 2005 of child assistance signaled a commitment to both targeting and universality: while child assistance payments were universal, the amounts received vary from one family to another. Yet, the most dramatic commitment to universality was demonstrated with the introduction the centres de la petites enfances (CPE) and pre- and after- school childcare services. Not only these services became universally accessible gradually after 1997, they provided parents with a high-quality educational alternative to home-care for their children.

The daunting question is whether these policies had a positive effect on social reproduction. This research has repeatedly demonstrated the difficulty of drawing clear-cut correlations between the introduction of new policies and changed in fertility trends. The 1990s and the early 2010s were no exception to this observation: the periodization between fertility trends and the introduction of Quebec's second family policy did not easily correspond. Moreover, when comparing Quebec's fertility regimes with other developed countries, the decreasing fertility observed between 1995 and 2000, along with the rising fertility that characterized the period between 2005 and 2009 corresponded, with minor exceptions, to fertility trends in the Nordic and the Anglo-Saxon countries. This observation called for cautious and nuanced reflections about the potential effect of policies on fertility. The full extent of demotherizing measures announced in 1997 were put in place in 2000 when children of all ages had access to low-cost childcare services and in 2006, when the QPIP became 
effective. Prior to year 2000, access to low-cost childcare spaces was limited to children below four. In a context of rising opportunities for women in the labour market, yet of high unemployment for women of childbearing age, motherhood became a social risk a smaller proportion of women were willing to make. Between 2005 and 2009, women of prime childbearing age maintained relatively high activity and employment rates, despite rising fertility, low intervals between births and an increasing proportion of third and subsequent births. Women no longer had to choose: in a good economic context, they could have it all, a job and a family. While all women received limited financial assistance from both levels of government (through Ottawa's UCCB and Quebec's refundable child assistance), they were offered the tools to maintain their position in the labour market. Furthermore, increasing fertility and birth rates were not the result of a tempo effect: though women postponed motherhood to a later age, third and fourth births became more frequent.

In the end, it is almost impossible to assess the extent to which the rise in fertility rates after 2005 was the result of international forces or local policies. For almost every argument that supports the existence of a correlation between fertility rates and the introduction of new family policy measures, a counter-argument can be made. Thus, while it was in 2006 that birth and fertility rates increased the most in Quebec, precisely the year of the implementation of Quebec's parental insurance plan, a rise in fertility was also experienced in the ROC. The last chapter is thus dedicated to the main conclusions this thesis was able to draw, some of the limitations of the dissertation, and new avenues for research on the social determinants of fertility. 


\section{CHAPTER 10 CONCLUSION}

The gender equity theory, understood here as the 'gender equality' theory, suggests that the low fertility experienced in developed countries results from the incoherence between high equality in public institutions and low equality within the caregiving structure of families. Building on this insight, this dissertation has argued that policy environments that have supported social reproduction and gender equality have had better fertility outcomes than policy environments that have supported fertility and equity. Thus in Quebec, while the 1988 baby bonus, a pronatalist measure, had a limited effect on births - precisely because it did not challenge the gendered division of care work - recent initiatives such as the implementation of a large-scale, state-funded, low-cost childcare network, along with dedicated daddy leaves have been successful in increasing fertility.

Conceptually, this thesis has shown the need to go beyond the notions of decommodification and defamilialization used in classic and feminist approaches to the study of gender inequalities. The concept of demotherization, defined as the extent to which mothers can download caregiving responsibilities on other family members, the state or the market, is one important determinant of fertility outcomes. Though the effect of specific policies on fertility outcomes varies across different institutional contexts, at least two demotherizing measures, the availability of childcare (in various forms) and parental leaves structured to promote sharing between both parents, were associated with a higher quantum of births. 
That said, in the 1960s and 1970s, Quebec and Ottawa chose to implement new familyrelevant policies that allowed a limited level of defamilialization and low demotherization. These included the 1971 federal maternity leave program, different family allowances and a childcare deduction. Equity, more than equality, was the driving force behind the implementation of these new measures, as both governments continued tacitly to support the male-breadwinner/female caregiver division of labour. Faced with new opportunities in the labour market but with enduring caring responsibilities, freed from the prescription of the Catholic Church and armed with family planning tools, women chose to dramatically limit their fertility.

Following the end of the Quiet Revolution, Quebec began to forge a distinctive approach to family policies. Though both levels of government chose to support implicit familialism, they did so via two different canals. Increasing pressure to redirect limited resources towards families who needed them the most, led Ottawa to adopt the Child Tax Benefit (CTB) a new targeted measure, as a replacement or the universal family allowances, the non-refundable credit for dependent children, and the refundable child tax credit. In addition, Ottawa's preoccupation with activation measures justified the introduction of a Work Income Supplement (WIS). Meanwhile, Quebec chose to pursue the goal of horizontal - rather than vertical - redistribution, through a set of three universal allowances, among which was the Allowance for newborn children (ANC). In accordance with previous international findings on the potential effect of the baby bonus on fertility, this research 
concluded that the influence of ANC on births remains uncertain, because of the potential tempo effect this measure entailed on reproductive decisions.

In the early 2000s, Quebec's fertility regime moved from implicit familialism to a hybrid version of the institutional and de-gendered/generational arrangements of care work, through the provision of a mix of universal and targeted measures. In this context, Quebec women maintained high activity rates and relatively high fertility as the policies put in place during that period allowed them to pursue a career, and challenged the gendered division of labour within households. Women in Quebec reached a post-modern compromise that scored high on equity, but also and most importantly on equality. While entitled to use time to perform childcare duties, women had the opportunity to download part of their caregiving work on the state and on fathers. Men were indeed encouraged to follow women's career trajectories by withdrawing temporarily from the labour market to do care work following the birth of a child.

Though pushing for gender equality is one way to increase fertility rates (Oláh, 2011), gender equality policies are not a panacea (Neyer, 2010). Economic factors also influence fertility decisions. However, the connections between the booms and the busts of economic cycles and fertility trends are not straightforward. Though motherhood and labour market participation were incompatible activities in the 1980s, women's high unemployment did not have a positive influence on births. Conversely, in the early 1990 s, birth and fertility 
rates peaked in the context of an economic slowdown. In the early 2000 s, fertility and activity rates rose in tandem.

In fact, this dissertation cannot rule out the possibility that gender egalitarian policies only positively affect fertility during good economic times. The most gender egalitarian and demotherizing measures ever implemented in Quebec's history - the CPE and the daddy leaves - were introduced during prosperous times. Perhaps, when confronted with economic insecurity and persistently high unemployment, gender equality policies could even have a negative effect on fertility. As an example, in 1990 Finland, like Sweden, was hit by a severe economic crisis. Contrary to Sweden, however, total fertility rates did not drop in Finland, most likely because unemployed women used the opportunity to benefit from a child home-care allowance which provided them with a source of livelihood during the recession (Vitak, 2004; Sipilä and Korpinen, 1998 cited in Neyer, 2010). In that case, a policy that strengthened the traditional gendered division of labour, in a context of economic slowdown, actually helped to maintain fertility levels. In addition, the limited effect of Quebec's pronatalist policy on fertility may be due to the economic context of the late 1980 s/early 1990 s, rather than to the design of the benefit.

Increased gender equality does not systematically lead to increased fertility either. In the 1960s and 1970s, as women were granted new rights and opportunities that began to limit gender inequalities, births nonetheless declined. The notion of the deinstitutionalization of the family proved to be a useful conceptual tool to understand the new sexual norms that 
have become mainstream in Quebec since the Quiet Revolution. These norms are related to the postponement of the transition into parenthood, decreasing marriage rates, rising divorce and the growing popularity of cohabitation and of extra marital births.

This dissertation highlighted some of the difficulties of drawing parallels between different sets of social policies and fertility outcomes. The first of these difficulties pertains to the issue of periodization. From a historical point of view, fertility rates in Quebec were the highest when the state offered only limited family-relevant measures that allowed a modest level of economic defamilialization and no demotherization. Quebec's first coherent family policy was implemented at the time fertility was at its lowest. To complicate matters, given that most fertility trends observed in Quebec since the 1960s closely corresponds with those observed in the Nordic and the Anglo-Saxon countries, it is difficult to show the existence of causal relationships between the introduction of specific policies and fertility outcomes. In addition, some family-relevant policies seemed to have had a positive effect on the quantum of births, while others only affected their tempo.

\section{Limits and future directions}

To some extent, the difficulty of assessing the effect of policies on fertility is linked to some of the limitations of this research. Each of these limitations provides fertile grounds for new research avenues. The first limitation has to do with the dependent variables that were defined in terms of total fertility rates and crude birth rates. While birth rates run the risk of being affected by variations to the age structure of the population, postponement or 
anticipation of fertility can make fertility rates different from the levels they would have been in the absence of calendar changes. Not only can total fertility rate as a dependent variable hide potential tempo effects, it also hides heterogeneity in the fertility outcomes of women with different social characteristics. Gender categories are not homogeneous (Siltanen, 2006, Siltanen and Doucet, 2008) and the diversities of fertility outcomes to similar policies are not significantly acknowledged in the dissertation. Perhaps, women with different educational levels did not react the same way to the economic recessions of the 1980s, 1990s and 2000s. Perhaps, the fertility increase experienced in the late 1980s was due to the fact that low- income households saw in the baby bonus an opportunity to conceive at that specific period of time. Perhaps, the small baby-boom of the early 2000s was caused by an increase in the fertility of highly-educated women. Perhaps, as Termotte (2003) has shown, the reproductive behaviour of French and English-speaking women differs greatly.

Thus, there is a possibility that the conclusions formulated in this dissertation may be first and foremost relevant for White women with high human capital, who have planned to be active in the labour market and to build a career (McDonald, 2013). It is a reasonable assumption that women who react against the social-institutional context of childbearing are those who have the most to lose. Loss of income or status following childbirth rises as a woman's human capital level increases (McDonald, 2013). Thus, there is a possibility that the 'gender equality' theory applies better to highly educated women, or to women who have invested greatly in their career. Perhaps, women with different levels of human capital 
or women of various ethnic origins react differently to demotherizing measures and to gender-egalitarian policies. An interesting avenue for further research would be to compare the reproductive decisions of women with different social characteristics, in terms of social class, age and ethnicity, following the introduction of new family-relevant policies. As McCall (2005) reminds us, however, despite the emergence of intersectionality as an important paradigm of research, there has been little discussion of how to study intersectionality.

A second limit of this research regards the lens that was used to study fertility outcomes. Reproductive decision-making was examined as the result of macro-sociological forces. Such an approach is problematic because it conceals the individual motivations that lead women and couples to forego parenthood or, conversely, to have more children than they initially planned. Personal events that can impact on fertility realization, such as the death of a child, the need for fulfilment or the desire to have a child of a particular sex are hard to theorize, especially at the macro-level of analysis. In addition, a closing gap between fertility ideals and realizations at the aggregate level does not necessarily imply that individual women bore as many children as they wished. Morgan and Rackin (2010) and Hagewen and Morgan (2005) have argued that the congruence, at the aggregate level, between ideal family size and family realization in the United States resulted from the fact that a substantial proportion of women had more children than they intended. Again, this raises the need for intersectional data that characterize fertility intentions and realizations of women with different social characteristics. Fertility rates of 2.1 with a dominant ideal 
among women for two or three children can hide the existence of one group of women whose fertility was raised relative to their intentions because of unwanted pregnancies, and another group whose fertility intentions were also unrealised, but because of institutional constraints.

A third drawback of this research concerns the two main unit of analysis, Quebec and the ROC. The literature on gender regimes has shown the existence of intra-regime variations between countries that belonged to similar arrangements of states, markets and families (Brennan and Mahon, 2011; O'Connor et al., 1999). The work of O'Connor et al. (1999) for instance showed that though Australia, Britain, Canada and the United States shared broad similarities, there were also important differences between these countries that mattered, most notably in Australia. A similar point was made by Saint-Arnaud and Bernard (2004) who shed light on significant regime variation across the four Canadian provinces of Alberta, British Columbia, Ontario and Quebec. They showed that while Alberta most resembled the 'ultra-liberal' United States, Quebec had social policies similar to those found in some Nordic countries. Without any doubt, the ROC is not a homogeneous unit of analysis, and this dissertation has to some extent glossed over the variations between family-relevant policies offered in different provinces. This is especially true in the area of childcare, in which provincial policies vary a lot. Similarly, this dissertation did not address intra-regional variations within Quebec. Within the province, waiting lists for the availability of childcare spaces vary greatly, even within cities like Montreal. Likewise, unemployment rates and women's labour force participation vary from 
one region to another. The trade-off between economic activity, caring responsibilities and fertility is thus likely to differ across different localities in Quebec, especially in rural areas, where total fertility rates are distinctly higher (Institut national de santé publique, 2008).

Fourth, the literature discussed in this dissertation showed that the availability of part-time employment is an important dimension affecting fertility behaviours. Though the connections between the availability of part-time work and fertility are still open for debate, access to part-time employment has been associated with increased fertility in Southern Europe. Part-time employment can be a means for non-working women to increase their economic independence; it can also be, however, a trap that locks women into their caregiving role. Similarly, while the availability of part-time employment in the Netherlands is perceived as being gender equitable (while not being gender equal), in other countries, equitable outcomes are contingent upon full-time work. The connection between 'flexible' employment, part-time work, fertility, gender equity and gender equality should be examined further, both theoretically and empirically.

A fifth limit regards the issue of agency. From a philosophical point of view, it is problematic to argue that low fertility outcomes are the results of a gap between the fertility intentions and the fertility realization of women. If the goal is indeed to have men doing more care work and to secure a more gender-egalitarian gendered division of labour, feminist researchers can no longer study fertility realization as being exclusively a women's issue. There is a pressing need to pay closer attention to men's perspective on fertility 
intentions. For most couples, reproductive decisions are made jointly. Accordingly, we cannot rule out the possibility that decreasing fertility is the result of new fertility intentions among men. Faced with caregiving responsibilities, and having to balance work and family obligations, a larger proportion of men may be reluctant to have children. This avenue cannot be ignored.

Finally, this dissertation has suggested that gender equality was not only about equal rights and equal opportunities. It is also about equal duties and responsibilities. Not only does gender equality promotes a dual earner model where mothers and fathers share the right to be economically active, gender equality also entails equal caregiving duties. In that regard, it should be noted that not all features of gender equality incentives lead to an increased demotherization of care work, which, in turn, is linked to higher fertility. Though the provision of childcare is one promising avenue that allows care work to be both defamilialized and demotherized, it does not contribute in itself to a better gender division of care work within the household. Similarly, the involvement of grandparents does not challenge the gendered division of care work, quite the contrary, as research has shown clear gender divisions in the involvement of grandparents in childcare, with grandmothers and maternal grandparents most likely to be involved. The greater and longer labour market participation of elderly also raise the question of the sustainability of a multigenerational pact between adult children and their mother in the share of caregiving duties. 
For all these reasons, this research has shown the need to further theorize the notion of care work. Caregiving responsibilities are not limited to child care; they also apply to handicapped children, sick partners, close relatives, etc. As Quebec's society is aging, elderly care is an increasing concern for many adult-children. Because lives are linked and because today's young adults frequently delay parenthood, it is not unusual for older family members to require care at a time when children are young and at a time when reproductive decisions are being made, thus producing a 'sandwich generation' (Miedema, 2009; Williams, 2005). One factor that is now associated with a growing sandwich generation is a lower fertility rate, as women are caught in between caring for their parents and caring for their children (Williams, 2005). A better theorization of care-work is also necessary to further develop the concept of demotherization, narrowly defined here as the extent to which fathers and grand-mothers step in to perform care work. Yet, the demotherization of care work is linked to additional dynamics than the involvement of family members other than the mother, such as the widespread use of market mechanisms to deliver caregiving services, and the employment of immigrant workers, the majority of whom are women (Williams and Brennan, 2012). In many Southern and Continental countries, migrant work has emerged as an important solution to the challenges of both child and elder care (Da Roit and Weicht, 2013; Williams and Brennan, 2012). Though the intersection of the three policy domains of care, markets and migration has recently been examined (see for instance the special issue of the Journal of European Social Policy in 2012), its effects on fertility outcomes remain unclear. Inevitably, the question of the involvement of migrant workers in 
caregiving work raises the broader question of the connections between gender equality and class inequalities. 


\section{REFERENCES}

Aassve, Arnstein and Trude Lappergård. 2009. "Childcare Cash Benefits and Fertility Timing in Norway", European Journal of Population, 25, 67-88.

Adsera, Alicia. 2004. "Changing Fertility Rates in Developed Countries: the Impact of Labour Market Institutions”, Journal of Population Economics, 17 (1), 17-43.

Ahn, Namkee and Pedro Mira. 1999. "A note on the changing relationship between fertility and female employment rates in developed countries", working paper 13, Madrid: Fundación de Estudios de Economía Aplicada.

Amoroso, Julie. 2010. "From Women to Children: Reframing Child Care in Canada", Queen's Policy Review, 1 (1), 29-46.

Anderson, Jerry and Peter Sotir Hussey. 2000. "Population Aging: A Comparison Among Industrialised Countries", Health Affairs, 19 (3), 191-203.

Andersson, Gunnar. 2001. "The impact of labour-force participation on childbearing behaviour: Pro-cyclical fertility in Sweden during the 1980s and the 1990s", European Journal of Population 16 (4), 293-333.

Andersson, Gunnar; Ann-Zofie Duvander and Karsten Hank. 2004. "Do Child Care Characteristics Influence Continued Childbearing in Sweden? An Investigation of the Quantity, Quality, and Price Dimension", Journal of European Social Policy, 14, 407-418.

Andersson, Gunnar. 2004. "Childbearing Developments in Denmark, Norway, and Sweden from the 1970s to the 1990s: A Comparison", Demographic Research, 155-176.

Andersson, Gunnar; Jan M. Hoem and Ann-Zofie Duvander. 2006. "Social differentials in speed-premium effects in childbearing in Sweden", Demographic Research 14, 5170.

Andersson, Gunnar. 2008. "Family policies and fertility in Sweden", contribution to the "Consultancy Study on Population Related Matters - A Study on Policies and Practices in Selected Countries that Encourage Childbirth" for the Government of Hong Kong Special Administrative Region.

Ang, Xiaoling. 2009. "The Effects of the Generosity of Parental Leave Benefits on Labor Supply and Fertility: Evidence from a Canadian Natural Experiment", Princeton University. 
Apps, Patricia and Ray Rees. 2001. "Fertility, Female Labour Supply and Public Policy", discussion paper 409, Bonn: Institute for the Study of Labour (IZA).

Apps, Patricia and Ray Rees. 2004. "Fertility, Taxation and Family Policy", Scandinavian Journal of Economics, 106 (4), 745-763.

Arts, Wil and John Gelissen. 2002. "Three Worlds of Welfare Capitalism of more? A state-of-the-art Report", Journal of European Social Policy, 12(2)137-158.

Averett, Susan L. and Leslie A. Whittington. 2001. "Does Maternity Leave Induce Births?", Southern Economic Journal, 68 (2), 403-417.

Azmat, Ghazala and Libertad González. 2009. "Targeting Fertility and Female Participation Through the Income Tax", discussion paper 4405, Bonn: Institute for the Study of Labor (IZA).

Bagavos, Christos and Claude Martin. 2000. «Faible fécondité, familles et politiques publiques. Rapport synthèse du séminaire annuel de Séville», Sévilla, Spain : Austrian Institute for Family Studies.

Baizán, Pau. 2009. "Regional child care availability and fertility decisions in Spain", Demographic Research, 21, 803-842.

Baker, Michael; Jonathan Gruber and Kevin Milligan. 2008. "Universal Child Care, Maternal Labor Supply and Family Well-Being", Journal of Political Economy, 116 (4), 709-745,

Baker, Maureen. 1995. Canadian Family Policies: Cross National Comparisons, Toronto: University of Toronto Press.

Baker, Maureen. 2006. Restructuring Family Policies: Convergence and Divergences, Toronto: University of Toronto Press.

Baril, Robert, Pierre Lefebvre and Philip Merrigan. 2000. "Quebec Family Policy : impact and options", Choices, Family Policy 6 (1), January, 1-52.

Battle, Ken and Sherri Torjman. 2002. "Architecture for National Child Care", Caldon Institute of Social Policy.

Battle, Ken. 2008. "A Bigger and Better Child Benefit: A \$5,000 Canada Child Tax Benefit", Caldon Institute of Social Policy.

Baughman, Reagan and Stacy Dickert-Conlin, S. 2003. Did expanding the EITC promote motherhood? The American Economic Review, 93 (2), 247-250. 
Beaujot, Roderic and Ali Muhammad. 2006. "Transformed Families and the Basis for Childbearing", in Kevin McQuillan and Zenaida R. Ravanera (eds.), Canada's Changing Families: Implications for Individuals and Societies, Toronto: University of Toronto Press, 15-48.

Becker, Gary S. 1960. “An Economic Analysis of Fertility”, Demographic and Economic Change in Developed Countries, NBER Conference Series No. 11, Princeton University Press, Princeton.

Becker, Gary S. 1981. A Treatise on the Family, Cambridge, MA: Harvard University Press.

Bélanger, Alain and Jean Dumas. 1998. Report on the Demographic Situation in Canada, 1997, Catalogue no. 91-209-XPE, Ottawa : Statistics Canada.

Bernard, Paul and Sébastien Saint-Arnaud. 2004. "More of the Same? The Position of the Four Largest Canadian Provinces in the World of Welfare Regime", Canadian Policy Resarch, Research Report F49.

Bezanson, Kate and Meg Luxton. 2006. "Social Reproduction and Feminist Political Economy", in Kate Bezanson and Meg Luxton (eds), Social Reproduction : Feminist Political Economy Challenges Neo-Liberalism, Montreal : McGill-Queen's University Press, 3-10.

Bezanson, Kate and Meg Luxton (eds). 2006. Social Reproduction : Feminist Political Economy Challenges Neo-Liberalism, Montreal : McGill-Queen's University Press

Billari, Francesco C. 2008. "Lowest-Low Fertility in Europe: Exploring the Causes and Finding Some Surprises", The Japanese Journal of Population, 6 (1), 2-18.

Bloom, David E; David Canning; Günther Fink and Jocelyn E. Finlay. 2010. "The cost of low fertility in Europe”, European Journal of Population, 26 (2), 141-158.

Blossfeld, Hans-Peter; Erik Klijzing; Melinda Mills and Karin Kurz (eds), Globalization, Uncertainty and Youth, New York: Routledge.

Bongaarts, John. 2001. "Fertility and reproductive preferences in post -transitional societies: Supplement on global fertility transition", Population and Development Review, 27, 260-281.

Bonoli, Giuliano. 1997. "Classifying Welfare States: a two dimensional approach", Journal of Social Policy, 26 (3), 351-372. 
Boychuk, Gerard. 1998. Patchworks of Purpose: The Development of Provincial Social Assistance Regime in Canada, Montreal and Kingston, McGill-Queen's University Press.

Boyer, Marcel. 2008. «La performance économique du Québec: constats et défis », Série scientifique, Cirano, Novembre.

Bradshaw, Jonathan and Shalhevet Attar-Schwartz. 2011. "Fertility and Social Policy", in Takayama, Noriyuki and Martin Werding (eds), Fertility and Public Policy: How to Reverse the Trend of Declining Birth Rates, Cambridge, MA : MIT Press, 183-202.

Braedley, Susan. 2006. "Someone to Watch over You: Gender, Class and Social Reproduction", in Kate Bezanson and Meg Luxton (eds), Social Reproduction: Feminist Political Economy Challenges Neo-Liberalism, Montreal : McGill-Queen's University Press, 215-230.

Brenman, Deborah and Rianne Mahon. 2011. "State Structures and the Politics of Child Care", Politics and Gender, 7 (20), 286-293.

Breton, Didier and France Prioux. 2005. "Two Children or Three? Influence of Family Policy and Sociodemographic Factors", Population, 60, 415-445.

Brewer, Mike; Anita Ratcliffe and Sarah Smith. 2007. "Does Welfare Reform Affect Fertility? Evidence from the UK”, working paper No. 07/177, Centre for Market and Public Organisation.

Brewster, Karin L. and Ronald R. Rindfuss. 2000. "Fertility and Women's Employment in Industrialised Nations", Annual Review of Sociology, (26), 271-296.

Brown, Robert L. and Claire Norville. 2001. Theories of Fertility, in IIR Research Reports.

Buber- Ennser, Isabella. 2002. "The Influence of the Distribution of Household and Childbearing Tasks between Men and Women", Vienna Yearbook of Population Research, 1, 165-180.

Bushnik, Travey. 2006. Child Care in Canada, Research Paper catalogue no. 89-599-MIE, Children and Youth Research Paper Series no. 003, Ottawa: Statistics Canada.

Butz, William P. and Michael P. Ward. 1979. "The emergence of countercyclical U.S. fertility", The American Economic Review, 69 (3), 318-328.

Cameron, Barbara. 2006. "Social Reproduction and Canadian Federalism", in Kate Bezanson and Meg Luxton (eds), Social Reproduction : Feminist Political Economy Challenges Neo-Liberalism, Montreal : McGill-Queen's University Press, 45-74. 
Campbell, Angela. 2006. "Proceeding with 'Care': Lessons to be Learned from the Canadian Parental Leave and Québec Daycare Initiatives in Developing a National Childcare Policy", Canadian Journal of Family Law, 22 (2), 171-222.

Castles, Francis G. 2003. "The world turned upside down: below replacement fertility, changing preferences and family-friendly policy in 21 OECD countries", Journal of European Social Policy, 13 (3), 209-227.

Chesnais, Jean-Claude. 1998. "Below-Replacement Fertility in the European Union (EU15): Facts and Policies, 1960-1997, Review of Population and Social Policy, 7, 83101.

Clavet, Nicholas-James and Jean-Yves Duclos. 2012. "Le financement des services de garde des enfants: effets sur le travail, le revenu des familles et les finances publiques", Working Paper 12-16, Centre Interuniversitaire sur le Risque, les Politiques Economiques et l'Emploi (CIRPÉE).

Clement, Wallace. 2004. "Revealing the Class-Gender Connections: Social Policy, Labour Markets and Households", Just Labour, 4, Summer.

Clement, Wallace and Leah F. Vosko (ed). 2003. Changing Canada, Political Economy as Transformation, Montreal : McGill-Queen's University Press.

Clement, Wallace, Sophie Mathieu, Steven Prus and Emre Uckardesler. 2009. "Precarious lives in the new economy: comparative intersectional analysis", in Leah F. Vosko, Martha MacDonald and Iain Campbell (eds.), Gender and the Contour of Precarious Employment, New York: Routledge, 240-255.

Clio Collective, the. 1987. Quebec Women: a History, translated by Roger Gannon and Rosaling Gill, Toronto: the Women's Press.

Coenen-Huthier, Josette. 2005. "Le souhait d'enfant: un ideal situé", in Jean-Marie LeGoff, Claudine Sauvain-Dugerdil, Clémentine Rossier and Josette Coenen-Huther, Maternité et parcours de vie, Berne: Peter Lang, 85-133.

Cooke, Lynn Prince. 2008. "Gender Equity and Fertility in Italy and Spain", Journal of Social Policy, 38 (1), 123-140.

D'Addio, Anna Cristina and Marco Mira d'Ercole. 2005. "Policies, institutions and fertility rates: a panel data analysis for OECD countries", OECD Economic Studies No. 41.

Da Roit, Barbara and Bernhard Weicht. 2013. "Migrant care work and care, migration and employment regimes: A fuzzy-set analysis", Journal of European Social Policy, 23 (5), 469-486. 
Datta Gupta, Nabanita; Nina Smith and Mette Verner. 2006. "Child Care and Parental Leave in the Nordic Countries: A Model to Aspire to?", discussion paper 2014, Bonn: Institute for the Study of Labour.

Day, Creina and Steve Dowrick. 2010. "What entices the Stork? Fertility, Education and Family Payments", Working papers in economics and econometrics, working paper 516, Australian National University.

Del Boca, Daniela. 2002. "The effect of Child Care and Part Time Opportunities on Participation and Fertility Decisions in Italy", Journal of Population Economics, 15 (3), 549-573.

Del Boca, Daniela; Silvia Pasqua and Chiara Pronzato. 2005. "Fertility and Employment in Italy, France, and the UK", Labour 19 (S1), 51-77.

Desgagné, Bernard. 2007. «Lettres: Le poids démographique et politique du Québec », Le Devoir, 13 mars, http://www.ledevoir.com/politique/quebec/136927/lettres-le-poidsdemographique-et-politique-du-quebec.

Dickinson, James and Bob Russels. 1986. Family, Economy and State: the Social Reproduction Process Under Capitalism, New York : St. Martin's Press.

Doucet, Andrea. 2006. Do Men Mother? Fathering, care and domestic responsibility, Toronto: University of Toronto Press.

Drago, Robert, Katina Sawyer, Karina Sheffler, Diana Warren and Mark Wooden. 2009. "Did Australia's Baby Bonus Increase the Fertility Rate?", Melbourne Institute Working Paper Series, working paper No.1/09.

Dribe, Martin and Maria Stranfors. 2005. "Education and labour market effects on becoming a parent: The experience of young men and women in post-war Sweden", Lund (Sweden), Lund University, Department of Economic History, 37p.

Dribe, Martin and Maria Stranfors. 2009. "Education, Work and Parenthood: Comparing the Experience of Young Men and Women in Sweden", Journal of Family and Economic Issues, 30, 32-42.

Duclos, Édith. 2000. Les politiques familiales et les naissances par rang au Québec et au Canada de 1981 à 1996, Mémoire présenté comme exigence partielle de la maîtrise en économique, Université du Québec à Montréal.

Duclos, Édith; Pierre Lefebvre and Philip Merrigan. 2001. "A Natural Experiment on the Economics of Storks : Evidence on the Impact of Differential Family Policy on 
Fertility Rates in Canada", Working Paper no. 136. Center for Research on Economic Flucturations and Employment (CREFE), Université de Montréal, Montréal.

Duvander, Ann-Zofie and Gunnar Andersson. 2006. "Gender equality and fertility in Sweden: a Study on the impact of the father's uptake of parental leave on continued childbearing, Marriage and Family Review, 39 (1/2), 121-142.

Duvander, Ann-Zofie; Trude Lappergård and Gunnar Andersson. 2010. "Family policy and fertility: fathers' and mothers' use of parental leave and continued childbearing in Norway and Sweden", Journal of European Social Policy, 20 (1), 45-57.

Duvander, Ann-Zofie; Trude Lappergård and Mats Johansson. 2013. "Family Policy Reform Impact on Continued Fertility in the Nordic Countries", Submission for the 2013 meetings of the Population Association of America.

Engelhardt, Henriette and Alexia Prskawetz. 2002. "On the Changing Correlation Between Fertility and Female Employment over Space and Time", working paper 2002-052, Rostock: Max Planck Institute for Demographic Research.

Easterlin, Richard A. 1961. "The American Baby Boom in Historical Perspective", American Economic Review, 51 (5), 869-911.

Easterlin, Richard A. 1968. Population, Labour Force and Long Swings in Economic Growth: the American Experience, New York: National Bureau of Economic Research.

Easterlin, Richard A. 1973. "Relative Economic Status and the American Fertility Swing", in Edeanor B. Sheldon (ed), Family Economic Behaviour, Philadelphia: Lippincott, 170-223.

Easterlin, Richard A. 1978. "What Will 1984 Be Like? Socioeconomic Implications of Recent Twists in Age Structure”, Demography, 15 (4), 397-432.

Easterlin, Richard A. 1980. Birth and Fortune: the Impact of Numbers on Personal Welfare, New York: Basic Books.

Easterlin, Richard A. and Gretchen A. Condran. 1976. "A note on the recent fertility swing in Australia, Canada, England and Wales and the United States Population”, in Hamish Richards (ed), Factor Movements and Economic Development: Studies Presented to Brinley Thomas, Cardiff: University of Wales Press, 140-151.

Edmonston, Barry; Sharon M. Lee and Zheng Wu. 2010. "Fertility Intentions in Canada: Change or No Change?", Canadian Studies in Population, 37 (3-4), Fall/Winter, 297337. 
Ellingsaeter, Anne Lise. 2009. 'Leave policy in the Nordic welfare state: a 'recipe' for high employment/high fertility?", Community, Work and Family, 12 (1), 1-19.

Elzinga, Cees H. and Aart C. Liefbroer. 2007. "Destandardization of the Life Course: A Cross-National Comparison using Sequence Analysis", European Journal of Population, 23 (3-4), 225-250.

Engelhardt, Henriette and Prskawetz. 2002. "On the Changing Correlation Between Fertility and Female Employment over Space and Time", working paper 2002-052, Rostock: Max Planck Institute for Demographic Research.

Engelhardt, Henriette; Toma Kögel and Alexia Prskawetz. 2001. "Fertility anf female employment reconsidered: A macro-level time serties analysis", working paper 2001021, Rostock: Max Planck Institute for Demographic Research.

Erler, Daniel. 2009, «La réforme du congé parental en Allemagne : vers le modèle nordique? », Politiques sociales et familiales, 95, 43-52.

Esping-Andersen, Gøsta. 1990. The Three Worlds of Welfare Capitalism, Princeton: Princeton University Press.

Esping-Andersen, Gøsta. 1999. Social Foundations of Postindustrial Economies, Oxford: Oxford University Press.

Esping-Andersen, Gøsta. 2009. The Incomplete Revolution: Adapting to Women's New Roles, Cambridge: Polity Press.

Fagnani, Jeanne. 2002. "Why do French women have more children than German women? Family policies and attitudes towards child care outside the home", Community, Work and Family, 5 (1), 103-119.

Fagnani, Jeanne. 2007. "Family Policies in France and Germany: Sisters or Distant Cousins?", Community, Work and the Family, 10 (1), 39-56.

Ferrera, Maurizio. 1996. "The Southern European Model of Welfare in Social Europe", Journal of European Social Policy, 6 (1), 17-37.

Finkel, Alvin. 2006. Social Policy and Practice in Canada: A History, Waterloo, Wilfrid Laurier University Press.

Fortin, Pierre. 2001. "Has Quebec's Standard of Living Been Catching up?”, in Patrick Grady and Andrew Sharpe (ed.) The State of Economics in Canada: Festschrift in Honour of David Slater, Centre for the Study of Living Standards, 381-402. 
Fraser, Nancy. 1994. "After the Family Wage: Gender Equity and the Welfare State", Political Theory, 22 (4), 591-618.

Fraser, Nancy. 1997. "After the Family Wage: a Post Industrial Thought Experiment", in Nancy Fraser Justice Interruptus: Critical Reflections on the 'Postsocialist Conditions', London: Routledge, 41-66.

Frejka, Tomas and Tomáš Sobotka. 2008. "Overview Chapter 1: Fertility in Europe: Diverse, delayed and below replacement", Demographic Research 19, 15-46.

Feyrer, James, Bruce Sacerdote, and Ariel Dora Stern. 2008. "Will the Stork Return to Europe and Japan? Understanding Fertility within Developed Nations", Journal of Economic Perspectives, 22 (3), 3-22.

Friendly, Martha and Susan Prentice. 2009. About Canada Childcare, Black Point, Nova Scotia : Fernwood Pubublishing.

Friendly, Martha; Shani Halfon, Jane Beach and Barry Rorer. 2013. Early childhood education and care in Canada 2012, Childcare Resource and Research Unit, Toronto.

Gagné, Lynda G. 2001. "Potential Income and the Equity of the Child-Care Expense Deduction”, Canadian Tax Journal, 49 (3), 636-673.

Gagnon, Alain-G and Mary Beth Montcalm. 1990. Quebec Beyond the Quiet Revolution, Scarborough: Nelson Canada.

Gans, Joshua S. and Andrew Leigh. 2009. "Born on the First of July: An (Un)natural Experiment in Birth Timing", Journal of Public Economics, 93 (1-2), 246-263.

Gauthier, Anne H. 2000. "Public policies affecting fertility and families in Europe : a survey of the 15 member states", Paper presented at the seminar Low Fertility, Families and Public Policies, Sevilla, September 15-16.

Gauthier, Anne H. 2001. "The impact of public policies on families and demographic behaviour", paper presented at the EFF/EURESCO conference. The second demographic transition in Europe: Bad Herrenalb, Germany, 23-28 June.

Gauthier, Anne H. and J. Hatzius. 1997. "Family benefits and fertility: an econometric analysis", Population Studies, 51 (3), 295-306.

Gauthier, Anne H. 2007. "The impact of family policies on fertility in industrialised countries: a review of the literature", Population Research Policy Review, 26 (3), 323-346. 
Gauvreau Danielle, Diane Gervais and Peter Gossage. 2007. La fécondité des Québécoises 1870-1970. D’une exception à l'autre, Montréal : Boréal.

Gíslason, Ingóful V. 2007. Parental Leave in Iceland: Bringing the Fathers in: Development in the Wake of New Legislation in 2000, Ministry of Social Affairs and Centre for Gender Equality.

Godbout, Luc and Suzie St-Cerny. 2008. Le Québec, un paradis pour les familles? Regards sur la famille et la fiscalité, Québec: Les Presses de 1'Université Laval.

Goldstein, Joshua; Wolfgang Lutz and Maria Rita. 2003. "The emergence of subreplacement family size ideals in Europe", Population Research and Policy Review, 22 (5-6), 479-496.

Goldstein, Joshua R.; Tomas Sobotka and Aiva Jasilioniene. 2009. "The End of 'LowestLow' Fertility?", Population and Development Review, 35 (4), 183-207.

Gornick, Janet C., Marcia K. Meyers, and Katherin E. Ross. 1997. "Supporting the Employment of Mothers: Policy Variation Across Fourteen Welfare States", Journal of European Social Policy 7 (1), 45-70.

Government of Quebec. 2008. Politique familiale, Famille et Aînés, www.mfa.gouv.qc.ca/famille/politique-familiale/historique/les-annees-1980 en.asp.

Government of Quebec. 2011. Un portrait statistique des familles au Québec, Ministère de la Famille et des Aînés, Québec.

Guest, Dennis. 1997. The emergence of Social Security in Canada, Third Edition, Vancover: UBC Press.

Haan, Peter and Katharina Wrohlich. 2011. "Can child care policy encourage employment and fertility?", Labour Economics, 18 (4), 498-512.

Haas, Linda and Tine Tostgaard. 2011. "Fathers' rights to paid parental leave in the Nordic countries: consequences for the gendered division of leave", Community, Work and Family, 14 (2), 177-195.

Hagewen, Kellie J. and Philip S. Morgan. 2005. "Intended and Ideal Family Size in the United States, 1970-2002”, Population Development Review, 31 (3), 507-527.

Hakim, Catherine. 2000. Work-Lifestyle Choices in the $21^{\text {st }}$ Century: Preference Theory, Oxford: Oxford University Press. 
Hakim, Catherine. 2003. "A New Approach to Explaining Fertility Patterns: Preference Theory", Population and Development Review, 29 (3), 349-374.

Hank, Karsten and Isabella Buber. 2009. "Grandparents Caring for their Grandchildren: Findings From the 2004 Survey of Health, Ageing, and Retirement in Europe", Journal of Family Issues, 30 (1), 53-73.

Hank, Karsten and Michaele Kreyenfeld. 2003. "A Multilevel Analysis of Child Care and Women's Fertility Decisions in Western Germany", Journal of Marriage and Family, 65 (3), 584-596.

Hantrais, Linda. 2004. Family policy matters: Responding to family change in Europe, Bristol: the Policy Press.

Harris, Fred R 2005. The Baby Bust: Who Will do the Work? Who will Pay the Taxes, Lanham: Rowman and Littlefield Publications

Henripin, Jacques. 1989. Naître ou ne pas être, Québec : Institut québécois de recherche sur la culture.

Hobson, Barbara, Livia Oláh and Ann Morrissens. 2004. "The Positive Turn or Birthstrikes? Sites of Resistance to Residual Male Breadwinner Societies and to Welfare State Restructuring", Paper presented prepared for the Annual Conference of RC 19 of the International Sociological Association, Paris, September 2-5.

Hoem, Britta and Jan M. Hoem. 1996. 'Sweden's family policies and roller-coaster fertility', Journal of Population Problems, 52 (3-4), 1-22.

Hoem, Britta. 2000. "Entry into motherhood in Sweden: the influence of economic factors on the rise and fall in fertility, 1986-1997”, Demographic Research 2.

Hoem, Jan M; Alexia Prskawetz and Gerda Neyer. 2001. "Autonomy or conservative adjustment? The effect of public policies and educational attainment on third births in Austria”, Population Studies, 55, 249-261.

Hoem, Jan M. 2008. "Overview 3 Chapter 8: The impact of public policies on European fertility”, Demographic Research, 19, 249-260.

Institut de la statistique du Québec (ISQ). 2013. Various statistics on Births and Fertility,Quebechttp://www.stat.gouv.qc.ca/statistiques/populationdemographie/naissance-fecondite/index an.html

Institut national de santé publique. 2008. Total fertility rate, urban and rural areas, Quebec 2000-2004, http://www2.inspq.qc.ca/Santescope/element.asp?Lg=en\&NoEle=791 
Jacobs, Josephine. 2009. The Impact of Indirect Cost-Reducing Family Policy on Fertility in Canada, Master's thesis in the Department of Economic History, Lund University.

Jenson, Jane. 2000. “ Le nouveau régime de citoyenneté du Canada: investir dans l'enfance ", Lien social et Politiques, 44, 11-23.

Jenson, Jane. 2002. "Against the Current: Child Care and Family Policy in Québec", in Sonya Michel and Rianne Mahon (eds), Child Care Policy at the Crossroads, Gender and Welfare State Restructuring, New York: Routledge, 309-332.

Jenson, Jane; Rianne Mahon and Susan Phillips. 2003. "No Minor Matter: The Political Economy of Childcare in Canada", in Wallace Clement and Leah F. Vosko (ed), Changing Canada, Political Economy as Transformation, Montreal: McGill-Queen's University Press, 135-160.

Jenson, Jane. 2009. "Rolling Out or Backtracking on Québec's Child Care System? Ideology Matters", in Majorie Griffin Cohen and Jane Pulkingham (eds), Public Policy for Women, Toronto: University of Toronto Press, 49-70.

Kalwij, Adriaan. 2010. "The Impact of Family Policy Expenditure on Fertility in Western Europe", Demography, 47 (2), 503-519.

Kaptijn, Ralf; Fleur Thomese, Theo G. van Tilburg and Aart C. Liefbroer. 2010. "How Grandparents Matter: Support for the Cooperative Breeding Hypothesis in a Contemporary Dutch Population", Human Nature, 21 (4), 393-405.

Karamessini, Maria. 2008. "The provision of childcare services in Greece", External report commissioned by and presented to the EU Directorate-General Employment and Social Affairs, Unit G1, 'Equality between women and men'.

Kearns, Philippe. 1996. «Les déterminants socio-économiques de la fécondité par rang au Canada et au Québec », Mémoire de maîtrise, Département d'économie, Université du Québec à Montréal.

Kohler, Hans-Peter, Francesco C. Billari and José Antonio Ortega. 2002. "The emergence of lowest-low fertility in Europe during the 1990s", Population and Development Review, 28 (4), 641-680.

Kohler, Hans-Peter; Francesco C. Billari and José Antonio Ortega. 2005. "Low and Lowest-fertility in Europe : Casuses, Implications and Policy Options", The Baby Bust: Who Will do the Work? Who will Pay the Taxes?, in Fred H. Harris (ed.), Lanham: Rowman and Littlefield Publications, 48-109. 
Kono, Shigemi. 1996. “The Relation Between Women's Economic Activity and Child Care in Low Fertility Countries", Population and Women : Proceedings of the United Nations Expert Group Meeting on Population and Women, June 1992, 322-345.

Kurz, Karin; Nikolei Steinhage and Katrin Golsch. 2001. "Case study Germany. Global competition, uncertainty and the transition to adulthood", in Hans-Peter Blossfeld, Erik Klijzing; Melinda Mills and Karin Kurz (eds), Globalization, Uncertainty and Youth, New York: Routledge, 51-82.

Lacoursière, Jacques. 1996. Histoire populaire du Québec: 1960 à 1970, Sillery: Septentrion.

Lain, Samatha J.; Jane B. Ford; Camille H. Raynes-Greenow; Ruth M. Hadfield; Judy M. Simpson; Jonathan Morris and Christine L. Roberts. 2009. "The impact of the Baby Bonus payment in New South Wales: who is saving 'one for the country'?, Medical Journal of Australia, 190 (4), 238-241.

Lalive, Rafael and Josef Zweimüller. 2005. "Does Parental Leave Affect Fertility and Return-to-Work? Evidence from a 'True Natural Experiment', Institute for Empirical Research in Economics, Working Paper No. 242.

Lalonde-Graton, Micheline. 2002. Des salles d'asile aux centres de la petite enfance. La petite histoire des services de garde au Québec, Sainte-Foy: Presses de l'Université du Québec.

Langlois, Simon. 2004. «Démographie : vieillissement, immigration, urbanisation et solitude », in Michel Venne (ed), L'Annuaire du Québec 2005, Montréal : Fides et Institut du Nouveau Monde, 142.

Lapierre-Adamcyk, Évelyne. 1981. «Les aspirations des Québécois en matière de fécondité en 1980 », Cahiers québécois de démographie, 10 (2), 171-188.

Lapierre-Adamcyk, Évelyne. 2001. "Portrait démographique du Québec", In Conseil de la Famille et de l'Enfance, Démographie et famille. Les impacts sur la société de demain. Les actes du colloque, Québec: Le Conseil, 34-44.

Lapierre-Adamcyk, Évelyne and Marie-Hélène Lussier. 2003. « De la forte fécondité à la fécondité désirée », in Victor Piché and Céline Le Bourdais (eds) La démographie québécoise: enjeux du XXIe siècle, Montréal: Les Presses de l’Université de Montréal, 66-109.

Lapierre-Adamcyk, Évelyne. 2010. «L'évolution de la fécondité et la politique familiale québécoise », Santé, Société et Solidarité, 9 (2), 63-74. 
Lappergård, Trude. 2010. "Family Policies and Fertility in Norway", European Journal of Population, 26, 99-116.

Lattimore, Ralph and Clinton Pobke. 2008. Recent Trends in Australian Fertility, Productivity Commission Staff Working Paper, Productivity Commission.

LeBourdais, Céline. 1989. «Politique familiale ou politique nataliste : un enjeu de taille pour les femmes », Revue canadienne de santé mentale, 8 (2), 83-102.

Leclerc, Jacques. 2010. « La question démographique », Aménagement linguistique dans le monde, Université Laval, http://www.tlfq.ulaval.ca/axl/amnord/quebecdemo.htm

Leibfried, Stephan. 1993. "Towards a European Welfare State?", in Catherine Jones (ed.) New Perspectives on the Welfare State in Europe, Great-Britain: Routledge, 133-156

Leitner, Ilona and Christoph Schmitt. 2008. "Family Policies in Germany", in Ilona Leitner and Christoph Schmitt (eds), Family Policies in the Context of Family Change The Nordic Countries in Comparative Perspective, Wiesbaden : VS, Verl. für Sozialwiss, 175-202.

Leitner, Sigrid. 2003. "Varieties of familialism: the caring function of the family in comparative perspective", European Societies, 5 (4), 353-375.

Leitner, Sigrid and Stephan Lessenich. 2005. "(In)dependence as Dependent Variable: conceptualising and measuring defamilisation", Paper presented for the Workshop "Exploring the dynamics of reform: the dependent variable problem in comparative welfare state analysis", University of Stirling, May 13-14.

Lefebvre, Pierre and Philip Merrigan. 2003. "Assessing Family Policy in Canada: A New Deal for Families and Children”, Choices, 9 (5), 1-100

Lefebvre, Pierre and Philip Merrigan. 2005. "The Québec's Experiment of \$5 per Day per Child Childcare Policy and Mother's Labour Supply: Evidence Based on the Five Cycles on the NLSCY", Project Report, Cirano Research Institute.

Lefebvre, Pierre and Philip Merrigan. 2008. "Child-Care Policy and the Labor Supply of Mothers with Young Children: A Natural Experiment from Canada, Journal of Labour Economics, 26 (3), 519-548.

Lefebvre, Pierre, Philip Merrigan and Francis Roy-Desrosiers. 2011. "Québec's Childcare Universal Low Fees Policy 10 Years After : Effects, Costs and Benefits", Working Paper 11-01, Centre Interuniversitaire sur le Risque, les Politiques Economiques et l'Emploi (CIRPÉE). 
Légaré, Jacques. 2003. "Un siècle de vieillissement démographique », in Victor Piché and Céline Le Bourdais (eds), La démographie québécoise: enjeux du XXIe siècle, Montréal : Les Presses de 1’Université de Montréal, 176-192.

Lesthaeghe, Ron L. and Guy M. Moors. 2000. "Recent Fertility and Household Formation in the Industrialised World", Review of Population and Social Policy, 9, 121-170.

Lesthaeghe, Ron L. and Karel Neels. 2002. "From the First to the Second Demographic Transition: An Interpretation of the Spatial Continuity of Demographic Innovation in France, Belgium and Switzerland", European Journal of Population/Revue européenne de Démographie, 18 (4), December, 325-360.

Létablier, Marie-Thérèse. 2003. "Fertility and Family Policies in France", Journal of Population and Social Security (Population), 1, 245-261.

Lewis, Jane. 1992. "Gender and the development of Welfare Regimes", Journal of European Social Policy, 2 (3), 159-173.

Linteau, Paul-André et al. 1991. Quebec since 1930 (translated by Robert Chodos and Ellen Garmaise), Toronto: James Lorimer and Company.

Lister, Ruth. 1994. "She has other duties - Women, citizenship and social security" in Sally Baldwin and Jane Falkingham (eds), Social Security and Social Change: New Challenges to the Beveridge model, Hemel Hemptstead: Harvester Wheatsheaf, 3144.

Luci-Greulich, Angela and Olivier Thévenon. 2013. "The Impact of Family Policies on Fertility Trends in Developed Countries", European Journal of Population, 2, 387 416.

Luxton, Meg. 2006. "Feminist Political Economy in Canada and the Politics of Social Reproduction", in Kate Bezanson and Meg Luxton (eds), Social Reproduction: Feminist Political Economy Challenges Neo-Liberalism, Montreal : McGill-Queen's University Press, 11-44.

Lyngstad, Torkild Hovde; Turid Noack and Kenneth Aa Wiik. 2010. "Have fertility intentions become harder to realize over the last thirty years", Paper prepared for the Paper prepared for the European Population Conference, Vienna Austria, 1-4 September.

Macunovich, Diane J. 1998. "Fertility and the Easterlin Hypothesis: An Assessment of the Literature", Journal of Population Economics, 11, 53-111. 
Mahon, Rianne. 2009. "Canada's Early Childhood Education and Care Policy: Still a Laggard?", International Journal of Child Care and Education Policy, 3 (1), 27-42.

Mahon, Rianne and Susan Phillips. 2002. "Dual-Earner Families Caughts in a Liberal Welfare Regime? The Politics of Child Care Policy in Canada", in Sonya Michel and Rianne Mahon, Child care policy at the crossroads: gender and welfare state restructuring, New York and London: Routledge, 191-218.

Mahon, Rianne. 2000. "The Never-Ending Story: the Struggle for Universal Child Care Policy in the 1970s", The Canadian Historical Review, 81 (4), 582-622.

Mandel, Hadas and Moshe Semyonov. 2006. "A Welfare State Paradox: State Interventions and Women's Employment Opportunities in 22 Countries", American Journal of Sociology, 111 (6), 1910-1949.

Maroney, Heather Jon. 1992. "Who has the baby', Nationalism, pronatalism and the construction of a 'demographic crisis' in Quebec 1960-1988', Studies in Political Economy 38, Autumn, 7-36.

Marshall, Katherine. 2008. "Fathers' use of paid parental leave", Perspectives on Labour and Income, Statistics Canada.

Mathews, Georges. 1984. Le choc démographique : Le déclin du Québec est-il inévitable? Saint-Laurent : Boréal Express

Mathieu, Sophie. 2003. Droits, marchandisation et défamilisation: une typologie des régimes de genre, Université de Montréal, Mémoire de Maîtrise.

Mathieu, Sophie. 2008. «Dénatalité et mesures de conciliation travail-famille », Le Devoir.

Mathieu, Sophie. 2013. «Entre l'effet tempo et l'effet quantum: une analyse de l'effet des politiques familiales sur la fécondité dans les pays avancés », Sociologie et sociétiés, 25 (1), 255-276.

Matysiak, Anna and Daniele Vignoli. 2008. 'Fertility and women's employment: a metaanalysis", European Journal of Population, 24 (4), 363-384.

McCall, Leslie (2005). "The complexity of intersectionality", Signs: Journal of Women in Culture and Society, 30 (3), 1771-1800.

McDaniel, Susan A. 2002. "Women's Changing Relations to the State and Citizenship: Caring and Intergenerational Relations in Globalizing Western Democracies", Canadian Review of Anthropology and Sociology, 39 (2), 125-150. 
McDaniel, Susan A. 2009. "The 'Growing Legs' of Generation as a Policy Construct: Reviving its Family Meaning”, Journal of Comparative Family Studies, 40 (2), 243253.

McDonald, Peter. 2000a. "Gender Equity in Theories of Fertility Transition", Population and Development Review, 26 (3), 427-439.

McDonald, Peter. 2000b. "Gender equity, social institutions and the future of fertility", Journal of Population Research, 17 (1), 1-16.

McDonald, Peter. 2000c. "The 'Toolbox' of Public Policies to Impact on Fertility- A Global View", Paper presented at the seminar Low Fertility, Families and Public Policies, Sevilla, September 15-16.

McDonald, Peter. 2002. "Sustaining fertility through public policy: the range of options", Population-E, 57 (3), 417-446.

McDonald, Peter. 2006. "Low fertility and the state: The efficacy of policy", Population and Development Review, 32 (3), 485-510.

McDonald. Peter. 2010. "Theoretical Foundations for the Analysis of Fertility: Gender Equity”, Paper presented to the BBAW/Leopoldina Conference, Lausanne, 14-16 October.

McDonald, Peter. 2013. "Societal foundations for explaining low fertility: Gender equity", Demographic Research, 28, 981-994.

McKeen, Wendy. 2007. "The national children's agenda: a neoliberal wolf in lambs clothing", Studies in Political Economy, 80, 151-173.

McLaughlin, Eithne and Caroline Glendinning. 1994. "Paying for care in Europe: is there a feminist approach?" in Linda Hantrais and Stephen P. Mangen, (eds) Family Policy and the Welfare of Women, Loughborough: Cross-National Research Group, European Research Centrer, Loughborough University of Technology, 42-69.

McRae, Susan. 2003. "Constraints and choices in mothers' employment careers: a consideration of Hakim's Preference theory," British Journal of Sociology, 54 (3), $317-338$

Mercarini, Letizia and Maria Letizia Tanrurri 2004. "Time Use, Family Role-Set and Childbearing among Italian Working Women”, Genus 60 (1), 111-137.

Michel, Sonya and Rianne Mahon. 2002. Child care policy at the crossroads: gender and welfare state restructuring, New York and London: Routledge. 
Miedema, Derek. 2009. "Care-Full? The Demographic Crunch and Senior Care in Canada", Institute of Marriage and Family Canada.

Migué, Jean-Luc. 1998. Étatisme et déclin du Québec, Montréal: Varia.

Milligan, Kevin. 2002. “Quebec's Baby Bonus: Can Public Policy Regime Raise Fertility?", Backgrounder, C.D. Howe Institute.

Milligan, Kevin. 2005. "Subsidizing the Stork: New Evidence on Tax Incentives and Fertility", Review of Economics and Statistics, 87 (3), August, 539-555.

Mills, Melinda; Letizia Mencarini; Maria Letizia Tanturri and Katia Begall. 2008. "Gender equity and fertility intentions in Italy and the Netherlands", Demographic Research, $18,1-26$.

Morgan, Philip S. and Heather Rackin. 2010. "The Correspondence Between Fertility Intentions and Behavior in the United States", Population Development Review, March, 36 (1), 91-118.

Mörk, Eva; Anna Sjögren and Helena Svaleryd. 2009. "Cheaper Child Care, More Children", discussion paper No. 3942, Bonn: Institute for the Study of Labour.

Neyer, Gerda. 2003. "Family Policies and Low Fertility in Western Europe", Journal of Population and Social Security, 1 (Supplement), 46-93.

Neyer, Gerda. 2010. "Should Governments in Europe be More Aggressive in Pushing for Gender Equality to Raise Fertility?", Stockholm Research Reports in Demography, 9.

Nishioka, Hachiro. 2003. "Low Fertility and Family Policies in Southern European Countries", Journal of Population and Social Security, Supplement to volume 1, 262283.

O'Connor, Julia S. 1993. "Gender, class and citizenship in the comparative analysis of welfare state regimes: theoretical and methodological issues", British Journal of Sociology, 4 (3), September, 501-518.

O’Connor, Julia S. 1996. "From Women in the Welfare State to Gendering Welfare State Regimes", Current Sociology, 44 (2), 1-124.

O’Connor, Julia S.; Ann Schola Orloff and Sheila Shaver. 1999. States, Markets, Families: Gender, Liberalism and Social Policy in Australia, Canada, Great Britain and the United States, Cambridge: Cambridge University Press.

OECD. 2005. "Does gender equality spur growth?”, OECD Observer 250. 
OECD. 2011. OECD Family Database, http://www.oecd.org/document/4/0,3746,en_2649_34819_37836996_1_1_1_1,00.ht $\mathrm{ml}$

OECD. 2012. OECD Family Database, OECD, Paris www.oecd.org/social/family/database.

OECD. 2013. Education at a Glance 2013: OECD Indicators, OECD Publishing.

Ohinata, Asako. 2008. "Fertility Response to Financial Incentives: Evidence from the Working Families Tax Credits in the UK", Warwick Economic Research Paper.

Oláh, Livia Sz.. 2011. "Should governments in Europe be more aggressive in pushing for gender equality to raise fertility? The second "Yes", Demographic Research 24, 217 224.

Orloff, Ann Shola. 1993. "Gender and the Social Rights of Citizenship: the Comparative Analysis of Gender Relations and Welfare States", American Sociological Review, 58, June, 303-328.

Pampel, Fred C. and Elizabeth Peters. 1995. "The Easterlin Effet", Annual Review of Sociology, 21 (1), 163-194.

Paquet, Gilles. 1999. Oublier la Révolution tranquille, Montréal: Liber.

Parent, Daniel. 2008. "Natalité et politiques gouvernementales", in Luc Godbout, and Suzie St-Cerny, Le Québec, un paradis pour les familles? Regards sur la famille et la fiscalité, Québec: Les Presses de 1'Université Laval, 162-165.

Parr, Nick and Ross Guest. 2011. "The Contribution of Recent Increases in Family Benefits to Australia's Early $21^{\text {st }}$ Century Fertility Increase: an Empirical Analysis", Demographic Research, 25, 215-244.

Pateman, Carole. 1988. "The Patriarchal Welfare State” in Amy Gutmann Democracy and the Welfare State: Princeton: Princeton University Press, 231-260.

Pépin, Lucille. 2006. "Panel on Reproductive Rights in Canada", Council of Women in Politics and Public Policy, Speech delivered at the University of Ottawa, February $5^{\text {th }}$, http://sen.parl.gc.ca/lpepin/index.asp?PgId=705.

Phipps, Shelley A. 2000. "Maternity and Parental Benefits in Canada: Are these Behavioural Implications?"» Canadian Public Policy, 26 (2), 415-436. 
Phipps, Shelley A. 2006. "Working for Working Parents: the Evolution of Maternity and Parental Benefits in Canada", IRPPC Choices, 12 (2).

Philipov, Dimiter and Hans-Peter Kohler. 1999. "Tempo Effects in the Fertility Decline in Eastern Europe: Evidence from Bulgaria, the Czech Republic, Hungary, Poland, and Russia”, working paper 1999-008, Rostock: Max Planck Institute for Demographic Research.

Piché, Victor and Céline Le Bourdais (eds). 2003. La démographie québécoise : enjeux du XXIe siècle, Montréal : Les Presses de l'Université de Montréal.

Piketty, Thomas. 2005. "L'impact de l'allocation parentale d'éducation sur l'activité féminine et la fécondité en France », in Cécile Lefebvre and Alexandra Filhon (eds), Histoires de familles, histoires familiales. Les résultats de l'enquête Famille de 1999, Les Cahiers de l'INED 156, Paris : INED, 79-110.

Porter, Ann. 2003. Gendered States: Women, Unemployment Insurance, and the Political Economy of the Welfare State in Canada, 1945-1997, Toronto: University of Toronto Press.

Prioux, France. 2003. "Age at First Union in France: A Two-Stage Process of Change", Population-E, 58 (4-5), 559-578.

Quesnel-Vallée, Amélie and Philip S. Morgan. 2003. "Missing the target? Correspondence of fertility intentions and behaviour in the US", Population Research and Policy Review, 22 (5/6), 497-525.

Ray, Rebecca. 2008. "A Detailed Look at Parental Leave Policies in OECD Countries", Washington, Center for Economic and Policy Research.

Ray, Rebecca; Janet C. Gornick and John Schmitt. 2009. "Parental Leave Policies in 21 Countries", Washington, Center for Economic and Policy Research.

Régnier-Loilier, Arnaud and Daniele Vignoli. 2010. "Fertility dynamics in France and Italy. Who are the couples who do not give birth to the intended child?", Paper prepared for the European Population Conference, Vienna Austria, 1-4 September.

Rindfuss, Ronald R., Karen Benjamin Guzzo and Philip S. Morgan. 2004. "The changing institutional context of low fertility", Population Research and Policy Review, 22, 411-438.

Rindfuss, Ronald R.; David Guilkey; Philip S. Morgan, Ǿystein Kravdal and Karen Benjamin Guzzo. 2007. "Child Care Availability and First-Birth Timing in Norway", Demography. 44 (2), 345-372. 
Rindfuss, Ronald R.; David Guilkey; Philip S. Morgan and Ǿystein Kravdal. 2010. "ChildCare Availability and Fertility in Norway", Population and Development Review 36 (4), December, 725-748.

Risse, Leonara. 2006. "Determinants of Maternity Leave Provisions in Australia and the Effects on Fertility: An Application of the Heckprobit Selection Model", Paper prepared for the Social Science Methodology Conference, University of Sydney.

Rønsen, Marit. 2004a. "Fertility and family policy in Norway- A reflection on trends and possible connections", Demographic Research, 10 (10), 265-286.

Rønsen, Marit. 2004b. "Fertility and Public Policies- Evidence from Norway and Finland", Demographic Research, 10, 143-170.

Rosenbluth, Frances McCall (ed.). 2007. The Political Economy of Japan's Low Fertility, Stanford: Stanford University Press.

Rose, Ruth. 2008 "Le soutien financier aux familles depuis 30 ans: pour mieux comprendre les tensions et preoccupations qui s'en dégagent", in Luc Godbout and Suzie StCerny, Le Québec, un paradis pour les familles? Regards sur la famille et la fiscalité, Québec: Les Presses de l’Université Laval, 91-98.

Roussel, Louis. 1987. "Deux décennies de mutations démographiques (1965-1985) dans les pays industrialisés", Population, 42 (3), 429-448.

Roussel, Louis. 1989. La famille incertaine, Paris : Éditions Odile Jacob.

Roy, Laurent and Jean Bernier. 2006. Family Policy, Social Trends and Fertility in Quebec: Experimenting with the Nordic Model?, Ministère de la Famille, des Aînés et de la Condition féminine.

Ryser, Valérie-Anne; Jean-Marie Le Goff and Laura Bernardi. 2010. "Gender role-set, family orientations and fertility intentions in Switzerland", Paper prepared for the European Population Conference, Vienna Austria, 1-4 September.

Saint-Arnaud, Sébastien and Paul Bernard. 2003. "Convergence or Resilience? A Hierarchical Cluster Analysis of the Welfare Regimes in Advanced Countries", Current Sociology, 51 (5), 499-527.

Salles, Anne; Clémentine Rossier and Sara Brachet. 2010. "Understanding the long term effects of family policies on fertility: the diffusion of different family models in France and Germany”, Demographic Research, 22, 1057-1096. 
Sanderson, Warren. 2011. "Low Fertility and Population Aging in Germany and Japan: Prospects and Policies", in Takayama, Noriyuki and Martin Werding (eds), Fertility and Public Policy: How to Reverse the Trend of Declining Birth Rates, Cambridge, MA : MIT Press, 51-80.

Santow, Gigi and Michael Bracher. 2001. "Deferment of the First Birth and Fluctuating Fertility in Sweden", European Journal of Population, 17 (4), 343-363.

Sarikaki, Alexandra. 2001. "The Second Demographic Transition in Europe", Euroconference on Family and Fertility Chance in Modern European Societies: Explorations and Explanations of Recent Developments, Bad Herrenalb, June 23-28.

Saxonberg, Steven. 2013. "From Defamilialization to Degenderization: Toward a New Welfare Typology", Social Policy and Administration, 47 (1), 26-49.

Schmitt, Christian. 2008. "Gender Specific Effects of Unemployment on Family Formation: Evidence from a Cross National View", Discussion Paper 841, BIQ Berlin.

Schofield, Roger and David Coleman (eds). 1986. The State of Population Theory. Forward from Matlthus, Oxford: Basil Blackwell.

Schoen, Robert; Nan Marie Kim; Young J. Nathanson; Constance A. Nathanson. 1999. "Do Fertility Intentions Affect Fertility Behaviour", Journal of Marriage and the Family, 61 (3), 790-799.

Sear, Rebecca and David Coall. 2011. "How Much Does Family Matter? Cooperative Breeding and the Demographic Transition", Population and Development Review, 37 , 81-112.

Shields, Alexandre. 2007. «Le Québec dépasse le cap des 7,7 millions d'habitants », Le Devoir, 28 décembre.

Schwartz, Susan. 1982. "Parents must apply for Quebec child allowance", The Gazette, March $18^{\text {th }}$, D7.

Siltanen, Janet. 2006. "Gender, Diversity and the Shaping of Public Policy: Recent Aspects of the Canadian Experience", Scottish Affairs, 56, 88-101.

Siltanen, Janet and Andrea Doucet. 2008. Gender Relations in Canada: Intersectionality and Beyond, Don Mills, Ontario : Oxford University Press

Sipilä, Jorma and Johanna Korpinen. 1998. "Cash versus child care services in Finland", Social Policy and Admiration, 32 (3), 263-277. 
Sleebos, Joëlle. 2003. "Low fertility rates in OECD countries: facts and policy responses", Social Employment and Migration Workshop, OECD, Paris.

Smith, Adam. 1776. The Wealth of Nations.

Sobotka, Tomáš and Laurent Toulemon. 2008. "Changing family and partnership behaviour: Common trends and persistent diversity across Europe", Demographic Research, 19, 85-138.

Sobotka, Tomáš, Vegard Skirbekk and Dimiter Philipov. 2010. "Economic recession and fertility in the developed world. A literature review", Vienna Institute of Demography, 10 February.

Sobotka, Tomáš. 2011. "Reproductive Decision-Making in a Macro-Micro Perspective (REPRO): Synthesis and Policy Implications" European Demographic Research Papers, 1, Vienna Institute of Demography.

Spengler, Joseph J. 1976. "Adam Smith on population growth and economic development", Population and Development Review 2 (2), 167-180.

Stasiulis, Daiva K. and Abigail B. Bakan. 2003. Negotiating citizenship : migrant women in Canada and the global system, Houndmills, Basingstoke, Hampshire: Palgrave Macmillan.

Statistics Canada. 2005. Population projections for Canada, Provinces and Territories 2005-2031, Statistics Canada catalogue no. 91-520-X.

Statistics Canada. 2006. Report on the Demographic Situation in Canada, 2001, Ottawa: Statistics Canada, catalogue no. 91-209-XIE.

Statistics Canada. 2008a. Report on the Demographic Situation in Canada, 2005-2006, Ottawa: Statistics Canada, catalogue no. 91-209X, Ottawa.

Statistics Canada. 2008b. Live births, crude birth rate, age-specific and total fertility rates, Canada, provinces and territories (Cansim Table 102-4505), Canadian Vital Statistics, Birth Database and Demography Division, Ottawa.

Statistics Canada. 2010. Estimates of population, by age group and sex for July 1, Canada, provinces and territories, annual (Cansim Table 051-0001), Ottawa.

Statistics Canada. 2012. "Employment Insurance Coverage, 2011”, The Daily, November $5^{\text {th }}$. 
Statistics Canada. 2013a. Estimates of Population, Canada, the Provinces and Territories (Persons) (Cansim Table 051-0001), Ottawa.

Statistics Canada. 2013b. Table 282-0002 - Labour force survey estimates (LFS), by sex and detailed age group, annual (persons unless otherwise noted), cansim (database).

Stier Haya, Lewin-Epstein Noah, Braun Michael. 2001. "Welfare Regime, FamilySupportive Policy, and Women's Employment along the Life Course", American Journal of Sociology, 106 (6), 1731-1760.

Takayama, Noriyuki and Martin Werding, eds. 2011. Fertility and Public Policy: How to Reverse the Trend of Declining Birth Rates, Cambridge, MA : MIT Press.

Termotte, Marc. 1999. Perspectives démolinguistiques du Québec et de la région de Montréal à l'aube du XXIe siècle: implications pour le français langue d'usage public, Québec : Conseil de la langue française.

Termotte, Marc. 2003. "La dynamique démolinguistique du Québec et de ses régions", in Victor Piché and Céline Le Bourdais (eds), La démographie québécoise : enjeux du XXIe siècle, Montréal : Les Presses de l’Université de Montréal, 264-299.

Testa, Maria-Rita and Laurent Toulemon. 2006. "Family Formation in France: Individual Preferences and Subsequent Outcomes", Vienna Yearbook of Population Research, 41-75.

Thévénon, Olivier. 2011a. "Does Fertility Respond to Work and Family-life Reconciliation Policies in France?" In Noriyuki Takayama and Martin Welding, Fertility and public policy: how to reverse the trend of declining birth rate, Cambridge: MIT Press, 219259.

Thévenon, Olivier. 2011b. "Family Policies in OECD Countries: A Comparative Analysis", Population and Development Review, 37 (1), 57-87.

Thévenon, Olivier and Anne H. Gauthier. 2011. "Family policies in developed countries: a 'fertility-booster' with side-effects”, Community, Work and Family, 14(2), 197-216.

Thomese, Fleur and Aart C. Liefbroer. 2013. "Child Care and Child Births: The Role of Grandparents in the Netherlands", Journal of Marriage and Family, 75 (2) , 403-421.

Torr, Berna Miller and Susan E. Short. 2004. "Second Births and the Second Shifts: a Research Note on Gender equity and fertility", Population and Development Review, 30 (1), 109-130. 
Tougas, Jocelyne. 2002. Reforming Québec's early childhood care and education: The first five years, Occasional Paper 17, Childcare Resource \& Research Unit, Centre for Urban \& Community Studies, University of Toronto

Toulemon, Laurent and Marie-Rita Testa, 2005. "Fertility intentions and actual fertility: a complex relationship", Population and societies, 415, September, 1-4

Toulemon, Laurent. 2006. "Fertility Among Immigrant Women and Men in France: New Data, a New Approach", paper presented at the Population Association of American 2006 Meeting, Los Angeles, California.

Toulemon, Laurent; Ariane Pailhé et Clémentine Rossier. 2008. "France : High and Stable fertility", Demographic Research, 19, 503-556.

Treasury Board of Canada. 2013. Early Childhood Development Agreement, Ottawa.

United Nations. 2002. World Population Ageing, 1950-2050, Population Division, New York.

United Nations. 2009. World Population Ageing 2009, Department of Economic and Social Affairs, Population Division, New Yok.

Uppal, Sharanjit. 2010. "Labour market activity among seniors", Perspectives, Statistics Canada, catalogue no. 75-001-X, Ottawa.

Van Peer, Christine. 2002. "Desired and realized fertility in selected FFS-countries", in Macura Miroslav and Beets Gijs (eds.), Dynamics of Fertility and Partnership in Europe: Insights and Lessons from Comparative Research, Vol. 1. New York and Geneva: United Nations, 117-142.

Verma, Ravi B.; Shirley Loh, S.Y. Dai and David Ford. 1996. Fertility Projections for Canada, Provinces and Territories, 1993-2016, Ottawa: Statistics Canada, catalogue no. 91F0015MPE.

Vignoli, Danièle and Arnaud Régnier-Loilier. 2009. "Chi non desidera due figli? Une studio comparativo tra Francia e Italia”, Rivista di Studi Familiari 1, 19-39.

Vitak, Andres. 2004. "Women's Labor Force Attachment and Childbearing in Finland", Demographic Research, special collection 3, 177-212.

Vitali, Agnese; Francesco C. Billari, Alexia Prskawetz and Maria Rita Testa. 2009. "Preference Theory and Low Fertility: A Comparative Perspective", European Journal of Population, 25 (4), 413-438. 
Walby, Sylvia. 2001."From gendered welfare state to gender regimes: National differences, convergence or re-structuring?", Paper presented to Gender and Society Group, Stockholm University, January 2001, University of Leeds, UK.

Weil, David N. 1997. "The Economics of Population Aging”, in Mark R. Rosenzweig and Oded Stark, (eds.), Handbook of Population and Family Economics, New York: Elsevier, 967-1014.

Weinkopf, Claudia. 2009. "Germany: Precarious employment and the rise of mini-jobs", in Leah F. Vosko, Martha MacDonald and Iain Campbell (eds.), Gender and the Contour of Precarious Employment, New York: Routledge, 177-193.

Wheaton, Blair. 2003. "When Methods Make a Difference", Current Sociology, 51 (5), 543-571.

Williams, Cara. 2005. “The Sandwich Generation”, Canadian Social Trends 77, 16-21.

Woods, Dorian R. 2006. "Focusing on Care: Family Policy and Problems of Analysis", Working Paper Nr. 30-2006, Institut für Politikwissenschaft.

Wright, Robert E. and Paul S. Maxim. 1987. "Canadian fertility trends: a further test of the Easterlin Hypothesis", Canadian Review of Sociology and Anthropology, 24 (3), 339357.

Werding, Martin. 2011. "The Economics of the Family and Its Policy Implications: Why Should We Care about Fertility Outcomes", in Noriyuki Takayama and Martin Werding, Fertility and Public Policy: How to Reverse the Trend of Declining Birth Rates, Cambridge, MA : MIT Press, 15-49.

Williams, Fiona and Deborah Brennan. 2012. "Care, markets and migration in a globalising world: Introduction to the Special Issue”, Journal of European Social Policy, 22 (4), 355-362.

Wollstonecraf, Mary. 1792. A Vindication of the Rights of Woman: With Strictures on Political and Moral Subjects, Boston: Peter Edes.

Yalnizyan, Armine. 2009. "Exposed: Revealing Truths About Canada's Recession", Growing Gap, Canadian Centre for Policy Alternatives.

Zabel, Cordula. 2009. "Eligibility for Maternity Leave and First Birth Timing in Great Britain", Population Research and Policy Review, 28, 251-270. 